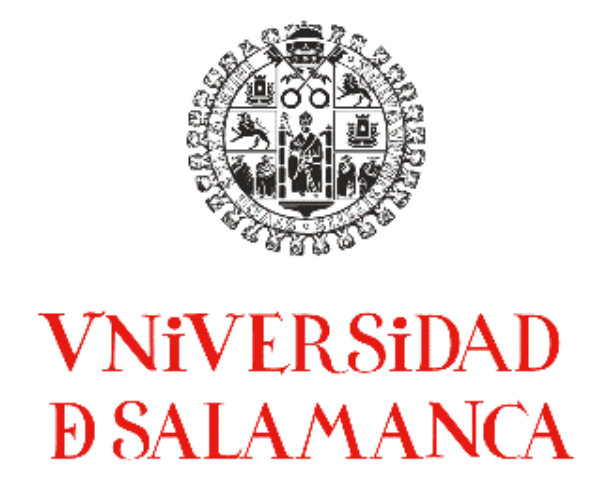

FACULTAD DE EDUCACIÓN

Departamento de Didáctica, Organización y Métodos de Investigación

TESIS DOCTORAL

\title{
Nivel lector y construcción del conocimiento en la universidad a partir de fuentes digitales e impresas
}

D. Gabriel Herrada Valverde

Dra. Anunciación Quintero Gallego Dra. Ma José Rodríguez Conde

Salamanca, 2015 


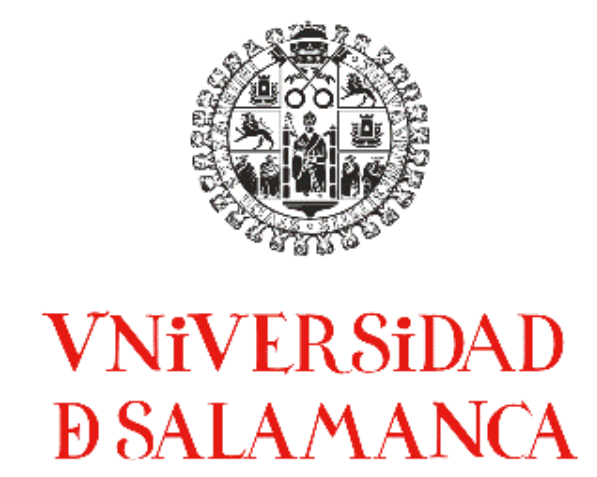

Departamento de Didáctica, Organización y Métodos de Investigación

FACULTAD DE EDUCACIÓN

TESIS DOCTORAL

\section{Nivel lector y construcción del conocimiento en la universidad a partir de fuentes digitales e impresas}

D. Gabriel Herrada Valverde 


\section{DECLARACIÓN}

Doña Anunciación Quintero Gallego y Doña María José Rodríguez Conde, profesoras y doctoras de la Universidad de Salamanca;

\section{CERTIFICAN:}

Que el trabajo titulado "Nivel lector y construcción del conocimiento a partir de fuentes digitales e impresas" ha sido realizado por Don Gabriel Herrada Valverde bajo nuestra dirección; reuniendo a nuestro juicio todos los requisitos científicos y formales para ser presentado y defendido públicamente. La investigación indaga sobre un problema relevante en investigación educativa y presenta un grado alto de innovación. El proceso metodológico seleccionado resulta adecuado para alcanzar los objetivos e hipótesis planteadas, la discusión es completa y basada en una actualizada fundamentación teórica. Presenta una contextualización adecuada, un riguroso procedimiento de obtención y análisis de datos, y extrae conclusiones valiosas para el área de conocimiento en el que está inmerso.

En Salamanca a de Septiembre de 2015 


\section{AGRADECIMIENTOS}

Desde el comienzo de la "carrera de fondo" que ha sido la realización de esta tesis doctoral, me han acompañado diferentes personas e instituciones que, de uno u otro modo, han puesto su granito de arena para que esta investigación haya sido posible. A todas ellas quiero dedicar mi más sincero agradecimiento.

Agradecer a la Universidad de Salamanca, en general, y al departamento Didáctica Organización y Métodos de Investigación, en particular, la tutorización académica de esta investigación. Especialmente, debo mencionar a mis dos directoras de tesis. Gracias a María José Rodríguez Conde, cuyo apoyo académico durante el proceso de investigación (fundamentalmente en la parte metodológica) ha sido imprescindible para que nuestro trabajo llegase a buen puerto. Y gracias a Anunciación Quintero Gallego, una persona a quien considero un referente profesional y humano, cuyo apoyo y asesoramiento desde el curso 2007/2008, primero, como profesora de la Licenciatura de Psicopedagogía, y después, como directora de tesis, han dado como fruto esta tesis, la última que dirige.

Manifestar también mi gratitud con: Verónica Basilotta, Eva María Torrecilla y Susana Olmos, por ayudarme durante la aplicación de las pruebas realizadas; José Orrantia, Luján Lázaro, Elena Ramírez y Ana García-Valcárcel, por facilitarme sus respectivos grupos-clase como muestra; Azucena Hernández, por revisar los análisis de contenido que realizamos; $\mathrm{M}^{\mathrm{a}}$ Esperanza Herrera, por ofrecerme su despacho para trabajar durante mis estancias en Salamanca; las personas de la copistería de la Facultad (especialmente a Ana), por su trabajo durante todos estos años; todos los alumnos que realizaron las pruebas, por su colaboración; mi prima Rocio por la corrección de los errores gramaticales del abstract.

Especialmente, deseo agradecer a mi familia más directa el cariño y apoyo manifestado durante todo el proceso. Gracias a mi padre, por su estima, generosidad y paciencia; gracias a mi madre, por su confianza, afecto y virtud; gracias a mi hermano Alberto, por su voluntad, amistad y apego; gracias a mi hermana Rosabel y a mi cuñado Raúl, por su consideración y aprecio, y por sus valiosos consejos al inicio de esta investigación; y gracias a mi sobrino Raúl, porque su nacimiento ha traído una enorme dicha a toda la familia.

Me gustaría también acordarme de otras personas que han contribuido a mi formación académica y personal. Gracias a mis maestros del colegio por su trabajo, con un recuerdo especial hacia Doña Concha, Mari Carmen (DEP) y Don Jerónimo (DEP); y gracias a M ${ }^{\mathrm{a}}$ Teresa García Gómez, profesora de la Universidad de Almería, por confiar en mis competencias académicas. 
En estos momentos de alegría quiero recordar también a aquellos que ya no están con nosotros. En concreto, mi buen amigo José Elías (DEP), antiguo encargado de Ieronimus en la catedral nueva de Salamanca; y mis cuatro abuelos, Salvador, Isabel, Gabriel y Dolores (Requiescant in pace).

En último lugar, aunque pueda pecar de falta de modestia, no puedo finalizar estas líneas sin agradecérmelo a mí mismo. Cuando abandoné la Licenciatura de Historia en 2001, nunca hubiera imaginado que un día llegaría hasta aquí. Sin la constancia, el esfuerzo y la resistencia a la frustración que he ido desarrollando durante los últimos 14 años, no lo habría logrado.

Gracias a todos

Gabriel Herrada Valverde 
"El estudio no se mide por el número de páginas leídas en una noche, ni por la cantidad de libros leídos en un semestre. Estudiar no es un acto de consumir ideas, sino de crearlas y recrearlas" (Paulo Freire) 


\section{RESUMEN}

El principal propósito de esta tesis doctoral es: a) determinar si los alumnos que comienzan y han finalizado alguna de las titulaciones de maestro en la Universidad de Salamanca, disponen de habilidades básicas de comprensión y expresión escrita; y b) comprobar en ambas muestras la influencia que tiene el tipo de texto, impreso e hipervinculado, en la utilización de las estrategias de comprensión y expresión escrita necesarias para realizar una determinada tarea académica (la realización de un resumen escrito). Para ello, utilizamos dos diseños diferentes: uno de carácter pre-experimental, cuya variable independiente es el momento formativo; y otro de carácter cuasiexperimental, que toma en consideración tanto el momento formativo como el formato textual. Los resultados obtenidos sugieren que el lector, independientemente del momento formativo en el que se encuentra (y en el caso de la tarea de resumen, del formato textual en el que lee el texto), no parte de un modelo de tarea adecuado que le permita obtener un producto de tarea satisfactorio. 


\begin{abstract}
The main purpose of this doctoral thesis is: a) to determine if the university students who start and have finished a teaching degree in Salamanca University, have the basic reading and writing skills; and b) to check in both samples the influence of text type, printed and hyperlinked, on the use of the reading and writing strategies which are necessary to do a given academic task (making a written summary). To do this, we use two different designs: one of them with a pre-experimental character whose independent variable is the formative moment, and the other with a quasi-experimental character that takes into account both the formative moment variable and the text format variable. The outcomes suggest that the reader, independently of his/her formative moment (and the text type in case of the summary task), does not take as point of departure an appropriate task model which leads to obtain a satisfactory product.
\end{abstract}




\section{PRIMERA PARTE: MARCO TEÓRICO}

\section{CAPÍTULO I. LA CONSTRUCCIÓN DE CONOCIMIENTO EN EL CONTEXTO UNIVERSITARIO COMO TAREA ACADÉMICA}

\subsection{LA LECTURA COMO ACTIVIDAD BÁSICA PARA LA CONSTRUCCIÓN DE CONOCIMIENTO}

1.1.1. Algunas consideraciones sobre la investigación en la comprensión lectora.....

1.1.1.1. Enfoques sobre el procesamiento de la información textual ......................... 29

1.1.1.2. Enfoques sobre estructuras cognitivas para la representación mental del texto

1.1.1.3. Enfoque desde el que parte nuestra investigación

1.1.2. El modelo de Construcción-Integración: un marco de referencia para el estudio de la comprensión lectora desde el punto de vista de la construcción del conocimiento

1.1.2.1. La Representación textual.

1.1.2.2. La Representación situacional

1.1.2.3. La construcción de la representación textual y situacional dentro de la memoria de trabajo

1.1.2.4. Principales limitaciones del modelo Construcción-Integración 50

1.1.3. Factores que inciden en la comprensión lectora.

1.1.3.1. Factores dependientes del texto: la cohesión textual y el formato textual

1.1.3.2. Factores dependientes del lector (cognitivos)

1.1.3.3. Factores dependientes del contexto. 65

1.1.3.4. Interacción entre factores implicados en la comprensión lectora durante el proceso de lectura. 
1.2. EL RESUMEN: UNA TAREA ELEMENTAL QUE FACILITA LA COMPRENSIÓN DE TEXTO/S ACADÉMICO/S.

1.2.1. Definición de resumen escrito

1.2.2. La incidencia del resumen en la comprensión del texto.

1.2.3. Diferencias entre lectores maduros e inmaduros a la hora de realizar un resumen escrito.

1.2.3.1. Tipo de ideas del texto original que aparecen en el resumen

1.2.3.2. Estrategias de síntesis que se reflejan en el resumen escrito

1.2.3.3. Orden en el que aparecen las ideas del texto original en el resumen escrito

1.2.3.4. Procesos cognitivos implicados en la composición del resumen escrito

1.3. LA COMPRENSIÓN LECTORA A PARTIR DE HIPERTEXTO 87

1.3.1. Definición de hipertexto

1.3.2. Aspectos que inciden en las características específicas de un sistema hipertextual

1.3.2.1. La granularidad o tamaño de los nodos

1.3.2.2. El número y el tipo de enlaces

1.3.2.3. La estructura global del hipertexto.

1.3.2.4. La disposición de ayudas a la navegación: los esquemas gráficos

1.3.3. Tareas y Procesos específicos asociados a la comprensión de hipertexto

1.3.3.1. Tareas implicadas en la lectura de hipertexto 98

1.3.3.2. Procesos específicos implicados en la lectura hipertextual: la selección del orden de lectura 
SEGUNDA PARTE: BLOQUE EXPERIMENTAL

CAPÍTULO II. METODOLOGÍA DE LA INVESTIGACIÓN.

2.1. FINALIDAD Y OBJETIVOS DE LA INVESTIGACIÓN

2.3. DISEÑO DE LA INVESTIGACIÓN

2.3.1. Diseño I: Evaluación de las habilidades básicas de comprensión y expresión escrita para la construcción de conocimiento

2.3.2. Diseño II: Evaluación del efecto del formato textual (impreso vs hipervinculado) sobre las estrategias de comprensión y expresión escrita

2.4.1. Variables en el Diseño I para la evaluación de las habilidades básicas de comprensión y expresión escrita para la construcción de conocimiento.

2.4.1.1. Variables Dependientes en el Diseño I para la evaluación de las habilidades básicas de comprensión y expresión escrita para la construcción de conocimiento ... 116

2.4.1.2. Variables Independientes en el Diseño I para la evaluación de las habilidades básicas de comprensión y expresión escrita para la construcción de conocimiento ... 123

2.4.1.3. Variables Control en el Diseño I para la evaluación de las habilidades básicas de comprensión y expresión escrita para la construcción de conocimiento

2.4.2. Variables en el Diseño II para la evaluación del efecto del formato textual sobre las estrategias de comprensión y expresión escrita

2.4.2.1. Variables Dependientes en el Diseño II para la evaluación del efecto del formato textual sobre las estrategias de comprensión y expresión escrita

2.4.2.2. Variables Independientes en el Diseño II para la evaluación del efecto del formato textual sobre las estrategias de comprensión y expresión escrita.

2.4.2.3. Variables Control en el Diseño II para la evaluación del efecto del formato textual sobre las estrategias de comprensión y expresión escrita 
2.5.1. Instrumentos de recogida de información en el Diseño I para la evaluación de las habilidades básicas de comprensión y expresión escrita para la construcción de conocimiento

2.5.1.1. Cuestionario identificativo de contexto

2.5.1.2. Prueba de Habilidades Básicas de Comprensión y Expresión Escrita (PHBC-E)..

2.5.2. Instrumentos de recogida de información en el Diseño II para la evaluación del efecto del formato textual sobre las estrategias de comprensión y expresión escrita .... 149

2.5.2.1. Pre-test

2.5.2.2. Post-test: Prueba resumen del texto impreso 149

2.5.2.3. Post-test: Prueba resumen del texto hipervinculado 161

2.6. POBLACIÓN Y MUESTRA 172

2.6.1. Características de la muestra 172

2.6.1.1. Muestra en el Diseño I :Tamaño y selección 173

2.6.1.2. Muestra en el Diseño II: Tamaño y selección

2.7. TRABAJO DE CAMPO: APLICACIÓN DE LAS PRUEBAS Y TEMPORALIZACIÓN 175

2.7.1. Aplicación de pruebas del Diseño I (fase Pre-test Diseño II) y temporalización 175

2.7.2. Aplicación de pruebas Pos-test del Diseño II y temporalización 177

2.8. INFORMATIZACIÓN Y TIPO DE ANÁLISIS DE DATOS 188 
3.1. RESULTADOS SOBRE EL DISEÑO I: EVALUACIÓN DE LAS HABILIDADES BÁSICAS DE C y E ESCRITA EN EDUCACIÓN PRIMARIA Y PSICOPEDAGOGÍA

3.1.1. Características de las muestras y contraste de homogeneidad: Educación Primaria vs Psicopedagogía. 191

3.1.1.1. Contraste para las variables de Identificación (VC1) para el Diseño I 192

3.1.1.2. Contraste para las variables Pedagógicas (VC2) para el Diseño I 194

3.1.1.3. Contraste para las variables Hábitos Lectores (VC3) para el Diseño I 196

3.1.2. Resultados de las hipótesis en el Diseño I: Habilidades básicas de comprensión y expresión escrita en Educación Primaria y Psicopedagogía.

3.1.2.1. Resultados en la Formación de la idea principal de cada párrafo (VD1) 200

3.1.2.2. Resultados en las Dificultades para formar la idea principal de cada párrafo (VD2)

3.1.2.3. Resultados para Construcción de un mapa conceptual donde se recoja la macroestructura del texto leído (VD3)

3.1.2.4. Resultados para Dificultades en la construcción del mapa conceptual (VD4) 207

3.1.3. Contraste de las hipótesis relativas a la variable dependiente Habilidades básicas de comprensión y expresión escrita en los grupos de Educación Primaria y Psicopedagogía

3.2. RESULTADOS SOBRE EL DISEÑO II: EVALUACIÓN DEL EFECTO DEL FORMATO TEXTUAL SOBRE LAS ESTRATEGIAS DE C Y E ESCRITA EN EDUCACIÓN PRIMARIA Y PSICOPEDAGOGÍA.

3.2.1. Resultados del Pre-test en el Diseño II

3.2.1.1. Características de las muestras y contraste de homogeneidad: EDP texto, EDP hipertexto, PSP texto, PSP hipertexto

3.2.1.2. Resultados de las hipótesis en el Diseño II: Habilidades básicas de comprensión y expresión escrita en EDP texto, EDP hipertexto, PSP texto y PSP hipertexto ....... 219 
3.2.2.1. Resultados en Habilidades específicas de comprensión y expresión escrita para la síntesis de información.

3.2.2.2. Evaluación de otras variables (secundarias)

4.1.1.1. Discusión sobre los resultados de la tarea 1: Identificar la idea principal de cada párrafo.

4.1.1.2. Discusión resultados tarea 2: Construcción de un mapa conceptual que recoja las relaciones jerárquicas que se dan entre las ideas del texto

4.1.1.3. Análisis conjunto de los resultados de las tarea 1 y 2

4.1.2. Discusión de los resultados del Diseño II 


\section{ÍNDICE DE CUADROS}

\section{$\underline{\text { Cuadros del capítulo I }}$}

Cuadro 1.1. Relaciones temáticas proposicionales que aparecen en el extracto textual......

Cuadro 1.2. Relaciones estructurales proposicionales

Cuadro 1.3. Texto sobre la economía de la España musulmana.

Cuadro 1.4. Macroestructura del texto sobre la economía de la España musulmana

Cuadro 1.5. Ejemplo de texto con referente ambiguo

Cuadro 1.6. Ejemplo de texto multidimensional 1 ......

Cuadro 1.7. Ejemplo de texto multidimensional 2.

Cuadro 1.8. Ejemplo de pasaje muy cohesivo

Cuadro 1.9. Ejemplo de pasaje cohesivo en el que aparecen palabras problemáticas

Cuadro 1.10. Ejemplo de pasaje poco cohesivo

Cuadro 1.11. Elementos cohesivos textuales 56

Cuadro 1.12. Ejemplo de pasaje muy cohesivo 56

Cuadro 1.13. Diferencias entre buenos y malos lectores en cuanto a habilidades y estrategias de lectura

Cuadro 1.14. Síntesis de las diferencias entre lectores maduros e inmaduros en habilidades y estrategias de lectura

Cuadro 1.15. Diferencias entre lectores maduros e inmaduros en la realización del resumen escrito

Cuadro 1.16. Tipologías en las que se puede enmarcar un enlace

Cuadro 1.17. Ejemplos de ayudas a la navegación con diferente grado de estructuración 96

\section{$\underline{\text { Cuadros del capítulo II }}$}

Cuadro 2.1. Diseño I

Cuadro 2.2. Diseño II 
Cuadro 2.6. Variables Dependientes en el Diseño II

Cuadro 2.7. Variables Secundarias en el Diseño II

Cuadro 2.8. Esquema de evaluación de PHBC-E

Cuadro 2.9. Texto adaptado

Cuadro 2.10. Tareas y objetivos, y tipo de análisis realizado 135

Cuadro 2.11. Idea principal de cada párrafo y nivel de dificultad 136

Cuadro 2.12. Contenido del párrafo 3

Cuadro 2.13. Relaciones superficiales de las ideas del párrafo 3

Cuadro 2.14. Relaciones estructurales de las ideas del párrafo 3

Cuadro 2.15. Grado de cohesión textual del párrafo 3

Cuadro 2.16. Idea principal e idea temática del párrafo 3 140

Cuadro 2.17. Nivel de dificultad del párrafo 3 141

Cuadro 2.18. Criterios generales de evaluación en la tarea 1.

Cuadro 2.19. Dificultades generales en la extracción de macroproposiciones en la tarea 1

Cuadro 2.20. Categorías específicas de evaluación en el párrafo 3

Cuadro 2.21. Dificultades para extraer la idea principal del párrafo 3 145

Cuadro 2.22. Macroestructura/Superestructura del texto

Cuadro 2.23. Criterios de evaluación en la tarea 2.

Cuadro 2.24. Dificultades para la realización del mapa conceptual.....

Cuadro 2.25. Esquema de evaluación del efecto del formato textual sobre las estrategias específicas de C y EE (texto impreso)

Cuadro 2.26. Contenido del apartado introductorio 151

Cuadro 2.27. Progresión temática en el apartado introductorio 
Cuadro 2.30. Macroestructura del artículo

Cuadro 2.31. Ejemplificación de resumen (modelo)

Cuadro 2.32. Uso de habilidades de comprensión y expresión escrita para realizar el resumen del texto $\left(\mathrm{VDTH}_{1}\right)$

Cuadro 2.33. Procedimiento que el alumnado considera haber seguido para realizar el resumen del texto $\left(\mathrm{VDTH}_{2}\right)$

Cuadro 2.34. Dificultades encontradas (VS1), Utilización de ayudas (VS2), y Opinión sobre la tarea (VS3) (texto impreso)

Cuadro 2.35. Esquema de evaluación del efecto del formato textual sobre las estrategias específicas de C y EE (Hipertexto)

Cuadro 2.36. Progresión temática en el apartado 2 del hipertexto

Cuadro 2.37. Relaciones estructurales en el apartado 2 del hipertexto.....

Cuadro 2.38. Grado de cohesión textual en el apartado 2 del hipertexto

Cuadro 2.39. Uso de habilidades de comprensión y expresión escrita para realizar el resumen de hipertexto

Cuadro 2.40. Procedimientos que el alumnado considera haber seguido para realizar el resumen de hipertexto

Cuadro 2.41. Dificultades encontradas (VS1), Utilización de ayudas (VS2), y Opinión sobre la tarea (VS3) (Hipertexto).

Cuadro 2.42. Temporalización de las pruebas del Diseño I (Pre-test Diseño II)

Cuadro 2.43. Temporalización de la prueba Pos-test del Diseño II

\section{Cuadros del Capítulo III}

Cuadro 3.1. Variables de control constituidas (Diseño I).

Cuadro 3.2. Variables Dependientes en el Diseño I (definición operativa)

Cuadro 3.3. Intervalo de puntación para identificar el nivel del alumnado en: Formación de la idea principal de cada párrafo (VD1) (Diseño I) 
Cuadro 3.4. Variables de control constituidas (Diseño II)

Cuadro 3.5. Intervalo de puntuación para identificar el nivel del alumnado en: Formación de la idea principal de cada párrafo (VD1) (Diseño II)

\section{Cuadros del Capítulo IV}

Cuadro 4.1. Ejemplo de resumen que muestra las dificultades de un alumno (EDP56) a nivel de párrafo, interpárrafo y de texto 


\section{ÍNDICE DE TABLAS}

\section{$\underline{\text { Tablas capítulo II }}$}

Tabla 2.1. Alumnado que accedió a los títulos de maestro en la Universidad de Salamanca en el curso 2012/2013

Tabla 2.2. Muestra final para el Diseño I 173

Tabla 2.3. Muestra final para el Diseño II 175

\section{Tablas capítulo III}

Tabla 3.1. Género (VC1.1) (Diseño I) 193

Tabla 3.2. Edad (VC1.2) (Diseño I)

Tabla 3.3. Calificación de entrada a la universidad (VC2.3) (Diseño I) 194

Tabla 3.4. Idioma de lectura (VC3.1) (Diseño I)

Tabla 3.5. Materia del último libro leído (VC3.3) (Diseño I)

Tabla 3.6. Razones para no leer con mayor frecuencia (VC3.5) (Diseño I)

Tabla 3.7. Lectura en soporte digital (VC3.6) (Diseño I).

Tabla 3.8. Resumen de los resultados en el Diseño I para Formación de la idea principal de cada párrafo (VD1), y análisis inferencial entre Psicopedagogía y Educación Primaria

Tabla 3.9. Prueba t de diferencia de medias en cuanto a: Formación de la idea principal de cada párrafo (VD1) (Diseño I)

Tabla 3.10. Resumen de los resultados en el Diseño I para Dificultades para formar la idea principal de cada párrafo (VD2), y análisis inferencial entre Psicopedagogía y Educación Primaria

Tabla 3.11. Dificultades para formar la idea principal del párrafo 7 (Diseño I) ......

Tabla 3.12. Construcción de un mapa conceptual donde se recoja la macroestructura del texto leído (VD3) (Diseño I). 
Tabla 3.15. Edad (VC1.2) (Diseño II)

Tabla 3.16. Calificación de entrada a la universidad (VC2.3) (Diseño II)

Tabla 3.17. Idioma de lectura (VC3.1) (Diseño II)

Tabla 3.18. Materia del último libro leído (VC3.3) (Diseño II)

Tabla 3.19. Razones para no leer con mayor frecuencia (VC3.5) (Diseño II).

Tabla 3.20. Lectura en soporte digital (VC3.6) en los grupos del Diseño II.

Tabla 3.21. Resumen de los resultados en el Diseño II para Formación de la idea principal de cada párrafo (VD1), y análisis inferencial entre PSP texto, PSP hipertexto, EDP texto y EDP hipertexto

Tabla 3.22. Pruebas ANOVA para determinar las diferencias entre alumnos de diferentes grupos en cuanto al nivel en Formación de la idea principal de cada párrafo (VD1)(Diseño II) ... 222

Tabla 3.23. Resumen de los resultados en el Diseño II para Dificultades para formar la idea principal del párrafo (VD2), y análisis inferencial entre PSP texto, PSP hipertexto, EDP texto y EDP hipertexto

Tabla 3.24. Construcción de un mapa conceptual donde se recoja la macroestructura del texto leído (VD3) (Diseño II)

Tabla 3.25. Dificultades en la construcción del mapa conceptual (VD4) (Diseño II) 225

Tabla 3.26. Tipo de información subrayada (Texto impreso) $\left(\mathrm{VDTH}_{1.1}\right) \ldots$

Tabla 3.27. Anotaciones realizadas en el artículo (Texto impreso) $\left(\mathrm{VDTH}_{1.2}\right)$ 228

Tabla 3.28. Integración intertextual (Hipertexto) $\left(\mathrm{VDTH}_{1.3}\right)$ 229

Tabla 3.29. Integración intertextual (Texto impreso) $\left(\mathrm{VDTH}_{1.4}\right)$ 230

Tabla 3.30. Realización de borrador $\left(\mathrm{VDTH}_{1.5}\right)$

Tabla 3.31. Resumen de la información de texto/hipertexto $\left(\mathrm{VDTH}_{1.6}\right)$

Tabla 3.32. Dificultades en la realización del resumen $\left(\mathrm{VDTH}_{1.7}\right)$

Tabla 3.33. Procedimiento lectura (Texto impreso) $\left(\mathrm{VDTH}_{2.1}\right)$

Tabla 3.34. Procedimiento escritura (Texto impreso) $\left(\mathrm{VDTH}_{2.2}\right)$ 
Tabla 3.35. Procedimiento lectura (Hipertexto) $\left(\mathrm{VDTH}_{2.3}\right)$

Tabla 3.36. Procedimiento escritura (Hipertexto) $\left(\mathrm{VDTH}_{2.4}\right)$ 235

Tabla 3.37. Dificultades encontradas por el alumnado que realizó la tarea a partir de texto impreso (VS1.1)

Tabla 3.38. Dificultades encontradas por el alumnado que hizo la tarea a partir de hipertexto (VS1.2).

Tabla 3.39. Utilización de las ayudas a la comprensión lectora (Glosario) (VS2) 239

Tabla 3.40. Opinión del alumnado (VS3) 


\section{ÍNDICE DE GRÁFICOS}

\section{Gráficos capítulo III}

Gráfico 3.1. Distribución de la muestra de Ed. Primaria para Modalidad de bachillerato y Sexo (Diseño I).

Gráfico 3.2. Distribución de la muestra de Psicopedagogía para Primer ciclo cursado y Sexo (Diseño I)

Gráfico 3.3. Distribución de las muestras de Ed. Primaria y Psicopedagogía para Causa de la lectura del último libro (VC3.2) (Diseño I)

Gráfico 3.4. Cantidad de libros leídos al año (VC3.4) (Diseño I) 198

Gráfico 3.5. Nivel del alumnado en: Formación de la idea principal de cada párrafo (VD1) (Diseño I)

Gráfico 3.6. Modalidad de bachillerato (EDP texto vs EDP hipertexto) y Sexo (Diseño II)

Gráfico 3.7. Primer ciclo cursado (PSP texto vs PSP hipertexto) y Sexo (Diseño II) 215

Gráfico 3.8. Causa de la lectura del último libro (VC3.2) (Diseño II)

Gráfico 3.9. Cantidad de libros leídos al año (VC3.4) (Diseño II)

Gráfico 3.10. Nivel del alumnado en: Formación de la idea principal de cada párrafo (VD1) (Diseño II) 


\section{ÍNDICE DE IMÁGENES}

\section{Imágenes capítulo I}

Imagen 1.1. Representación de los agentes implicados en el proceso de comprensión lectora

Imagen 1.3. Representación de las diferentes estructuras topológicas en hipertexto

\section{Imágenes capítulo II}

Imagen 2.1. Contenido del apartado 2 (página principal del hipertexto) 164

Imagen 2.2. Información asociada al hipervínculo "el lenguaje audiovisual”.....

Imagen 2.3. Información asociada al hipervínculo " hipertextualidad” 165

Imagen 2.4. Diagrama de temas

Imagen 2.5. Grupo A (alumnos que realizaron la tarea a partir de texto impreso) 179

Imagen 2.6. Contenido del enlace "Indicaciones para realizar la tarea Grupo A"

Imagen 2.7. Contenido del enlace "Subir resumen Grupo A"

Imagen 2.8. Contenido del enlace "Subir descripción pasos resumen Grupo A"

Imagen 2.9. Grupo B (alumnos que realizaron la tarea a partir de hipertexto)

Imagen 2.10. Contenido del enlace "Indicaciones para realizar la tarea Grupo B"

Imagen 2.11. Contenido del enlace "Subir resumen Grupo B"

Imagen 2.12. Contenido del enlace "Subir descripción pasos resumen Grupo B”....

\section{Imágenes capítulo IV}

Imagen 4.1. Ejemplo de mapa conceptual que organiza las ideas en torno a una estructura subordinada.

Imagen 4.2. Ejemplo de mapa conceptual que muestra dificultades para realizar la tarea satisfactoriamente 


\section{INTRODUCCIÓN}

En el ámbito universitario, la construcción de conocimiento está íntimamente ligada a la realización de actividades de lectura orientada a tareas que implican, usualmente, la comprensión y redacción de productos escritos. Para llevarlas cabo, los estudiantes suelen enfrentarse a textos académico-científicos que, debido a su complejidad, suponen una considerable demanda cognitiva para la memoria de trabajo (carga cognitiva intrínseca) ${ }^{1}$. Por ello, es fundamental que el alumnado universitario:

a) Posea habilidades/estrategias básicas de lectura que le permita seguir el hilo conductor de un texto, extraer la esencia de dicho texto y autorregular el proceso de lectura.

b) Disponga de habilidades/estrategias vinculadas a la expresión escrita que favorezcan, a través de la reflexión, la mejora de la comprensión adquirida durante la lectura. En este sentido, existen técnicas, como la extracción de macroproposiciones o palabras clave del texto, la elaboración de esquemas y la construcción de resúmenes; que facilitan que el lector tenga mayor consciencia del nivel de comprensión alcanzado, puesto que le pemiten descargar (con mayor o menor grado de estructuración) la información esencial del texto sobre el papel.

c) Utilice las habilidades mencionadas en el contexto específico de la tarea concreta que debe realizar.

Por otra parte, la integración de las nuevas tecnologías en todos los aspectos de nuestra vida cotidiana ha hecho que surjan textos digitales no lineales o multilineales, llamados hipertextos, que requieren la puesta en marcha de algunos procesos de lectura específicos, entre los que destaca la selección del orden de lectura. De manera que un mismo documento presentado en dos formatos diferentes, impreso e hipertextual, puede conllevar procesos cognitivos similares o diferenciales, en función de la libertad que tiene el lector de hipertexto para decidir el orden de lectura de los nodos.

\footnotetext{
${ }^{1}$ La interacción de las variables conocimiento de dominio y cohesión textual será la que finalmente determine si esa carga cognitiva es efectiva o inefectiva.
} 
Teniendo en cuenta la gran importancia de la comprensión lectora para la construcción de significado, los resultados de los informes PIAC (Programa internacional para la evaluación de las competencias de la población adulta) (OCDE, 2012, 2013) no son nada alentadores. Según estos informes, España obtiene la puntuación más baja entre los países de la OCDE en lo que se refiere a la comprensión lectora de textos en formato impreso y en formato digital (hipertextos e hipermedias).

Tomando todo ello en consideración, hemos realizado una investigación que trata de determinar, por un lado, si el alumnado universitario que se encuentra en diferentes momentos formativos dispone de habilidades básicas de comprensión y expresión escrita; y por otro lado, si el formato textual (texto impreso o hipervinculado) tiene un efecto diferencial en la puesta en marcha de habilidades de comprensión y expresión escrita, cuando el alumno realiza una actividad de lectura orientada a una tarea de escritura simple (resumir el texto/hipertexto).

Comenzaremos nuestro trabajo revisando el estado de la cuestión a través de un marco teórico que, tomando como referencia el modelo Construcción-Integración de Kinstch $(1988,1998,2004)$, se adentra en los factores que inciden en la comprensión (texto, contexto y lector), poniendo especial énfasis en dos aspectos: el formato hipertextual y el resumen escrito.

Posteriormente, describimos la metodología de la investigación utilizada, explicitando: nuestros objetivos e hipótesis, los dos tipos de diseño que conforman la investigación, las variables tomadas en consideración, los instrumentos de recogida de datos elaborados, la muestra que fue objeto de estudio, el trabajo de campo realizado y el tipo de análisis de datos utilizado.

Seguidamente, comunicamos los resultados obtenidos para los dos diseños de investigación.

Finalmente, discutimos los resultados obtenidos en relación con el marco teórico, y, apoyándonos en dichos resultados y discusiones, elaboramos una serie de conclusiones finales, explicitando también las líneas de investigación susceptibles de abrirse en un futuro. 
PRIMERA PARTE: MARCO TEÓRICO 


\section{CAPÍTULO I. LA CONSTRUCCIÓN DE CONOCIMIENTO EN EL CONTEXTO UNIVERSITARIO COMO TAREA ACADÉMICA}

El carácter ambicioso de esta tesis doctoral ha exigido elaborar un marco teórico holístico con el que sustentarla. Por lo que consideramos imprescindible partir de fundamentos generales vinculados a la comprensión lectora, para progresivamente ir abordando aspectos específicos que vamos a tratar en nuestra investigación.

El apartado primero, comienza dando una visión general del proceso de comprensión, que se va especificando durante el transcurso del mismo. En primer lugar, revisamos, brevemente, los diferentes enfoques sobre comprensión (sobre el procesamiento y sobre las estructuras cognitivas); y en base ellos, describimos el enfoque desde el que parte nuestra investigación, y justificamos la elección del modelo Construcción-Integración como marco de referencia para nuestro estudio. En segundo lugar, nos adentramos en el modelo Construcción-Integración, analizando cuáles son sus postulados fundamentales (la representación textual, la representación situacional, y la construcción de ambos tipos de representación dentro de la memoria de trabajo) y observando cuáles son sus principales limitaciones. Para finalizar, abordamos los factores vinculados a las variables que inciden en la comprensión: factores dependientes del texto (cohesión textual y formato textual), del lector (conocimiento de dominio, habilidades/estrategias de lectura y la carga cognitiva del texto para el lector) y del contexto (comprobaremos la utilidad del modelo MD-TRACE para adecuarse a cualquier tipo de tarea de lectura, puesto que nos permite observar el proceso de comprensión y expresión escrita desde que el lector crea un modelo de tarea hasta que construye un producto de tarea final).

En el apartado segundo, analizamos la comprensión lectora en el contexto de una de las tareas híbridas más simples: el resumen. Concretamente, definimos qué entendemos por resumen, revisamos qué incidencia tiene el resumen en la comprensión según diversos estudios y describimos las diferencias entre lectores maduros e inmaduros a la hora de realizar un resumen escrito.

En el apartado tercero, analizamos qué implica la comprensión dentro de un formato textual en particular, el hipertexto. Conceptualizamos el término hipertexto, 
describimos las principales características de los sistemas hipertextuales, y analizamos las tareas y procesos específicos asociados a la comprensión lectora de hipertexto.

Finalizamos el capítulo con unas conclusiones que nos permiten enlazar el marco teórico con la parte práctica de nuestra investigación.

\subsection{LA LECTURA COMO ACTIVIDAD BÁSICA PARA LA CONSTRUCCIÓN DE CONOCIMIENTO}

\subsubsection{Algunas consideraciones sobre la investigación en la comprensión lectora}

El estudio de la actividad lectora conforma un contexto de investigación multidisciplinar (Lingüística, Psicolingüística, Inteligencia Artificial, Pedagogía, etc.) caracterizado por la fluidez comunicativa entre disciplinas. Por ejemplo, las categorías descriptivas de la lingüística delimitan el campo de estudio de la psicolingüística; los hallazgos de la psicolingüística se refutan a través de los estudios en Inteligencia Artificial; los resultados obtenidos en los estudios de Inteligencia Artificial confirman o reformulan los postulados de teorías psicológicas y pedagógicas sobre el proceso lector, etc.

Este carácter interdisciplinar ha permitido enriquecer los diferentes ámbitos de investigación, pero también, ha restringido el estudio de la lectura a los límites impuestos por los paradigmas lingüísticos y psicológicos dominantes en cada momento. Así se explica que durante el predominio de la Psicología Conductista, la mayor parte de los estudios concibieran la comprensión como un acto externo a la lectura.

No podríamos hablar del estudio de la comprensión lectora propiamente dicho, hasta que el auge de la psicología cognitiva y la aparición de teorías linguísticas, como la gramática generacional (Chomsky, 1965, 1972) y la gramática funcional (Halliday, 1961, 1970), centraron la atención investigadora en los procesos internos del lector y en el análisis semántico de textos a distintos niveles. Sólo entonces surgieron un conjunto de estudios desde los ámbitos de la lingüística (Petofi, 1973; Van Dijk, 1972), la psicolingüística (Kintsch, 1972, 1974, 1977; Kintsch y Keenan, 1973) y la inteligencia artificial (Shank y Abelson, 1977; Winograd, 1975, 1976), que supusieron el punto de partida de la investigación actual sobre los procesos de lectura.

En este primer apartado, describiremos brevemente distintos enfoques vinculados a la lectura entendida como proceso de comprensión; y partiendo de ellos, justificaremos la elección del modelo Construcción-Integración (Kintsch, 1988, 1998, 2002, 2004) como marco de referencia de nuestro estudio. Como veremos, la investigación sobre comprensión coincide en considerar la lectura como un proceso multinivel cuyo fin es la construcción de la representación mental del texto; pero sin embargo, difiere a la hora de explicar: a) cómo se comunican los diferentes niveles 
durante el procesamiento de la información, y b) qué estructuras cognitivas utiliza el lector para construir una representación mental del texto.

\subsubsection{Enfoques sobre el procesamiento de la información textual}

Cabe destacar dos enfoques que intentan explicar cómo se produce el procesamiento de la información durante la actividad lectora: el unidireccional y el bidireccional.

\section{A. Enfoque unidireccional}

El enfoque unidireccional sugiere que los niveles de procesamiento que intervienen durante el proceso de lectura se comunican entre sí de forma unidireccional, lineal y jerárquica. Partiendo de esta concepción, se desarrollaron dos modelos explicativos que contrastan a la hora de señalar desde qué niveles parte el procesamiento: los modelos ascendentes y los modelos descendentes.

Según los modelos ascendentes o Bottom-up (Gough, 1972, 1985,1991; Hunt, 1978; Laberge y Samuels, 1974; Samuels, 1987), el lector parte de procesos de bajo nivel o microprocesos (reconocimiento léxico y fonológico de palabras, identificación significado de palabras, establecimiento del valor sintáctico de palabras dentro de frases) para llegar a los procesos de alto nivel o macroprocesos (representación del significado semántico de párrafos y del texto). Así pues, como indica Gough (1991) al describir su propio modelo, una vez que la letra impresa se refleja en la retina, el lector va procesando de manera ascendente la información a través de una serie de etapas, que comienzan con la representación icónica de la palabra impresa, y finalizan con la integración de las diferentes oraciones textuales dentro de un guión o esquema mental:

Gough (1972) intented to describe what happens in the first second after print is reflected onto retina. The model consisted of a series of seven stages beginning with an iconic representation of the printed word, proceeding trough recognition of its letters and their phonological recoding to its meaning. Word meanings were placed in primary memory, were they were integrated into sentences. To read aloud, the resulting sentence was then edited into script, which was then delivered by the vocal system (p.141).

Desde este punto de vista, la información necesaria para que se produzca la comprensión está únicamente en el texto, por lo que el objetivo principal del lector será tratar de reproducir fielmente el contenido de éste en su mente.

Los modelos descendentes o Top-down (Goodman, 1967, 1971; Smith, 1971, 1973), en cambio, consideran que el procesamiento de la información se produce 
fundamentalmente de arriba abajo. Por lo que en este caso, como afirma Grellet (1981), la comprensión dependerá principalmente del lector, quien, partiendo de sus conocimientos previos, formula hipótesis sobre el posible contenido textual que confirma o refuta durante el procesamiento del texto:

Reading is an activity involving constant guesses that are later rejected o confirmed. This means that one does not read all the sentences in the same way, but one relies on a number of words-or cues- to get an idea of what kind of sentence is likely to follow (p. 56).

\section{B.Enfoque bidireccional}

El enfoque bidireccional trata de aunar los postulados de los modelos ascendentes y descendentes del enfoque unidireccional a través de un modelo interactivo (Just y Carpenter, 1980, 1984; McClelland, 1979, 1987; Perfetti y Roth, 1981; Rummenhart y McClellland, 1981, 1985). Este modelo, como señalan Rummelhart y McClellland (1981), "is one in which data driven, Bottom-up processing combines with Top-down, conceptually driven processing to cooperatively determine the most likely interpretation of the input "'(p.37). Por lo tanto, el procesamiento de la información ocurre tanto de abajo a arriba (conducido por el texto) como de arriba a abajo (conducido el sujeto), produciéndose una activación simultánea de niveles superiores e inferiores, que lleva a cada nivel a consultar a niveles contiguos para ejecutar sus propias funciones. Concretamente, Hernández y Quintero (2001) afirman que el lector al inicio de la lectura se guía principalmente por los datos textuales, procesando ascendentemente aspectos semánticos, léxicos, sintácticos, etc.; lo que le permite también activar progresivamente esquemas con los que formula hipótesis sobre el contenido textual, que va verificándo o refutándo de forma descendente. "Como consecuencia, el lector obtiene simultáneamente información de los diferentes niveles (léxico, semántico, sintáctico, esquemático, interpretativo), integrándola en sus esquemas de conocimiento" (Hernández y Quintero, 2001, p.13). Estamos de acuerdo, la comprensión lectora va a depender tanto de los conocimientos previos que el lector activa partiendo de la información textual, como del contenido textual que el lector anticipa o infiere a partir de dichos conocimientos.

La escueta descripción que acabamos de realizar permite vislumbrar que, como sugieren Hernández (1999), Solé (1987) y Strange (1980), el enfoque unidireccional no se ajusta a lo que realmente ocurre durante las situaciones de lectura, ya que:

a) Los modelos ascendentes no tienen en cuenta el papel fundamental de los conocimientos previos para realizar inferencias o para reconstruir la información textual; y

\footnotetext{
${ }^{2}$ [traducción: “..combina el procesamiento Bottom-up, dirigido por los datos, con el procesamiento Topdown, conceptualmente dirigido, para determinar cooperativamente la mejor interpretación del input]
} 
b) Los modelos descendentes no explicarían cómo varios sujetos que leen el mismo texto pueden llegar a la misma conclusión general si parten de conocimientos previos diferentes.

Estas dificultades parecen solventarse dentro del enfoque bidireccional, que ofrece una visión mucho más holística de los procesos de comprensión lectora. Por ésta y otras razones que posteriormente trataremos, gran parte de los estudios actuales sobre lectura, realizados tanto en ámbito nacional como internacional, parten desde este enfoque.

\subsubsection{Enfoques sobre estructuras cognitivas para la representación mental del texto}

La construcción de la representación mental del texto podemos atribuirla a diferentes constructos cognitivos en función de si partimos desde las teorías del esquema o de si lo hacemos desde las teorías de los modelos mentales.

\section{A. Teorías del esquema}

Partiendo del supuesto de que la memoria semántica está compuesta por conceptos genéricos que han sido abstraídos a partir de experiencias análogas, las teorías del esquema han desarrollado dos líneas de investigación que difieren a la hora de explicar: a) cómo se organizan dichos conceptos en la base de conocimiento del lector, y b) cómo actúan estos conocimientos durante el proceso de lectura. Nos referimos, concretamente, a la perspectiva simbólica o clásica y a la perspectiva conexionista.

La perspectiva simbólica se fundamenta en la hipótesis de que el acto de pensar supone crear un conjunto de representaciones mentales del entorno, a través de la manipulación de símbolos semánticos (llamados proposiciones) almacenados en la memoria en forma de paquetes cerrados de conocimiento (conocidos como esquemas) (Bartlett, 1932; Minsky, 1975; Rumelhart, 1980; Rumelhart y Ortony, 1977). Teniendo esto en cuenta, construir la representación mental de un texto, supone elaborar una representación proposicional del mismo bajo la supervisión de aquellos esquemas que mejor respondan a su contenido semántico. Estas estructuras, tal y como afirma Kinstch (1998), van a actuar, por un lado, como filtros perceptuales que admiten el material consistente y bloquean el material irrelevante con ellos mismos; y por otro, como mecanismos inferenciales para rellenar los vacios informativos que aparecen en el texto. Por lo que, desde esta perspectiva, la comprensión se concibe como un proceso principalmente descendente o Top-down:

A schema in this view serves as a control structures that regulates comprehension processes in a Top-down fashion. It work, on the one hand, like perceptual filter, in that it admit material consistent with it self but 
blocks irrelevant materials, and the other hand, it serves as a inference machine, in that it fills the gaps that are inevitably found in the actual stimulus material (p. 94).

Por su parte, la perspectiva conexionista subraya que el conocimiento está distribuido a través de unidades similares a las neuronas, llamadas nodos, que se conectan entre sí formando una gran red asociativa, en la que los esquemas existen como conjuntos de correlaciones estadísticas (Miikkulainen y Dyer, 1989, 1991). Teniendo esto en cuenta, cuando el lector recibe un input lingüístico, se activarán de forma paralela y distribuida todas las conexiones de la base de conocimiento con las que dicho input correlaciona (se activan tanto conexiones contextualmente adecuadas como inadecuadas); constituyéndose así una representación mental inconsistente, que sólo será coherente cuando el umbral de activación de las conexiones determine cuáles de ellas son contextualmente adecuadas y cuáles inadecuadas. Por lo tanto, desde el punto de vista conexionista la comprensión será un proceso Bottom-up y Top-down que implica reconstruir el contenido textual partiendo de las conexiones que el lector va activando e inhibiendo durante el transcurso de la lectura.

\section{B. Modelos mentales}

La investigación sobre modelos mentales o modelos de la situación no refleja un consenso general en torno a la naturaleza de estos constructos. Cabe destacar que mientras Johnson-Laird (1983, 2010a, 2010b, 2012), Johnson-Laird y D'Ydewalle (1996) y Schaeken y Thevenot (2010) diferencian los modelos mentales de las representaciones proposicionales e imágenes; autores como Gentner y Gentner (1983), Kintsch (1988, 1992, 1998, 2004) y Kintsch y Greeno (1985) abren la posibilidad de que ciertas representaciones proposicionales puedan considerarse como un tipo particular de modelos mentales.

A pesar de estas divergencias, la mayor parte de los estudios coinciden en considerar los modelos mentales como representaciones episódicas que se construyen en un contexto concreto a partir de analogías estructurales entre una situación familiar y otra nueva. Generar un modelo mental supondría, por tanto, integrar lo que se pretende conocer dentro de lo conocido, de forma que la representación construida pueda ser recuperada y aplicada en situaciones o contextos diferentes.

Esto implica que el lector cuando lee, más que activar un conjunto de conocimientos estereotipados, construye una representación de la situación a la que se refiere el texto, que le permite ir más allá del propio texto y aplicar los conocimientos adquiridos a otras situaciones de aprendizaje. En otras palabras, como subraya Sánchez (1989), para generar un modelo de la situación en torno al texto es necesario "la construcción de un mundo para el texto" (p.27). 
La controversia sobre cómo se organiza el conocimiento (esquemas o modelos mentales) está relacionada con la vieja distinción entre memoria semántica (donde se ubican los aspectos más genéricos del conocimiento) y memoria episódica (donde se ubican los aspectos más experienciales del conocimiento); por lo que es factible considerar la existencia de ambos tipos de constructo en la mente del lector. De hecho, autores como De Vega, Carreiras, Gutiérrez-Calvo y Alonso-Quecuty (1990), Iza y Ezquerro (1999) y Van Dijk (2006a) hablan de conexiones funcionales entre esquemas y los modelos mentales, poniendo como ejemplo los "scripts" o guiones, un tipo particular de esquema (formado por secuencias típicas de eventos que ocurren en situaciones comunes) que dispone del carácter autobiográfico que sólo posee la memoria episódica y el carácter estereotipado que sólo poseen los conocimientos almacenados en la memoria semántica. Otro ejemplo de interacción entre ambos constructos, lo encontramos en la visión conexionista del proceso de lectura, que concibe que los esquemas o conexiones entre nodos que mejor reflejan el contenido textual, se descubren en función del contexto situacional en el que se enmarca la información. En este sentido De Vega et al. (1990) afirma, "puede ser que los modelos mentales se elaboren, al menos parcialmente, a partir de contenidos esquemáticos. Asimismo, es posible que los esquemas se abstraigan o sinteticen a partir de trazos procedentes de experiencias individuales o de modelos mentales" (p.122).

Lo que acabamos de señalar nos lleva a pensar que, durante el proceso de comprensión, el lector utiliza ambos tipos de constructo (esquemas y modelos mentales) para construir una representación mental basada, tanto en las relaciones proposicionales que aparecen en el texto, como en el modelo de la situación en la que se enmarcan dichas proposiciones. En este sentido, estudios como los de McNamara y Kintsch (1996), O’Reilly y McNamara (2007) y Ozuru, Dempsey y McNamara (2009) muestran que la representación mental que el lector elabora durante el proceso de lectura se sitúa dentro de un continuum, en cuyos extremos se localizarían, por un lado, una representación más cercana al texto (proposicional), y por otro, una representación más cercana a la situación que se deriva del texto.

\subsubsection{Enfoque desde el que parte nuestra investigación}

El modelo Construcción-Integración (en adelante modelo CI) (Kinstch, 1988, 1998, 2004) supone la reformulación de dos aspectos relevantes del modelo estratégico de comprensión y producción escrita concebido originalmente por Van Dijk y Kintsch (1978, 1983). Por una parte, sustituye la percepción simbólica del proceso de comprensión por una visión híbrida del mismo (simbólica y conexionista), y por otra, pone mayor énfasis en el carácter bidireccional de la lectura. Dichas modificaciones no han afectado al postulado básico del que parte el modelo desde su concepción original: el lector cuando recibe el estímulo lingüístico-gramatical que le supone el texto (código de superficie) activa sus conocimientos previos (base de conocimiento), para construir una 
representación de carácter simbólico proposicional, llamada representación textual o base textual, y una representación de carácter episódico, conocida como representación situacional o modelo de la situación.

Partiendo de esta breve descripción, podemos explicitar las principales razones que nos han llevado a tomar el modelo CI como marco de referencia para nuestra investigación:

- Concibe el procesamiento de la información desde un enfoque bidireccional: se habla de un proceso de construcción, que se realiza de forma ascendente; y de un proceso de integración, que se realiza de manera descendente.

- Es un modelo híbrido en el que unidades simbólicas (proposiciones) se relacionan entre sí de modo conexionista a través de una red asociativa.

- Considera que el lector construye dos tipos de representación: una más cercana al significado del texto, que tiene un carácter semántico-proposicional, y otra más cercana "al mundo" en la que se enmarca al texto, que tiene un carácter episódico.

- Es el modelo de referencia en la mayor parte de los estudios actuales sobre lectura.

Describiremos de forma exhaustiva este modelo, vinculándolo a otras investigaciones más recientes que lo han tomado como referencia para el estudio de la comprensión lectora.

\subsubsection{El modelo de Construcción-Integración: un marco de referencia para el estudio de la comprensión lectora desde el punto de vista de la construcción del conocimiento.}

El modelo CI, como hemos adelantado, supone la construcción de dos tipos de representación mental: la base textual o representación textual y el modelo de la situación o representación situacional.

La elaboración de la representación textual va a suponer, por un lado, acceder al nivel semántico superficial o microestructura con el fin de establecer la coherencia local del texto (las relaciones lineales que se dan entre las proposiciones); y por otro, penetrar en el nivel semántico profundo o macroestructura con el objetivo determinar la coherencia global del texto (las relaciones jerárquicas que dan entre las ideas principales del texto). Por su parte, la construcción de la representación situacional, va a implicar simular mentalmente la situación en la que se enmarca el contenido textual con el fin recrear el mundo en el que éste se ubica. 
Antes de entrar a valorar de forma más sistemática qué implican ambos tipos de representación, hemos de precisar que la diferenciación entre base textual y modelo de la situación es un recurso metodológico utilizado en el modelo CI para tratar discernir entre un nivel de comprensión más cercano a lo literal (de carácter semántico-proposicional) y otro más cercano a lo inferencial (de carácter episódico) (Kintsch, 1988, 1994, 1998; Van Dijk, 2006; Sánchez, 1998). En realidad, más que dos representaciones, el lector va a construir una que va ser producto de la interacción entre la base textual y el modelo de la situación. Así se explica la existencia de una base textual incoherente hasta que se enmarca dentro de un modelo mental o de la situación; que define lo que Van Dijk (1994, 2006a, 2006b) llama aspectos intensionales del texto (hechos que se describen en las relaciones semánticas que se dan a nivel local y global) y que, además, concreta lo que ese mismo autor conoce como aspectos extensionales del texto (plausibilidad de los hechos que se describen dentro la realidad en la que éstos son posibles).

Para profundizar en todo lo que acabamos de señalar, hemos considerado oportuno dividir este epígrafe en un conjunto de sub-apartados:

a) En primer lugar, abordaremos los aspectos implicados en la elaboración de la representación textual, concretamente:

- la proposición como estructura básica de significado;

- la microestructura como nivel semántico superficial que permite determinar la coherencia local del texto; y

- la macroestructura como nivel semántico profundo que permite establecer la coherencia global del texto.

b) Posteriormente, explicaremos qué supone construir la representación situacional.

c) En tercer lugar, nos introduciremos en la memoria de trabajo del lector para clarificar cómo interactúan ambos tipos de representación.

d) Y para finalizar, analizaremos las principales limitaciones que presenta el modelo.

\subsubsection{La Representación textual}

Tal y como afirman la mayoría de los autores consultados (Jáñez, 2014; Kintsch, 1988, 1998, 2004; Sánchez, 1993, 1998; Sánchez, Rosales y García, 2010; Van Dijk, 1994, 2006a, 2006b), elaborar la base textual implica extraer las proposiciones textuales, reconocer cómo se relacionan a nivel local y determinar cuáles de ellas son relevantes a nivel global para establecer cómo se relacionan jerárquicamente. 


\section{A. La proposición como estructura básica de significado}

Acceder al nivel semántico superficial o microestructura textual supone, en primer lugar, identificar el significado de cada palabra teniendo en cuenta el contexto verbal en el que se enmarca. Este trazo predicativo simple, llamado proposición, constituye la unidad mínima de significado dentro del texto a la que se puede atribuir valores de verdad; y por tanto, representa la estructura semántica básica que el lector va a manejar durante el proceso de lectura.

Una proposición, concretamente, es una estructura atómica que consta de un predicado (un verbo, un adverbio o un sintagma nominal) y uno o más argumentos (Kintsch, 1972; Kintsch y Van Dijk, 1978; Meyer, 1975). Cada predicado va a disponer de unas características semánticas particulares que determinan el número y el tipo de argumentos que lo acompañan; por lo que para constituir una proposición es necesario que: a) la información textual recoja explícitamente tanto el predicado como los argumentos que éste requiere; o b) el lector ponga en marcha mecanismos inferenciales que permitan extraer aquellos argumentos requeridos por el predicado que no aparecen explícitamente en el texto. Por ejemplo, si el verbo "dar", que requiere tres argumentos para formar proposición (el agente que da, el objeto que se da y el objetivo a quien se da), es utilizado en una oración en la que aparecen sólo dos (por ejemplo, "Raúl dio un regalo”, donde Raúl es el agente y regalo es el objeto), será necesario inferir el argumento ausente (en el ejemplo, inferir que Raúl dio un regalo a alguien que no conocemos) para construir una estructura proposicional con significado completo:

\section{DAR [RAÚL, REGALO, ALGUIEN]}

Según Kintsch (1998), las unidades semánticas a las que nos referimos, suelen incrustarse unas dentro de otras formando estructuras de mayor complejidad que facilitan la fluidez comunicativa en los procesos discursivos. Desde el punto de vista de este autor, esas proposiciones complejas están constituidas por un núcleo proposicional (una proposición supraordinada) que integra los argumentos y obvia los predicados de las proposiciones que le son subordinadas: "complex propositions are compounds composed of several atomic propositions that are subordinated to a core propositional meaning" (p. 38).

Para ilustrar mejor lo que tratamos de explicar nos vamos a servir de las siguientes oraciones.

"Raúl juega al futbol con sus amigos en la playa"

"Raúl juega al fútbol con amigos que él tiene, en la playa en la que ellos están" 
La primera oración recoge tres proposiciones atómicas, concretamente, una proposición supraordinada (JUGAR [RAÚL, FÚTBOL]) que se relaciona con las dos proposiciones que se le subordinan a través de los conectores "con" y "en":

JUGAR [RAÚL, FÚTBOL] CON [RAÚL, AMIGOS, TENER] EN [RAÚL, AMIGOS, PLAYA, ESTAR]

La segunda oración en cambio, contiene una proposición compleja compuesta por un núcleo proposicional (JUGAR [RAÚL, FÚTBOL]) en el que se integran los argumentos y se omiten los predicados de las proposiciones subordinadas.

\section{JUGAR [RAÚL, FÚTBOL, modificador: AMIGOS, circunstancia lugar: PLAYA]}

Como se puede observar, las proposiciones atómicas de la primera oración y la proposición compleja de la segunda recogen el mismo significado, sin embargo, esta última dota de mayor fluidez al discurso, ya que omite aspectos subordinados que no requieren ser explicitados para que la oración sea comprensible.

Tomando como referencia las características atribuidas al lenguaje proposicional, el campo de la comprensión ha considerado las proposiciones (tanto las atómicas como las complejas) desde una doble perspectiva: como unidades textuales que permiten determinar la complejidad semántica de textos (Bovair y Kieras, 1985; Meyer, 1975; Van Dijk y Kintsch, 1983; Turner y Greene, 1978); y como unidades psicológicas que el lector construye a partir del texto (Kintsch y Van Dijk, 1978; Van Dijk y Kintsch, 1983).

El concepto de proposición, al vincular el significado del texto con la representación mental que el lector construye del mismo, constituye la base sobre la que se sustentan las diferentes teorías de comprensión lectora. Esto explica que, desde sus inicios, la investigación haya tratado de demostrar empíricamente el nexo entre proposición textual y proposición psicológica. En este sentido, destacan dos trabajos realizados por Walter Kintsch; uno en el que analizó la relación entre el número de proposiciones y el tiempo de lectura (Kintsch y Keenan, 1973), y otro en el que indagó en los vínculos entre el recuerdo de información y estas unidades de significado (Kintsch, 1974). Las conclusiones de estos estudios señalaron que los sujetos, por un lado, empleaban más tiempo en leer aquellas frases que tenían un mayor número de proposiciones; y por otro, tendían a recordar las proposiciones como un todo. Lo que supuso un indicio claro de que los lectores procesaban la información tomando como unidad básica la proposición.

Estos resultados han sido apoyados y ampliados por estudios posteriores, como los de Ratcliff y McKoon (1978) y Wanner (1975), que indican que se recuerdan mejor las palabras provenientes de una misma proposición que las palabras procedentes de distintas proposiciones; o como los de Graesser, Hoffman y Clark (1980) y Habertlandt, 
Beria y Sandson (1980), quienes, utilizando esta vez textos completos, corroboraron la relación lineal entre el número de proposiciones y el tiempo de lectura.

En resumen, queremos señalar que el concepto de proposición es básico para explicar los procesos implicados en la comprensión lectora, ya que constituye el soporte sobre el que se sustenta la mayor parte de las teorías sobre comprensión lectora (en particular el modelo CI).

\section{B. La microestructura como nivel semántico superficial que permite determinar la coherencia local del texto}

Acceder al nivel semántico superficial o microestructura textual, además de extraer proposiciones (atómicas y/o complejas), supone determinar la coherencia que existe entre las mismas a nivel local. Para ello, según Hernández (1999), Kintsch y Van Dijk (1983), Sánchez (1993) y Van Dijk (2006a) es imprescindible reconocer o inferir los dos tipos de relaciones que se dan entre una proposición y la proposición anterior y posterior: las relaciones temáticas y relaciones estructurales. En particular, Sánchez (1993) explica que:

Todo enunciado contiene una parte temática y otra que es comentario. El tema alude a aquello de lo que se habla o, mejor, de lo que se viene hablando: es el objeto de la predicación. Mientras que el comentario es lo que se dice o predica del tema... Por otro lado, y además de las relaciones temáticas, entre unas y otras proposiciones cabe establecer otro tipo de relaciones. Por ejemplo, entre una idea y otra pueden darse relaciones de carácter causal...o motivacional.... o descriptivas (p. 37).

Las relaciones temáticas son básicamente vínculos de correferencialidad argumental que implican el solapamiento argumental entre proposiciones. Este tipo de relaciones, fundamentalmente, permiten secuenciar la progresión temática del texto favoreciendo:

a) la continuidad de un tema cuando la información nueva (aquello se añade a un tema o lo que se dice sobre un tema) se solapa argumentalmente con la información dada (el tema que ha sido introducido); y

b) el cambio de tema o la introducción de un subtema cuando la información nueva se convierte en información dada (lo que se dice sobre un tema se convierte en tema).

Teniendo esto en cuenta, un lector podrá determinar progresiva y secuencialmente la coherencia temática de un texto identificando tanto su hilo conductor (o tema principal) como sus cambios temáticos (Escoriza, 2003, 2006; Kintsch y Van 
Dijk, 1978; Van Dijk y Kinstch, 1983; Kintsch, 1988). Con el objeto de clarificar lo que hemos descrito, nos vamos a situar dentro de un extracto de texto en particular, para observar las relaciones temáticas que se dan entre sus proposiciones.

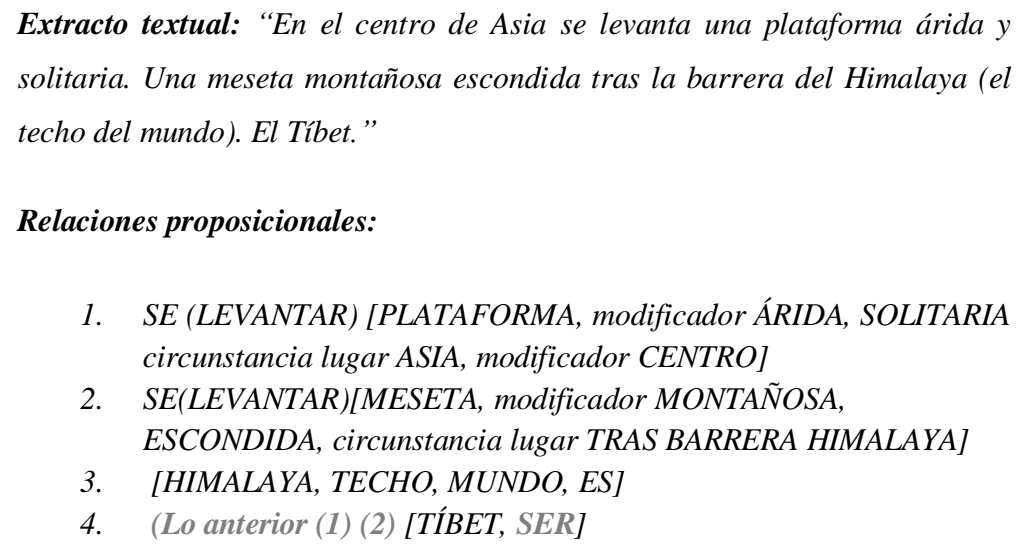

1. SE (LEVANTAR) [PLATAFORMA, modificador ÁRIDA, SOLITARIA circunstancia lugar ASIA, modificador CENTRO]

2. SE(LEVANTAR)[MESETA, modificador MONTAÑOSA, ESCONDIDA, circunstancia lugar TRAS BARRERA HIMALAYA]

3. [HIMALAYA, TECHO, MUNDO, ES]

4. (Lo anterior (1) (2) [TÍBET, SER]

Cuadro 1.1. Relaciones temáticas proposicionales que aparecen en el extracto *En gris inferencias automáticas que el lector debería realizar partiendo de la información del texto ${ }^{3}$.

Observando las relaciones proposicionales del cuadro 1.1 se aprecia que el pasaje comienza tratando información nueva (aquello que se dice sobre el tema) en las proposiciones (1) y (2) ${ }^{4}$; y finaliza presentando de manera implícita la información dada (el tema) en la proposición (4). Así pues, en este caso, el extracto de texto va mostrar continuidad temática en torno al Tíbet, que va a ser el argumento que implícitamente comparten la mayor parte de sus proposiciones y por tanto el tema principal del pasaje.

Por otra parte, como hemos adelantado al inicio del subapartado, además de estas relaciones temáticas, hay que tener en cuenta otro tipo de relaciones que permiten darle un significado completo a las secuencias proposicionales. Se trata, concretamente, de unas relaciones de carácter estructural que, aunque no añaden nuevo contenido al discurso, van a facilitar la progresión temática. En este sentido, Mann y Thompson $(1986,1988)$ señalan que dos proposiciones adyacentes pueden mostrar principalmente dos tipos de relaciones estructurales:

- Relaciones en las que unas proposiciones tienen un papel específico sobre otras. Por ejemplo, la estructura de Solución (unas proposiciones representan la solución a un problema o necesidad que describen otras proposiciones); de Resultado (unas proposiciones representan el resultado que provocan otras que representan una acción); de Causa (unas proposiciones producen otras); de

\footnotetext{
${ }^{3}$ Nota: en el lenguaje proposicional los verbos copulativos (SER, ESTAR) no conforman predicados, de hecho, no suelen ser incluidos dentro de las proposiciones. A pesar de ello, nosotros hemos considerado que sería clarificador incluirlos como argumentos.

${ }^{4}$ Como vemos en el cuadro 1, un argumento de la proposición (2), el Himalaya, se convierte en un subtema sobre el que se habla en la proposición (3).
} 
Motivación (unas proposiciones incluyen el deseo de llevar a cabo otra acción); de Propósito (unas proposiciones expresan la intención de realizar una acción); de Justificación (unas proposiciones apoyan lo señalado en otras proposiciones), etc.

- Relaciones en las que unas proposiciones adoptan un rol similar a otras. Por ejemplo, la estructura de Contraste (unas proposiciones contrastan con lo que expresan otras), de Listado (las proposiciones representan una serie de elementos de una lista), etc.

Posteriormente, autores como Hernández (1999), Hernández y Quintero (2001) y Sánchez $(1993,1998)$ vuelven a incidir en este tipo de relaciones, aunque las categorizan de otro modo: relaciones Descriptivas (unas proposiciones son atributos o características que describen a otras), Causales (unas proposiciones son consecuencia de otras), Explicativas (unas proposiciones explican a otras), Comparativas (unas proposiciones se comparan con otras), Problema-solución (unas proposiciones representan un problema mientras que otras representan la solución a ese problema); Especificativas (unas proposiciones concretan algo de un algún aspecto mencionado en otras proposiciones), etc.

Las relaciones estructurales, en definitiva, sea cual sea la categorización utilizada, permiten definir las relaciones de coordinación o subordinación que existen entre una proposición y la proposición anterior y ulterior. Así pues, volviendo al pasaje que utilizamos para explicar las relaciones temáticas, se percibe una relación descriptiva dominante que tiene el Tíbet como objeto de descripción, así como una relación especificativa subordinada que aporta un dato concreto en torno al Himalaya. Esto se puede observar de forma clara en el siguiente mapa conceptual.

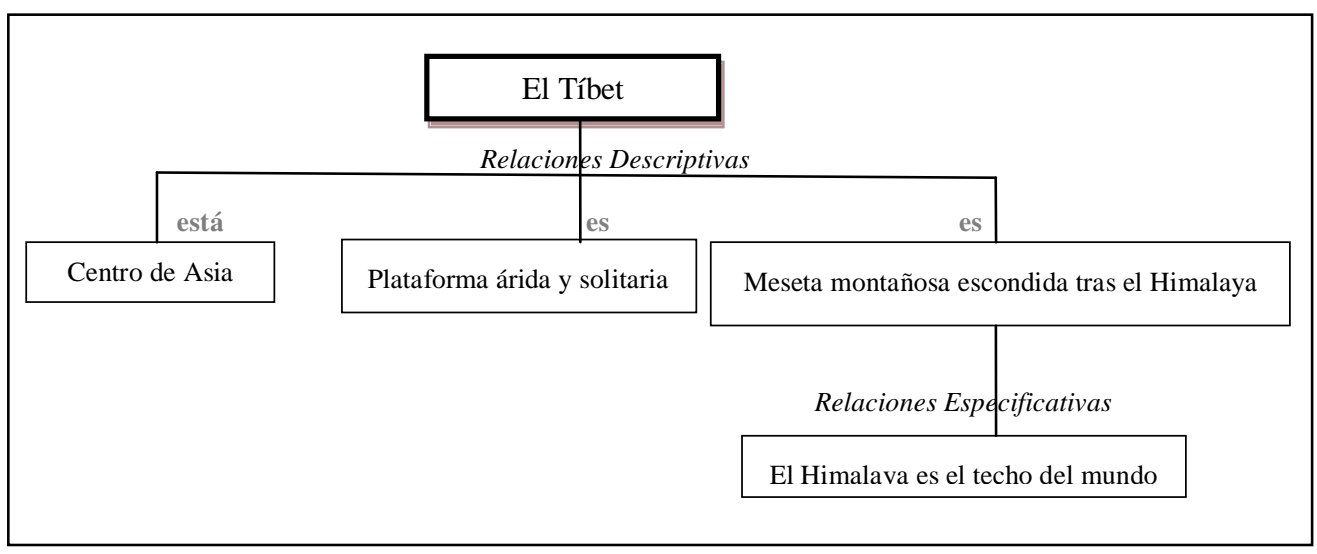

Cuadro 1.2. Relaciones estructurales proposicionales

Resumiendo, mientras que las relaciones temáticas permiten determinar el paso de un tema a otro a lo largo del texto, las relaciones estructurales permiten establecer relaciones de coordinación o subordinación que existen entre una proposición y la proposición anterior y ulterior. 


\section{La macroestructura como nivel semántico profundo que permite establecer la coherencia global del texto}

Elaborar la representación textual no sólo implica identificar proposiciones y determinar el grado de coherencia que se da entre las mismas a nivel local; también supone reconocer cuáles de esas proposiciones son textualmente relevantes (macroproposiciones) y establecer la coherencia que existe entre ellas a nivel global. Para ello, el lector debe acceder a un nivel semántico profundo, llamado macroestructura, que le va permitir identificar y reorganizar jerárquicamente las ideas esenciales de la microestructura (Escoriza, 2003, 2006; Kinstch y Van Dijk, 1983; Van Dijk, 2006a).

Con el fin de explicar qué aspectos de la microestructura pueden ser potencialmente importantes en la construcción de la macroestructura, vamos a centrarnos en el efecto de niveles, que parte de la hipótesis de que el lector recuerda principalmente la información que se recoge a nivel macroestructural. Concretamente, cabe destacar los estudios de Kintsch y Van Dijk, cuyos trabajos en torno a este efecto permitieron determinar qué aspectos de la microestructura son necesarios tener en cuenta para formar la macroestructura. Estos autores, en un principio consideraron que la información más recordada era la que más veces se procesaba durante la lectura del texto (Kintsch y Van Dijk, 1978), si bien, años más tarde descubrieron: a) que los sujetos no sólo recordaban las ideas más procesadas, sino también otras ideas que por su situación dentro del texto permitían formar macroestructura; y b) que para recordar las ideas importantes, además de almacenarlas, era imprescindible saber recuperarlas adecuadamente (Van Dijk y Kintsch, 1983). En este sentido, la superestructura textual o forma organizativa del texto adquirió un rol fundamental al proporcionar una serie de claves acerca de qué proposiciones de la microestructura podrían formar macroproposiciones, y al facilitar un esquema para almacenar y recuperar las macroproposiciones de forma organizada y jerárquica. Concretamente, Madler y Johnson (1977), Meyer (1975) y Meyer y Ray (2011) aseguran que los lectores que aprovechan la organización textual o superestructura del texto utilizan una estrategia estructural que facilita la comprensión:

Readers who use a "structure strategy" seek to identify and use the author's organization to organize their own understanding.... The structure strategy facilitates comprehension by helping the reader to organize concepts based on the explicit or implied relationships that are communicated by the text (Meyer y Ray, 2011, p. 128).

Dicha estrategia requiere la disposición de ciertas nociones sobre tipologías textuales o formas características en las que se organizan los textos, las cuales funcionan como criterios flexibles que, teniendo en cuenta las claves que presenta cada texto, permiten categorizarlos dentro de una forma organizativa concreta (Sánchez ,1993, 1998). Basándonos en los trabajos de Hernández (1999), Meyer (1975, 1985) y Meyer, y Barlett (1989) y Van Dijk $(1995,1998)$ concebimos que el lector debería conocer que: 
- En un texto Problema-Solución, el autor explica un problema al que se trata de dar una solución o soluciones.

- En un texto Causal, el autor trata unos hechos que tienen unas consecuencias; o unos hechos que son condición o consecuencia de unos antecedentes o causas.

- En un texto Comparativo, el autor bien compara las similitudes y diferencias entre dos entidades (comparación); o bien, se centra únicamente las diferencias o en las similitudes.

- En un texto Enumerativo, el autor enumera hechos que siguen una secuencia temporal.

- En un texto Descriptivo, el autor presenta un referente y articula las ideas que expone en el texto como rasgos o características del mismo.

- En un texto Argumentativo, el autor trata de apoyar una tesis a través de un conjunto de argumentos.

El siguiente pasaje nos va a permitir ejemplificar lo que acabamos de señalar:

Durante el Siglo VII, la economía de la España musulmana alcanzó un gran desarrollo basándose en la agricultura, industria y comercio. A continuación describiremos las principales características de cada una de éstas actividades.

En la agricultura se desarrollaron importantes técnicas de regadío, las norias que permitieron una mayor extensión de los productos hortícolas y de los frutales; y se difundieron muchos cultivos nuevos, el naranjo, el arroz, y la caña de azúcar, sirvieron para renovar la primitiva actividad agrícola.

La industria fue importante en las ciudades musulmanas y experimentó un gran avance debido a la necesidad de suministrar los productos solicitados por la población urbana. Entre sus productos principales destacaban los tejidos, el vidrio y la cerámica.

El comercio también alcanzó el mismo desarrollo que ya hemos visto en la agricultura y en la industria. Los musulmanes establecieron grandes rutas comerciales, tanto terrestres como marítimas y fluviales que comunicaban todo el mediterráneo con el Mar Rojo y el Océano Índico.

Los comerciantes musulmanes vendían al extranjero artesanía y compraban materias primas como el hierro y la madera. Realizaban también un importante comercio de esclavos y además compraban en Oriente especias (pimienta, jengibre, azafrán...) que después vendian a los países de Occidente.

Cuadro 1.3. Texto sobre la economía de la España musulmana (extraído de Hernández, A. 1999, p.37)

Este texto contiene una serie de claves que son reflejo de una superestructura descriptiva. Para empezar, en el primer párrafo existen una serie de señalizaciones textuales, como el punto y seguido, el conector "a continuación" y el verbo "describir"; que adelantan que se van describir cada una de las actividades que hicieron posible que la economía se desarrollase en España en época musulmana, y que por tanto, permiten identificar la frase tópica que recoge la idea principal del texto: "la economía de la España 
musulmana alcanzó un gran desarrollo basándose en la agricultura, industria y comercio”. En los siguientes párrafos, el autor le da aún mayor cohesión a la estructura descriptiva que adelanta en el primer párrafo, hablando de la agricultura (en el segundo párrafo), de la industria (en el tercero) y del comercio (en el cuarto y quinto párrafo), y utilizando además elementos como "se desarrollaron importantes...., fue importante....., también alcanzó el mismo desarrollo".

Partiendo de todas estas claves, el lector puede poner en marcha un conjunto de macroestrategias sobre la microestructura para extraer las macroproposiciones que se van a subordinar al enunciado principal del texto. Concretamente, Van Dijk y Kinstch (1983) señalan tres tipos de macroestrategias:

- Omisión/ selección: cuando una proposición que no sea directa ni indirectamente una condición interpretativa de una proposición subsecuente puede ser eliminada ("Give a sequence of propositions, delete each proposition that is no an interpretation condition for another proposition in the sequence” (p.190)). Lo que significa que bajo esta estrategia todos los elementos triviales, irrelevantes y redundantes que aparezcan en la secuencia de ideas serán suprimidos. Por ejemplo, en el párrafo 3 se omitiría "Entre sus productos principales destacaban los tejidos, el vidrio y la cerámica" ya que es una especificación del resto de la información que recoge este párrafo; mientras que en el párrafo 4 se omitiría "tanto terrestres como marítimas y fluviales que comunicaban todo el mediterráneo con el Mar Rojo y el Océano Índico", puesto que es una especificación de "Los musulmanes establecieron grandes rutas comerciales".

- Generalización: cuando una secuencia de proposiciones puede ser sustituida por una proposición más abstracta y general (explícita o implícita) que esté implicada en cada una de las proposiciones de dicha secuencia ("Give a sequence of propositions, substitute the sequence by a proposition that is entailed by each of the propositions of the sequence" (p.190)). Esto significa que cada una de las proposiciones es percibida por el lector como un ejemplo de una realidad conocida por él. Por ejemplo, en el párrafo 2, "se desarrollaron importantes técnicas de regadío y se difundieron nuevos cultivos", es una idea general que engloba al resto de las ideas del párrafo, que constituyen una ejemplificación de dicha idea.

- Construcción: cuando una secuencia de proposiciones puede ser sustituida por una nueva proposición (implícita) que denota un hecho global que se deriva del conjunto de proposiciones de dicha secuencia ("Give a sequence of propositions, replace it by a proposition that is entailed by the joint set of propositions of the sequence" (p.190)). Esto significa que la secuencia de proposiciones en su conjunto es percibida por el lector como componentes de una realidad más compleja. Por ejemplo, a partir de la información del párrafo 5 se podría construir la idea de que "los comerciantes compraban y vendian productos al extranjero". Esta idea, a su vez, se podría relacionar con la idea extraída del apartado 4 construyéndose una nueva idea que se 
infiere a partir de ambas, "el desarrollo de las grandes rutas comerciales permitió a los comerciantes comprar y vender productos al extranjero".

De esta forma, la superestructura del texto permitiría al lector extraer la macroestructura desde la microestructura, facilitando además, un esquema organizativo tanto para almacenar la información como para recuperarla en el momento en el que se precise. Este esquema sería similar al siguiente mapa conceptual.

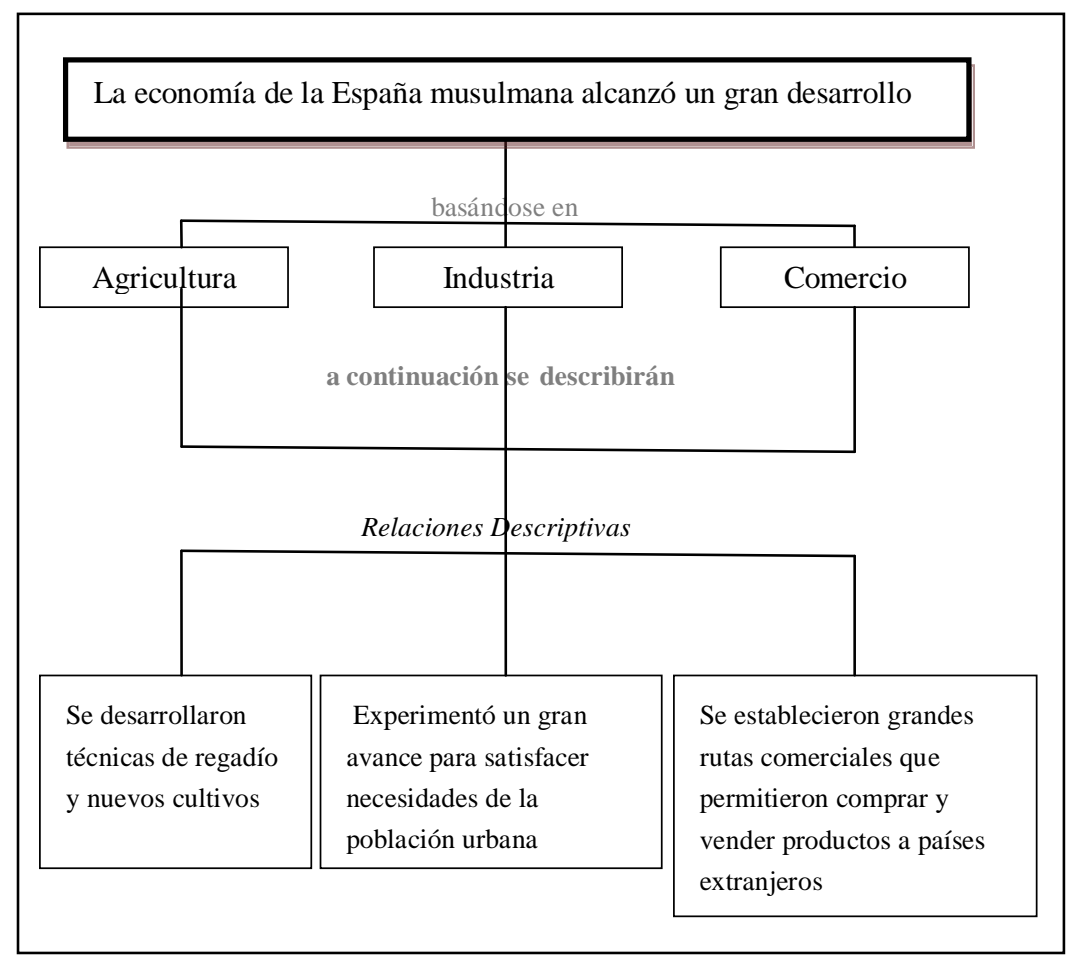

Cuadro 1.4. Macroestructura del texto sobre la economía de la España musulmana

En definitiva, la extracción de la macroestructura es un proceso estratégico que requiere el uso de la superestructura textual sobre la microestructura, para extraer los aspectos esenciales que el autor del texto quiere comunicar.

\subsubsection{La Representación situacional}

Comprender un texto en su totalidad implica generar un modelo mental que permita integrar la base textual dentro de los conocimientos previos del lector. Este modelo de la situación se va a caracterizar, principalmente, por: su referencialidad situacional, su multidimensionalidad y su significatividad.

En lo que respecta a la referencia situacional, autores como Jhonson y Laird (1983), Van Dijk y Kintsch (1983), Kintsch (1988, 1998), Van Dijk (2006a) afirman que si un lector no es capaz de encontrar un referente claro que le permita entender la situación a la que se refiere el texto, la comprensión fracasa y el recuerdo será escaso. Para demostrar esto, se han llevado a cabo estudios (Bransford y Jhonson, 1990; Ferreti, 
Kutas y McRae, 2007; Ferreti, Rhode, Kheler y Crutchley, 2009), cuyas conclusiones se podrían resumir a través del siguiente ejemplo:

Había pasado mucho tiempo desde que llamé. Así que comencé a impacientarme y decidí volver a llamar, sin embargo, antes de que pudiera hacerlo sonó el timbre. Me dirigí a la puerta y cuando llegué, allí estaba. Era más pequeña de lo que esperaba, pero llevaba tanto tiempo esperándola que, en lugar de quejarme, me abalancé sobre ella ansiosamente.

Cuadro 1.5. Ejemplo de texto con referente ambiguo (Elaboración propia)

El texto está compuesto por un conjunto de relaciones proposicionales locales y globales que no deberían entrañar dificultad, sin embargo, la mayoría de los lectores no tendrían del todo claro a qué se refiere el texto, ya que se pueden aplicar diferentes modelos mentales. Pero si se incluye al inicio del texto el título PETICIÓN DE PIZZA, entonces dispondremos una referencia clara y plausible que nos permitirá enmarcar el contenido del texto dentro esa situación concreta.

En lo que se refiere a la multidimensionalidad de los modelos de la situación, los principales estudios hablan de unos parámetros situacionales que llevan al lector a situar el contenido textual dentro de dimensiones temporales, causales y espaciales (Madden y Zwan, 2003; Magliano y Schliech, 2000; Zwaan, 1999; Zwaan y Radvansky, 1998). Por ejemplo, en el siguiente texto, los conocimientos históricos del lector le pueden llevar a situarlo espacio-temporalmente en la antigua Roma, concretamente en el año 46 A.C.; y también a determinar las causas del asesinato de Cesar: era un cónsul de la República Romana que cada vez acaparaba más poder, y por ello un conjunto de opositores liderados por Casio y Bruto, le asesinaron basándose en que Cesar estaba acumulando los poderes de un rey.

El día de los Idus de marzo, Cesar era asesinado por un grupo de opositores liderados por Bruto y Casio.

Cuadro 1.6. Ejemplo de texto multidimensional 1 (Elaboración propia)

Otro ejemplo vinculado a la multidimensionalidad de los modelos de la situación, es la capacidad de éstos para situar la información dentro del mismo escenario situacional a pesar de que se produzca un cambio de perspectiva. Como se puede observar en el cuadro que aparece a continuación, aunque el protagonismo de la acción pasa de Raúl a Ana, dentro del modelo de la situación, que formamos el escenario situacional (espacio-tiempo) sigue siendo el mismo. Por otra parte, partiendo del modelo mental creado, podemos realizar inferencias elaboradas basadas en nuestras propias experiencias, para conjeturar la causa que llevó a Ana a reírse en esa situación. Por ejemplo, puede ser que Raúl sea muy despistado y a Ana esto le parezca gracioso, o puede ser que Ana haya escondido las llaves para gastarle una broma a Raúl. 
Raúl estaba nervioso porque no encontraba las llaves del coche. Ana le miró y

comenzó a reír.

Cuadro 1.7. Ejemplo de texto multidimensional 2 (Elaboración propia)

Para finalizar, cabe señalar que los modelos de la situación están estrechamente vinculados al concepto de aprendizaje significativo de Ausubel (1968), ya que permiten aplicar lo aprendido en otros contextos situacionales. En este sentido, podemos destacar la investigación de Perrig y Kintsch (1985), quienes, partiendo de un texto en el que se describía la disposición espacial de una ciudad, solicitaron a un grupo de alumnos universitarios realizar tres tareas: recordar por escrito lo que habían leído (representación textual), determinar el grado de corrección de ciertas inferencias espaciales y elaborar un mapa de la ciudad (estas dos últimas relacionadas con la representación situacional). Los resultados indicaron que los estudiantes universitarios aunque no tuvieron problemas para recordar el texto, los tuvieron a la hora de utilizar funcional y significativamente dicha información para realizar las otras dos tareas. En este mismo sentido, otros estudios más vinculados con el aprendizaje de las matemáticas insisten en la importancia de generar buenos modelos situacionales a la hora de resolver problemas matemáticos. Así por ejemplo, Orrantia, Tarín y Martín (2011) y Rosales, Orrantia, Martín y Chamoso (2008) señalan que si el lector no es capaz de simular mentalmente la situación que se deriva del problema, fracasará en la resolución del mismo.

En conclusión, construir una adecuada representación situacional del texto conlleva:

a) tener un referente claro para interpretar la información;

b) conocer o inferir las dimensiones espaciales, temporales y causales del texto;

c) saber realizar inferencias elaboradas que rellenen los vacios; y

d) ser capaz de aplicar lo aprendido a otras situaciones o contextos.

\subsubsection{La construcción de la representación textual y situacional dentro de la memoria de trabajo}

La base textual y el modelo de la situación se elaboran partiendo de la relación que el lector establece dentro de su memoria de trabajo, entre los inputs lingüísticos que recibe del texto, y los conocimientos previos que activa de su memoria a largo plazo (en adelante MLP). Tomando esto como referencia, el modelo Construcción-Integración concibe la comprensión lectora como un proceso híbrido (en parte simbólico y en parte conexionista) en el que la memoria de trabajo: a) recibe como input un conjunto de símbolos lingüísticos que se relacionan entre sí gramaticalmente (código de superficie); b) construye como output una red conexionista de símbolos semánticos (base textual) basada en correlaciones estadísticas entre el input y los conocimientos previos del lector; 
y c) refina la base textual construida a través de la creación de un modelo mental (modelo de la situación), que a su vez, integra dicha representación dentro la base de conocimiento del lector, pasando así a formar parte de la MLP. A continuación, nos introduciremos dentro de la memoria de trabajo del lector con el fin de explicar de forma más exhaustiva cada uno de los aspectos señalados.

La memoria de trabajo, también conocida como memoria operativa, es “....un mecanismo dinámico que implica la capacidad para almacenar información durante periodos cortos de tiempo" (Escoriza, 2009, p. 56). Esto supone que, durante la lectura, el lector en lugar de procesar la información del texto de una vez, lo hace por partes o ciclos de procesamiento que retienen durante un tiempo limitado (20 segundos sin repetición) una cantidad reducida de proposiciones (cada ciclo puede retener $7 \pm 2$ proposiciones) (Baddeley, 1966a; Baddeley, 1966b; Baddeley, 2003; Baddeley y Hitch, 1974; Baddeley y Logie, 1999).

Según Kintsch (1988, 1998) y Kintsch y Welsch (1991), cada ciclo está compuesto por dos fases:

a) la fase de construcción o resonancia, en la que se construye la representación textual o base textual a través de un conjunto de reglas de producción "débiles" que no discriminan lo que es contextualmente adecuado de lo que no lo es; y

b) la fase de integración o de satisfacción de restricciones, donde se refina la base textual construida creando una representación situacional o modelo de la situación que: desactivaría los significados contextualmente inapropiados, seleccionaría los aspectos que se van a mantener para el siguiente ciclo y situaría el contenido textual dentro de un "mundo" concreto.

Durante la primera fase, la memoria de trabajo recibe una entrada linguística que activa de modo ascendente todos los nodos (proposiciones) de la base de conocimiento con los que el input correlaciona estadísticamente (Kintsch, 1988, 1998; Kintsch y Welsch, 1991); creándose así una red conexionista o base textual incoherente (y en ocasiones contradictoria) que no tiene en cuenta el contexto textual (hemos de tener en cuenta que el lector descubre el contexto en el que se enmarca la información conforme avanza la lectura). De esta manera, cuando un lector accede al nivel semántico superficial o microestructura textual, extrae tanto proposiciones y relaciones proposicionales adecuadas como inadecuadas; de la misma forma que, cuando penetra en el nivel semántico profundo o macroestructura textual, extrae macroproposiciones (ideas principales del texto) y relaciones jerárquicas entre macrocroposiciones, tanto adecuadas como inadecuadas.

Para clarificar lo que acabamos de mencionar, analizaremos a través de ejemplos las cuatro etapas en las que Kintsch (1988) divide esta fase de construcción: 
a) se forman tanto proposiciones correctas como proposiciones incorrectas directamente del código de superficie (cabe señalar que el lector puede activar diferentes conjeturas con respecto a la superestructura partiendo de las claves lingüísticas que va encontrando en el texto). Por ejemplo, a partir de El abogado discutió el caso con el juez. Él dijo "es necesario enviar al acusado a prisión porque existen pruebas claras de su culpabilidad", se formarían tanto proposiciones adecuadas como inadecuadas:

- DISCUTIR [ABOGADO, JUEZ, CASO]

- $\quad$ DECIR [JUEZ, ABOGADO [ ENVIAR [NECESARIO [ACUSADO, PRISIÓN]]]

- DECIR [ABOGADO, JUEZ [ENVIAR [NECESARIO [ACUSADO, PRISIÓN]]]

- PORQUE [EXISTIR [PRUEBAS, ACUSADO, CULPABILIDAD] ]

b) las proposiciones formadas sirven como señal para la recuperación de "vecinos semánticos" asociados a éstas, dentro de la red de conocimiento general (se trata de inferencias automáticas basadas en conocimientos estereotipados):

- DEFENDER [ABOGADO, ACUSADO]

- JUZGAR[ JUEZ, ACUSADO]

- DiscUTIR [ABOGADO, JUEZ, LEY]

- $\quad$ SEGÚN [LEY [ EXISTIR [PRUEBAS, CULPABILIDAD, ACUSADO]]]

c) además de inferencias no dirigidas, se generarían inferencias dirigidas o controladas para la resolución de problemas (cabe destacar que el lector puede reflexionar en torno al tipo de superestructura que aparece en el texto). En el extracto textual que hemos puesto como ejemplo, no parece factible un esquema que muestre a un abogado enviando a prisión a su defendido, por lo que el agente al que se refiere "ENVIAR" parece corresponder más al juez que al abogado.

d) se asignaría una intensidad a todos los pares de conexiones que se han creado (entre $-1 \mathrm{y}+1$ ), dependiendo de: su proximidad en la base textual (en el caso de las proposiciones directamente extraídas del texto) y de los valores que heredan de la red general de conocimiento (en el caso de las proposiciones inferidas). En cuanto al reconocimiento de la superestructura del texto, se asignaría valores a los nodos que se activan partiendo de la correlación entre las claves textuales y las relaciones organizativas o tipologías textuales que el lector conoce. En el ejemplo que estamos siguiendo, las proposiciones extraídas directamente del texto estarían formadas por conexiones positivas, como DISCUTIR [ABOGADO, JUEZ, CASO], y por enlaces negativos (o proposiciones alternativas que se inhiben entre Sí) como DECIR [JUEZ [\$] ]]; DECIR [ABOGADO [\$ ] ]]. Por otra parte, las proposiciones inferidas heredarían sus conexiones positivas de la base de conocimiento del lector, de manera que DEFENDER [ABOGADO, ACUSADO] JUZGAR [JUEZ, ACUSADO] 
estarían positivamente conectadas formando un esquema en el que el juez juzga y el abogado defiende.

Una vez generada la red proposicional conexionista, el proceso de integración toma el control creando un modelo mental que refina la base textual a través de un procesamiento descendente, el cual permite identificar las proposiciones y macroproposiciones que son adecuadas en el contexto situacional que se deriva del texto (Kintsch, 1988, 1998, 2004). Esta representación situacional, además, por una parte, mantiene las macroproposiciones extraídas para el siguiente ciclo de procesamiento; y por otra, integra dichas macroproposiciones en los conocimientos previos del lector. Volviendo a nuestro ejemplo, se generaría un modelo mental en el que el juez hablaría con el abogado de la necesidad de enviar al acusado a prisión, siendo las proposiciones relacionadas con el mismo las que mayor nivel de activación tendrían. Sin embargo, si agregamos al pasaje otra oración: El abogado discutió el caso con el juez. Él dijo "es necesario enviar al acusado a prisión porque existen pruebas claras de su culpabilidad". El juez miró al abogado con cara de incredulidad; la reacción del juez crearía un modelo mental totalmente diferente, concretamente, el abogado sugeriría al juez que enviara a su defendido a prisión, y éste último se sorprendería puesto que no es habitual que un abogado sugiera enviar a su cliente a la cárcel.

Finalizado el ciclo de procesamiento, el lector, conserva las proposiciones más importantes (ya sean explícitas o implícitas) y la última proposición procesada dentro un retén cognitivo (buffer a corto plazo), que mantiene activas dichas ideas para el siguiente ciclo de procesamiento. En caso de que las macroproposiciones de un ciclo no conecten con el siguiente, éstas se almacenan en la memoria a largo plazo, de donde se tratan de recuperar macroproposiciones almacenadas en ciclos previos; y si éstas últimas tampoco lo permitiesen, el lector intentaría conectar la información realizando una inferencia puente basada en sus conocimientos previos.

Teniendo en cuenta todo lo que hemos señalado podemos extraer tres conclusiones:

a) El lector genera una base textual que es inconsistente y contradictoria hasta que se define a través del contexto situacional.

b) El modelo de la situación permite, además, integrar la base textual dentro de los conocimientos previos, favoreciendo así el aprendizaje significativo, y por tanto la aplicación de los contenidos adquiridos a contextos diferentes.

c) La representación textual y la situacional se construyen de forma simultánea, dentro de cada ciclo de procesamiento; y de manera progresiva, a través de los diferentes ciclos. 
La visión flexible del proceso de lectura que propone el modelo CI ha calado profundamente en la investigación actual, si bien, a pesar de su popularidad, el modelo $\mathrm{CI}$ adolece de ciertas carencias que mostraremos a continuación.

\subsubsection{Principales limitaciones del modelo Construcción-Integración}

Aunque Kintsch $(1988,1998,2004)$ admite que no existe un proceso unitario de comprensión, supone que el modelo Construcción-Integración es lo suficientemente general y flexible como para adaptarse a los diferentes tipos de discurso. Sin embargo, como afirma Rouet (2006), ese grado generalidad hace que se obvien ciertos aspectos implicados en dicho proceso, que están vinculados con el texto que se lee, el lector que lo lee y el contexto en el que se lee.

En cuanto al texto, este modelo explicativo no especifica el papel que desempeña el grado de cohesión textual durante el proceso de comprensión; ni toma en consideración los aspectos cognitivos y lingüísticos que trae consigo la lectura de textos múltiples o los diferentes tipos de formato textual. Concretamente, autores como Eveland, Cortese, Park y Dunwoody (2004), Parush, Shwartz, Shtub y Chandra (2005), DeStefano y LeFevre (2007) y Scott y Schwartz (2007) señalan que la lectura no lineal, particularmente la hipertextual, aumenta la carga cognitiva en relación al texto. Además de esto, el modelo ha recibido duras críticas por sustentarse en el lenguaje proposicional, cuyo carácter puramente sintáctico obvia aspectos morfológicos que aparecen en el código de superficie (tiempos verbales, determinantes, etc.), sin los cuales no es posible reconocer la dimensión temporal del texto. En este sentido, autores como Alonso Tapia, Carriedo y Mateos (1992), García Madruga, Martín Cordero, Luque y Santamaría (1995)

y García Madruga, Gómez y Carriedo (2002) proponen las unidades-idea, una unidad semántica superior a las proposiciones que constituye una idea completa (puede abarcar una o más frases) que recoge tanto los aspectos sintácticos como morfológicos de la información extraída. Si bien, hemos de señalar que este tipo de unidades-idea tampoco han sido ajenas a la controversia, ya que debido a su extensión no permiten determinar la complejidad semántica de los textos.

En lo que se refiere al lector, el modelo CI no contempla la posibilidad de que diferentes tipos de lectores puedan tener diferentes estilos y modos de comprensión; ni considera incidencia de la carga cognitiva que supone un texto con unas características concretas para un lector en particular. A ello se une, que Kintsch $(2001,2002,2004)$ no pudo diseñar un modelo computacional que demostrara que el lector activa proposiciones directamente del código de superficie; y tubo de adoptar para su modelo el Latent Semantic Analysis (LSA) de Landauer y Dumais $(1994,1996)$ y Landauer, Foltz, Laham (1998). Éste, le permitía extraer las proposiciones a través del recuento de palabras que aparecen en contextos semánticos similares dentro del texto, concretamente, a través del 
significado que se le atribuía a esas palabras en virtud de dichos contextos textuales. En este sentido, Kintsch afirma:

LSA extracts word meaning from such data by disregarding the accidents of word use in specific contexts and focusing on what is common in all contexts. (Kintsch, 2002, p. 160)

Meaning, for LSA, is a relation among words. In such a relational system, one cannot talk about the meaning of a word isolation; words have meaning only by virtue of their relations to other words -meaning is a property of the system as a whole. (Kintsch, 2007, p. 91)

Con respecto al contexto, cabe señalar que Kintsch, en los trabajos previos que realiza junto a Van Dijk (1978, 1983), admite que la información textualmente importante (que depende de la macroestructura textual) no tiene por qué coincidir con la información contextualmente relevante (que depende del grado de relevancia que tiene contenido textual en relación a los objetivos de lector). A pesar de ello, este autor, en su modelo CI (Kintsch 1988,1998), se limita a describir un proceso de lectura en el que ambos tipos de información se fusionan para satisfacer las demandas de una tarea general: leer para comprender globalmente un texto. Esto hace que el modelo no profundice en las diferentes situaciones sociales en las que se puede presentar el discurso, y por tanto, obvie la importancia que el contexto de tarea tiene en el establecimiento de objetivos específicos de lectura, que influyen en el modo en el que el lector procesa la información textual y en las estrategias que éste pone en marcha. A este respecto, autores como Cerdán, Vidal-Abarca, Martínez, Gilabert y Gil (2009), Cerdán, Vidal-Abarca, Salmerón, Martínez y Gilabert (2009), Kintsch (2004) y Vidal-Abarca, Salmerón y Mañá (2011) sugieren que los objetivos, intereses y creencias del lector están íntimamente ligados al tipo de tarea a realizar, de tal manera, que el modelo de la situación construido a partir de un proceso de lectura variará en función de los objetivos que se planteen para satisfacer la demandas de dicha tarea. Así pues, no será lo mismo leer para hacer un resumen que leer para dar una opinión, leer para localizar información, etc.

\subsubsection{Factores que inciden en la comprensión lectora}

En este apartado revisaremos la bibliografía en busca de información sobre los factores dependientes del lector, del texto y del contexto de tarea que inciden en el proceso de comprensión lectora. 
The RRSG (Reading study group) began its thinking by defining the term reading comprehension as the process of simultaneously extracting and constructing meaning through interaction and involvement with written language. It consists of three elements: the reader, the text, and the activity or purpose for reading (RAND Reading study group, 2002. p.12).

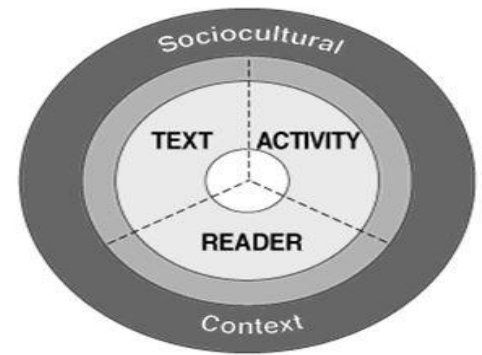

Imagen 1.1. Representación de los agentes implicados en el proceso de comprensión lectora (Extraída de RAND reading study group, 2002, p.14)

Como indica la cita y la imagen, la lectura es un proceso comunicativo situado dentro de un entorno sociocultural en el que interactúan tres elementos: el lector, el texto y el contexto de tarea. Estos agentes, están a su vez influenciados por un conjunto de factores, cuya variación incide de forma determinante en el proceso de comprensión. Concretamente, apoyándonos en los trabajos de Hernández (1999), del RAND reading study group (2002) y de Rouet (2006) destacamos los:

- factores dependientes del texto, como el grado de cohesión textual y el formato textual;

- factores dependientes del lector (cognitivos), como los conocimientos previos almacenados en la MLP y la carga cognitiva que soporta la memoria de trabajo;

- factores dependientes del contexto, como el tipo de tarea a realizar.

Abordaremos estos factores realizando, en primer lugar, un análisis individualizado de cada uno de ellos; y revisando, en segundo lugar, diversas investigaciones que muestran cómo interactúan entre sí durante el proceso de comprensión.

\subsubsection{Factores dependientes del texto: la cohesión textual y el formato textual}

Entre los factores dependientes del texto que inciden en el proceso de comprensión lectora hemos de destacar dos: la cohesión textual y el formato textual. 


\section{A. La cohesión textual}

El concepto de cohesión suele confundirse con el de coherencia, si bien, aunque un texto que dispone de elementos cohesivos normalmente será percibido como más coherente que uno que nos los tiene, "la cohesión no es ni suficiente ni necesaria para la coherencia. En otras palabras, la cohesión no siempre garantiza la coherencia mientras que la ausencia de la cohesión no impide la coherencia" (Louwerse, 2004, p.41). Por ello, para definir qué entendemos por cohesión textual, comenzaremos clarificando las diferencias que existen entre éste término y el de coherencia; y posteriormente, analizaremos el papel de los elementos cohesivos en la determinación de los dos tipos de cohesión que presenta el texto: la cohesión local y la cohesión global.

\section{a) Diferencias entre cohesión y coherencia textual}

Desde un punto de vista teórico, podemos afirmar, por una parte, que la cohesión es una propiedad del texto que indica el grado en el que las ideas que aparecen en el mismo y las relaciones que se dan entre dichas ideas se hacen explícitas a través de la combinación de elementos lingüísticos (Graesser, McNamara y Louwerse, 2003; Graesser, McNamara, Louwerse, y Cai, 2004; Louwerse, 2004; McNamara, 2004; O'Reilly y McNamara, 2007; Ozuru et al., 2009); y por otra, que la coherencia se asocia principalmente a la consistencia que los elementos del texto muestran en la representación mental que el lector construye (Louwerse, 2004; Oakhill, Cain y Bryant, 2003; Ozuru et al., 2009). Teniendo en cuenta que la cohesión depende del texto, y que la coherencia depende de la interacción entre el texto y el lector, comprenderemos que un texto cohesionado puede ser coherente para algunos lectores y poco coherente para otros; de la misma forma que un texto poco cohesionado puede ser poco coherente para algunos lectores, y coherente para otros. Con el fin de clarificar lo que tratamos de explicar, partiremos del siguiente pasaje:

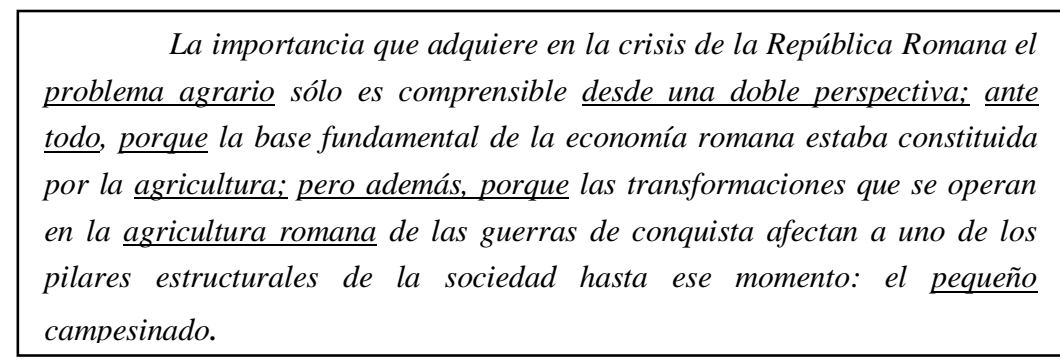

Cuadro 1.8. Ejemplo de pasaje muy cohesivo (Elaboración propia)

Como vemos, existen elementos cohesivos que otorgan un alto grado de cohesión al párrafo. Nos referimos concretamente a dos aspectos; a) el uso de hiperónimos ("problema agrario", "agricultura", "agricultura romana", "pequeño campesinado") que favorecen la correferencia argumental a lo largo de todo el extracto textual; y b) el uso de señalizaciones estructurales (“desde una doble perspectiva”; "ante 
todo porque"; "pero además porque") que explicitan una estructura causal dominante en la que se enmarca la información del pasaje. Estos elementos normalmente facilitan la construcción por parte del lector de una representación mental coherente del texto.

Si alteramos el pasaje sustituyendo las palabras, República Romana, economía romana, agricultura y pequeños campesinos, por sus denominaciones en latín (como ocurre muchos textos académicos de historia), el pasaje seguirá manteniendo el mismo grado de cohesión, pero la percepción de coherencia dependerá de si el lector dispone de conocimientos que le permitan traducir dichas palabras.

La importancia que adquiere en la crisis de la res publica romanum el problema agrario sólo es comprensible desde una doble perspectiva; ante todo, porque la base fundamental de la oeconomía romanis estaba constituida por la agrucultio; pero además, porque las transformaciones que se operan en la agrucultio romana de las guerras de conquista afectan a uno de los pilares estructurales de la sociedad hasta ese momento: el agricola.

Cuadro 1.9. Ejemplo de pasaje cohesivo en el que aparecen palabras problemáticas (Elaboración propia)

Si en lugar de sustituir palabras, alteramos el pasaje modificando la primera frase y eliminando las señalizaciones estructurales, la cohesión textual quedará limitada a la correferencia argumental que aportan los hiperónimos: "problema agrario", "agricultura", "agricultura romana" y "pequeño campesinado".

En la crisis de la república romana el problema agrario es importante. La base fundamental de la economía romana estaba constituida por la agricultura. Las transformaciones que se operan en la agricultura romana de las guerras de conquista afectan a uno de los pilares estructurales de la sociedad hasta ese momento: el pequeño campesinado

Cuadro 1.10. Ejemplo de pasaje poco cohesivo (Elaboración propia)

Esto, como se vislumbra en el cuadro 1.10, supone un vacio cohesivo que, dependiendo de los conocimientos previos del lector, puede dificultar o no la elaboración de una representación mental coherente. En este sentido, McNamara (2001), McNamara y Kintsch (1996), y McNamara, Kintsch, Songer y Kintsch (1996) afirman que un lector construirá una representación coherente, siempre y cuando, sea capaz de generar inferencias basadas en sus conocimientos previos que rellenen los vacios textuales. Concretamente, en el extracto textual que nos ocupa, el lector deberá utilizar, por un lado, sus conocimientos previos en torno al tópico (el problema agrario durante la crisis de la república romana) para situar el contenido textual dentro de una realidad concreta; y por otro, sus conocimientos previos en torno a tipologías textuales para mejorar la estructuración de las ideas del texto (imponiendo por ejemplo una estructura causal). Si por el contrario, el lector adolece de conocimientos previos que le permitan generar las 
inferencias necesarias, éste obtendrá una pobre comprensión del texto, y por tanto, construirá una representación mental menos coherente: "the reader often lacks either the knowledge or skill to generate the inferences, resulting in poor comprehension of the text" (McNamara, Cai y Louwerse, 2013, p.380).

b) Rol de los elementos cohesivos en la determinación de la cohesión textual: la cohesión local y la cohesión global

Una vez clarificadas las diferencias entre cohesión y coherencia, analizaremos cuál es el papel de los elementos cohesivos a la hora de establecer la cohesión de un texto. Cabe señalar que, al igual que diferenciábamos entre coherencia local (vinculada a la elaboración de la microestructura textual) y coherencia global (relacionada la construcción de la macroestructura textual) cuando hablábamos sobre la representación mental que el lector elabora a partir del texto, vamos a diferenciar entre elementos textuales que favorecen la cohesión local y elementos textuales que favorecen la cohesión global, para hablar del grado de la consistencia que tiene un texto por sí mismo.

En este sentido, Givon (1995), Kintsch (1995) y Louwerse y Graesser (2005) sugieren que mientras la cohesión local se corresponde con la consistencia secuencial entre frases textuales (es decir, la cohesión de cada frase con respecto a la siguiente frase); la cohesión global se vincula con la consistencia jerárquica entre nodos textuales mayores (es decir, la cohesión de las ideas dentro de un párrafo, de un párrafo en relación a otros párrafos y de los párrafos dentro del texto). Partiendo de esto, parece claro que, dependiendo del tamaño del extracto textual que se tome como referencia, podemos hablar de uno u otro tipo de cohesión. Este hecho implica que, salvo señalizaciones estructurales como los títulos y los subtítulos (que organizan jerárquicamente el texto a nivel global); los principales elementos cohesivos (que mostramos en el siguiente cuadro), más que favorecer un tipo de cohesión en particular, van a promover en mayor o menor medida tanto la cohesión local como la cohesión global. 


\begin{tabular}{|c|c|c|c|}
\hline & \multicolumn{3}{|c|}{ Elementos cohesivos que promueven la cohesión local y global del texto } \\
\hline & $\begin{array}{l}\text { Correferencia } \\
\text { argumental }\end{array}$ & $\begin{array}{c}\text { Dimensión espacio- } \\
\text { temporal }\end{array}$ & $\begin{array}{l}\text { Elementos que permiten la } \\
\text { estructuración de las ideas }\end{array}$ \\
\hline $\begin{array}{c}\text { Cohesión } \\
\text { guiada por } \\
\text { vocabulario }\end{array}$ & $\begin{array}{l}\text { Reiteración del } \\
\text { referente }\end{array}$ & $\begin{array}{l}\text { Indicadores temporales } \\
\text { Ejemplos: } \\
\text { - } \quad \begin{array}{l}\text { ayer, hoy, mañana, la } \\
\text { semana que viene, en } \\
\text { unos minutos..... }\end{array} \\
\text { Indicadores espaciales } \\
\text { Ejemplos: } \\
\text { - preposición+ lugar }\end{array}$ & $\begin{array}{l}\begin{array}{l}\text { Señales lexicales que indican una } \\
\text { relación estructural } \\
\text { Ejemplos: }\end{array} \\
\text { - } \quad \begin{array}{l}\text { Pistas de relación Causal: una } \\
\text { posible causa, los motivos, las } \\
\text { consecuencias, el desencadenante } \\
\text { es.. } \\
\text { - Pistas de relación Argumentativa: } \\
\text { puede deducirse, un dato a favor, } \\
\text { las razones, como conclusión... }\end{array}\end{array}$ \\
\hline $\begin{array}{l}\text { Cohesión } \\
\text { guiada por } \\
\text { gramática }\end{array}$ & $\begin{array}{l}\text { Uso de } \\
\text { pronombres y de } \\
\text { adjetivos } \\
\text { posesivos } \\
\\
\text { Aplicación de } \\
\text { reglas de } \\
\text { concordancia }\end{array}$ & $\begin{array}{l}\text { Indicadores temporales } \\
\text { Ejemplos: } \\
\text { - } \quad \begin{array}{l}\text { luego, después, } \\
\text { anteriormente, } \\
\text { previamente, ... }\end{array} \\
\text { - } \begin{array}{l}\text { tiempos y aspectos } \\
\text { verbales utilizados en } \\
\text { el texto. }\end{array} \\
\text { Indicadores espaciales } \\
\text { Ejemplos: } \\
\text { - } \\
\text { alli, aquí, donde, } \\
\text { junto a, debajo } \\
\text { de....... }\end{array}$ & 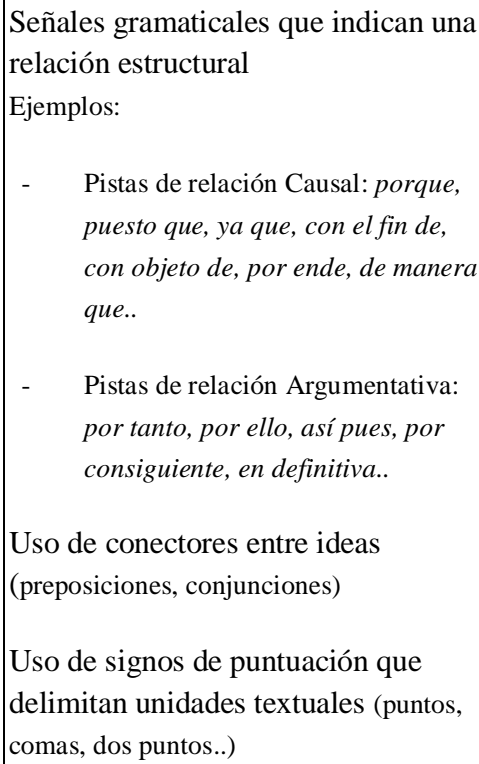 \\
\hline
\end{tabular}

Cuadro 1.11. Elementos cohesivos textuales

(Construido a partir de la revisión de los trabajos de Givon (1995), Hernández (1999), Hernández y Quintero (2001, 2002) y Louwerse (2004)

Para ejemplificar lo que acabamos de señalar retomaremos el extracto textual que hemos venimos utilizando.

La importancia que adquiere en la crisis de la república romana el problema agrario sólo es comprensible desde una doble perspectiva; ante todo, porque la base fundamental de la economía romana estaba constituida por la agricultura; pero además, porque las transformaciones que se operan en la agricultura romana de las guerras de conquista afectan a uno de los pilares estructurales de la sociedad hasta ese momento: el pequeño campesinado.

Cuadro 1.12. Ejemplo de pasaje muy cohesivo (Elaboración propia) 
Como vemos, las señalizaciones estructurales "desde una doble perspectiva", "ante todo porque", y "pero además porque", así como, la correferencia argumental establecida por el uso de hiperónimos ("problema agrario", "agricultura”, "agricultura romana", "pequeño campesinado"); al tiempo que otorgan gran cohesión global al párrafo (permiten estructurar la información en torno a una estructura causal dominante), favorecen el paso de información nueva a información dada facilitando la cohesión local entre frases.

En definitiva, la cohesión aunque es un factor clave para la coherencia, no la garantiza, ya que un texto que dispone de elementos cohesivos puede percibirse como poco coherente, y un texto sin elementos cohesivos puede percibirse como coherente (Louwerse, 2004). Además, estos elementos cohesivos, normalmente, favorecerán en mayor o en menor medida tanto la cohesión local como la cohesión global del texto.

\section{B. El Formato textual}

Otro factor vinculado al texto que puede incidir en el proceso de comprensión lectora es el formato textual. En relación a éste, los trabajos que hemos consultado en torno a la lectura de textos múltiples (Cerdán y Vidal-Abarca, 2008; Braten y Stromso, 2006a; Braten y Sromso, 2006b; Britt y Sommer, 2004; Le Bigot y Rouet, 2007; Perfetti, Rouet y Britt, 1999; Stromso, Braten y Samuelstuen, 2003) y a la lectura de hipertexto (Potelle y Rouet, 2003; Rouet, 2003; Salmerón, Cañas, Kintsch y Kintsch (2010); Voros, Rouet y Pléh, 2011) nos permiten señalar que la multilinealidad que favorece este tipo de formatos, exige que el lector ponga en marcha estrategias específicas (vinculadas fundamentalmente a la inferencia de relaciones intertextuales) con el fin construir una representación mental integrada de los diferentes nodos o extractos textuales. De modo similar, autores como Mayer, (2001, 2005, 2014), Schnotz (2005) y Schnotz y Bannert (2003) apuntan que el documento multimedia, compuesto por texto e imágenes (estáticas o en movimiento), implica procesos cognitivos diferentes a los vinculados a documentos formados únicamente por texto.

No es nuestra intención, ni es objetivo de esta tesis, profundizar en la lectura multimedia o en la lectura de textos múltiples, puesto que, como adelantábamos en el apartado introductorio, nuestra investigación se centra, además de en los procesos de lectura que venimos analizando en este primer apartado (asociados a la lectura de un texto); en procesos de lectura asociados de manera específica al formato hipertextual, que analizaremos en profundidad en el epígrafe 1.3. 


\subsubsection{Factores dependientes del lector (cognitivos)}

Entre los factores dependientes del sujeto que inciden en el proceso de comprensión lectora, vamos a hacer hincapié en dos: el conocimiento previo y la carga cognitiva que supone el material para el lector.

\section{A. Conocimiento previo}

Mulcahy-Ernt y Carverly (2009) recogen las dos principales variables que los estudios sobre comprensión lectora asocian al conocimiento previo 5 : a) la familiaridad con el tópico/tema del texto (lo que llaman conocimiento de dominio), y b) las habilidades/estrategias lectoras:

We view prior knowledge as individual's storehouse of domain knowledge (such as knowing the concepts and principles about science), which influences in the depth of understanding when reading. The term prior knowledge can also refer to the students background reading ability. (p. 179)

En cuanto a la primera variable, cabe decir que está ligada a la memoria consciente o declarativa del lector (compuesta por la memoria semántica y la episódica) y se refiere, concretamente, a conocimientos relacionados con el tema que trata el texto. Gran número de estudios (Afflerbach, 1986; Chi, 1978; Chi, Feltovich y Glaser, 1981; Means y Voss, 1985; Dochy, Segers y Buehl, 1999; Recht y Leslie, 1988) afirman que poseer un alto conocimiento de dominio supone una gran ventaja a la hora de comprender un texto, ya que la disposición de dichos conocimientos, en comparación con la escasez o ausencia de los mismos, permite al lector generar un modelo de la situación más rico, y por tanto, alcanzar un nivel de comprensión más profundo. Siguiendo esta línea de investigación, Kendeou y Van den Broek (2005, 2007) y Van den Broek y Kendeou (2008) especifican que el conocimiento de dominio sólo favorecerá la comprensión, cuando, además de ser amplio en lo que se refiere a su cantidad, sea adecuado en lo que respecta a su calidad. Dichos estudios indican que las concepciones erróneas en torno al tópico del texto, al tener un papel intrusivo en la representación mental que el lector elabora, pueden interferir en la adquisición de nuevos conocimientos, y por tanto, dificultar la comprensión.

En lo que respecta a las habilidades/ estrategias lectoras, cabe destacar que están ligadas a dos aspectos: a) destrezas ubicadas en la memoria declarativa, que son dirigidas de forma consciente e intencional hacia la obtención de una meta concreta (noción de estrategia); y b) destrezas de naturaleza inconsciente ubicadas en la

\footnotetext{
${ }^{5}$ Existen otros tipos de conocimiento previo como el conocimiento grafémico, fonológico y semántico de las
} palabras; el conocimiento de las reglas gramaticales; el conocimiento de las tipologías textuales, etc. 
memoria procedimental, que son utilizadas de forma automática para satisfacer las demandas de una tarea cotidiana (noción de habilidad).

Según Escoriza (2003), por un lado, una habilidad puede convertirse en estrategia cuando es utilizada de forma intencional, y por otro, una estrategia puede automatizarse a través del entrenamiento y convertirse en habilidad. De manera que una misma destreza puede ser considerada habilidad o estrategia dependiendo de su grado de automatización. Por ejemplo, para un alumno de primer curso de primaria, la descodificación de palabras suele ser un proceso consciente e intencional (estratégico) que exige reconocer los grafemas que las componen, asociar dichos grafemas con sus correspondientes fonemas y acceder al significado semántico de cada palabra; sin embargo, con el paso de los cursos académicos y el debido entrenamiento, dicha estrategia se automatiza y se convierte en una habilidad que permite descifrar automáticamente la mayor parte de las palabras. Esta habilidad, a su vez, volverá a utilizarse estratégicamente (de forma consciente) en el momento en que el lector se enfrente a palabras que no tenga representadas en su memoria. Por lo tanto, como afirman Afflerbach, Pearson y Paris (2008), durante la lectura el lector debe encontrar el equilibrio entre la puesta en marcha de habilidades automáticas y la utilización de estrategias intencionales, partiendo de su destreza para cambiar de unas a otras cuando la situación lo requiera:

At the heart of accomplished reading is a balance of both automatic application and use of reading skills, and intentional, effortful employment of reading strategies - accompanied by the ability to shift seamlessly between the two when the situation calls for it. (p. 371)

Las habilidades y estrategias de las que hablamos han sido estudiadas tradicionalmente comparando buenos y malos lectores. En este sentido, hemos partido de los trabajos de Anderson y Thiede (2008), Block y Pressley (2007), Hernández (1999), Madler y Johnson (1977), McNamara, Ozuru, Best y O’Reilly (2007), Meyer y Ray (2011), Meyer (1975, 1984), Kintsch (1998), Scardamalia y Bereiter (1984), Salmerón y Gutiérrez-Braojos (2012), Sánchez (1993, 1998), Thiede y Anderson (2003), Thiede, Griffin, Wiley y Anderson (2010), Thiede, Griffin, Wiley y Redford (2009), Thiede, Dunlonsky, Griffin y Wiley (2005) y Van Dijk y Kintsch (1983) para elaborar el cuadro 1.13, donde presentamos sintéticamente las principales diferencias entre ambos tipos de lectores a la hora de utilizar:

a) Habilidades y estrategias vinculadas a la identificación de la microestructura.

b) Habilidades y estrategias vinculadas a la extracción de la macroestructura.

c) Habilidades y estrategias metacognitivas para la regulación y supervisión del proceso de comprensión lectora. 


\begin{tabular}{|c|c|c|}
\hline \multicolumn{3}{|c|}{ Habilidades y Estrategias de lectura } \\
\hline & Lectores inmaduros & Lectores maduros \\
\hline $\begin{array}{l}\text { Tipo de } \\
\text { representación }\end{array}$ & $\begin{array}{c}\text { Tema + colección inarticulada de } \\
\text { detalles }\end{array}$ & Coherente \\
\hline $\begin{array}{l}\text { Habilidades y } \\
\text { Estrategias } \\
\text { vinculadas a la } \\
\text { identificación de } \\
\text { microestructura }\end{array}$ & $\begin{array}{l}\text { Deficiencias en el uso de la progresión } \\
\text { temática } \\
\text { El lector muestra dificultades durante la lectura } \\
\text { para pasar de información nueva a información } \\
\text { dada, que le llevan a perder el hilo conductor del } \\
\text { texto. }\end{array}$ & \begin{tabular}{|l|} 
Uso estratégico de la progresión temática \\
El lector, durante la lectura, pasa de información nueva a \\
información dada siguiendo el hilo conductor del texto.
\end{tabular} \\
\hline $\begin{array}{l}\text { Habilidades y } \\
\text { Estrategias } \\
\text { vinculadas al } \\
\text { extracción de la } \\
\text { macroestructura }\end{array}$ & $\begin{array}{l}\text { Estrategia decir algo o Estrategia de } \\
\text { listado } \\
\text { El lector no utiliza la superestructura del texto } \\
\text { para identificar las ideas principales, integrarlas } \\
\text { en la memoria y facilitar la recuperación de las } \\
\text { mismas; ya que su objetivo es simplemente } \\
\text { decir algo sobre el texto. En consecuencia: } \\
\text { a) Recuerda la información de forma } \\
\text { desestructurada. } \\
\text { b) No identifica la importancia ideas } \\
\text { textuales con respecto al tema. }\end{array}$ & \begin{tabular}{|l} 
Estrategia Estructural \\
El lector reconoce la organización del texto y la asume para \\
ordenar en su memoria los significados que de él derivan y \\
para planificar el recuerdo. En consecuencia: \\
a) Se vale de las claves que le proporciona el texto y de \\
sus nociones acerca de tipologías textuales, para \\
identificar la forma organizativa predominante \\
(superestructura). \\
b) Utiliza dichas claves para poner en marcha un \\
conjunto de macroestrategias (construcción, \\
generalización y omisión) sobre la microestructura \\
con el fin extraer la macroestructura.
\end{tabular} \\
\hline $\begin{array}{c}\text { Habilidades y } \\
\text { Estrategias } \\
\text { metacognitivas para } \\
\text { la regulación y } \\
\text { supervisión de la } \\
\text { comprensión }\end{array}$ & $\begin{array}{l}\text { Ausencia de supervisión del grado de } \\
\text { comprensión } \\
\text { - Percibe la lectura como actividad basada } \\
\text { en el texto donde la aportación de } \\
\text { conocimientos previos es irrelevante. } \\
\text { - No es consciente de su meta de lectura o } \\
\text { su meta simplemente es recordar algo } \\
\text { del texto, por lo que se reduce la } \\
\text { probabilidad de que el lector alcance una } \\
\text { comprensión global. }\end{array}$ & $\begin{array}{l}\text { Supervisión constante del grado de comprensión } \\
\text { alcanzando } \\
\text { - Antes de la lectura: establece objetivos de lectura } \\
\text { (ajustados a genero textual y al tipo de tarea,) y } \\
\text { utiliza estrategias de pre-lectura } \\
\text { - Durante la lectura: toma notas en el texto, subraya } \\
\text { y/o relee partes del texto; se plantea preguntas } \\
\text { acerca de lo que sabe y de lo que necesita saber; } \\
\text { trata de resolver problemas de comprensión a través } \\
\text { de autoexplicaciones. } \\
\text { Después de la lectura: genera palabras clave y/o } \\
\text { realiza resúmenes y/o mapas conceptuales que le } \\
\text { permiten mejorar la precisión de la } \\
\text { metacomprensión. }\end{array}$ \\
\hline
\end{tabular}

Cuadro 1.13. Diferencias entre buenos y malos lectores en cuanto a habilidades y estrategias de lectura 
La mayor parte de las estrategias que utilizan los lectores maduros (uso estratégico de la progresión temática y estrategia estructural) fueron analizadas con anterioridad, cuando hablábamos del modelo Construcción-Integración; por lo que, en lo que respecta a este tipo de lectores, sólo vamos a comentar brevemente las estrategias metacognitivas que ponen en marcha.

Como vemos en el cuadro anterior, los buenos lectores controlan el proceso de lectura a través de tres fases que interactúan entre sí:

a) Antes de la lectura: plantean objetivos de lectura ajustados al género textual del texto/s que van a leer y al tipo de tarea que van a realizar; estas metas, según Pressley (2002), se van a caracterizar por su flexibilidad y su adaptabilidad durante el proceso de comprensión. Además, en esta fase, los lectores utilizan estrategias de pre-lectura como: a) la exploración textual, que implica revisar partes claves del texto, como títulos, subtítulos, palabras en negrita o cursiva, gráficos y tablas, el epígrafe introductorio, las conclusiones, las frases tópicas que suelen estar al principio de párrafo o de apartado, etc.; o b) el ojeado, que supone una lectura rápida del texto. Gracias a dichas estrategias, el lector construye una visión previa del texto que le permite: definir los objetivos de lectura planteados, activar el conocimiento previo (lo que ayuda a hacer predicciones en torno al contenido textual) e identificar y tomar ventaja de la estructura del texto (para usar estratégicamente la superestructura textual). Esta información va a ser de suma importancia para guiar el proceso de lectura y seleccionar estrategias de lectura adecuadas.

b) Durante la lectura: utilizan técnicas como la toma notas en el texto y el subrayado del texto para liberar recursos cognitivos de su memoria de trabajo (hecho que analizaremos cuando hablemos sobre la carga cognitiva); releen partes del texto para procesar en mayor profundidad aquella información que consideran relevante; generan cuestiones relacionadas con el grado de comprensión alcanzado; y se dan autoexplicaciones para tratar de resolver problemas que surgen en el transcurso de la lectura.

c) Después de la lectura: supervisan y toman consciencia del grado de comprensión global adquirido ayudándose de técnicas como la expresión escrita de ideas clave, la elaboración de mapas conceptuales o la construcción de resúmenes. De acuerdo con Thiede y colaboradores (Anderson y Thiede, 2008; Thiede y Anderson, 2003; Thiede et al., 2005; Thiede et al., 2010) el efecto de estas técnicas varía en función del momento concreto en el que se ponen en marcha. El mapa conceptual mejora la precisión de la metacomprensión, principalmente, si se realiza inmediatamente después de la lectura (Thiede et al., 2010), mientras que las ideas clave (Thiede et al. 2005), y el resumen (Anderson y Thiede, 2008; Thiede y Anderson, 2003) lo hacen, 
fundamentalmente, cuando pasa cierto tiempo entre el final de la lectura y el principio de la redacción.

En cuanto a los malos lectores, el cuadro muestra que tienen dificultades a la hora de reconocer la microestructura, de identificar la macroestructura y de controlar el proceso de lectura. En primer lugar, pueden perder el hilo conductor del texto en el paso de información nueva a información dada, lo cual suele vincularse a dificultades a la hora de percibir solapamiento argumental entre ideas a nivel local. En segundo lugar, pueden tener dificultades para identificar el nivel de importancia de las ideas con respecto al tema del texto, puesto que parten de una meta de lectura limitada (recordar algo del texto) que les lleva a utilizar estrategias inadecuadas (decir algo sobre el texto). $\mathrm{Y}$ en tercer lugar, no controlan el proceso de comprensión ni antes, ni durante, ni después de la lectura ya que: no se plantean objetivos de lectura adecuados, no suelen releer el texto, no suelen hacer resúmenes, habitualmente dan por válida la primera interpretación que hacen de la información, etc.

En conclusión, los lectores maduros disponen de unas habilidades y estrategias lectoras que le permiten construir una representación coherente del texto; mientras que los lectores inmaduros, poseen otras que les llevan a elaborar una representación poco coherente (tema + detalles).

\section{B. La carga cognitiva}

Otro de los factores que incide en la comprensión lectora es la carga cognitiva, es decir, la cantidad de recursos mentales que el lector precisa poner en marcha para satisfacer las demandas de una tarea de comprensión.

Desde nuestro punto de vista, este factor ha sido ampliamente estudiado desde la teoría de la carga cognitiva (Sweller, 1988, 2005; Pass y Sweller, 2014; Sweller, Ayres y Kalyuga, 2011), que postula que el número de recursos movilizados por un sujeto durante cualquier actividad de comprensión obedece principalmente a tres variables: a) la carga intrínseca que supone el material de lectura para el sujeto, b) la carga ineficaz o extraña que el sujeto recibe del contexto de tarea en el que utiliza el material, y c) la carga eficaz que el sujeto toma del contexto de tarea donde usa el material.

La carga intrínseca depende de la dificultad del material que se utiliza durante una actividad lectora. Situando el grado de dificultad dentro de un continuum que va desde materiales (sean texto, hipertexto o multimedia) que suponen una carga cognitiva alta hasta los que implican una carga muy baja, podemos decir que:

- en el extremo más alto aparecen materiales formados por elementos que interactúan entre sí de forma compleja, donde la comprensión de un elemento depende de la comprensión del resto de los elementos, y viceversa; 
- en el centro se sitúan materiales cuyos elementos interactúan de forma más simple, donde la comprensión de un elemento textual depende en menor medida de la comprensión de el resto de elementos, y viceversa;

- en el extremo más bajo se encuentran materiales formados por elementos que no interactúan entre sí, donde cada elemento tiene significado independientemente del resto de los elementos.

Por ejemplo, una argumentación, que presenta un conjunto de argumentos que se apoyan en una serie de hechos para justificar una tesis, supondrá mayor carga cognitiva para el lector que una descripción, que recoge un objeto que se describe y un conjunto de descriptores; y dicha descripción, a su vez, supondrá mayor carga cognitiva que la definición de una lista de conceptos.

La carga ineficaz o extraña y la carga eficaz, por su parte, dependen del contexto de tarea (interacción entre instrucciones del profesor, el tiempo que dispone el alumno para realizar la tarea, espacio en el que la realiza, el conocimiento de dominio del lector, sus habilidades de lectura, el grado de cohesión del texto); y aunque ambas aumentan la carga cognitiva durante la lectura, su efecto es muy diferente: mientras la primera, puede llegar a ser un obstáculo importante para la comprensión, la segunda puede facilitarla. Por ejemplo, si las instrucciones que recibe el lector para realizar una tarea de lectura no están claras, éste se verá obligado a utilizar recursos cognitivos para tratar de averiguar qué es lo que debe hacer (carga extraña o ineficaz); si por el contrario, el lector recibe unas instrucciones claras acerca de la tarea que debe realizar, los recursos cognitivos que invierte le facilitarán la realización de dicha tarea (carga eficaz).

Las tres variables que hemos mencionado actúan de forma sumativa dentro de la memoria de trabajo, la cual, recordemos, procesa el texto por ciclos porque sólo tiene capacidad para activar simultáneamente una limitada cantidad de información durante un escaso espacio de tiempo. Por tanto, la comprensión dependerá fundamentalmente de que la carga cognitiva no exceda los escasos recursos mentales disponibles dentro de cada ciclo; puesto que una sobrecarga de la memoria de trabajo resentiría todo el proceso de lectura. Teniendo esto en cuenta, en un ciclo en el que confluyen una alta carga intrínseca, una alta carga ineficaz y una baja carga eficaz; habrá mayor riego de saturación cognitiva que en un ciclo en el que se den una alta carga intrínseca, una baja carga ineficaz y una alta carga eficaz.

Además de las variables señaladas por la teoría de la carga cognitiva, hemos de destacar otra variable, que es tanto o más importante que las anteriores a la hora determinar la carga cognitiva que supone el proceso de comprensión: la capacidad del lector para gestionar sus recursos cognitivos. 
Para clarificar este punto, consideremos la complejidad que supone el procesamiento de la información textual a nivel local y global dentro de cada ciclo y entre ciclos. Cuando acaba un ciclo y comienza el siguiente, algunos de los contenidos elaborados hasta entonces se desplazan desde la memoria de trabajo hacia la MLP (principalmente aquellas ideas que, aun siendo relevantes, no son imprescindibles para mantener la coherencia local). Dichos contenidos, se podrán recuperar en cualquier otro ciclo para mantener la coherencia global del texto, si bien, los recursos cognitivos destinados para tal fin, ya no se podrán utilizar para continuar estableciendo relaciones locales entre ideas. Ésto, en palabras de Sánchez et al. (2010), significa que, "restaurar una idea vieja no sale gratis,...esos recursos dedicados a recuperarla no pueden destinarse a interpretar las palabras que siguen llegando a nuestra mente" (p.53).

Partiendo de este supuesto, Sánchez y sus colaboradores (Sánchez et al., 2010; Sánchez, García y Rosales, 2009; Sánchez, Solé y Gallart, 2009) consideran que es muy difícil que procesemos el texto a nivel local y global simultáneamente; en lugar de eso sostienen que, para ahorrar recursos cognitivos, simplificamos la tarea de comprensión. Por ejemplo, si nuestro objetivo es extraer las ideas fundamentales del texto, nos centraremos principalmente en las señales textuales que indican la organización superestructural para identificar la macroestructura textual, y no tanto en los vínculos que se dan entre las proposiciones a nivel local; del mismo modo que si, en un momento dado, decidimos revisar la relación local que existe entre una idea y la contigua, perderemos la perspectiva del texto como un todo durante ese ciclo de procesamiento. Tomando esto como referencia, comprenderemos por qué cuando realizamos una tarea compleja que requiere el procesamiento del texto en profundidad, es muy útil el uso de técnicas, como la relectura, la extracción de ideas claves y la realización de resúmenes o mapas conceptuales, que nos permitan liberar recursos cognitivos que se puedan destinar, por ejemplo, al procesamiento local del texto, a enriquecer el modelo de la situación creado, etc.

La economía cognitiva, por lo tanto, va a ser fundamental para evitar que, durante el proceso de lectura, se den periodos críticos asociados a la sobrecarga de la memoria de trabajo, que puedan dificultar o cortocircuitar la comprensión (Sweller, 2005). En este sentido, un lector que haya automatizado estrategias de lectura (convirtiéndolas en habilidades) no destina recursos cognitivos para ponerlas en marcha, ya que, al ser inconscientes, no ocupan espacio dentro de la memoria operativa; mientras que un lector que apenas haya automatizado dichas estrategias, las utiliza de forma consciente, lo cual le supone un esfuerzo cognitivo, y por tanto, un gasto de recursos mentales. De modo similar, un lector que tiene alto conocimiento sobre el tema del texto necesita utilizar menos recursos cognitivos que otro que tiene bajo conocimiento, ya que este último debe destinar una gran cantidad de recursos a identificar el significado semántico de las palabras técnicas que aparecen. 
En definitiva, la carga cognitiva que soporta la memoria de trabajo durante el proceso de comprensión dependerá fundamentalmente de tres aspectos:

- la dificultad intrínseca del texto;

- las facilidades y obstáculos que presenta el contexto de tarea; y

- la capacidad del lector para gestionar sus recursos cognitivos.

\subsubsection{Factores dependientes del contexto}

La actividad lectora en cualquier entorno educativo, y en particular en el ámbito universitario, se realiza dentro de un contexto de tarea concreto que influye en: los objetivos específicos de lectura que plantea el lector, el tipo de estrategias que pone en marcha y la información que considera contextualmente relevante (Cerdan, Gil y VidalAbarca, 2011; McCrudden y Schraw, 2007; Rouet y Vidal-Abarca, 2002; Rouet y Britt, 2011; RAND reading study group, 2002; Vidal-Abarca et al., 2011).

Tal como señalábamos, el modelo Construcción-Integración de Kintsch (1988, 1998, 2004) ofrece una explicación muy completa acerca de los procesos utilizados por el lector cuando lee un texto con el objetivo de comprenderlo globalmente; pero no analiza los procesos implicados en la lectura orientada a tareas más específicas en las que se plantean otro tipo de objetivos. En este sentido, el modelo Múltiple Documents TaskBased Relevance Assesment and Content Extraction (en adelante MD-TRACE) de Rouet y Britt (2011) es el complemento perfecto al modelo de Kintsch, ya que, a pesar de estar orientado a la lectura de textos múltiples, permite explicar procesos y recursos que están involucrados en cualquier tarea de comprensión lectora.

La imagen 1.2 recoge el modelo MD-TRACE con algunas adaptaciones que hemos considerado oportuno introducir, tanto para adecuarlo a las diferentes tareas de comprensión, como para facilitar su integración dentro del contenido de este capítulo. Específicamente: a) en lugar de referirnos a un modelo de documentos (vinculado principalmente a la lectura de textos múltiples), hablamos de representación mental del documento/s (en la que se pueden enmarcar todos los formatos textuales); y b) en lugar de diferenciar el conocimiento previo (lo que nosotros llamamos conocimiento del tema o de dominio) de las habilidades/estrategias de lectura y estrategias de autorregulación, hemos enmarcado las habilidades/estrategias de lectura, las habilidades/estrategias metacognitivas de autorregulación y el conocimiento de domino/tema, dentro del conocimiento previo. 


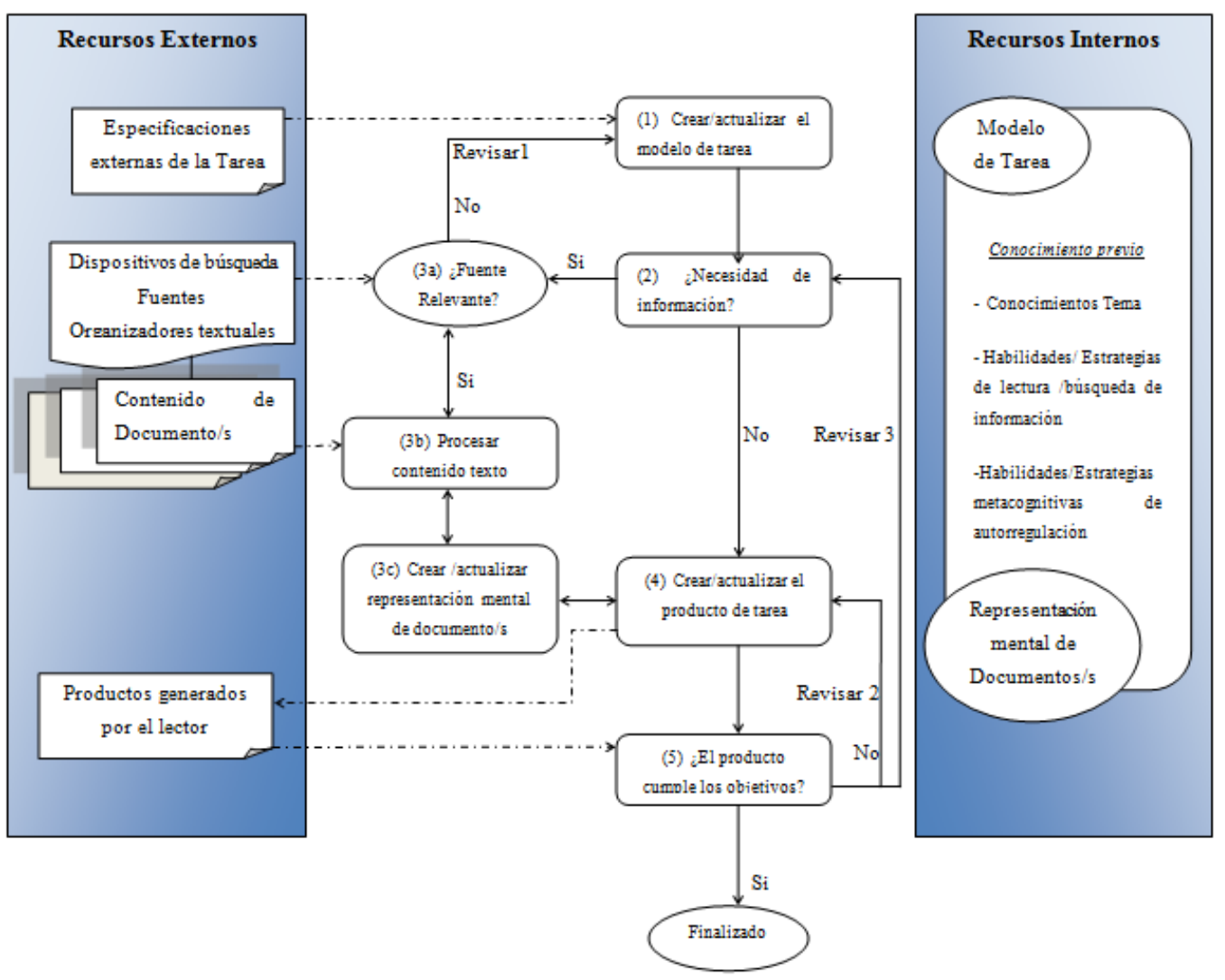

Imagen 1.2. Modelo MD-TRACE (Traducido y adaptado de Rouet y Britt, 2011)

Teniendo estas especificaciones en cuenta, analizaremos brevemente el modelo MD-TRACE, comenzando por señalar que el lector, para realizar una tarea concreta, utiliza recursos internos y recursos externos.

Entre los recursos externos destacan:

- Las especificaciones externas de la tarea, un recurso de información que, según Rouet y Britt (2011), abarca un conjunto de señales verbales y no verbales que especifican la tarea de lectura: "The first information resource is the Task specifications, i.e., the set of verbal and non-verbal cues that specify the reading task”(p. 5). Las señales verbales suelen estar vinculadas con la cuestión en la que se centra la tarea, las instrucciones e indicaciones necesarias para realizarla, el rendimiento esperado y las consecuencias potenciales de su realización (por ejemplo, aprobar o suspender una asignatura); mientras que las señales no verbales suelen asociarse a aspectos como la limitación temporal de la tarea (el tiempo del que dispone el lector para realizarla), la calidad del entorno en el que se realiza (por ejemplo, no es lo mismo leer en una aula silenciosa o en un sala de biblioteca, que hacerlo en un autobús en hora punta) y el coste de acceso a un recurso (por ejemplo, no es lo mismo disponer de un artículo de investigación en el aula en el que se realiza la tarea, que tener que desplazarse a la biblioteca). 
- El conjunto de fuentes/documentos (incluyendo el contenido textual) e instrumentos de acceso a la información (dispositivos de búsqueda, organizadores textuales) que están disponibles en el contexto en el que se realiza la tarea. Este sistema de información varía según la cantidad de fuentes de información a las puede tener acceso el lector para realizar la tarea (desde un artículo o un libro, hasta una biblioteca completa o una base de datos online) (Rouet y Britt, 2011).

- Los productos generados por el lector durante el proceso de lectura, como resúmenes, mapas conceptuales, borradores, subrayado textual o anotaciones en el texto: "The third type of external resource is the set of task products generated by the reader as part of his or her use of the documents. These include highlighting, annotations, drafts, responses or essays" (Rouet y Britt, 2011, p.6). Este tipo de productos permiten descargar la información importante sobre un papel, lo cual supone un importante ahorro de recursos cognitivos a la hora de recuperar dichas ideas.

Por su parte, entre los recursos internos, destacan lo que Rouet y Britt (2011) denominan:

- Recursos permanentes, como los conocimientos previos del lector, concretamente, su conocimiento sobre la temática del texto/s, sus experiencias previas en tareas similares, sus habilidades/estrategias de lectura y búsqueda de información, y sus habilidades/estrategias metacognitivas de autorregulación; y

- Recursos transitorios, como el modelo de tarea, una representación que elabora el lector sobre las demandas de la tarea (suele incluir un plan de acción para tratar de cumplirlas); o como la representación mental del contenido del documento/s, que supone una "representación global sobre los contenidos y fuentes de los documentos para responder o cumplir un objetivo de la tarea o parte de la misma” (Jáñez, 2014, p.17).

Partiendo de ambos recursos, Rouet y Britt (2011) señalan que el lector pone en marcha cinco pasos para construir dos tipos de representación: un modelo de tarea y una representación mental del contenido del documento/s que es contextualmente relevante para dicha tarea. Hemos de puntualizar que descomponer en pasos un proceso tan complejo como la lectura responde más a las necesidades explicativas del modelo MDTRACE que al procesamiento real llevado a cabo por el lector, quien puede realizar dichos pasos de forma desordenada o paralela. No obstante, no cabe duda de la utilidad de los cinco pasos propuestos por Rouet y Britt, para ayudarnos comprender los procesos que tienen lugar durante la lectura orientada a cualquier tipo de tarea: 
a) El primer paso es crear un modelo de tarea, que incluya un conjunto de objetivos y procedimientos para alcanzar esos objetivos, así como, un conjunto de criterios que ayuden a: evaluar la relevancia del tema del documento/s y de los pasajes de ese documento/s; establecer el número de documentos que deben ser localizados y leídos; y prever el tipo de resultado que exige la tarea.

The result of Step 1 is a Task Model which includes a set of goals and procedures for reaching those goals as well as a set of criteria that will help the reader (a) assess the topical relevance of potential documents and passages within documents, $(b)$ set a number of documents to be located and read, and (c) envision the kind of output that the teacher is asking for. (Rouet y Britt, 2011, p.9)

Esta representación mental de la tarea pasa a ser parte de los recursos internos del lector, siendo, concretamente, unos recursos transitorios que podrán ser actualizados a la luz de etapas subsiguientes.

b) El segundo paso es evaluar la necesidad de información. En esta etapa, el lector compara sus conocimientos sobre el tema con las demandas de la tarea, para decidir cuáles son sus necesidades informativas. Según Jáñez (2014), este paso se relaciona con el resto de pasos del modelo, puesto que:

Ya sea para revisar el modelo de tarea (Pasol), decidir si una información es relevante para la tarea (Paso 3a), dar una respuesta a la tarea (Paso 4) o evaluar la validez de dicha respuesta (Paso 5), siempre se evalúa si necesitamos más información para continuar buscando, o si ya hemos encontrado la respuesta que buscábamos. (p.17)

De acuerdo con Vidal Abarca (2011), este paso es crítico para el proceso de comprensión lectora, y para explicarlo pone dos ejemplos: por un lado, el lector puede pensar incorrectamente que es capaz de realizar la tarea sin información adicional, y por otro, puede invertir innecesariamente recursos cognitivos persistiendo en la búsqueda de información a pesar de que podría satisfacer las demandas de la tarea sin buscar información adicional.

c) El tercer paso es procesar el documento/s, lo que incluye tres sub-procesos altamente interrelacionados que permiten acceder, procesar e integrar la información dentro del texto, y en su caso, entre textos. En este sentido, teniendo en cuenta la imagen 1.2 de este trabajo, el lector, en primer lugar, evalúa la relevancia del documento/s o fragmento/s textual/es para la tarea que debe realizar (3a); en segundo lugar, procesa en profundidad el contenido textual seleccionado (3b); y en tercer lugar, crea una representación mental del texto/s que, al igual que el modelo 
de tarea, pasa a ser un recurso interno del lector que será actualizado conforme avanza el proceso de lectura (3c).

d) El cuarto paso es crear/actualizar un producto de tarea, con el que el lector, teniendo en cuenta el modelo de tarea creado y la información procesada del documento/s leído/s, construye una respuesta para dicha tarea.

e) El quinto paso es evaluar el producto de tarea. Una vez generado un producto, el lector evalúa el grado en el que se ajusta a los objetivos de lectura planteados: "Once a task product has been generated the reader may need to assess whether the product (4) meets the task goals (1)" (Rouet y Britt, 2011, p.16). Si el resultado obtenido responde a las demandas de la tarea, ésta se da por finalizada, si no, puede ser necesario revisar alguno de los pasos anteriores.

Como vemos, el modelo MD-TRACE establece un conjunto de recursos y procesos comunes a cualquier tarea de lectura, por lo que supone un marco de referencia fundamental para una tarea de lectura orientada a la escritura que analizaremos en el segundo punto: el resumen de la información (Summarizing).

\subsubsection{Interacción entre factores implicados en la comprensión lectora durante el proceso de lectura}

Una vez vistos los diferentes factores que inciden en la comprensión, vamos a analizar cómo interactúan algunos de ellos durante el proceso de lectura. Específicamente, nos vamos a centrar en el conocimiento previo (conocimiento de dominio y habilidades lectoras), en la carga cognitiva y en la cohesión textual. El resto de factores, concretamente, la tarea de lectura y el formato textual, se tratarán en profundidad más adelante, cuando hablemos de lo que implica resumir un texto y cuando analicemos qué implica leer un el hipertexto.

A. Interacción entre cohesión textual y conocimientos previos del lector durante el proceso de comprensión

Existe cierta controversia en la investigación en lo que se refiere a la relación entre cohesión textual y conocimiento previo, cuando éste último se limita al conocimiento que el lector tiene del tema.

Por un lado, encontramos estudios como los de Kintsch (1988, 1998), McNamara y Kintsch (1996) y McNamara et al. (1996) que afirman que: a) conforme se incrementa la cohesión de un texto, los lectores con bajo conocimiento previo mejoran la base textual y el modelo de la situación que generan; y b) conforme disminuye la cohesión, son los sujetos con alto conocimiento previo los que obtienen mayor beneficio en ambos tipos de representación. 
Y por otro lado, existen trabajos cuyos resultados muestran que la cohesión textual favorece a sujetos con bajo conocimiento previo, fundamentalmente, en la elaboración de la base textual; y beneficia a sujetos con alto conocimiento previo tanto en la elaboración de la base textual como en la construcción del modelo de la situación. Entre estos estudios, en particular, vamos a destacar dos: a) el realizado por Ozuru et al. (2009), donde los lectores, al enfrentarse a un texto cohesionado de ciencias naturales sin disponer de conocimientos generales relacionados con el tópico, no fueron capaces de generar un modelo mental suficientemente rico en el que enmarcar la información específica que se trataba en el texto; y b) el realizado por Gilabert, Martínez y VidalAbarca (2005), en el que los lectores, al enfrentarse a un texto cohesionado de ciencias sociales con disposición de nociones acerca de cómo se relacionan los eventos del texto dentro de una estructura general (por ejemplo, las historias sobre una guerra comparten elementos como la intervención de múltiples países, las causas del conflicto, etc.), fueron capaces de integrar la información específica del texto dentro de un marco general, que, a su vez, mejoraba los procesos inferenciales (y por tanto, el modelo de la situación construido).

Esta controversia, como veremos seguidamente, se diluye en el momento en el que las diferentes investigaciones concretan los tipos de conocimiento previo (conocimiento de dominio y habilidades lectoras) que interactúan con el grado de cohesión textual durante el proceso de lectura.

\section{B. Incidencia del grado de cohesión textual en el proceso de comprensión lectora, en función del conocimiento de dominio y de las habilidades lectoras}

La variación de la variable cohesión textual incide en el grado de importancia del conocimiento sobre el tema y de las habilidades de lectura durante el proceso de comprensión.

En este sentido, Voss y Silfies (1996) subrayan que mientras la comprensión de textos poco cohesivos depende principalmente del conocimiento de dominio, la comprensión de textos muy cohesivos depende fundamentalmente de las habilidades lectoras. En la misma línea, McNamara (2001) sugiere que un lector con alto conocimiento previo del tema construirá una mejor representación mental cuando se enfrente a un texto de baja cohesión; y Beck, McKeown, Sinatra y Loxterman (1991) indican que un lector con altas habilidades de lectura se beneficiará fundamentalmente de textos muy cohesionados.

Más recientemente, Óreilly y McNamara (2007) y Ozuru et al. (2009) analizan con mayor profundidad los vínculos entre estas tres variables, encontrando una interacción mucho más estrecha. Entre los resultados que obtienen cabe destacar que: la cohesión textual beneficia a los que tienen alto conocimiento y altas habilidades lectoras, 
y a los que tienen bajo conocimiento (no existen diferencias significativas (n.s.=.05) entre los que tiene altas y bajas habilidades); mientras que la baja cohesión textual beneficia a aquellos que tienen alto conocimiento y bajas habilidades lectoras ${ }^{6}$.

En conclusión, los textos muy cohesivos favorecen principalmente a los lectores que disponen de un bajo conocimiento de dominio (independientemente de sus habilidades lectoras), y a los lectores con alto conocimiento de dominio que disponen de habilidades lectoras para procesar activamente dichos textos. Por otro lado, los textos poco cohesivos van a beneficiar, fundamentalmente, a los lectores que tienen alto conocimiento de dominio pero bajas habilidades lectoras, ya que procesan la información de forman más activa cuando tienen que generar inferencias para construir una representación mental coherente.

C. Incidencia de la interacción del conocimiento dominio, las habilidades lectoras y la cohesión textual en la carga cognitiva que soporta la memoria de trabajo

La teoría de la carga cognitiva explica la interacción que se establece entre los factores que venimos señalando, partiendo de lo que denomina el efecto inverso de la experiencia ("expertise reversal effect").

Desde esta perspectiva, el incremento en la cohesión de un texto tiene un efecto distinto en lectores con diferente conocimiento de dominio, concretamente, el efecto inverso: mayor beneficio para los lectores con bajo conocimiento del tema, y menor beneficio (o mayor perjuicio) para lectores con alto conocimiento. Sweller, Ayres, Kalyuga y Chandler (2003) atribuyen este efecto principalmente a dos razones:

a) El lector que dispone de alto conocimiento de dominio basa el proceso de comprensión principalmente en dicho conocimiento. En este sentido, construirá un mejor modelo de la situación a partir de un texto poco cohesivo, que le exige destinar parte importante de los recursos cognitivos de su memoria de trabajo a la recuperación de información relacionada con el tópico del texto (carga cognitiva efectiva); mientras que elaborará un modelo de la situación más pobre a partir de un texto muy cohesivo, que procesa pasivamente, y por consiguiente, no le exige asignar tantos recursos mentales a la recuperación de las ideas almacenadas en la MLP.

\footnotetext{
${ }^{6}$ Estos estudios utilizaron, en primer lugar, el test estadarizado Nelson-Denny (Brown, Fishco y Hanna, 1993) para medir la habilidad de comprensión lectora de los sujetos de la muestra; y una vez que determinaron las habilidades de cada sujeto, evaluaron el nivel de comprensión de un pasaje breve a través de tres tipos de preguntas: unas sobre la base textual (cuyas respuestas eran ideas que aparecían explícitamente en el texto) y dos sobre el modelo de la situación (cuyas respuestas exigían realizar bien inferencias locales, o bien inferencias globales).
} 
b) El lector que posee escasos conocimientos sobre el tema basa el proceso de comprensión principalmente en la información textual, por lo que debe emplear sus recursos cognitivos para procesar activamente dicha información (carga cognitiva efectiva), con el fin de elaborar una representación mental del mismo.

El efecto del que hablamos, además del conocimiento de dominio y de la cohesión textual, depende también de las habilidades lectoras. De acuerdo con Daneman y Hannon (2001) y Kalyuga $(2007,2013)$, un lector con alto conocimiento del tema puede beneficiarse de un texto de alta cohesión, si dispone de habilidades lectoras que le permitan procesar activamente el texto; mientras que un lector con bajo conocimiento sobre el tema puede no beneficiarse de un texto muy cohesionado, si carece de habilidades lectoras que le permitan gestionar adecuadamente sus recursos cognitivos.

Tomando como referencia lo que venimos señalando en torno a la interacción entre los factores implicados en la comprensión lectora (cohesión textual, conocimiento previo (conocimiento de dominio y habilidades lectoras) y carga cognitiva), podemos decir a modo de conclusión que:

- El aumento de la cohesión textual beneficia tanto a lectores con alto conocimiento y altas habilidades lectoras, como a lectores con bajo conocimiento; y su disminución, beneficia fundamentalmente a aquellos que tienen alto conocimiento y bajas habilidades lectoras.

- La carga cognitiva que soporta la memoria de trabajo del lector durante el proceso de lectura está determinada por la interacción de los tres factores anteriores.

\subsection{EL RESUMEN: UNA TAREA ELEMENTAL QUE FACILITA LA COMPRENSIÓN DE TEXTO/S ACADÉMICO/S}

El contexto universitario, en lo que se refiere a la actividad lectora, supone un cambio substancial con respecto a las etapas educativas anteriores. Mientras la Educación Obligatoria y el Bachillerato se orientan, fundamentalmente, a la lectura de textos que se adaptan al nivel formativo de los alumnos (por ejemplo: libros de texto o materiales elaborados por el profesor); la Universidad se enfoca, principalmente, hacia la lectura de fuentes de información que no están dirigidas específicamente al alumnado, sino a una comunidad científica concreta.

El lenguaje disciplinar de los textos académicos supone una importante carga cognitiva para la memoria de trabajo del lector (principalmente para los lectores no familiarizados con dicho lenguaje); por lo que el alumno universitario necesitará gestionar sus recursos cognitivos mejor que en etapas educativas previas, para que el 
volumen de información que maneja dentro cada ciclo de procesamiento no exceda la capacidad de su memoria operativa. En este sentido, autores como Sánchez et al. (2009, 2010) y McNamara et al. (2007) afirman que para comprender textos complejos es necesario simplificar la tarea de lectura partiendo de estrategias de autorregulación como: a) la relectura, que permite procesar en profundidad el texto o partes concretas del mismo; b) el subrayado y la toma de notas en el texto, que permiten destacar y/o enfatizar la información importante; y c) la construcción de mapas conceptuales ${ }^{7}$ y la elaboración de resúmenes escritos, que facilitan la comprensión lectora a nivel global. A estas estrategias, cabría añadir la expresión escrita de ideas clave del texto, la cual, de acuerdo con Thiede et al. (2005), también favorece el procesamiento global.

Todo ello, desde la perspectiva del modelo MD-TRACE de Rouet y Britt (2011) (que vimos en el sub-apartado 1.1.3.3), implica que, para comprender un texto académico, puede ser necesario generar textos escritos o productos de tarea parciales (expresar por escrito ideas clave, elaborar resúmenes y/o construir mapas conceptuales) e ir actualizándolos hasta constituir un texto/producto de tarea definitivo (un mapa conceptual o un resumen del texto) que satisfaga los objetivos de lectura planteados en el marco del modelo de tarea establecido (concretamente alcanzar una comprensión global del texto). Si tenemos en cuenta que una tarea de lectura cotidiana para el alumnado universitario, como es leer un texto académico, suele exigirle generar productos escritos que favorezcan la comprensión global del mismo; entenderemos por qué la mayor parte de las tareas de lectura en este contexto son, además, tareas de escritura.

Entre las diferentes tareas híbridas de lectoescritura que se realizan en la Universidad, nos vamos a centrar en el resumen por ser una de las tareas más frecuentemente demandadas, y ser además, una tarea básica para la construcción de conocimiento por las siguientes razones:

- Favorece el desarrollo de habilidades de comprensión lectora. De acuerdo con Hernández y Quintero $(2001,2002)$ y McNamara et al. (2007), resumir un texto supone organizar, reestructurar y sintetizar el contenido del mismo, a partir de un proceso reflexivo que refina y mejora la representación mental elaborada durante la fase de lectura propiamente dicha.

\footnotetext{
${ }^{7}$ Un mapa conceptual es un organizador gráfico compuesto por una red de conceptos que se relacionan entre sí a través conectores (palabras enlace) formando proposiciones o unidades semánticas (Novak, 1972, 1991, 2006, 2010). Según McNamara et al. (2007) y Romance y Vitale (2001), elaborar este tipo de gráfico mejora la comprensión global de un texto; ya que permite transformar un texto lineal, que presenta sus ideas de forma secuencial, en una representación gráfica no lineal, que distribuye viso-espacialmente las ideas esenciales del texto y las organiza jerárquicamente en función de la superestructura del mismo.
} 
- Favorece el desarrollo de habilidades de expresión escrita ${ }^{8}$. Resumir, como la mayor parte de las tareas de escritura, requiere organizar la redacción a dos niveles:

a) el nivel local o microestructural, que exige explicitar el paso de información nueva a información dada, utilizando, entre otros recursos, el solapamiento argumental de proposiciones (progresión temática); y

b) el nivel global o macroestructural, que precisa introducir señales textuales de carácter superestructural que determinen cuáles son las ideas más importantes (macroproposiciones) y cómo se relacionan entre sí jerárquicamente (macroestructura).

Este tipo de composición escrita, además, permite poner en práctica habilidades de escritura dentro de una situación más estructurada que la escritura puramente creativa (el escritor toma como macroestructura del texto que escribe, la macroestructura del texto que lee); lo que facilita que los alumnos aprendan progresivamente a redactar textos informacionales por ellos mismos: "Summarization tasks further a student's writing skills by providing practice in a situation that is more structured than open-ended, creative writing, thus forming a bridge for students to learn how to write informational texts of their own" (Wade-Stein y Kintsch, 2004, p.7).

- Constituye un instrumento de evaluación que permite al profesor valorar, a través de la expresión escrita, la comprensión lectora del alumno, puesto que la calidad del resumen escrito va a reflejar el nivel de comprensión adquirido: "the quality of summary writing mirrors the reading comprehension of the text" (McNamara et al., 2007, p.490).

- Es el punto de partida de tareas y procesos más complejos que se llevan a cabo en el contexto académico: "Summary writing serves as a foundation for more complex, creative processes that people are often required to perform in academic and professional settings" (McNamara et al., 2007, p.490). Cabe señalar que resumir reduce la exigencia cognitiva de la síntesis del discurso (Discourse Synthesis o Writing from sources), una tarea híbrida que implica integrar el contenido de varias fuentes de información dentro de un texto escrito que presenta una macroestructura propia. En efecto, elaborar un resumen escrito de cada fuente de información permite al lector-escritor, entre otras cosas, reservar para el proceso de integración intertextual los recursos cognitivos de su

\footnotetext{
${ }^{8}$ Tanto el resumen como el mapa conceptual mejoran la comprensión lectora, pero sólo el resumen precisa habilidades de expresión escrita; puesto que su elaboración supone generar relaciones microestructurales entre proposiciones que reflejen a través de indicadores superestructurales la macroestructura del texto leído. En este sentido, Gatti (2008) afirma que el resumen escrito requiere al lector considerar todos los aspectos que se ponen en juego durante la producción escrita.
} 
memoria de trabajo que, de otra forma, hubieran sido utilizados para recuperar de la MLP las ideas principales de cada texto.

Tomando esto como referencia, a continuación, analizaremos qué supone resumir un texto (Summarizing). Para ello, comenzaremos definiendo el concepto de resumen a través de las aportaciones de diferentes autores. Y una vez aclarado el significado de este término, revisaremos qué dice la investigación en comprensión lectora acerca de: a) la incidencia del resumen en la comprensión lectora, y b) diferencias entre lectores maduros e inmaduros a la hora de realizar un resumen.

Queremos destacar que, aunque en nuestra investigación el alumnado debía resumir un artículo académico presentado, bien en formato impreso, o bien en formato hipertextual; no consideramos necesario tratar específicamente el resumen de hipertexto, teniendo en cuenta que el proceso de integración intertextual lo analizaremos en el apartado sobre comprensión lectora a partir de hipertexto.

\subsubsection{Definición de resumen escrito}

El resumen es una tarea híbrida que precisa coordinar actividades de lectura y escritura en un grado que pocas tareas lo hacen (Tierney y Shanahan, 1991; Wade-Stein y Kintsch, 2004). Según Hedgcock y Ferris (2009), en lo que se refiere a la lectura, requiere que el lector extraiga las ideas clave del texto, partiendo de su habilidad para distinguir la información importante de la que no lo es; y en cuanto a la escritura, exige que escritor exprese las ideas extraídas de forma sucinta y personal:

Where reading is concerned, effective summarizing requires an understanding of the key ideas in a text and an ability to distinguish among main points (which belong in a summary) and supporting details (which typically do not). For writing, summarizing requires the writer to express the main points of a text she has read succinctly and in her own words. (p.185)

En esta misma línea, Hernández y Quintero (2001) afirman que:

..resumir será tanto una actividad de lectura, al requerir que previamente se haya logrado una buena comprensión del pasaje, mediante la identificación de la información importante, como de escritura, por cuanto que los alumnos deben tomar decisiones acerca de qué incluir $u$ omitir y cómo expresar mejor esa información, sin sacrificar la brevedad que debe caracterizar los resúmenes. (p.145)

Por su parte, autores como McNamara et al. (2007), conciben el resumen escrito como una estrategia que: 
- exige al lector reformular el contenido del texto utilizando sus propias expresiones, lo que favorece la integración de la información textual dentro del conocimiento previo;

- obliga al lector a revisar el proceso de comprensión utilizando metaestrategias de autorregulación que le permiten, por un lado, identificar las dificultades de lectura, y por otro, llevar cabo acciones correctivas; y

- ayuda al lector a organizar el texto a nivel macroestructural y a discernir la información importante de la que no lo es.

Otros autores, diferencian el resumen de otros términos con los que suele confundirse. Hirvela y Du (2013) por ejemplo, señalan que, aunque la paráfrasis es uno de los recursos que se suelen utilizar para realizar un resumen, no es lo mismo resumir un texto que parafrasearlo. Mientras resumir requiere operar a un nivel global para condesar la información del texto incluyendo solamente sus aspectos clave, parafrasear implica operar a un nivel local para mantener el nivel de especificidad que ofrece el texto: "While summarizing seeks to condense source information by including the main points only, paraphrasing allows the writer to retain the same level of specificity as the original source text" (p.88). De manera similar, Westby, Culatta, Lawrence y HallKenyon (2010) afirman que resumir es mucho más que volver a decir el contenido textual (Retell), ya que implica analizar información, distinguir elementos importantes de los no importantes y traducir una gran cantidad de trazos de información en unas pocas frases cohesivas: "Summarizing is more than retelling; it involves analyzing information, distinguishing important from unimportant elements and translating large chunks of information into a few short cohesive sentences" (p.227).

Finalmente, Kissner (2006) define el resumen como una versión abreviada del texto original que recoge las ideas principales y los detalles importantes del texto manteniendo la misma superestructura: "A summary, is a shortened version of an original text, stating the main ideas and important details of the text with the same text structure and order of the original'(p.8).

En definitiva, el resumen escrito es una tarea que exige coordinar habilidades de comprensión lectora (identificar la macroestructura del texto) y destrezas de expresión escrita (expresar las ideas extraídas de forma breve y personal manteniendo la superestructura del texto original) bajo la supervisión de metaestrategias que permiten al lector-escritor autorregular el proceso de comprensión y expresión escrita. Por tanto, elaborar resúmenes supone "un ejercicio de reflexión acerca de cómo escribirlos en función de los propósitos concretos de lectura que se hayan establecido" (Hernández y Quintero, 2001, p.145). 


\subsubsection{La incidencia del resumen en la comprensión del texto}

La evidencia empírica indica, mayoritariamente, que el resumen escrito permite al lector mejorar la comprensión lectora a través de la expresión escrita. Entre las diferentes investigaciones que así lo acreditan, destacan dos informes: el Writing to Read Report y el National Reading Panel.

El Writing to Read Report (Graham y Hebert, 2010) revisa y compara, a través de la técnica del meta-análisis estadístico, un total de 19 estudios que examinan el impacto de la escritura en la comprensión lectora. Partiendo de esos análisis, la investigación muestra que la elaboración de resúmenes escritos mejora significativamente la comprensión en comparación a otras actividades que implican únicamente la lectura (leer el texto, leerlo y releerlo, leerlo y estudiarlo, recibir instrucción sobre cómo leer un texto):

For students in grades 3-12, writing summaries about text showed a consistently positive impact on reading comprehension... Writing summaries about a text proved to be better than simply reading $i$, reading and rereading it, reading and studying it, and receiving reading instruction. (pp.15-16)

Concretamente, el informe atribuye esa mejora a dos aspectos estrechamente vinculados al proceso de escritura: a) transformar un resumen mental del texto en una composición escrita requiere pensar adicionalmente sobre la esencia del material leído (la macroestructura del texto); y b) el resumen, una vez que ha sido plasmado por escrito, crea un registro externo de la sinopsis mental construida por el lector que facilita la revisión y la reelaboración de dicha representación.

Transforming a mental summary of text into writing requires additional thought about the essence of the material, and the permanence of writing creates an external record of this synopsis that can be readily critiqued and reworked. As a result, summary writing seems likely to improve comprehension of the material being summarized. (p.15)

El National Reading Panel (2000), por su parte, a través del análisis de un total de 203 estudios sobre la enseñanza de la actividad lectora; identifica 8 tipos de instrucción que, desde una base científica sólida, mejoran la comprensión: "Of the 16 types of instruction, 8 offered a firm scientific basis for concluding that they improve comprehension" (pp.4-6). Entre esos 8 procedimientos, el informe destaca de manera específica la enseñanza-aprendizaje de técnicas de resumen, que permitan identificar y escribir aquellas ideas del texto original (las ideas principales) que integran todos los significados de dicho texto en un todo coherente: "Summarization in which the reader 
attempts to identify and write the main or most important ideas that integrate or unite the other ideas or meanings of the text into a coherent whole" (pp.4-6).

Además de estos dos informes, nos parece interesante destacar algunos estudios que ponen de manifiesto la importancia del resumen escrito para la comprensión de textos.

Por una parte, Westby et al. (2010), en el marco de un proyecto formativo cuyo objetivo era facilitar técnicas de enseñanza al profesorado universitario para instruir a su alumnado en la elaboración de resúmenes escritos; realizaron un estudio en el que comparaba los resúmenes elaborados por alumnos que fueron formados para realizar este tipo de tareas, con los resúmenes de alumnos que no habían recibido ningún tipo de instrucción al respecto. Los resultados obtenidos mostraron que los alumnos instruidos (grupo tratamiento) obtuvieron una puntuación significativamente más alta en comprensión lectora (basada en el análisis de la macroestructura y la microestructura de los resúmenes producidos) que los alumnos no instruidos (grupo control): "Students in the treatment condition produced significantly higher microstructure and macrostructure scores than students in the control group" (p.275). Lo que indicaba que el resumen escrito mejoraba la comprensión lectora, principalmente, cuando el alumnado había sido formado para realizar adecuadamente dicha tarea. En el ámbito español, Hernández (1999) llega también a esta conclusión, en un estudio realizado con alumnado de Educación Secundaria.

Por otra parte, Thiede y sus colaboradores (Thiede y Anderson, 2003; Anderson y Thiede, 2008; Thiede et al., 2010) realizaron un conjunto de trabajos sobre la incidencia del resumen escrito en la metacomprensión (la autorregulación del proceso de comprensión), cuyas principales conclusiones vamos explicar partiendo del estudio de Anderson y Thiede (2008).

Estos autores, establecieron una muestra compuesta por tres grupos que leían varios textos en tres condiciones diferentes:

a) el grupo en la condición no resumen, leía los textos (sin relectura), después valoraba el grado de comprensión que consideraba haber alcanzado, y tras esto respondía a un conjunto de preguntas de opción múltiple que evaluaban el nivel comprensión realmente alcanzado;

b) el grupo resumen inmediato, realizaba un resumen tras la lectura de cada texto (sin relectura), después valoraba el grado de comprensión que consideraba haber alcanzado, y tras esto respondía a un conjunto de preguntas de opción múltiple que evaluaban el nivel comprensión realmente alcanzado;

c) el grupo resumen retrasado, realizaba un resumen de cada texto una vez había leído todos los textos (sin relectura), después valoraba el grado de comprensión 
que consideraba haber alcanzado, y tras esto respondía a un conjunto de preguntas de opción múltiple que evaluaban el nivel comprensión realmente alcanzado.

Los resultados del estudio indicaron que las dos condiciones de resumen mejoraban la precisión de la metacomprensión con respecto a la condición no resumen, y que esa mejora se incrementaba exponencialmente cuando pasaba un cierto tiempo entre la finalización de la lectura y el comienzo de la redacción. Específicamente, los análisis señalaban que dentro del grupo resumen retrasado (cuya percepción de comprensión aumentaba conforme se extraían mayor número de ideas relacionadas con la esencia del texto) la correlación entre el nivel de comprensión percibido y el nivel de comprensión alcanzado era mucho más fuerte que dentro el grupo resumen inmediato (cuya percepción de comprensión aumentaba conforme se extraían mayor número de detalles del texto). Estas diferencias, de acuerdo con Anderson y Thiede (2008), se pueden asociar fundamentalmente a un factor: el grado de consciencia que tenía cada lector de haber integrado o no el contenido textual dentro de su base de conocimiento. En este sentido, el estudio enfatiza que cuando un lector realiza un resumen inmediatamente después de leer un texto, persisten detalles secundarios del documento en su memoria de trabajo, que le impiden percibir hasta qué punto el contenido textual se ha integrado en sus conocimientos previos, y por consiguiente, hasta qué punto ha comprendido el texto. Por el contrario, si el lector deja transcurrir cierto tiempo entre el final de la lectura y el comienzo de la redacción, los detalles secundarios desaparecen de su mente, y permanece, únicamente, la información que ha integrado en sus conocimientos previos. De esta manera, va a ser más consciente del nivel de comprensión que realmente ha alcanzado.

A pesar de que, como hemos mencionado, la mayor parte de la investigación sobre comprensión coincide en señalar la importancia del resumen; recientemente, Leopold y sus colaboradores (Leopold y Leutner, 2012; Leopold, Sumfleth y Leutner, 2013) han realizado una serie de estudios ligados al aprendizaje multimedia, que muestran resultados inconsistentes con respecto a dicha investigación. Estos trabajos, cuyo objetivo ha sido determinar el efecto del modo de representación (verbal vs pictorial) y del tipo de tarea de aprendizaje (resúmenes autogenerados vs resúmenes predefinidos) en la comprensión de textos de ciencias naturales; han arrojando unos resultados que parecen indicar que la construcción de un resumen verbal (escrito) no sólo no mejora el modelo de la situación construido por el lector, sino que incluso lo empeora.

La aparente controversia de estos resultados con respecto a los estudios que hemos señalado anteriormente, no lo es tanto, si tenemos en cuenta varios factores que incidían en los mismos: a) el tipo de tarea que debía realizar el alumno, y por consiguiente, el modelo de tarea que éste creaba; b) la formación que recibían el 
alumnado para la realización de dicha tarea; y c) el tipo de texto que debían leer los alumnos.

En cuanto al tipo de tarea, tanto en el estudio de Leopold y Leutner (2012) como en el de Leopold et al. (2013), el grupo "construcción de resumen escrito" leía un texto por párrafos con el fin de extraer y expresar la información esencial de dichos párrafos. Esto significa que la tarea que debían realizar los alumnos pertenecientes a este grupo no era resumir el texto, sino extraer y expresar las ideas principales de cada párrafo. Lo cual, con toda seguridad, llevo al alumnado a generar un modelo de tarea cuyo objetivo no era comprender el texto como un todo, sino extraer las macroproposiciones de los párrafos. Por lo que no es extraño que los alumnos de dicho grupo no obtuvieran buenos resultados cuando realizaron un test que medía el nivel de comprensión del texto, ya que el tipo de tarea propuesta y el modelo de tarea generado no se correspondían con la destreza que pretendían evaluar los investigadores.

En lo que se refiere a la formación que recibía el alumnado, los integrantes del grupo "construcción de resumen escrito" no fueron instruidos explícitamente para realizar dicha tarea. Mientras Leopold y Leutner (2012) se limitaron a indicar a los alumnos que debían relacionar las ideas importantes dentro de cada párrafo; Leopold et al. (2013) únicamente facilitaron una hoja de instrucciones donde aparecía, a modo de ejemplo, el resumen de un párrafo. Si tenemos en cuenta que, como afirman MulcahyErnt y Caverly (2009), Nist y Simpson (2000) y Westby et al. (2010), la realización de resúmenes mejora la comprensión lectora especialmente cuando los estudiantes han sido instruidos explícitamente sobre cómo hacerlos; entenderemos por qué, el alumnado no encontró beneficio alguno en la realización de dicha tarea. Esto refleja un problema al que han hecho referencia autores como Wade-Stein y Kintsch (2004); y es que, a pesar de que es más que conocido el gran potencial del resumen para mejorar el aprendizaje del alumnado, desafortunadamente la enseñanza-aprendizaje de esta tarea se descuida a lo largo de la formación académica: "Summarization clearly has a great deal of potential for improving students' learning and writing. Hence, it is unfortunate that is largely neglected throughout children's academic training” (p.7). De hecho, según estos autores, un gran número de estudios han documentado que algunas de las debilidades que presentan de los alumnos de niveles educativos inferiores a la hora de realizar tareas de resumen, persisten hasta la etapa universitaria, entre otras razones, porque los profesores asumen que los estudiantes adquirirán esa habilidad por su cuenta:

..studies also documented a developmental progression in learning this skill, with persistent weaknesses that extend to college students. It is simply assumed that students will acquire the skill on their own as they read instructional text. It is simply assumed that students will acquire the skill on their own as they read instructional text. (p.4) 
En tercer lugar, los alumnos se enfrentaron a un texto de ciencias naturales no siendo expertos en dicha materia, lo que pudo suponer un obstáculo para la comprensión. Recordemos que en el estudio de Ozuru et al. (2009), los lectores que leyeron un texto cohesionado de ciencias naturales sin disponer de conocimientos generales relacionados con el tópico, no fueron capaces de generar un modelo mental suficientemente rico en el que enmarcar la información que se trataba en el texto.

En conclusión, el resumen escrito crea un registro externo de la representación mental del texto construida por el lector, que permite pensar adicionalmente sobre la esencia del material leído (la macroestructura textual), y por consiguiente, mejorar la comprensión lectora alcanzada. Sin embargo, para que esa mejora sea efectiva es necesario que confluyan tres aspectos: a) que el modelo de tarea del lector sea efectivamente expresar por escrito la macroestructura del texto leído; b) que el alumnado haya recibido formación adecuada en torno a esta tarea; y c) que transcurra cierto tiempo entre el final de la lectura y el comienzo de la redacción.

\subsubsection{Diferencias entre lectores maduros e inmaduros a la hora de realizar un resumen escrito}

La investigación en comprensión lectora muestra diferencias significativas (n.s.=.05) entre los lectores maduros e inmaduros a la hora de realizar un resumen escrito. Estas diferencias, como veremos, están estrechamente asociadas con las habilidades y estrategias de lectura analizadas en el epígrafe 1.1.3.2; por lo que antes hablar sobre qué supone resumir un texto dentro de cada nivel de competencia lectora, conviene recordar cuáles son las destrezas de lectura de cada lector.

\begin{tabular}{|c|c|c|}
\hline \multicolumn{3}{|c|}{ Habilidades y Estrategias de lectura } \\
\hline & Lectores inmaduros & Lectores maduros \\
\hline Tipo de representación & $\begin{array}{l}\text { Tema }+ \text { colección } \\
\text { inarticulada de detalles }\end{array}$ & Coherente \\
\hline $\begin{array}{l}\text { Habilidades y Estrategias vinculadas } \\
\text { a la identificación de microestructura }\end{array}$ & $\begin{array}{l}\text { Deficiencias en el uso de la } \\
\text { progresión temática }\end{array}$ & Uso estratégico de la progresión temática \\
\hline $\begin{array}{l}\text { Habilidades y Estrategias vinculadas } \\
\text { al extracción de la macroestructura }\end{array}$ & $\begin{array}{c}\text { Estrategia decir algo o Estrategia } \\
\text { de listado }\end{array}$ & Estrategia estructural \\
\hline $\begin{array}{c}\text { Habilidades y Estrategias } \\
\text { metacognitivas para la regulación y } \\
\text { supervisión de la comprensión }\end{array}$ & $\begin{array}{l}\text { Ausencia de supervisión del } \\
\text { grado de comprensión }\end{array}$ & $\begin{array}{l}\text { Supervisión constante del grado de } \\
\text { comprensión alcanzando }\end{array}$ \\
\hline
\end{tabular}

Cuadro 1.14. Síntesis de las diferencias entre lectores maduros e inmaduros en habilidades y estrategias de lectura 
El lector inmaduro muestra deficiencias a la hora de seguir la progresión temática (pierde el hilo conductor del texto), utiliza estrategias inadecuadas para extraer la macroestructura (toma como criterio de selección de información recordar algo del texto), y suele tener un bajo grado de consciencia del nivel de comprensión alcanzado (no se apoya en estrategias para la supervisión y mejora de la comprensión, como la generación de palabras clave, el resumen o el mapa conceptual); por lo que la representación mental que elabora se limita al tema del texto más una colección inarticulada de detalles. Como contraste, el lector maduro sigue el hilo conductor del texto, utiliza estrategias adecuadas para extraer la macroestructura (identifica la estructura organizativa del texto, valiéndose de ella para utilizar sobre la microestructura macroestrategias de omisión, generalización y construcción) y tiene un alto grado de autoconsciencia del nivel de comprensión alcanzado (se apoya en técnicas como la generación de palabras clave, el resumen o el mapa conceptual); por lo que es capaz de construir una representación mental coherente.

Tomando esto en consideración, y teniendo en cuenta trabajos como los de Bereiter y Scardamalia (1992), Brown y Day (1983), Hare y Borchart (1984), Howard (1995, 1999), Hirvela y Du (2013), Kinstch (1990), Mandin, Lemaire y Dessus (2007), Pecorari (2003, 2008), Sánchez (1988, 1993, 1998), Shi (2004, 2008), Wade-Stein y Kintsch (2004), Westby et al. (2010) y Winograd (1984), hemos elaborado el siguiente cuadro, que destaca las principales diferencias entre los lectores maduros e inmaduros a la hora de realizar un resumen escrito. Concretamente, el análisis comparativo se centra en cuatro aspectos que analizaremos individualmente:

a) el tipo de ideas del texto original que aparecen en el resumen;

b) las estrategias de síntesis que refleja el resumen;

c) el orden en el que aparecen las ideas del texto en el resumen; y

d) los procesos cognitivos implicados en la composición del resumen. 


\begin{tabular}{|c|c|c|}
\hline \multicolumn{3}{|c|}{ Comparación lectores maduros e inmaduros en la realización del resumen escrito } \\
\hline & Lector-escritor inmaduro & Lector-escritor maduro \\
\hline $\begin{array}{l}\text { Tipo de ideas del texto } \\
\text { original que aparecen } \\
\text { en el resumen }\end{array}$ & $\begin{array}{l}\text { - } \quad \text { Principalmente ideas secundarias } \\
\text { - } \quad \text { Ideas importantes e ideas secundarias } \\
\text { en similar medida }\end{array}$ & Principalmente ideas importantes \\
\hline $\begin{array}{l}\text { Estrategias de síntesis } \\
\text { que se reflejan en el } \\
\text { resumen }\end{array}$ & $\begin{array}{l}\text { - } \quad \text { Ligadas al código de superficie: } \\
\text { - } \quad \begin{array}{l}\text { Copia literal y omisión de } \\
\text { información (copy- delete) }\end{array} \\
\text { - } \quad \begin{array}{l}\text { Paráfrasis cercana a la copia } \\
\text { (patchwriting) y omisión de } \\
\text { información }\end{array} \\
\text { - Combinación enlazada y omisión } \\
\text { de información } \\
\text { Ligadas a una mala interpretación del } \\
\text { contenido textual: } \\
\text { Elaboración de ideas } \\
\text { malinterpretadas (Off-the-subject) }\end{array}$ & $\begin{array}{l}\text { - } \quad \text { Ligadas al modelo de la situación: } \\
\text { - } \quad \text { Paráfrasis personal y omisión } \\
\text { información } \\
\text { - Generalización de ideas } \\
\text { - Construcción de ideas } \\
\text { - Combinación estructural y } \\
\text { omisión de información }\end{array}$ \\
\hline $\begin{array}{l}\text { Ordenación ideas del } \\
\text { texto original en el } \\
\text { resumen }\end{array}$ & $\begin{array}{l}\text { - Sigue el orden secuencial del } \\
\text { contenido del texto fuente }\end{array}$ & $\begin{array}{l}\text { Reordenaciones/reorganizaciones } \\
\text { del contenido del texto fuente }\end{array}$ \\
\hline $\begin{array}{l}\text { Procesos cognitivos } \\
\text { implicados en la } \\
\text { composición del } \\
\text { resumen }\end{array}$ & $\begin{array}{l}\text { Modelo volver a DECIR contenido } \\
\text { textual (Retell): } \\
\text { - } \quad \begin{array}{l}\text { Ausencia de planificación global } \\
\text { del proceso de redacción }\end{array} \\
\text { - } \quad \text { Escritura basada en el escritor } \\
\text { - } \quad \begin{array}{l}\text { Revisión superficial producto } \\
\text { escrito }\end{array}\end{array}$ & $\begin{array}{l}\text { Modelo TRANSFORMAR } \\
\text { contenido textual: } \\
\text { - } \quad \begin{array}{l}\text { Planificación global de la } \\
\text { escritura }\end{array} \\
\text { - } \quad \text { Escritura basada en el lector } \\
\text { - } \quad \begin{array}{l}\text { Revisión profunda del producto } \\
\text { escrito (Polishing strategy) }\end{array}\end{array}$ \\
\hline
\end{tabular}

Cuadro 1.15. Diferencias entre lectores maduros e inmaduros en la realización del resumen escrito

\subsubsection{Tipo de ideas del texto original que aparecen en el resumen}

Las ideas del texto original que aparecen en el resumen escrito, en gran medida, dependen de las habilidades/ estrategias de lectura de cada lector.

El lector maduro, a diferencia del inmaduro, pone en práctica estrategias de lectura que le permiten discernir la información importante de la secundaria, por lo que no va a tener dificultades a la hora de focalizar el resumen que redacta en las ideas fundamentales del texto fuente (macroestructura textual). En consecuencia, los resúmenes de los lectores maduros, centrados en la esencia del texto, suelen ser bastante 
más breves que los de los lectores inmaduros, que recogen gran cantidad de ideas secundarias.

\subsubsection{Estrategias de sintesis que se reflejan en el resumen escrito}

Existen notables diferencias entre lectores maduros e inmaduros en cuanto a las estrategias de síntesis que ponen en marcha unos y otros para resumir un texto. En concreto, estudios como los de Brown y Day (1983) ${ }^{9}$, Kinstch (1990), Wade-Stein y Kintsch (2004), y Westby et al. (2010) indican que: a) los lectores inmaduros aunque utilizan la estrategia de selección-omisión en mayor medida que los maduros, no la usan de forma tan adecuada como éstos; y b) los lectores maduros utilizan estrategias de construcción y generalización en mayor medida y de manera más apropiada que los lectores inmaduros.

Estas diferencias están estrechamente relacionadas con el nivel de comprensión textual que alcanza cada tipo de lector.

Los lectores inmaduros tienen problemas de comprensión tanto a nivel local como global, y por ello elaboran una composición muy ligada al código de superficie del texto original, valiéndose de estrategias de omisión-selección como:

- La copia o copy-delete, que implica reproducir en el resumen escrito frases literales del texto original (Mandin et al., 2007)

- La paráfrasis cercana a la copia o patchwriting, que supone retocar frases textuales modificando sus estructuras gramaticales, omitiendo algunas de sus palabras y/o sustituyendo otras por sinónimos (Hirvela y Du, 2013; Howard, 1995, 1999; Pecorari, 2003, 2008)

- La combinación enlazada, que supone integrar de forma poco estructurada dos o más frases copiadas o parafraseadas del texto original (Winograd, 1984)

Dichas dificultades de comprensión, además, suelen llevar a este tipo de lector a construir/inferir ideas partiendo de una mala interpretación del contenido textual. Estas ideas, llamadas off-the-subject, aparecen en el resumen escrito dentro de frases que se alejan claramente de la temática del texto fuente: "An off-the-subject sentence is a summary sentence which is not close to any source text sentences" (Mandin et al., 2007, p.20).

\footnotetext{
${ }^{9}$ Brown y Day (1983) dividen en dos las macroestrategias de omisión (omitir información trivial y omitir información redundante) y de generalización (sustitución de una lista de elementos por un elemento supraordinado y selección de tema de la frase); y modifican el nombre a la macroestrategia de construcción (llamándola invención del tema de la frase).
} 
Los lectores maduros, por su parte, no tienen dificultades para comprender el texto a nivel local y global, así que, elaboran un resumen muy ligado al modelo de la situación, que construyen valiéndose de las estrategias de:

- Omisión-selección, tales como: a) la paráfrasis personal, que exige al lectorescritor expresar con sus propias palabras las ideas que subyacen a las frases del texto original (Mandin et al., 2007); y b) la combinación estructural, que precisa integrar de forma estructurada dos o más ideas extraídas del texto original (Kinstch, 1990; Westby et al., 2010; Winograd, 1984);

- Generalización, que implican sustituir un conjunto de frases del texto original por una frase semánticamente cercana a cada una de ellas: "Generalization is a summary sentence which is close to serveral source text senteces" (Mandin et al., 2007, p.20); y

- Construcción, que implican sustituir un conjunto de frases del texto original por una frase, que aunque no es semánticamente cercana a cada una de ellas, está muy relacionada con todas ellas en su conjunto: "Construction is a summary sentence which is close to no source text but is as least related to one of them" (Mandin et al., 2007, p.20).

En conclusión, los lectores maduros parten del modelo de la situación para darle un carácter personal a los resúmenes que escriben, mientras que los lectores inmaduros suelen componer resúmenes muy cercanos al código de superficie del texto en los que pueden aparecer ideas malinterpretadas.

\subsubsection{Orden en el que aparecen las ideas del texto original en el resumen escrito}

El nivel de comprensión adquirido por uno u otro tipo de lector vuelve a jugar un papel importante cuando es necesario reorganizar el contenido del texto para extraer la macroestructura textual.

El lector inmaduro, debido a sus dificultades de comprensión, redacta un resumen muy ligado al código de superficie del texto, que respeta escrupulosamente el orden secuencial en el que aparecen las ideas que ha seleccionado. En contraste, el lector maduro, gracias al nivel de comprensión lectora que alcanza, compone un resumen ligado al modelo de la situación, en el que, cuando es preciso, reordena algunas de las ideas extraídas para reflejar más claramente las relaciones jerárquicas que se dan entre las ideas importantes del texto. 
De esta forma, la capacidad de cada tipo de lector para reorganizar el contenido textual va a estar asociada con los procesos inferenciales que ponen en marcha unos y otros lectores:

The limitated used of inferred information in summaries of the younger students indicates that their summaries were composed largely of information selected sequencially from the original text. In contrast, older students...used inference to formulate their summaries and would reorder the information to highlight the main points of the passage $e^{10}$ (Westby et al., 2010, p. 278).

\subsubsection{Procesos cognitivos implicados en la composición del resumen escrito}

Situando los estudios de Bereiter y Scardamalia (1992) sobre buenos y malos escritores dentro del modelo MD-TRACE de Rouet y Britt (2011), podemos afirmar que los procesos de planificación y revisión que ponen en marcha los lectores maduros a la hora de realizar un resumen, difieren significativamente de los procesos característicos de los lectores inmaduros.

El lector inmaduro se limita a Volver a Decir contenido del texto fuente (Retell) en el resumen que escribe, ya que sus problemas, tanto para generar un modelo de tarea apropiado (considera que la tarea de resumir consiste en recordar/ seleccionar algo del texto) como para elaborar una representación mental adecuada (tiene dificultades de comprensión lectora); le impiden desarrollar un modelo de la situación claro desde el que planificar globalmente el proceso de redacción.

Esto se traduce en un producto de tarea (el resumen escrito) en el que se reflejan dificultades de expresión que muestran problemas de comprensión (ideas mal estructuradas y/o ideas en las que no queda claro el modelo de la situación) y se perciben dificultades de comprensión a través de la expresión (mala interpretación de contenido textual, y/o extracción de ideas secundarias). En este sentido, cabe señalar que:

- Los problemas de comprensión lectora llevan al lector a utilizar, principalmente, estrategias de resumen ligadas al código de superficie del texto (copia, paráfrasis cercana a la copia y/o combinación enlazada) que suelen provocar dificultades de expresión escrita, como por ejemplo: realizar cambios en la estructura gramatical de frases del texto original que obstaculicen la progresión temática del resumen, intentar fallidamente parafrasear frases del texto en el resumen,

\footnotetext{
10 [traducción: El uso limitado de información inferida en los estudiantes más jóvenes indican que sus resúmenes están compuestos principalmente por información seleccionada secuencialmente del texto original. Como contraste, los estudiantes más mayores... utilizan la inferencia para formular sus resúmenes y reordenan la información para mostrar la esencia de los principales puntos del pasaje].
} 
utilizar conectores inadecuados para integrar en el resumen oraciones extraídas del texto fuente, etc.

- Las concepciones erróneas sobre el contenido textual pueden llevar al lector a realizar inferencias inadecuadas, que se reflejan en el resumen a través de frases que encierran ideas malinterpretadas (Off-the-subject).

- Las dificultades para diferenciar información importante de la secundaria pueden hacer que el resumen escrito se centre en la información secundaria del texto fuente.

El producto de tarea elaborado por este tipo de lector apenas va a ser objeto de revisión, de hecho, las pocas modificaciones a las que se ve sometido son tan meramente superficiales (ortografía, puntuación, alguna palabra), que no van a traer consigo transformaciones substanciales en su contenido. En consecuencia, el lector inmaduro va a redactar un resumen basado en el escritor (escritura egocéntrica), que no se adapta a los conocimientos previos de un posible destinatario (incluso cuando ese destinario sea él mismo como lector).

Por su parte, el lector maduro trata de Transformar el contenido textual en el resumen que escribe, partiendo de un modelo de tarea apropiado y de una representación mental adecuada, que le permiten disponer de un modelo de la situación claro para establecer de forma global qué va a transmitir y cómo va a hacerlo. Esto se traduce en un conjunto de productos de tarea parciales (borradores), que van a ser sometidos a una revisión profunda (estrategia de pulido o Polishing strategy) hasta lograr un producto de tarea definitivo (el resumen escrito) que, además de estar centrado en la macroestructura del texto fuente, esté expresado y organizado de forma clara y personal. En consecuencia, el lector maduro compone un resumen basado en el lector, que se adapta a los conocimientos previos de un posible destinatario (ya sea éste él mismo u otros lectores).

\subsection{LA COMPRENSIÓN LECTORA A PARTIR DE HIPERTEXTO}

Antes de comenzar, hemos de subrayar que los procesos de lectura no lineal o multilineal (donde es el lector y no el texto, el que establece el orden secuencial en el que se lee la información) no son exclusivos del formato hipertextual (cuya estructura rompe la linealidad del discurso); ya que mucho antes de la aparición de Internet (y por ende del hipertexto) era posible realizar este tipo de lectura partiendo de textos impresos. Cabe señalar que: a) un lector guiado por un modelo de tarea particular puede leer un texto impreso de forma no lineal; b) un texto de estructura lineal puede remitir a información no lineal situada dentro del texto (pie de página) o ubicada en otro texto (citas y referencias bibliográficas); y c) un lector puede leer diferentes textos impresos 
integrando la información extraída de dichas fuentes (lo que supone la construcción de lo que se conoce como modelo de documentos).

Teniendo esto en cuenta, la principal aportación del hipertexto en lo que se refiere a la lectura no lineal, es que su soporte tecnológico (las tecnologías informáticas) agiliza enormemente el acceso a la información (el lector clickeando un enlace puede desplazarse desde un nodo hacia otro). Ribas (2007), apoyándose en palabras de Lévy (1996), afirma que gracias a la velocidad en el paso de un nodo a otro, el hipertexto permite utilizar en toda su extensión el principio de no linealidad.

Una vez hecha esta aclaración, analizaremos los aspectos específicos de la lectura hipertextual. Para ello, definiremos qué es un hipertexto, señalaremos los aspectos que inciden en las características concretas de cada sistema hipertextual y explicaremos qué procesos específicos implica la lectura de este tipo de documento.

\subsubsection{Definición de hipertexto}

Para clarificar qué es un hipertexto vamos considerar distintas definiciones que aportan a este concepto diferentes grados de concreción.

Comenzando por una perspectiva global, Salmerón (2006) afirma en pocas palabras que: "el hipertexto puede definirse de forma genérica como un conjunto de documentos enlazados entre sí” (p.6).

Landau (2006), por su parte, elabora una definición más holística que recoge tanto los elementos básicos que componen un hipertexto, como el tipo de lectura que favorece. En concreto, este autor considera el documento hipertextual como un texto digital formado por bloques textuales (lexías) unidos a través de vínculos electrónicos (links) que favorecen una experiencia de lectura no lineal (también conocida como multilineal o multisecuencial):

\section{"Hypertext,...denotes text composed of blocks of text -what Barther} terms a lexia- and the electronic links that join them...Electronic links connect lexias "external" to worksay, -commentary on it by another author or parallel or contrasting texts- as well as within it and thereby create text that is experienced as nonlinear, or more properly, as multilinear or multisequential" (Landau, 2006, p.3).

Profundizando un poco más en la idea de la no linealidad o multilinealidad textual, Nielsen (1996) indica que el hipertexto es un documento que no dispone de un orden preestablecido que determine la secuencia en la que el lector debe leer el texto: "Hypertext is not sequential, there is no single order that determines the sequence in which the text is to be read" (p.1). En este sentido, Madrid (2010) define el hipertexto como “... un sistema compuesto por bloques ofragmentos de textos que se comunica por 
medio de enlaces, de forma que ofrecen al lector numerosos senderos de lectura "(p.23). Esto significa que los hipertextos, a diferencia de los textos lineales, presentan diferentes rutas de lectura que permiten a cada lector elegir su propia ruta: “...unlike single linear texts, hypertexts present several paths between the pages, allowing for each reader to construct individual pathways" (Voros et al., 2011, p.2048). De esta forma, como aseguran Amadeu y Salmerón (2014), una parte importante de las tareas de comprensión de hipertexto requieren que los lectores sigan secuencias propias de lectura e integren la información procedente de diferentes nodos estableciendo relaciones semánticas entre los mismos: "For readers, a major portion of hypertext comprehension tasks involves construction of their own reading sequence through the hypertext and the integration of information from different locations by establishing semantic relationships between information nodes" (p.42).

Tomando todo esto como referencia, consideraremos el hipertexto como un documento digital que, a través de una estructura no lineal o multilineal compuesta por textos o fragmentos textuales (denominados nodos o lexías) y por enlaces o hipervínculos (cuya función es comunicar dichos nodos); ofrece al lector la posibilidad de escoger una ruta de lectura propia, para establecer relaciones semánticas entre los nodos.

\subsubsection{Aspectos que inciden en las características específicas de un sistema hipertextual}

Aunque cualquier sistema hipertextual dispone de dos elementos básicos responsables de su estructura no lineal (los nodos y los enlaces), cada hipertexto en particular posee unas características específicas asociadas a:

- la granularidad o tamaño de sus nodos;

- el número y el tipo de enlaces que utiliza;

- $\quad$ su estructura global; y

- las ayudas a la navegación que facilita.

\subsubsection{La granularidad o tamaño de los nodos}

Los nodos de un hipertexto pueden abarcar desde pequeños trazos de información (como un párrafo textual) hasta grandes bloques de contenido (como un capítulo de libro o un libro completo), dependiendo de los criterios organizativos que se tomen como referencia a la hora de diseñarlos. De esta manera, a partir de un texto lineal, se pueden crear diferentes hipertextos variando la cantidad de información de los nodos. 
A pesar de ser una característica importante del hipertexto, el tamaño de los nodos no ha recibido suficiente atención por parte de la investigación. Entre los escasos estudios que hemos localizado, únicamente, vamos a destacar el de Zhu (1999), que indica que los hipertextos con un mayor número de nodos y una mayor cantidad de información por nodo, favorecen la desorientación durante la navegación e incrementan la carga cognitiva inefectiva en la memoria de trabajo del lector.

Lo que sí encontramos, es una gran cantidad de recomendaciones para el diseño de hipertexto que aconsejan crear nodos que no sean ni muy finos ni muy gruesos (Codina, 1998, 2000, 2001; Iriarte, 2004; Nielsen, 1995, 2004, 2012; Rovira, 1999). En este sentido, Iriarte (2004) afirma que:

“.....si son muy finos...la lectura de un hipertexto con nodos tan pequeños puede resultar frustrante para el lector. Si los nodos son muy grandes, se desaprovecha la genuina ventaja de los hipertextos: el establecimiento de relaciones asociativas entre partes significativas de un documentos" (p.54).

En definitiva, tanto los estudios destacados como las recomendaciones mencionadas parecen indicar que "los nodos deben tener un tamaño ni demasiado grande ni demasiado pequeño, sino que resulte apropiado al propósito, el contenido y el público del hipertexto" (Codina, 2001, p. 40).

\subsubsection{El número y el tipo de enlaces}

Los hipertextos también varían dependiendo de: la cantidad de hipervínculos que poseen (lo que está íntimamente relacionado con el número de nodos) y el tipo de relaciones que dichos enlaces favorecen entre los nodos.

En lo que se refiere a la cantidad de enlaces, gran parte de los estudios muestran que cuanto mayor sea el número de hipervínculos mayor será la carga cognitiva que soporta la memoria de trabajo del lector (Barab, Young y Wang, 1999; DeStefano y LeFevre, 2007; Eveland et al., 2004; Jacko y Salvendy, 1996; Parush et al., 2005; McDonald y Stevenson, 1996; Zhu, 1999). Sin embargo, algunos trabajos contradicen esos resultados, bien porque cuando consideran el número de links no encuentran diferencias significativas (n.s.=.05) en la carga cognitiva (McDonald y Stevenson, 1998), o bien porque indican que los lectores navegan más lentamente en hipertextos con pocos enlaces (Lin, 2003 a,b).

Esta inconsistencia, parece resolverse en estudios como los Madrid, Van Oostendorp y Puerta (2009) y Madrid y Cañas (2009), que sugieren que lo que afecta realmente a la carga cognitiva es el orden de lectura (esta variable se analizará en profundidad en el apartado 1.3.3). Ambos trabajos muestran que, independientemente de 
la cantidad de enlaces del hipertexto, los lectores que leen en un orden más coherente sufren menor carga cognitiva que los que lo hacen en un orden menos coherente. Específicamente, Madrid y Cañas (2009) señalan que leer en un orden de baja coherencia supone, por un lado, una carga cognitiva efectiva para lectores con alto conocimiento de dominio, y por otro, una carga cognitiva inefectiva para lectores con bajo conocimiento de dominio.

Teniendo en cuenta el orden de lectura, la correlación entre el número de enlaces y la carga cognitiva (que reflejan gran parte de los estudios) se puede asociar a la probabilidad de que el lector siga un orden de lectura poco coherente cuando navega por un hipertexto que dispone de un gran número de enlaces.

En cuanto al tipo de enlaces, partimos de la base de la tipología propuesta por Codina $(1998,2000,2001)$ y las aportaciones de autores como Iriarte (2004), Jáñez (2014) y Nielsen (1995) para elaborar un cuadro en el que consideramos 8 características que determinan las principales categorías en las que se puede enmarcar un enlace.

\begin{tabular}{|c|c|}
\hline \multicolumn{2}{|c|}{ Tipologías de Enlace } \\
\hline Características consideradas & Tipos de enlace \\
\hline Dirección & Sireccionales VS Bidireccionales \\
\hline Secuencia & Superpuestos VS Implicados \\
\hline Modelo Navegación & Estructurales VS Semánticos \\
\hline Lógica & $1: 1$ VS 1:N VS N:1 \\
\hline Grado & de Autor VS de Lector \\
\hline Creación & Sustitución VS Superposición \\
\hline Conmutación & Parte nodo VS Nodo global \\
\hline Anclaje & \\
\hline
\end{tabular}

Cuadro 1.16. Tipologías en las que se puede enmarcar un enlace

Como vemos en el cuadro, un enlace puede categorizarse de diferentes maneras según su:

- Dirección: el enlace unidireccional comunica el nodo A con el B pero no al contrario; mientras que el enlace bidireccional vincula el nodo A con el B, y viceversa.

- Secuencia: el enlace secuencial no permite ir desde el nodo A hasta D sin pasar antes por los nodos B y C; mientras que el enlace no secuencial permite ir directamente desde nodo A hasta el D.

- Modelo de navegación: los enlaces superpuestos actúan a modo de menú vinculando meta-información con la información de los nodos (estos enlaces suelen estar situados 
en un mapa de contenido, un índice, un sumario, etc.); mientras que los enlaces implicados están incrustados dentro de la información de los nodos.

- Lógica: los enlaces estructurales conforman un meta-texto que facilita la navegación por los nodos (dan cohesión global al hipertexto); mientras que los enlaces semánticos establecen relaciones semánticas entre el contenido de los nodos (estas relaciones pueden ser de concepto-definición, de causa-efecto, de semejanza entre ideas, etc.).

- Grado: los vínculos 1:1 permiten ir de un nodo a otro nodo, los enlaces 1: $\mathrm{N}$ de un nodo a diversos nodos, y los links $\mathrm{N}$ : 1 de diversos nodos a un nodo.

- Creación: los enlaces definidos por el autor del hipertexto son aquellos que se establecen en el momento de la creación del documento; mientras que los enlaces definidos por el lector son aquellos que éste agrega a un documento ya creado (un ejemplo claro de este último tipo de enlaces son las wikis).

- Commutación: el enlace de sustitución, como su propio nombre indica, permite sustituir el nodo de inicio por el de destino (cuando se clickea el link, en la ventana aparece un nuevo nodo); mientras que el enlace de superposición superpone el nodo de destino sobre el de inicio (cuando se clickea en el link, aparece una nueva ventana que recoge el nodo de destino, la cual se superpone a la ventana donde se encuentra el nodo de partida).

- Anclaje: cada enlace dispone de un punto de inicio y un punto de destino, conocidos como anclajes, que permiten conectar los dos nodos. Dichos anclajes pueden comunicar un nodo con otro nodo en general, o un nodo con una parte concreta de otro nodo.

\subsubsection{La estructura global del hipertexto}

El hipertexto posee una estructura global que refleja el modo particular en el que sus nodos se organizan espacial y conceptualmente a través de sus conexiones. De acuerdo con Voros et al. (2011), cualquier hipertexto en general se estructura a nivel conceptual o de contenido (relaciones locales y globales que se dan entre el contenido semántico de los nodos) y a nivel topológico o de organización espacial (conexiones que se dan entre los nodos a través de menús y enlaces incrustados); pero cada hipertexto en particular presenta unas características propias, que dependen tanto de las peculiaridades de sus niveles estructurales, como del grado de solapamiento que existe entre dichos niveles:

A hypertextual network of pages can be defined at two levels: the informational content level and the layout level. The informational content level corresponds to the semantic contents at the local and 
global levels within the network... The layout level corresponds to the linking of pages within the hypertext through menus and embedded links. The configuration of link defines a topological space, which may, but does not necessarily overlap with the global semantic content of the hypertext. (p.2048)

Debido a ello, la mayor parte de la investigación categoriza los documentos hipertextuales en función del tipo de estructura que favorecen. Concretamente, destacan cuatro estructuras básicas de hipertexto (a pesar de algunos autores difieren en ciertas categorías ${ }^{11}$ ): lineal, jerárquica, en red y mixta (ver imagen 1.3).

Un hipertexto lineal dispone de una estructura topológica (organización espacial) que determina la secuencia de lectura de sus nodos (el primer nodo permite el acceso a un segundo nodo, que a su vez, permite el acceso a un tercer nodo, y así sucesivamente); por lo que la única decisión de navegación que toma el lector es avanzar o retroceder dentro de dicha secuencia. Esta organización espacial establece una estructura conceptual que, dependiendo de cómo se secuencia el contenido semántico dentro de cada nodo y entre los nodos, puede favorecer o no la cohesión semántica del hipertexto.

A diferencia del anterior, el hipertexto jerárquico posee una estructura topológica que, a pesar de ser menos secuencial, favorece en mayor medida la cohesión semántica de la estructura conceptual. Cada nodo (a excepción de aquellos que se sitúan en la posición jerárquica más alta, y los que lo hacen en la posición más baja) conecta con nodos que contienen información subordinada, y con el nodo al que está subordinado, pero no comunica directamente con los nodos que se encuentran en su mismo nivel de la estructura jerárquica; lo que obliga al lector a volver siempre al nodo supraordinado, para acceder a cada uno de los nodos que se le subordinan. Debido a ello, DeStefano y LeFevre (2007) sugieren que en cada nodo habrá un limitado número de links (aquellos que llevan a información subordinada o supraordinada) y sólo unos pocos tipos de links (principalmente aquellos que relacionan la información jerárquicamente): "Strictly hierarchical hypertxts allow readers to navigate to superordinate or subordinate topics only, resulting in a limited number of links and only a few links types" (1622)

Por su parte, el hipertexto en red posee una estructura topológica que favorece la lectura no secuencial, por lo que, en este caso, la cohesión entre nodos dependerá fundamentalmente de la conducta de navegación del lector (que se refleja en los nodos que selecciona y el orden en el que los selecciona). Al igual que en las estructuras

\footnotetext{
${ }^{11}$ Calisir y Gurel (2003), Jañez (2014) y Mohageg (1992) distinguen entre estructura lineal, jerárquica, en red y mixta; Codina y Rovira (2001) elaboran una clasificación similar incluyendo una estructura lineal con alternativas y categorizando la estructura jerárquica como estructura en árbol; Schoon y Cafolla (2002) divide la estructura en red en estructura de estrella y estructura arbitraria; Iriarte (2004) categoriza la estructura en red como estructura de nodos encadenados, etc.
} 
anteriores, cada nodo conecta con diversos nodos y desde esos nodos se puede volver al nodo anterior; pero a diferencia de ellas, ni existe una secuencia predeterminada de lectura (como ocurre en el hipertexto lineal), ni un criterio jerárquico global a la hora de conectar los nodos (como ocurre en el hipertexto jerárquico). En concreto, las conexiones entre nodos siguen un criterio principalmente local, que hace que aparezcan diferentes tipos de links semánticos dentro de estos hipertextos (por ejemplo: vínculos causa-efecto, categoría-ejemplo, concepto-definición): "networked hypertexts have several types of semantics links that connect related nodes (cause-effect, categoryexample, item-definition)" (DeStefano y LeFevre, 2007, p.1622).

Para finalizar, el hipertexto mixto mezcla algunas de las estructuras mencionadas. Este tipo de organización topológica normalmente se asemeja a la jerárquica, pero tiene la peculiaridad de: a) conectar nodos que se encuentran en el mismo nivel de la jerarquía (nodos hermanos), y b) permitir ir directamente desde el nodo de mayor grado de supraordinación hasta el nodo de mayor grado subordinación. Cuanto mayor número de conexiones existan, más similar será a la estructura en red, y por tanto, menor grado de estructuración habrá.

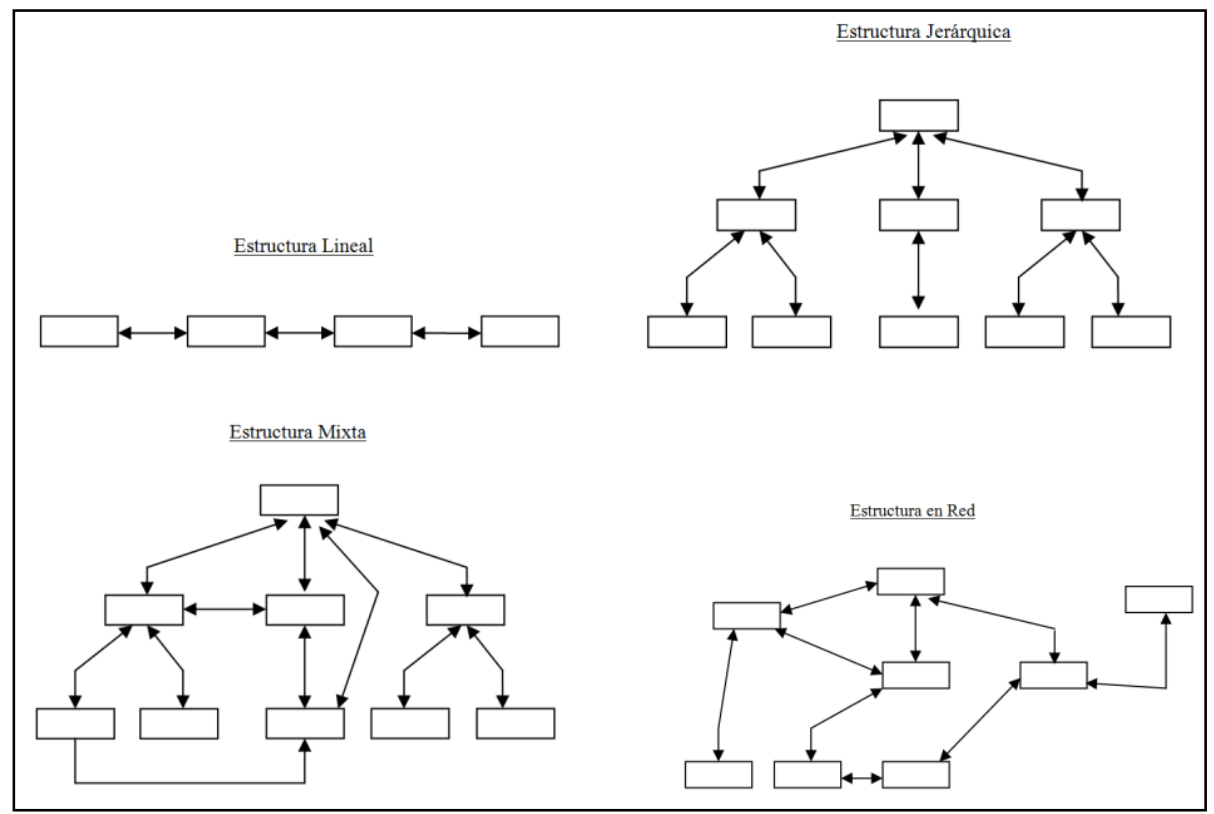

Imagen 1.3. Representación de las diferentes estructuras topológicas en hipertexto (Elaboración propia)

*los rectángulos representan los nodos y las flechas los enlaces

La investigación en el ámbito de la comprensión lectora ha estudiado la estructura hipertextual tratando de determinar en qué medida la interacción de ésta con otras variables (como el conocimiento de dominio y las habilidades/estrategias de lectura) incide en la representación mental que construye el lector (Potelle y Rouet, 2003; Scheiter y Gerjets, 2007; Scheiter, Gerjets, Vollmann y Cantrambone, 2009; Shapiro y Niederhauser, 2004; Amadeu, Tricot y Mariné, 2009; Calisir, Eryazici y Lehto, 2008). En este sentido, gran parte de los estudios han puesto de manifiesto, que 
las estructuras hipertextuales afectan a los lectores con bajo conocimiento de dominio pero no a los de alto conocimiento. Concretamente:

a) Los lectores con bajo conocimiento de dominio, se benefician fundamentalmente de estructuras hipertextuales que limitan la navegación a nivel topológico y establecen relaciones de supraordinación-subordinación entre nodos a nivel conceptual (estructuras jerárquicas y mixtas); ya que éstas, al favorecer un orden de lectura coherente (Calisir y Gurel, 2003; Calisir, Eryazici y Lheto, 2008) y reducir la sensación de desorientación ${ }^{12}$ (Amadeu et al., 2009; Last, ODonell y Kelly, 2001), les permite recordar la información de forma eficiente (Mohageg, 1992; Amadeu et al., 2009) y construir una representación mental adecuada (De Jong y Van der Hults, 2002).

b) Los lectores con alto conocimiento de dominio, por el contrario, no parecen estar influenciados por la estructura hipertextual, puesto que el beneficio que éstos obtienen de la lectura depende, fundamentalmente, del grado de activación de su conocimiento previo (Amadeu et al., 2009; Calisir y Gurel, 2003; Potelle y Rouet, 2003; Muller-Kalthoff y Muller, 2003).

Como veremos en el apartado 1.3.3, estos resultados están estrechamente asociados al proceso de selección del orden de lectura.

\subsubsection{La disposición de ayudas a la navegación: los esquemas gráficos}

Los sistemas hipertextuales también difieren unos de otros dependiendo de la disposición o no de ayudas a la navegación, y en caso de poseerlas, del tipo de ayudas que ofrecen. Esos sistemas de apoyo a la lectura varían principalmente en función de su: a) grado de navegabilidad, pudiendo ser estáticos (cuando no son navegables) o dinámicos (cuando son navegables); y b) grado de estructuración, pudiendo ser desde poco o nada estructurados hasta estructurados o altamente estructurados.

Centrándonos en el grado de estructuración, hemos elaborado el siguiente cuadro, que recoge las características esenciales de las ayudas a la navegación que son más representativas según los estudios que hemos revisado (Potelle y Rouet, 2003; Salmerón, 2006; Su y Klein, 2006; Voros et al., 2011).

\footnotetext{
${ }^{12}$ Según Calisir et al. (2008), la desorientación hipertextual se divide en conceptual (cuando los lectores no pueden relacionar diferentes conceptos del hipertexto) y estructural (cuando el lector se pierde dentro del hipertexto al no poder especificar dónde se encuentra): "conceptual disorientation occurs when learners are unable to relate different concepts presented knowledge structures. In contrast, structural disorientation occurs when learners are unable to specify their location and get lost within the hypertext" (440).
} 


\begin{tabular}{|c|c|c|}
\hline \multicolumn{3}{|c|}{ Sistemas de apoyo a la navegación con diferente grado de estructuración } \\
\hline Tipo de ayuda & Grado de estructuración & Características \\
\hline Lista Alfabética & No estructurado & $\begin{array}{l}\text { El menú principal del hipertexto presenta de forma } \\
\text { alfabética los links que comunican con los nodos que lo } \\
\text { componen. }\end{array}$ \\
\hline $\begin{array}{l}\text { Lista de Temas o de } \\
\text { Contenidos }\end{array}$ & No estructurado & $\begin{array}{l}\text { El menú principal del hipertexto presenta un conjunto de } \\
\text { links categorizados a modo de temas independientes, que } \\
\text { comunican con nodos que recogen contenido asociado } \\
\text { semánticamente a dichos temas. }\end{array}$ \\
\hline Mapas de Red & Poco estructurado & $\begin{array}{l}\text { En el menú principal del hipertexto aparece un esquema } \\
\text { gráfico que ofrece una visión global de las relaciones } \\
\text { espaciales (y en ocasiones de las relaciones conceptuales) } \\
\text { que se dan entre los links, pero que no refleja el grado de } \\
\text { importancia de cada links dentro del esquema, ni ofrece } \\
\text { recomendaciones sobre a qué links acceder primero. }\end{array}$ \\
\hline $\begin{array}{l}\text { Sugerencias de } \\
\text { Enlaces }\end{array}$ & Estructurado & $\begin{array}{l}\text { El hipertexto ofrece recomendaciones a los lectores sobre el } \\
\text { orden en el que deben leer los links para construir una } \\
\text { representación mental coherente. }\end{array}$ \\
\hline $\begin{array}{l}\text { Mapas de } \\
\text { Contenido o } \\
\text { Jerárquicos }\end{array}$ & Altamente estructurado & $\begin{array}{l}\text { En el menú principal del hipertexto aparece un esquema } \\
\text { gráfico que representan las relaciones globales que existen } \\
\text { entre los links a nivel topológico (indica la localización de } \\
\text { los nodos dentro de una estructura jerárquica) y a nivel } \\
\text { conceptual (muestra las relaciones jerárquicas que se dan } \\
\text { entre el contenido de los nodos). }\end{array}$ \\
\hline
\end{tabular}

Cuadro 1.17. Ejemplos de ayudas a la navegación con diferente grado de estructuración

Entre las ayudas a la navegación que aparecen en el cuadro anterior, la investigación sobre comprensión en hipertexto se ha centrado, principalmente, en el estudio comparativo del efecto de los esquemas gráficos dinámicos altamente estructurados (mapas de contenido) con respecto a esquemas dinámicos poco estructurados (mapas de red) y/o a hipertextos sin organizadores gráficos. Si bien, como veremos a continuación, no existe un consenso generalizado en relación al valor de estos instrumentos para mejorar la comprensión lectora.

Algunos estudios otorgan un efecto positivo a los mapas de contenido en comparación con esquemas gráficos menos estructurados o con hipertextos sin ayudas a la navegación. En particular, los trabajos de Dee-Lucas y Larkin (1995), De Jong y Van der Hulst (2002), McDonald y Stevenson (1996, 1999) y Voros et al. (2011) muestran que los mapas jerárquicos mejoran la comprensión y reducen la desorientación que sufre el lector cuando lee hipertextos pocos cohesivos.

Otros trabajos, como los de Hofman y Van Oostendorp (1999), Nilsson y Mayer (2002), Shapiro (1998) y Waniek y Edwald (2008), por el contrario, otorgan un efecto negativo a los esquemas gráficos muy estructurados. Según estos estudios, los mapas de contenido aumentan la carga cognitiva inefectiva (y por tanto dificultan la comprensión), 
ya que la percepción global de las relaciones jerárquicas que se dan en el hipertexto inhibe en el lector el uso de estrategias de lectura para procesar la información en profundidad.

Además de estudios que conceden un efecto positivo o negativo a los esquemas gráficos estructurados, encontramos otros, como el de Muller-Kalthoff y Muller (2003), que no encuentra diferencias significativas (n.s.=.05) en la comprensión de hipertextos con y sin esquemas gráficos.

Por su parte, Amadieu, Tricot y Marine (2010) sugieren que el efecto de los esquemas gráficos en la comprensión depende principalmente de la variable conocimiento de dominio. En este sentido, señalan que los lectores con bajo conocimiento de dominio se benefician más de mapas jerárquicos que de mapas de red, ya que mejoran la comprensión y limitan la sensación de desorientación; mientras que los lectores con alto conocimiento se benefician más de los mapas en red que de los mapas jerárquicos, puesto que, los primeros, les obligan a procesar activamente la información: "non-lineal document with a hierarchical structure supported better comprehension for the low prior knowledge readers...As far as the high prior knowledge readers were concerned, there was no effect of the estructure...prior knowledge acted only in the network structure"'(pp.7-8).

Amadieu, Tricot y Marine (2009) y Potelle y Rouet (2003) coinciden con el estudio anterior en el beneficio de los mapas de contenido en los lectores con bajo conocimiento, pero difieren en relación a éste, en que los esquemas gráficos no tienen efectos significativos para la comprensión en lectores con alto conocimiento de dominio: "The hierarchical map improved comprehension for the low knowledge participants...There was no effect of the content representation on the comprenhension of high prior knowledge" (Potelle y Rouet, 2003, p. 327).

Para finalizar, Salmeron y sus colaboradores (Salmerón, Cañas, Kintsch y Fajardo, 2005; Salmerón, Baccino y Cañas, 2006; Salmerón, Baccino, Cañas, Madrid y Fajardo, 2009), además de tener en cuenta la variable conocimiento de dominio, sugieren que el efecto de los mapas jerárquicos en la comprensión depende del grado de coherencia que favorecen en las transiciones entre nodos, del momento en el que el lector accede a estos esquemas gráficos y del tiempo que éste dedica al procesamiento de los mismos. En un primer trabajo, Salmerón et al. (2005) estructuraron un hipertexto utilizando dos mapas de contenido diferentes: uno que favorecía transiciones entre nodos de alta coherencia y otro que favorecía transiciones de baja coherencia. Los resultados mostraron que los lectores con bajo conocimiento de dominio construían un mejor modelo de la situación cuando seguían un orden de lectura coherente, y que los de alto conocimiento lo construían mejor cuando seguían un orden de lectura poco coherente. Posteriormente, Salmerón et al. (2006) realizaron otro estudio que refinó un poco más el estudio anterior, mostrando, por un lado, que los lectores con bajo conocimiento previo 
mejoraban la comprensión cuando procesaban al inicio de la lectura el mapa de contenido de un hipertexto poco coherente, y por otro, que los lectores con alto conocimiento de dominio empeoraban sus resultados en comprensión conforme más reprocesaban el mapa de contenido (independientemente de si esto lo hacían al inicio o al final de lectura, o de si el hipertexto favorecía un orden de lectura coherente o incoherente). Estos resultados fueron confirmados en el trabajo de Salmerón et al. (2009), que además añadió, que los lectores con bajo conocimiento de dominio obtenían peor comprensión cuando procesaban el mapa jerárquico al final de la lectura de un hipertexto coherente.

Resumiendo, la investigación ofrece gran diversidad de resultados en torno a la utilidad de los esquemas gráficos para la mejora de la comprensión lectora en hipertexto. $\mathrm{Si}$ bien, observándolos detenidamente, las contradicciones entre estudios parecen resolverse, en parte, cuando se tiene en cuenta la variable conocimiento de dominio; pero sobre todo, cuando se hace hincapié en aspectos como: a) el momento en el que procesan los esquemas gráficos (principalmente los estructurados) los lectores con bajo conocimiento; y b) la cantidad de veces que los lectores con alto conocimiento reprocesan dichos esquemas.

\subsubsection{Tareas y Procesos específicos asociados a la comprensión de hipertexto}

Cuando un lector se enfrenta a un texto hipervinculado gestiona simultáneamente tareas de lectura (que le permiten representar la estructura de contenido del documento) y de navegación ${ }^{13}$ (que le permiten representar la organización topológica de los nodos). Como fruto de la acción conjunta de estas tareas, pone en marcha un proceso específico de la lectura hipertextual: la selección del orden de lectura.

A continuación analizaremos esas tareas, para después profundizar en dicho proceso.

\subsubsection{Tareas implicadas en la lectura de hipertexto}

La lectura hipertextual implica acceder a un determinado número de nodos (lectura intratextual) "saltando" de uno a otro en un orden concreto (lectura intertextual). Esto supone la realización simultánea de dos tareas que el lector debe gestionar satisfactoriamente para alcanzar la comprensión lectora: las tareas de navegación y las tareas de lectura.

\footnotetext{
${ }^{13}$ El lector, en ocasiones, antes de comenzar las tareas de lectura y navegación propiamente dichas, debe localizar la información en la World Wide Web. Estas tareas de búsqueda (searching) escapan a los objetivos de nuestra investigación, por ello, para conocerlas en profundidad, remitimos a los trabajos de Rouet, Vidal-Abarca, Bert-Erboul y Millogo (2001) y Rouet (2003).
} 
Las tareas de navegación exigen, como su propio nombre indica, establecer una ruta de navegación a través de la estructura espacial (topológica) del hipertexto. Lo que conlleva:

- específicamente, reconocer qué palabras o frases de cada nodo representan un enlace y seleccionar/accionar los enlaces que se van a leer en base a unos objetivos lectura; y

- globalmente, identificar la estructura topológica del hipertexto y representar dicha estructura mentalmente.

Teniendo esto en cuenta, la organización espacial de un hipertexto lineal (donde el orden de las transiciones entre nodos está totalmente establecido) supondrá menor carga cognitiva que la estructura de un hipertexto jerárquico (donde el lector puede elegir entre diferentes enlaces dentro de cada nodo que llevan a nodos subordinados); y ésta, a su vez, menor carga que la de un hipertexto en red (donde los nodos se comunican entre sí sin un criterio jerárquico que los estructure).

Por su parte, las tareas de lectura suponen integrar el contenido de los nodos para elaborar una representación mental coherente (una representación intertextual); lo que, desde el modelo MD-TRACE (Rouet y Britt, 2011), se traduce en tres procesos altamente interrelacionados que permiten acceder, procesar e integrar la información hipertextual. Reproducimos la imagen 1.2 con el fin de facilitar la lectura: 


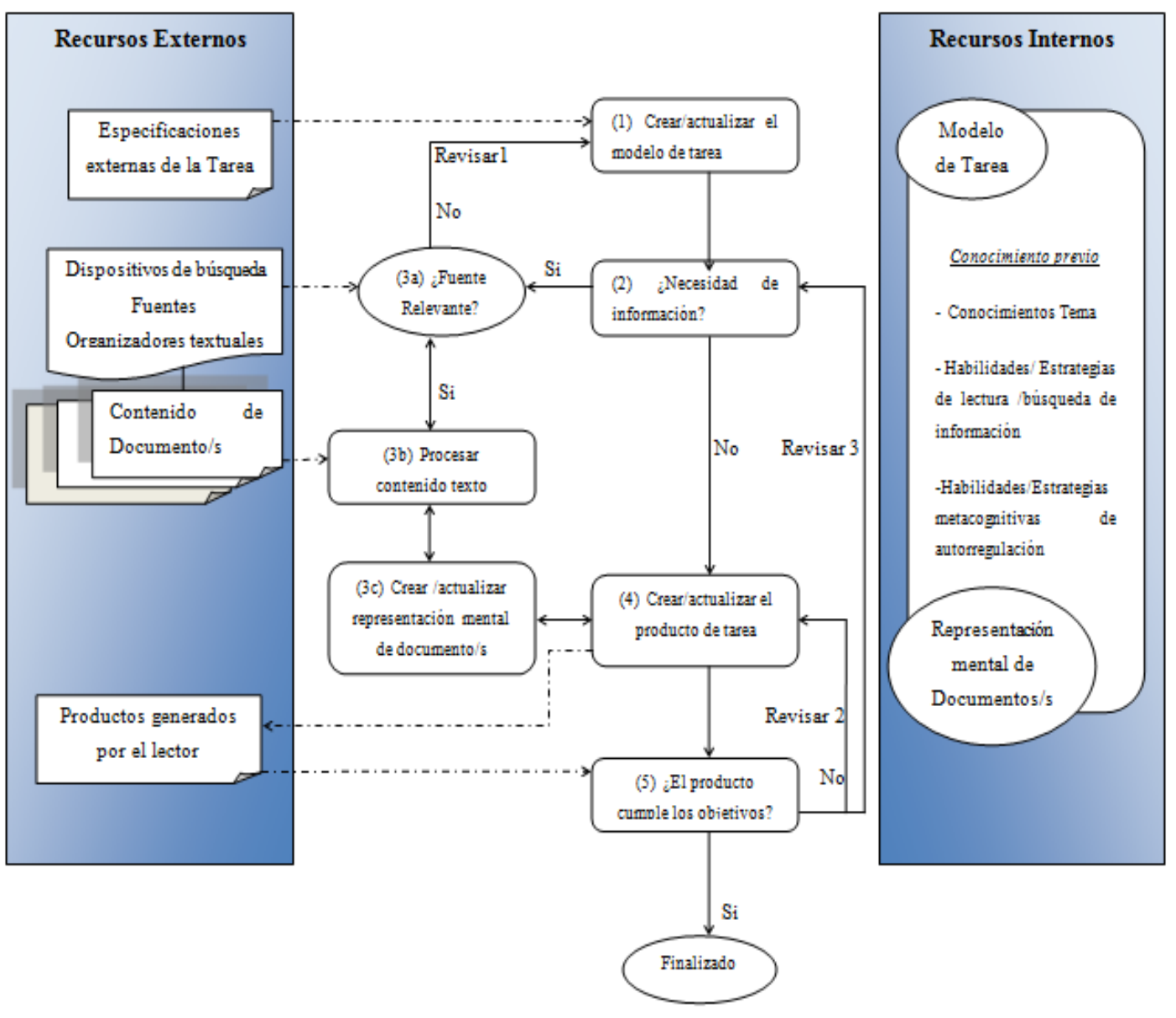

Imagen 1.2. Modelo MD-TRACE. Traducido y adaptado de Rouet y Britt (2011)

En primer lugar, el lector evalúa la relevancia de los nodos para la tarea que va realizar (3a); seguidamente, procesa en profundidad el contenido ${ }^{14}$ de los nodos que selecciona, leyéndolos en un orden concreto (3b); y finalmente, crea una representación mental del contenido del hipertexto, que pasa a ser un recurso interno del lector que será actualizado conforme avanza el proceso de lectura (3c). Estos procesos, especialmente el $3 \mathrm{~b}$, exigirán al lector, por un lado, reconocer qué elementos cohesivos del hipertexto permiten identificar las relaciones semánticas explícitas que se dan entre nodos, y por otro, utilizar sus conocimientos previos para realizar inferencias que rellenen los vacios de información entre nodos. En este sentido, como ocurre en la lectura de texto impreso, una menor cohesión del documento supondrá una mayor carga cognitiva para la memoria de trabajo (una carga que será efectiva en lectores con bajo conocimiento de dominio, e inefectiva en lectores con alto conocimiento de dominio).

\footnotetext{
${ }^{14}$ Los procesos descritos se refieren concretamente a hipertextos compuestos por nodos que constituyen una unidad informativa (es decir, hipertextos elaborados partiendo de un mismo texto), que son los documentos hipervinculados que hemos utilizado en nuestra investigación. En el caso de hipertextos compuestos por nodos que constituyen distintas unidades informativas (es decir, hipertextos elaborados a partir de diferentes fuentes de información), además de relaciones semánticas entre el contenido de los nodos, sería necesario establecer relaciones entre las fuentes. En este sentido, Perfetti, et al. (1999) destacan 4 aspectos a tener en cuenta: la identidad del autor, el contexto en el que se creó el texto, la forma del documento y los objetivos retóricos.
} 
Partiendo de lo que hemos señalado, leer un hipertexto es una actividad que implica navegar a través de los enlaces hipertextuales e integrar intertextualmente el contenido de los nodos. En consecuencia, los problemas de navegación pueden dificultar la representación mental del contenido textual, y a su vez, los problemas para establecer relaciones entre el contenido de los nodos pueden suponer la ausencia de criterios adecuados para establecer una ruta de lectura (Madrid, 2010).

\subsubsection{Procesos específicos implicados en la lectura hipertextual: la selección del orden de lectura}

La selección del orden de lectura es el principal proceso ${ }^{15}$ que diferencia la lectura multilineal de texto hipervinculado de la lectura lineal de texto impreso.

Para explicar este proceso, vamos a tomar como referencia los trabajos de dos investigadores: a) Salmerón y colaboradores (Salmerón et al., 2005, Salmerón et al., 2006a, Salmerón, Kinstch y Cañas 2006b), que estudian el efecto de las variables conocimiento de dominio, estrategias de lectura hipertextual y grado de cohesión semántica entre nodos, en la comprensión de hipertexto; y b) Madrid y colaboradores (Madrid, Van Oostendorp y Puerta, 2009; Madrid y Cañas, 2009), que analizan la incidencia de las mismas variables tanto en la comprensión lectora como en la carga cognitiva.

Estos estudios incorporan una variable que no hemos analizado previamente, las estrategias de lectura hipertextual; por lo que antes de revisarlos, consideramos oportuno describirla brevemente.

\footnotetext{
${ }^{15}$ Además de la selección del orden de lectura, Salmerón et al. (2005), Salmerón, Kinstch y Cañas (2006a), Salmerón (2006), Scheiter y Gerjects (2007) y Shapiro (2004) mencionan otro proceso, denominado elección de secciones de lectura, que tiene gran importancia para la comprensión cuando el hipertexto está compuesto por una enorme cantidad de nodos o cuando el lector, únicamente, necesita acceder a un determinado número de nodos para lograr sus objetivos de lectura. En ambos casos, es necesario decidir qué enlaces consultar y cuáles ignorar en virtud a un modelo de tarea; por lo que, como afirma Shapiro (2004), el grado de precisión de la metacomprensión del lector determinará si éste accede o no a los nodos que contienen información relevante para sus metas de lectura.

De cualquier modo, la elección de nodos de lectura está estrechamente relacionada con el orden en el que se leen dichos nodos, en concreto, con la estrategia utilizada para decidir ese orden. Los estudios de Salmerón et al. (2005) y Salmerón et al. (2006a) muestran que si los lectores siguen una estrategia de interés, leerán los nodos por orden de interés, seleccionando aquellos que les parecen más interesantes; mientras que si los lectores utilizan una estrategia de coherencia, establecerán una secuencia de lectura coherente, decidiendo qué enlace accionar en función de su grado de coherencia con respecto al contenido del nodo en el que se encuentran. Según estos autores, la acción conjunta de ambos procesos permitirá al lector representar mentalmente la información del hipertexto; en particular, los nodos que se consultan incidirán en la base textual, y el orden en el que se consultan influirá en el modelo de la situación: "we proposed that the amount of information read by a given reader affects the textbase and that the orden followed influences the situation model" (176).
} 


\section{A. Estrategias de lectura hipertextual}

De acuerdo con Jañez (2014) y Madrid (2010), cuando un lector se enfrenta a un hipertexto, pone en marcha una serie de estrategias o reglas de decisión que, específicamente, le permiten decidir qué nodos lee y en qué orden los lee, y, globalmente, le llevan a establecer una conducta/perfil de navegación concreto (reflejada en el número de nodos que ha visitado, el orden en el que los ha visitado y el tiempo que ha permanecido en cada nodo).

Como reglas de decisión destacan: la estrategia de coherencia, que lleva al lector a tratar de leer los nodos en un orden coherente (Foltz, 1996); la de interés, que le lleva a accionar los enlaces en función del interés que le suscitan (Ainley, Hidi y Berndorff, 2002); y la de posición en pantalla, que le lleva a abrir los enlaces en el orden en el que aparecen en la pantalla (Salmerón, 2006). Mientras que como conductas de navegación, Barab, Bowdish y Lawless (1997), Barab, Bowdish, Young y Owen (1996), Lawless y Kulikowich (1998), Lawless, Mills y Brown (2002) y Lawless, Brown, Mills y Mayall (2003) identifican 3 patrones:

a) los buscadores de conocimiento, que se centran en información relacionada con el contenido del hipertexto: "Knowledge seekers typify those readers who pursue information related to the content of the hypertext" (Lawless et al., 2003, p.917).

b) los exploradores de rasgo, que invierten más tiempo tratando de comprender cómo funciona el hipertexto que reuniendo información importante del texto escrito: "Feature seekers.... seem to invest more time in understanding how the hypertext works and what kinds of screens it contains than trying to gather important information from the written text" (Lawless et al., 2003, p.917).

c) los usuarios apáticos, que no parecen preocuparse ni por extraer contenido del hipertexto ni por explorar sus características; y se caracterizan por permanecer poco tiempo en cada nodo y seguir un patrón de navegación lineal: "the apathetic hypertext users are characterized by the short intervals of time they spend interacting with the text and their linear pattern of choices within the environment" (Lawless et al., 2003, p.917).

Teniendo esto en cuenta, un lector que utiliza fundamentalmente estrategias de coherencia se puede considerar un buscador de conocimiento; uno que usa principalmente estrategias de interés, un buscador de conocimiento (si se interesa por el contenido de los nodos) o un explorador de rasgo (si se interesa por elementos secundarios del hipertexto, como imágenes o efectos de sonido); y uno que usa estrategias de posición en pantalla, un usuario apático. 
B. Análisis de la investigación sobre el proceso de Selección del orden de lectura

Salmerón y colaboradores (Salmerón et al., 2005; Salmerón et al., 2006a; Salmerón et al., 2006b) realizaron una serie de trabajos que reflejan el rol fundamental del proceso de selección del orden de lectura para la comprensión lectora de hipertexto.

En un primer estudio, Salmerón et al. (2005) observaron que los lectores con bajo conocimiento aprendían más siguiendo un orden de lectura coherente, mientras que los de alto conocimiento mejoraban su rendimiento siguiendo un orden de baja coherencia: "Low-knowledge participants learned more by following a high coherent reading order, whereas high-knowlege participants learned more by reading the hypertext in a low-coherence order" (171).

Esta conclusión fue matizada en dos trabajos posteriores (Salmerón et al., 2006 a, b) que, además de las variables conocimiento de dominio y grado de coherencia del orden de lectura, tenían en cuenta la variable estrategias de lectura hipertextual. Concretamente, los dos estudios mostraron que:

a) Los lectores con bajo conocimiento previo obtenían beneficio a la hora de construir el modelo de la situación, bien cuando seleccionaban el orden de lectura siguiendo una estrategia de coherencia (fueran o no instruidos en dicha estrategia), o bien cuando leían el hipertexto en orden coherente sin poder elegir el orden de lectura; pero encontraban perjuicio en la comprensión, bien cuando seguían una estrategia de interés o posición en pantalla, o bien cuando leían el hipertexto en orden incoherente sin poder elegir el orden de lectura.

b) Los lectores con alto conocimiento se beneficiaban de la lectura de hipertexto, independientemente del tipo de estrategia utilizada.

A la vista de los resultados, Salmerón et al. (2006 a, b) hablan de efectos inducidos por el texto y efectos inducidos por la estrategia. Por un lado, la comprensión lectora en los lectores con bajo conocimiento de dominio parecía estar inducida por el texto. Estos lectores, de la misma forma que cuando leen textos lineales, mejoran la comprensión ante un orden de lectura muy cohesivo (estrategia de coherencia) y la empeoran ante uno poco cohesivo (estrategias de interés y posición en pantalla). Por otro lado, la comprensión lectora de lectores de alto conocimiento de dominio parecía estar inducida por la propia estrategia, ya que el uso de estrategias les llevaba a procesar activamente la información utilizando su conocimiento previo para lograr una representación más coherente del texto: "Overall, results support the claim that hypertext can be beneficial for readers with prior knowlegdge, particularity when they are induced to actively select the reading order" (Salmerón, Kintsch y Cañas, 2006a, p.1168). 
Por su parte, Madrid y colaboradores (Madrid et al., 2009; Madrid y Cañas, 2009), realizaron un conjunto de estudios en los que analizaron el efecto del proceso de selección del orden de lectura no sólo en la comprensión, sino también en la carga cognitiva que soporta la memoria operativa.

En un primer trabajo, Madrid et al. (2009) percibieron que los lectores que seleccionaban un orden de lectura de alta coherencia sufrían menor carga cognitiva durante la lectura y obtenían mejor aprendizaje que aquellos que seguían un orden de baja coherencia (específicamente, parecían sufrir menos carga cognitiva en la elección de los links).

First, readers selecting a low coherent order suffer more cognitive load during reading than those selecting a high coherent order. Second, subjects who were able to select a high coherent reading order also seemed to have suffered less cognitive load during link selection than those subjects who selected a low coherent reading order. (73)

Estos hallazgos se concretaron en un segundo estudio, realizado por Madrid y Cañas (2009), que introdujo variables que no se tuvieron en cuenta en el anterior (en concreto, el conocimiento de domino y las estrategias de lectura hipertextual). En particular, esta investigación indicaba que: a) los lectores con bajo conocimiento de dominio que seguían una estrategia de coherencia soportaban menor carga cognitiva durante la lectura y alcanzaban mejor nivel de comprensión que los que seguían las estrategias de interés o de posición en pantalla; y b) los lectores de alto conocimiento que seguían una estrategia de interés producían una mayor carga cognitiva que los que usaban una estrategia de coherencia (aunque ambos aprendieron igualmente con ambas estrategias).

Resumiendo, los trabajos de Salmerón y colaboradores (Salmerón et al., 2005; Salmerón et al., 2006a; Salmerón et al., 2006b) y Madrid y colaboradores (Madrid et al., 2009; Madrid y Cañas, 2009) indican que la comprensión lectora de hipertexto depende de aspectos similares a los asociados a la comprensión lectora de texto impreso:

- En primer lugar, la cohesión textual es un elemento fundamental para la comprensión en lectores con bajo conocimiento de dominio. Como hemos visto, este tipo de lectores cuando leen un texto impreso cohesivo o lee los nodos de un hipertexto en orden cohesivo, alcanzan un mayor nivel de comprensión y sufren menor carga cognitiva, que cuando leen un texto poco cohesivo o lee un hipertexto en un orden poco cohesivo.

- En segundo lugar, el lector con alto conocimiento de dominio alcanza un buen nivel de comprensión independientemente del grado de cohesión textual, pero lo mejora cuando procesa activamente la información de texto/hipertexto. Concretamente, el uso de habilidades/estrategias de lectura le van a permitir 
aumentar la carga cognitiva efectiva en su memoria de trabajo, lo que le lleva a activar más conocimientos previos, y por tanto, a generar un modelo de la situación más rico.

\section{CONSIDERACIONES FINALES}

Teniendo en cuenta que la comprensión lectora depende de la interacción de factores vinculados al lector (el conocimiento de dominio, las habilidades/estrategias lectoras y la carga cognitiva que supone el texto para el lector), al texto (la cohesión textual y el formato textual) y al contexto (el tipo de tarea en la que se enmarca la actividad lectora), de cara a nuestra investigación elaboramos dos diseños.

En el primer diseño, tratamos de comprobar si los alumnos universitarios que se encuentran en diferentes momentos formativos, poseen habilidades básicas de comprensión y expresión escrita para satisfacer las demandas de dos tareas:

a) leer un texto impreso con el fin de extraer la idea principal de cada párrafo textual; lo que nos permitía observar la capacidad que tendría el alumnado a la hora de seguir la progresión temática del texto; y

b) elaborar un mapa conceptual que recoja las relaciones jerárquicas que se dan entre las ideas fundamentales de dicho texto; lo que nos permitía percibir la representación mental del lector plasmada sobre un papel.

Recordemos que, durante la lectura, los alumnos con alto conocimiento de dominio alcanzan mejor nivel de comprensión si logran destinar recursos cognitivos de la memoria de trabajo para la recuperación de conocimientos almacenados en la memoria a largo plazo (esta carga cognitiva efectiva aparece cuando leen un texto de baja cohesión, o cuando utilizan sus habilidades lectoras para procesar activamente un texto de alta cohesión); mientras que los de bajo conocimiento, se benefician en mayor medida de textos altamente cohesivos (aunque, en ocasiones, pueden no beneficiarse de ellos, si carecen de habilidades lectoras que le permitan gestionar adecuadamente los recursos cognitivos de la memoria de trabajo).

Debido a esto, para evaluar las habilidades básicas de comprensión y expresión escrita, era imprescindible encontrar un documento textual cuyas características garantizasen que el éxito o fracaso en la realización de las tareas dependiera fundamentalmente de dichas habilidades. En este sentido, utilizamos un texto de baja cohesión que: a) habla de un tema muy denunciado en los medios de comunicación, la invasión china del Tíbet; b) recoge términos y conceptos que deberían evocar modelos de la situación conocidos para el alumnado que ha finalizado con éxito el bachillerato; y c) tiene unas características estructurales muy familiares para alumnos de etapas educativas tan dispares como secundaria, bachillerato y universidad (las historias sobre guerras o 
invasiones presentan antecedentes, intervención de múltiples países, las causas del conflicto, consecuentes, etc.). Con ello conseguimos, por una parte, promover el procesamiento activo de la información en alumnos con alto conocimiento de dominio (era un texto poco cohesivo), y por otra, facilitar una estructura y unos conceptos familiares para los alumnos con pocos conocimientos previos sobre el tema. De esta manera, independientemente del conocimiento de dominio, el alumnado que dispusiese de habilidades básicas de comprensión y expresión escrita sería capaz de identificar relaciones temáticas y estructurales a nivel de párrafo (y en su caso, realizar las inferencias necesarias) para de extraer la macroposición de cada uno de ellos (tarea 1); y además, sería capaz de identificar/reconocer una estructura global en el texto para construir un mapa conceptual que refleje las relaciones jerárquicas que se dan entre las ideas principales del texto $(\operatorname{tarea} 2)^{16}$.

A esto hay que añadir que, como vimos en el marco teórico, los lectores, en general, mejoran la precisión de la metacomprensión cuando elaboran eficazmente tareas escritas como la extracción de macroproposiciones textuales (ideas clave de cada párrafo) o la elaboración de mapas conceptuales; por lo que un buen desempeño en la realización de estas tareas será indicador de un alto grado de control metacognitivo del proceso de lectoescritura.

Por su parte, en el Diseño II, tratamos de determinar si la acción conjunta de las variables momento formativo y formato textual (texto o hipertexto), incide en la puesta en práctica de habilidades/estrategias de comprensión y expresión escrita durante la realización de una tarea que implica resumir un documento académico.

Como hemos visto en este capítulo, el principal proceso que diferencia la lectura lineal de la no lineal es la selección del orden de lectura. El grado de cohesión de un texto siempre depende del autor, pero el de un hipertexto puede depender, bien del autor, si la secuencia de lectura está pre-determinada; o bien del lector, si tiene libertad para seleccionar el orden de lectura de los nodos. Por lo que, conforme aumenta la libertad del lector para seleccionar el orden de lectura, se incrementa la probabilidad de que aparezcan diferencias significativas (n.s.=.05) en la comprensión de texto e hipertexto,

\footnotetext{
16 Teniendo en cuenta los estudios que hemos visto sobre la interacción entre habilidades de comprensión lectora, conocimiento de dominio y cohesión textual; podríamos pensar que el texto que utilizamos para las pruebas del Diseño I, al ser de baja cohesión, facilitaría la comprensión a los alumnos de alto conocimiento independientemente de si disponían o no de habilidades de comprensión. Sin embargo, recordemos que los estudios revisados medían las habilidades lectoras a través de un test estandarizado (el Nelson-Denny de Brown, Fishco y Hanna, 1993), y posteriormente, analizaba el nivel lector que mostraban los sujetos a través de sus respuestas a preguntas sobre la base textual de un texto y a cuestiones sobre el modelo de la situación que se derivaba de ese texto. De esta manera, un lector de alto conocimiento, ante un texto de baja cohesión, podría dar respuestas adecuadas dispusiese o no de habilidades lectoras. Pero si en lugar de responder preguntas, se exige poner en prácticas esas habilidades durante la lectura del texto para realizar dos tareas determinadas (que implican, por un lado, diferenciar información importante de la que no lo es, y por otro, organizar las ideas jerárquicamente partiendo de las señales textuales), como es el caso de nuestra investigación, las habilidades de comprensión serán las que finalmente determinen el éxito o fracaso en las tareas.
} 
en función del conocimiento de dominio y las habilidades de lectura (la información que es cohesiva en formato textual, puede leerse de forma poco cohesiva en formato hipertextual).

Tomando esto en consideración, nos planteamos establecer el mismo orden de lectura en texto e hipertexto, para determinar si la lectura intertextual de los nodos hipertextuales, tiene un efecto diferencial en la puesta en marcha de estrategias de comprensión y expresión escrita. En este sentido, tratamos que la secuencia de lectura del hipertexto fuera lo más similar posible a la del texto; incrustando los hipervínculos dentro de la información de la página/nodo principal, de manera que el lector, conforme encuentra los enlaces, únicamente tiene que decidir entre clickearlos para acceder a la información hipervinculada o ignorarlos y seguir leyendo el texto principal.

Este texto/hipertexto secuencial era un documento académico sobre tecnología en educación, lo que, en principio, podría llevar a pensar que beneficiaría a los alumnos que se encontraban en un momento formativo superior, y perjudicaría a los que se encontraban en uno inferior (consideramos que los primeros, al haber cursado asignaturas relacionadas con la temática, deberían poseer más conocimiento de dominio que los segundos ${ }^{17}$ ). Sin embargo, las características estructurales del texto/hipertexto favorecían que el éxito o fracaso en la realización de la tarea (hacer un resumen del texto/hipertexto) dependiera fundamentalmente de la disposición o no de habilidades de comprensión y expresión escrita. El documento que utilizamos se caracterizaba por tener muy alta cohesión en cuanto a aspectos estructurales ${ }^{18}$ (introducción, títulos y conclusión) y baja cohesión en cuanto a la información que aparece durante desarrollo del artículo (principalmente en el primer y segundo apartado); por lo que si el lector poseía las habilidades mencionadas, podría realizar adecuadamente la tarea que se le solicitaba (aunque no comprendiese toda la información) siempre y cuando partiese de un modelo de tarea adecuado.

Teniendo en cuenta que el lector del texto y el del hipertexto seguían una secuencia de lectura similar (diferenciándose únicamente en la lectura intertextual) y que el nivel de desempeño en la tarea de resumen dependía de las habilidades de comprensión y expresión escrita, en este segundo diseño, tratamos de evaluar:

\footnotetext{
${ }^{17}$ Herrada y Herrada Valverde $(2011,2012)$ realizaron una revisión exahustiva de las asignaturas sobre tecnologías de la información y comunicación (TIC) que cada universidad española ofertaba (esta revisión se centró tanto en los planes de estudio que se extinguieron progresivamente durante la implantación del Espacio Europeo de Educación Superior (EEES), como en los planes vigentes desde la implantación del mismo). En lo que se refiere a la Universidad de Salamanca, se observa que los alumnos que habían finalizado alguna diplomatura de magisterio en los planes antiguos habían cursado dos troncales sobre tecnología educativa y, en su caso, dos optativas; mientras que los alumnos que acababan de empezar un Grado de Maestro iban a cursar dos troncales y, en su caso, seis optativas. Esto indica que, en nuestra investigación, la muestra estaba compuesta tanto por los alumnos de Psicopedagogía que deberían estar familiarizados con la temática del texto, como por los alumnos que iniciaban el Grado de Educación Primaria que iban a enfrentarse durante la carrera a este tipo de temática.

${ }^{18}$ Esos indicadores estructurales se recogían tanto en el texto como en la página principal del hipertexto.
} 
- El resumen realizado por cada alumno, comprobando si recogía la macroestructura del texto/hipertexto, si era breve (es decir, si se centraba en la información importante) y si estaba expresado de modo personal (utilizando estrategias de generalización, construcción y/o paráfrasis personal).

- El borrador realizado por cada alumno (en el caso de que éste fuese realizado), centrándonos en su grado de estructuración (lista de ideas, mapa conceptual, texto secuencial) y su grado de similitud con el resumen (si la relación entre el borrador y el resumen seguía un modelo decir conocimiento o un modelo transformar conocimiento).

- La información subrayada y las anotaciones realizadas en el texto impreso (lo que nos permitió comprobar si los alumnos que leyeron el texto impreso utilizaban técnicas para descargar la memoria operativa, y en caso de usarlas, si las utilizaban para destacar información importante del texto).

- El grado de integración intertextual de la información hipervinculada dentro del resumen (lo que nos permitió observar si los alumnos que leyeron el hipertexto eran capaces de integrar en el resumen la información de los vínculos y la de la página principal del hipertexto).

- Los procedimientos que los alumnos consideraban haber puesto en marcha para la realización de la tarea, observando si manifestaban: haber utilizado técnicas de prelectura (como la exploración o el ojeado); haber accedido a todos los nodos (en el caso del hipertexto); haberse planteado preguntas sobre lo que saben y lo que no saben acerca de la temática del texto; haberse dado autoexplicaciones para resolver problemas de lectura; haber hecho un borrador (estructurado o desectructurado), etc. De esta manera, analizamos los aspectos metacognitivos vinculados con la tarea, así como el grado de adecuación de dichos procesos para la realización de la misma. 
SEGUNDA PARTE. BLOQUE EXPERIMENTAL 


\section{CAPÍTULO II. METODOLOGÍA DE LA INVESTIGACIÓN}

En este segundo capítulo, nos adentraremos en los aspectos metodológicos de la investigación. En el primer apartado trataremos su finalidad y objetivos; en el segundo, las hipótesis planteadas; en el tercero mostraremos el diseño de investigación que hemos seguido; en el cuarto explicitaremos las variables de investigación; en el quinto describiremos los instrumentos utilizados; en el sexto, la población y muestra; en el séptimo, el trabajo de campo realizado; en el octavo nos centraremos en la informatización y el tipo de análisis de datos; y, finalmente, en el noveno mostraremos un esquema que refleja los diferentes pasos que fueron llevados a cabo durante la realización de la investigación.

\subsection{FINALIDAD Y OBJETIVOS DE LA INVESTIGACIÓN}

Nuestra investigación tiene como principal finalidad analizar las competencias de comprensión y expresión escrita que poseen los alumnos que acceden a la universidad, ya que, presumiblemente, van a tener que enfrentarse a un modelo de enseñanza centrado en el aprendizaje, que requiere el dominio de determinadas estrategias $^{19}$, entre las que se encuentran, fundamentalmente, las subordinadas a la comprensión y expresión escrita.

La investigación se ha centrado en el alumnado de la Universidad de Salamanca del Grado en Educación Primaria, que en el curso académico 2012/2013 accedía por primera vez a la universidad; y en los alumnos titulados en alguna de las Diplomaturas de Maestro de la Universidad de Salamanca, que accedieron al segundo ciclo de la Licenciatura en Psicopedagogía durante ese mismo curso académico. En este sentido, además de analizar las competencias de los alumnos que accedieron al Grado, nos pareció oportuno e interesante indagar, al mismo tiempo, si los alumnos que se habían

\footnotetext{
${ }^{19}$ En el primer capítulo vimos que una misma destreza puede ser considerada habilidad, de carácter inconsciente e instintivo, o estrategia, de carácter consciente e intencional, dependiendo de su grado automatización. Esto significa que usar una estrategia supone un gasto de recursos cognitivos de la memoria de trabajo, mientras que poner en marcha una habilidad no supone gasto cognitivo alguno. Según Escoriza (2003), las estrategias pueden convertirse en habilidades a través del entrenamiento, y a su vez, las habilidades se pueden usar estratégicamente (conscientemente) cuando el lector lo estima oportuno. Partiendo de esto, cuando hablemos de habilidades nos referimos también a estrategias, y viceversa.
} 
enfrentado durante al menos tres años a aprendizajes y tareas académicas de nivel universitario, habían experimentado alguna mejora en el dominio de las estrategias subordinadas a la comprensión y expresión escrita.

Por otro lado, actualmente, los entornos de aprendizaje están inmersos en una realidad social cada vez más influenciada por las Tecnologías de la Información y Comunicación (en adelante TIC); y esto implica que los alumnos van a tener que consultar en sus tareas de acceso al conocimiento, tanto textos lineales en formato impreso, como textos no lineales (hipervinculados) en formato digital. Esta última razón nos ha llevado también a plantearnos en nuestra investigación, si realmente existen diferencias significativas (n.s.=.05) en función del estímulo presentado (texto vs hipertexto) a la hora de aplicar las estrategias mencionadas en una tarea académica de acceso al conocimiento.

Como consecuencia de todo ello, partimos de los siguientes objetivos:

1. Describir si los estudiantes que comienzan el Grado de Maestro en Educación Primaria poseen las habilidades básicas de comprensión y expresión escrita para la construcción de conocimiento.

2. Identificar el nivel de habilidades básicas en comprensión y expresión escrita de los alumnos titulados en alguna de las Diplomaturas de Maestro que iniciaban la Licenciatura en Psicopedagogía.

3. Comparar el nivel en habilidades básicas de comprensión y expresión escrita en los dos grupos de la muestra: Educación Primaria y Psicopedagogía.

4. Comprobar la influencia que tiene el tipo de texto (impreso e hipervinculado) en ambas muestras, en la utilización de las estrategias de comprensión y expresión escrita, necesarias para una determinada tarea académica.

\subsection{HIPÓTESIS}

Partiendo de los objetivos citados y de la revisión bibliográfica realizada sobre el tema (Bereiter y Scardamalia, 1992; DeStefano y LeFevre, 2007; Hirvela y Du, 2013; Jáñez, 2014; Kintsch, 1988, 1998, 2004; Scott y Schwartz, 2007; Salmerón, Cañas y Fajardo, 2005; Scardamalia y Bereiter, 1984; Salmerón et al., 2005; Salmerón et al., 2006a,b; Salmerón et al., 2010; Sánchez ,1993, 1998; OCDE, 2012, 2013; Van Dijk, 1994, 1995; Wade-Stein y Kintsch, 2004; Westby et al., 2010), nos planteamos las siguientes hipótesis, que formulamos en términos operativos con el fin de orientar el proceso de recogida de información, determinar los criterios de análisis de datos y facilitar la contrastación de hipótesis. 
1. Los alumnos de nuevo ingreso en la Universidad de Salamanca, matriculados en el primer curso del Grado de Maestro en Educación Primaria, presentan dificultades en el dominio de habilidades básicas de comprensión y expresión escrita para la construcción de conocimiento.

2. Los alumnos que acceden a $1^{\circ}$ curso de la Licenciatura en Psicopedagogía desde alguna de las Diplomaturas de Maestro que se imparten en la Universidad de Salamanca tienen dificultades para realizar adecuadamente una prueba de lectura, que requiere la disposición de habilidades básicas de comprensión y expresión escrita para la construcción de conocimiento.

3. Existen diferencias en el nivel de habilidades básicas en comprensión y expresión escrita entre los alumnos de nuevo ingreso en la Universidad de Salamanca y los que han finalizado alguna de las Diplomaturas de Maestro en dicha Universidad.

4. El tipo de texto (impreso e hipertexto) implica la puesta en práctica de tareas de comprensión y expresión escrita diferenciales en ambos grupos.

\subsection{DISEÑO DE LA INVESTIGACIÓN}

A partir de las hipótesis anteriores, seleccionamos un tipo de diseño de investigación experimental (Tejedor, 1994). En concreto, existen diferentes procedimientos, enmarcados dentro de las metodologías pre-experimental y cuasiexperimental, que se pueden utilizar para minimizar el problema de la ausencia de asignación al azar (Campbell y Stanley, 1967, 1978; Shadish, Cook y Campbell, 2002; Shadish, Luellen y Clark, 2006) que presentaba el contexto educativo en el que se llevó a cabo nuestra investigación. Un contexto formado por grupos incidentales preestablecidos, que impedía la selección aleatoria de los sujetos de la muestra, y por tanto, dificultaba el control experimental completo de las variables extrañas intervinientes.

Teniendo esto cuenta, establecimos dos diseños diferentes en los que realizamos observaciones múltiples para sustituir el control experimental y tuvimos en cuenta las variables de control (que especificaremos en el siguiente apartado) con el fin de minimizar los efectos de las fuentes de validez interna, tales como la selección muestral, historia intersensorial, maduración y regresión hacia la media. 


\subsubsection{Diseño I: Evaluación de las habilidades básicas de comprensión y expresión escrita para la construcción de conocimiento}

Este diseño partió de tres hipótesis principales:

1. Los alumnos de nuevo ingreso en la Universidad de Salamanca, matriculados en el primer curso del Grado de Maestro en Educación Primaria, presentan dificultades en el dominio de habilidades básicas de comprensión y expresión escrita para la construcción de conocimiento.

2. Los alumnos que acceden a $1^{\circ}$ curso de la Licenciatura en Psicopedagogía desde alguna de las Diplomaturas de Maestro que se imparten en la Universidad de Salamanca; tienen dificultades para realizar adecuadamente una prueba de lectura, que requiere la disposición de habilidades básicas de comprensión y expresión escrita para la construcción de conocimiento.

3. Existen diferencias en el nivel de habilidades básicas en comprensión y expresión escrita entre los alumnos de nuevo ingreso en la Universidad de Salamanca y los que han finalizado alguna de las Diplomaturas de Maestro en dicha Universidad.

Con el fin de contrastar estas hipótesis, establecimos un diseño de carácter transversal en el que partimos de una misma población de estudio, estudiantes y titulados de las carreras de maestro de la Universidad de Salamanca (curso 2012/2013), para seleccionar dos grupos que se encontraban en diferentes momentos formativos:

- Grupo Educación Primaria (en adelante EDP): compuesto por alumnos matriculados en el primer curso del Grado en Educación Primaria que acababan de ingresar en la Universidad (curso 2012/2013).

- Grupo Psicopedagogía (en adelante PSP): compuesto por alumnos de $4^{\circ}$ curso ${ }^{20}$ de la Licenciatura en Psicopedagogía que habían finalizado alguna de las diferentes Diplomaturas de Maestro en la Universidad de Salamanca (curso 2012/2013).

Concretamente, utilizamos un diseño de carácter pre-experimental en el que no se tomaron medidas pre y pos-tratamiento de la variable dependiente dentro de un mismo grupo, ya que cada grupo de estudio supuso una medida diferente al representar dos momentos formativos distintos.

Como se puede observar en el cuadro 2.1, tomamos EDP como medida Pretratamiento/Pre-test. En la segunda línea del diseño, consideramos el proceso formativo

\footnotetext{
${ }^{20}$ Primer año de una titulación de $2^{\text {o }}$ ciclo (previamente el alumno había cursado una diplomatura de 3 años)
} 
por el que había pasado PSP como tratamiento o Test. Y establecimos PSP como medida Pos-tratamiento/ Pos-test.

Además de ello, establecimos diferentes variables de control (ver Anexo I.1. Cuadro 2) para comprobar si existían diferencias significativas intergrupales (n.s.=.05), que pudiesen ofrecer una explicación alternativa al momento formativo (el hecho de haber cursado durante al menos tres años la Diplomatura de Maestro) para los resultados obtenidos en la variable dependiente (que trataremos en el apartado 2.4).

\begin{tabular}{|c|c|c|c|c|}
\hline Grupos & $\begin{array}{c}\text { Asignación } \\
\text { aleatoria }\end{array}$ & Pre-test & $\begin{array}{c}\text { Tratamiento } \\
\text { (cursar 3 años } \\
\text { de diplomatura) }\end{array}$ & Pos-test \\
\hline EDP & NR & $O_{1}$ & - & - \\
\hline PSP & NR & - & $X$ & $O_{2}$ \\
\hline
\end{tabular}

Cuadro 2.1. Diseño I

$N R=$ No asignación aleatoria al tratamiento o no asignación al tratamiento

$O_{l}=$ Primera observación/ medición de la variable dependiente

$X=$ Puesta en práctica del tratamiento (proceso formativo por el que pasaron los titulados)

$\mathrm{O}_{2}=$ Segunda observación/ medición de la variable dependiente

\subsubsection{Diseño II: Evaluación del efecto del formato textual (impreso vs hipervinculado) sobre las estrategias de comprensión y expresión escrita}

El objetivo principal de este diseño era comprobar la influencia que tenía el formato textual (impreso o hipervinculado) en ambas muestras (EDP y PSP) a la hora de utilizar las estrategias de comprensión y expresión escrita necesarias para la realización de una determinada tarea académica. La hipótesis de estudio ha sido:

4. El tipo de texto (impreso e hipertexto) implica la puesta en práctica de tareas de comprensión y expresión escrita diferenciales en ambos grupos.

Para cumplir este objetivo establecimos un diseño de carácter transversal, en el que partimos de las muestras del diseño anterior, para formar cuatro grupos de estudio compuestos por alumnos que se encontraban en un momento formativo concreto y que habían realizado la tarea académica en un formato textual específico. Los grupos son los siguientes:

- Grupo 1. EDP Texto: Grupo compuesto por los alumnos de nuevo ingreso que habían realizado la tarea a partir de la lectura de un texto impreso.

- Grupo 2. EDP Hipertexto: Grupo compuesto por alumnos que acababan de ingresar a la carrera de maestro, que habían realizado la tarea a partir de la lectura de un hipertexto. 
- Grupo 3. PSP Texto: Grupo compuesto por los alumnos titulados en alguna las titulaciones de maestro, que habían realizado la tarea a partir de la lectura de un texto impreso.

- Grupo 4. PSP Hipertexto: Grupo compuesto por alumnos titulados en alguna de las titulaciones de maestro, que habían realizado la tarea a partir de la lectura de un hipertexto.

En este caso, utilizamos una metodología cuasi-experimental con observaciones múltiples de la variable dependiente en cada uno de los grupos de estudio para sustituir el control experimental (la variable dependiente de este diseño se describirá en el apartado 2.4). Para ello, tomamos como medida pre-tratamiento/pre-test los resultados que obtuvo en la prueba del Diseño I el alumnado que compone la muestra de este segundo diseño; consideramos como Test o tratamiento el estímulo del formato textual (texto o hipertexto) a la hora de hacer la tarea; y tomamos los resultados obtenidos en la realización de la tarea académica específica como medida Pos-tratamiento/Pos-test.

\begin{tabular}{|l|c|c|c|}
\hline \multicolumn{1}{|c|}{ Grupos } & Pre-test & $\begin{array}{c}\text { Tratamiento } \\
\text { (tipo de texto) }\end{array}$ & Pos-test \\
\hline Grupo1. EDP Texto & $O_{1}$ & $X_{1}$ & $O_{2}$ \\
\hline Grupo2. EDP Hipertexto & $O_{1}$ & $X_{2}$ & $O_{2}$ \\
\hline Grupo3. PSP Texto & $O_{1}$ & $X_{1}$ & $O_{2}$ \\
\hline Grupo 4. PSP Hipertexto & $O_{1}$ & $X_{2}$ & $O_{2}$ \\
\hline
\end{tabular}

Cuadro 2.2. Diseño II

$O_{1}=$ Primera observación/ medición de la variable dependiente (resultados obtenidos en prueba Diseño I)

$X_{l}=$ Estímulo formato texto

$X_{2}=$ Estímulo formato hipertexto

$\mathrm{O}_{2}=$ Segunda observación/ medición de la variable dependiente (resultados obtenidos en tarea académica propuesta para el Diseño II)

Además, tuvimos en cuenta las mismas variables de control que en el Diseño I con el fin de minimizar los efectos de las fuentes de validez interna. 


\subsection{VARIABLES DE INVESTIGACIÓN}

2.4.1. Variables en el Diseño I para la evaluación de las habilidades básicas de comprensión y expresión escrita para la construcción de conocimiento

Para este diseño pre-experimental establecimos tres tipos de variables: Dependientes, Independientes y de Control.

2.4.1.1. Variables Dependientes en el Diseño I para la evaluación de las habilidades básicas de comprensión y expresión escrita para la construcción de conocimiento

El nivel de habilidades básicas en comprensión y expresión escrita, como variable compleja en la que intervienen distintas habilidades, va a ser definida a partir de múltiples variables operativas que se explicarán a continuación.

Las destrezas básicas a las que nos referimos (cuadro 2.3), están muy ligadas a los estudios de Kintsch $(1988,1998,2004)$, Van Dijk (1994,1995) y Van Dijk y Kintsch (1978, 1983), y aquellas otras investigaciones que desarrollaron los postulados de estos autores, tales como Anderson y Thiede (2008); Hernández y Quintero (2001, 2002), Jáñez (2014), McNamara y Magliano (2009), Quintero (1998), Ozuru et al. (2009), Sánchez (1993, 1998), Salmerón y Gutiérrez-Braojos (2012), Sánchez et al. (2009), Thiede et al. (2005) y Thiede et al. (2010). 


\begin{tabular}{|c|c|c|}
\hline $\begin{array}{l}\text { Habilidades básicas de comprensión y } \\
\text { expresión escrita }\end{array}$ & Definición conceptual & Comportamiento asociado a la definición conceptual \\
\hline $\begin{array}{l}\text { Habilidad para seguir la progresión temática durante el } \\
\text { proceso de comprensión lectora }\end{array}$ & $\begin{array}{l}\text { Capacidad para seguir la progresión temática } \\
\text { del texto que se está leyendo }\end{array}$ & $\begin{array}{l}\text { El alumno, conforme va leyendo, va progresando de un tema a otro apoyándose en dos tipos de relaciones proposicionales que } \\
\text { se dan en el texto a nivel microestructural. Por una parte, las relaciones superficiales o temáticas, que secuencian el paso de } \\
\text { información conocida a información novedosa; y por otra, las relaciones profundas o estructurales, que recogen la posición } \\
\text { estructural que ocupa cada proposición en relación a las proposición anterior y posterior. }\end{array}$ \\
\hline $\begin{array}{l}\text { Habilidad para el uso de la microestructura textual con el } \\
\text { fin de construir macroproposiciones durante el proceso de } \\
\text { comprensión lectora }\end{array}$ & $\begin{array}{l}\text { Destreza en el uso de macroestrategias para } \\
\text { la construcción de macroproposiciones }\end{array}$ & $\begin{array}{l}\text { El alumno, conforme va leyendo, va identificando/construyendo macroproposiciones dentro de cada ciclo de procesamiento } \\
\text { con el fin de conectar los diferentes ciclos. Para lograr este objetivo, debe seleccionar las macroestrategias que mejor se } \\
\text { adecuen a las relaciones proposicionales que se dan en el texto a nivel microestructural. }\end{array}$ \\
\hline $\begin{array}{l}\text { Habilidad para identificar la superestructura del texto } \\
\text { durante el proceso de comprensión lectora }\end{array}$ & $\begin{array}{l}\text { Capacidad para identificar la superestructura } \\
\text { textual }\end{array}$ & $\begin{array}{l}\text { El alumno identifica la organización textual que es dominante en el texto, a través de las señales textuales que aparecen en el } \\
\text { mismo. }\end{array}$ \\
\hline $\begin{array}{l}\text { Habilidad para el uso de la superestructura textual con el } \\
\qquad \text { fin de extraer la macroestructura }\end{array}$ & $\begin{array}{l}\text { Competencia para utilizar la superestructura } \\
\text { del texto con el fin de identificar la } \\
\text { macroestructura textual }\end{array}$ & $\begin{array}{l}\text { El alumno toma como referencia la superestructura del texto que lee, para aplicar un conjunto de macroestrategias sobre la } \\
\text { microestructura (o sobre macroproposiciones que va construyendo durante el transcurso de la lectura), que le permiten extraer } \\
\text { la macroestructura textual. }\end{array}$ \\
\hline \multirow[t]{2}{*}{$\begin{array}{l}\text { Habilidades de expresión escrita que mejoran la } \\
\text { comprensión lectora }\end{array}$} & $\begin{array}{l}\text { Destreza a la hora de expresar por escrito las } \\
\text { macroproposiciones que se van extrayendo } \\
\text { durante el proceso de lectura }\end{array}$ & $\begin{array}{l}\text { El alumno reflexiona en torno a la macroproposición que acaba de extraer para expresarla de modo personal. Durante este } \\
\text { proceso, integra dicha idea dentro de su base de conocimiento; por lo se enriquece el modelo de la situación en el que se } \\
\text { enmarca la idea y, como consecuencia, mejora la comprensión de la misma. }\end{array}$ \\
\hline & $\begin{array}{l}\text { Capacidad para plasmar por escrito la } \\
\text { macroestructura del texto leído }\end{array}$ & $\begin{array}{l}\text { El alumno reflexiona en torno a la macroestructura del texto leído para expresarla de modo personal. Durante este proceso, } \\
\text { integra dichas ideas dentro de su base de conocimiento, por lo que, se enriquece el modelo de la situación en el que se } \\
\text { enmarcan las ideas y, en consecuencia, mejora la comprensión de las mismas. }\end{array}$ \\
\hline \multirow[t]{3}{*}{$\begin{array}{l}\text { Habilidades para la regulación y supervisión del proceso } \\
\qquad \text { de comprensión }\end{array}$} & $\begin{array}{l}\text { Establecimiento de metas antes de la lectura } \\
\text { y utilización estrategias de pre-lectura }\end{array}$ & $\begin{array}{l}\text { El alumno define claramente los objetivos que van a guiar su proceso de comprensión y hace una lectura previa utilizando } \\
\text { estrategias como el ojeado o la exploración textual. }\end{array}$ \\
\hline & $\begin{array}{l}\text { Supervisión del grado de comprensión } \\
\text { durante lectura }\end{array}$ & $\begin{array}{l}\text { El alumno revisa constantemente el grado de comprensión alcanzado teniendo en cuenta los objetivos que guían el proceso de } \\
\text { lectura. }\end{array}$ \\
\hline & $\begin{array}{l}\text { Uso de estrategias que mejoran la precisión } \\
\text { de la metacomprensión tras la lectura }\end{array}$ & $\begin{array}{l}\text { El alumno elabora productos de tarea escritos (anotación de palabras clave, resúmenes, mapas conceptuales) que, además de } \\
\text { permitir mejorar la comprensión lectora, incrementan el grado de autoconsciencia del nivel de comprensión alcanzando. }\end{array}$ \\
\hline
\end{tabular}

Cuadro 2.3. Habilidades básicas de comprensión y expresión escrita (definición conceptual y comportamiento asociado) 
La variable dependiente general, Habilidades básicas de comprensión y expresión escrita para la construcción conocimiento; quedó definida a través de las variables que aparecen en el siguiente cuadro (las definiciones conceptuales y operativas de cada variable aparecen en el Anexo I.1. Cuadro 1).

\begin{tabular}{|c|c|c|}
\hline $\begin{array}{l}\text { Variable } \\
\text { Dependiente }\end{array}$ & Definición Conceptual & Variables Dependientes Operativas \\
\hline \multirow{4}{*}{$\begin{array}{l}\text { Habilidades básicas de } \\
\text { comprensión y } \\
\text { expresión escrita para } \\
\text { la construcción } \\
\text { conocimiento }\end{array}$} & \multirow{4}{*}{$\begin{array}{l}\text { Capacidad para usar } \\
\text { estratégicamente tanto la } \\
\text { microestructura del texto (con } \\
\text { el fin de extraer } \\
\text { macropoposiciones) como la } \\
\text { superestructura textual (con el } \\
\text { objetivo de identificar la } \\
\text { macroestructura); y Habilidad } \\
\text { para mejorar la comprensión y } \\
\text { la precisión de la } \\
\text { metacomprensión a través de la } \\
\text { expresión escrita }\end{array}$} & $\begin{array}{l}\text { VD1. Formación de la idea principal de } \\
\text { cada párrafo }\end{array}$ \\
\hline & & $\begin{array}{l}\text { VD2. Dificultades para formar la idea } \\
\text { principal de cada párrafo }\end{array}$ \\
\hline & & $\begin{array}{l}\text { VD3. Construcción de un mapa conceptual } \\
\text { donde se recoja la macroestructura del } \\
\text { texto leído }\end{array}$ \\
\hline & & $\begin{array}{l}\text { VD4. Dificultades en la construcción del } \\
\text { mapa conceptual }\end{array}$ \\
\hline
\end{tabular}

Cuadro 2.4. Variables Dependientes en el Diseño I (definición operativa)

Como podemos observar, existen dos tipos de variables, unas reflejan el grado en el que las respuestas del alumno se adecuaban a las demandas de cada tarea (VD1, VD3), y otras explicitan qué tipo de dificultades tenían los alumnos que no habían realizado adecuadamente las tareas (VD2, VD4). Mientras el primer grupo de variables estaba directamente asociado a la disposición o ausencia de habilidades básicas de comprensión y expresión escrita; el segundo grupo trataba de profundizar en las razones que llevaban a fracasar en el desempeño de la tarea a aquellos que carecían de dichas habilidades básicas.

A continuación explicaremos de forma exhaustiva la relación que se establece entre la variable dependiente general (Habilidades básicas de comprensión y expresión escrita para la construcción conocimiento) y las variables dependientes operativas.

\section{A) Relación de la Variable Dependiente General con VD1: Formación de la idea principal de cada párrafo}

Para comprender un texto, el lector, en primer lugar, debe ser capaz de seguir su progresión temática. Es decir, debe identificar (o inferir en el caso de textos con baja cohesión) el paso de información nueva a información dada a través de los dos tipos de relaciones proposicionales que se establecen a nivel microestructural (relaciones superficiales o temáticas, que indican la correferencia argumental de un texto, y relaciones profundas o estructurales, que marcan los vínculos estructurales interproposicionales). 
Teniendo esto en cuenta, el lector ha de sintetizar estratégicamente la información que va leyendo (utilizando macroestrategias de omisión-selección, generalización y construcción) con el fin de ir construyendo un hilo conductor para el texto.

Como vimos en el primer capítulo, la limitada capacidad de nuestra memoria de trabajo hace que procesemos la información mediante ciclos. El lector, para ir generando una representación mental coherente del discurso: extrae las proposiciones más importantes de cada ciclo, las guarda en el retén cognitivo y las trata de conectar con las proposiciones del siguiente ciclo. Debido a esto, la capacidad del alumnado para discernir la información supraordinada (que se encuadra dentro del hilo conductor que el autor establece) de la información subordinada (que el autor utiliza para aportar detalles que ayuden a clarificar la situación en la que se enmarca el texto) es, junto a sus conocimientos previos, un factor fundamental a la hora de sintetizar la información durante el transcurso de la lectura.

Desde esta perspectiva, la primera de las tareas de la prueba que tuvieron que realizar los alumnos (VD1. Formación de la idea principal de cada párrafo) requería la puesta en marcha de las siguientes habilidades básicas:

- Habilidad para seguir la progresión temática durante el proceso de comprensión lectora

- Habilidad para el uso de la microestructura textual con el fin de construir macroproposiciones durante el proceso de comprensión lectora

Además, cabe señalar que, en nuestra investigación, evaluamos la comprensión lectora partiendo de la expresión escrita, puesto que en el contexto universitario la lectura y la escritura suelen ser actividades interdependientes.

Estas tareas híbridas de lectura y escritura suponen la puesta en marcha de procesos de comprensión lectora y expresión escrita que se retroalimentan mutuamente. En este sentido, Smeets y Solé (2008) destacan las tareas de síntesis de la información, donde el lector/escritor:

a) utiliza las ideas extraídas durante la lectura para guiar el proceso de escritura, de manera que el texto escrito se convierte en la expresión del texto leído; y

b) reflexiona durante la escritura para tratar de expresar de modo personal las ideas que fueron extraídas durante el proceso lectura, de forma que llega a comprender el texto leído con mayor profundidad.

A consecuencia de esto, la primera tarea que realizaron los alumnos (VD1. Formación de la idea principal de cada párrafo) requería disponer, junto a las dos 
habilidades mencionadas, destrezas de expresión escrita vinculadas con la comprensión lectora:

- Habilidades de expresión escrita que permiten mejorar la comprensión lectora (destreza a la hora de expresar por escrito las macroproposiciones que se van extrayendo durante el proceso de lectura)

B) Relación de la Variable Dependiente General con VD3: Construcción de un mapa conceptual donde se recoja la macroestructura del texto leído

En segundo lugar, comprender un texto, además de lo anterior, implica establecer relaciones proposicionales a un nivel macroestructural.

Tal como comentamos en el marco teórico, la mayor parte de los textos poseen una estructura global o superestructura más o menos definida, que el lector puede utilizar de manera estratégica sobre la microestructura para extraer información globalmente importante. Para reconocer la superestructura, el lector, debe tener en cuenta las señales textuales que aparecen de forma explícita o implícita en el texto, tales como: títulos, subtítulos, organizadores previos del texto (resúmenes, esquemas), introducción y conclusiones, frases temáticas, palabras clave (cabe apuntar, por el contrario, como consecuencia, etc). Partiendo de estas señales, debe determinar qué tipo de estructura predomina en el texto, y para ello, necesita poseer ciertos conocimientos sobre tipologías textuales.

Esto no significa que todos los textos se estructuren de forma rígida dentro de una tipología determinada siguiendo unos criterios preestablecidos (Meyer, 1975, 1985; Meyer et al., 1989; Van Dijk y Kitsch, 1983); sino, más bien, que los autores de los textos utilizan estos criterios de forma flexible en función de sus preferencias e intereses de escritura. Por lo que, como señala Sánchez (1993, 1998), la disposición de nociones sobre las diferentes tipologías textuales permitirá al lector no sólo la posibilidad de extraer la macroestructura de textos con un alto grado de cohesión, sino también la de reorganizar aquellos textos que por una u otra razón no estén organizados de forma clara.

En relación ello, la segunda tarea de la prueba (VD3. Construcción de un mapa conceptual donde se recoja la macroestructura del texto leído) requería dos habilidades básicas comprensión lectora:

- Habilidad para identificar la superestructura del texto durante el proceso de comprensión lectora

- Habilidad para el uso de la superestructura textual con el fin de extraer la macroestructura 
Una vez extraída la macroestructura textual, el alumno tenía que reflejarla por escrito a través de la elaboración de un mapa conceptual. En este sentido, McNamara et al. (2007), Novak (1991) y Romance y Vitale (2001) afirman que la construcción del mapa ayuda al lector organizar de modo no lineal las ideas extraídas del texto lineal, distribuyendo viso-espacialmente (de forma jerárquica y paralela) las relaciones que se dan entre las ideas principales de dicho texto. Ello supone: a) la liberación de recursos cognitivos de la memoria operativa, para procesar en profundidad la macroestructura textual; b) un proceso de reflexión por parte del lector, que mejora significativamente la comprensión lectora; y c) un punto de partida para realizar tareas de expresión escrita.

Esto hace que aunque un mapa conceptual no sea un texto escrito propiamente dicho (ya que no es lineal), podamos considerarlo como un primer paso para escribirlo (define con claridad la macroestructura del texto que se va a escribir). En este sentido, la segunda tarea (VD3. Construcción de un mapa conceptual donde se recoja la macroestructura del texto leído) requería disponer de habilidades de expresión escrita vinculadas con la comprensión lectora:

- Habilidades de expresión escrita que mejoran la comprensión lectora (capacidad para plasmar por escrito la macroestructura del texto leído)

C) Relación de Variable Dependiente General con VD1: Formación de la idea principal de cada párrafo y con VD3: Construcción de un mapa conceptual donde se recoja la macroestructura del texto leído

En tercer lugar, la comprensión lectora es un proceso metacognitivo en el que el lector se autorregula constantemente a la luz de los objetivos de lectura que establece cuando define el modelo de tarea (es decir, cuando crea una representación mental de la tarea que debe realizar). Un lector maduro suele crear productos de tarea escritos que, al facilitar la detección de dificultades y la posterior puesta en marcha de acciones correctivas (metacomprensión), mejoran su grado de autoconsciencia del nivel de comprensión que ha alcanzado. En este sentido, tanto la primera (VD1: Formación de la macroproposición de cada párrafo) como la segunda tarea (VD3: Construcción de un mapa conceptual donde se recoja la macroestructura del texto leído) requerían:

\section{- Habilidades para la regulación y supervisión del proceso de comprensión}


D) Relación de Variable Dependiente General con VD2: Dificultades para formar la idea principal de cada párrafo y con VD4: Dificultades en la construcción del mapa conceptual

Conviene tener en cuenta que, al evaluar la comprensión lectora de los alumnos partiendo de la expresión escrita, las dificultades de comprensión de los alumnos se hacían visibles a través de la forma en la que expresaban las ideas.

Como se verá en el siguiente apartado, cuando evaluamos la variable VD2. Dificultades para formar la idea principal de cada párrafo, en ocasiones aparecían dificultades de comprensión pero no dificultades expresión, sea porque el alumno se centraba en información secundaria (lo que indicaba que seguía la estrategia de lectura no estructural que conocemos como decir algo del texto), porque extraía una idea demasiado general (lo que indicaba que no era capaz de concretar la idea principal/temática del párrafo), o porque malinterpretaba la información del párrafo (lo que indicaba que realizaba inferencias inadecuadas basadas en concepciones erróneas, conocidas como off-the-subject). Pero en otras ocasiones, el alumno tenía dificultades de expresión que reflejaban sus problemas de comprensión:

a) Dificultades para mantener la correferencia argumental, como por ejemplo, realizar cambios en la estructura gramatical de frases del texto original que supongan un obstáculo para la progresión temática. Lo que puede asociarse al uso de técnicas de síntesis como la paráfrasis cercana a la copia.

b) Dificultades relacionadas con la estructuración de la idea, que le llevan a no expresar de forma integrada las frases extraídas. Lo que se puede relacionar con el uso de estrategias de síntesis como la combinación enlazada.

c) Dificultades relacionadas con el modelo de la situación en que se enmarca la idea, como por ejemplo, expresar las ideas extraídas de modo incoherente y/o contradictorio. Lo que puede asociarse al uso de técnicas de síntesis como la paráfrasis cercana a la copia y/o la combinación enlazada.

Por otra parte, cuando medimos la variable VD4. Dificultades en la construcción del mapa conceptual, los alumnos, unas veces construían un mapa conceptual que no se centraba en las ideas importantes del texto (no eran capaces de detectar el nivel de importancia de las ideas del texto con respecto al tema del mismo); y otras veces tenían dificultades para elaborar el mapa conceptual. Entre éstas últimas podemos señalar: a) dificultades para clarificar significado global del mapa (el alumno tiene problemas de comprensión que le dificultan construir un mapa conceptual globalmente coherente); y b) dificultades para organizar jerárquicamente las ideas que aparecen en el mapa conceptual (el alumno no sabe elaborar un mapa conceptual, o bien tiene dificultades de comprensión que le dificultan construir un mapa conceptual que sea globalmente coherente). 


\subsubsection{Variables Independientes en el Diseño I para la evaluación de las habilidades básicas de comprensión y expresión escrita para la construcción de conocimiento}

Entendemos por variable independiente aquella que es sometida a variación para comprobar su efecto sobre la variable dependiente. Obsérvese que hablamos de variación en términos generales y no únicamente de la manipulación de variables propia de los métodos experimentales. Esto es así, porque, como señalan Buendía, Colás y Hernández Pina (1998), la investigación educativa se suele realizar en contextos ecológicos donde no siempre es necesario manipular la variable independiente, ya que pueden existir diferentes niveles de variación de dicha variable previos al estudio. En estos casos, el investigador se limitará a seleccionar aquellos niveles de variación de la variable independiente según su interés.

En este primer diseño, seleccionamos dos niveles de la variable independiente Momento Formativo (inicial y final):

- Alumnos pertenecientes a $1^{\circ}$ curso en Educación Primaria que acababan de acceder a la Universidad de Salamanca, y;

- Alumnos pertenecientes a $4^{\circ}$ de Psicopedagogía que habían finalizado con éxito alguna de las titulaciones de Maestro de la Universidad de Salamanca.

Con el objetivo de comprobar si haber finalizado la formación universitaria causaba una diferencia significativa positiva en la variable dependiente (habilidades básicas de comprensión y expresión escrita) con respecto a aquellos que inician la carrera; controlamos posibles variables extrañas/control del diseño (recordemos que, por motivos económicos, utilizamos un modelo transversal y no longitudinal).

\subsubsection{Variables Control en el Diseño I para la evaluación de las habilidades básicas de comprensión y expresión escrita para la construcción de conocimiento}

Entendemos por variables de control aquellas variables que pueden afectar a la variable dependiente y no forman parte del diseño experimental. Con el fin de minimizar sus posibles efectos sobre la variable dependiente debemos controlarlas. En nuestra investigación establecimos un conjunto de mediciones en torno a las variables que se explicitan en el cuadro 2.5 (las definiciones conceptuales y operativas de cada variable pueden verse en el Anexo I.1. Cuadro 2). 


\begin{tabular}{|c|c|}
\hline Variables Control & Variables Control Operativas \\
\hline \multirow[t]{2}{*}{ VC1. Variables de Identificación } & VC1.1. Género \\
\hline & VC1.2. Edad \\
\hline \multirow[t]{6}{*}{ VC2. Variables Pedagógicas } & VC2.1. Centro de procedencia \\
\hline & VC2.2. Modalidad de bachillerato (Primaria) \\
\hline & VC2.3. Calificación de entrada a la universidad \\
\hline & VC2.4. Primer ciclo cursado (Psicopedagogía) \\
\hline & $\begin{array}{l}\text { VC2.5. Calificación obtenida en el Primer ciclo cursado } \\
\text { (Psicopedagogía) }\end{array}$ \\
\hline & VC2.6. Matrícula en otra carrera universitaria \\
\hline \multirow[t]{6}{*}{ VC3. Hábitos lectores } & VC3.1. Idioma de lectura \\
\hline & VC3.2. Causa lectura último libro \\
\hline & VC3.3. Materia del último libro leído \\
\hline & VC3.4. Cantidad de libro leídos \\
\hline & VC3.5. Razones para no leer con mayor frecuencia \\
\hline & VC3.6. Lectura en soporte digital \\
\hline
\end{tabular}

Cuadro 2.5. Variables de Control en el Diseño I

\subsubsection{Variables en el Diseño II para la evaluación del efecto del formato textual sobre las estrategias de comprensión y expresión escrita}

Para este diseño Cuasi-experimental establecimos, al igual que en el diseño anterior, tres tipos de variables: Dependientes, Independientes y de Control.

\subsubsection{Variables Dependientes en el Diseño II para la evaluación del efecto del formato textual sobre las estrategias de comprensión y expresión escrita}

En este segundo diseño, nos vamos a centrar en una variable, a nuestro juicio muy importante, que nos permitirá analizar el grado de idoneidad de las estrategias y procedimientos utilizados por los alumnos, a la hora de realizar un resumen escrito a partir de un texto que se presenta en diferentes formatos (bien texto o bien hipertexto). Se trata de la variable Habilidades específicas de comprensión y expresión escrita para la sintesis de información. 


\begin{tabular}{|c|c|c|}
\hline Variable Dependiente & Definición conceptual & $\begin{array}{c}\text { Variables Dependientes } \\
\text { Operativas }\end{array}$ \\
\hline \multirow[t]{2}{*}{$\begin{array}{l}\text { Habilidades específicas de } \\
\text { comprensión y expresión } \\
\text { escrita para la síntesis de } \\
\text { información }\end{array}$} & \multirow{2}{*}{$\begin{array}{l}\text { Capacidad del alumnado para usar } \\
\text { habilidades de comprensión y expresión } \\
\text { escrita con el fin de realizar el resumen de } \\
\text { un texto/hipertexto; y Grado de } \\
\text { consciencia que tiene el alumnado de los } \\
\text { procedimientos utilizados a la hora de } \\
\text { realizar dicha tarea }\end{array}$} & $\begin{array}{l}\mathrm{VDTH}_{1} \text {. Uso de habilidades } \\
\text { de comprensión y expresión } \\
\text { escrita para realizar la tarea }\end{array}$ \\
\hline & & $\begin{array}{l}\text { VDTH }_{2} \text {. Procedimientos que } \\
\text { el alumno considera haber } \\
\text { seguido para realizar la tarea }\end{array}$ \\
\hline
\end{tabular}

Cuadro 2.6. Variables Dependientes en el Diseño II

*VDTH: Variable dependiente texto/hipertexto

Como sugieren Hernández y Quintero (2001), “resumir” es una actividad híbrida de lectura y escritura:

..resumir será tanto una actividad de lectura, al requerir que previamente se haya logrado una buena comprensión del pasaje, mediante la identificación de la información importante, como de escritura, por cuanto que los alumnos deben tomar decisiones acerca de qué incluir $u$ omitir y cómo expresar mejor esa información, sin sacrificar la brevedad que debe caracterizar sus resúmenes. En definitiva, supone un ejercicio de reflexión acerca de cómo escribirlos en función de los propósitos concretos de lectura que se hayan establecido. (p.145)

Por tanto, para realizar un resumen, el lector/escritor, además de ser capaz de identificar la macroestructura del texto que lee, debe saber expresar las ideas extraídas de forma breve y personal a través de un texto escrito.

Según Hernández y Quintero (2001, 2002), McNamara et al. (2007) y Smeets y Solé (2008), esto supone un proceso de reflexión en el que el escritor parte de aquello quiere transmitir (en este caso, la macroestructura del texto que lee) para organizar la redacción a dos niveles: a) un nivel local o microestructural, que requiere asegurar la cohesión local y global entre las distintas proposiciones; y b) un nivel global o superestructural, que exige introducir señales textuales que indiquen la superestructura empleada. De esta manera, resumir, por una parte, permite mejorar la comprensión lectora a través de la expresión escrita; y por otra, facilita el aprendizaje progresivo de habilidades para la redacción de textos informacionales.

Tomando esto en consideración, para revisar si el alumno disponía de Habilidades específicas de comprensión y expresión escrita para la síntesis de información, consideramos apropiado centrar nuestra atención principalmente en 2 variables operativas (la definición conceptual y operativa de las sub-variables que 
utilizamos para evaluar estas variables operativas puede consultarse en el Anexo II.1. Cuadro 1):

a) $\mathrm{VDTH}_{1}$. Uso de habilidades de comprensión y expresión escrita para realizar la tarea; $y$

b) $\mathrm{VDTH}_{2}$. Procedimientos que el alumno considera haber seguido para realizar la tarea.

La variable operativa $\mathrm{VDTH}_{1}$ (Uso de habilidades de comprensión y expresión escrita para realizar la tarea) se analizó partiendo de los siguientes aspectos:

- Información subrayada y la toma de notas en el texto: durante la lectura de un texto, el lector puede utilizar técnicas como el subrayado y la toma de notas (Gil, Vidal-Abarca y Martínez, 2008; McNamara et al., 2007) para destacar aquella información que considera importante, y de esta manera, reservar recursos cognitivos (concretamente aquellos que hubiera asignado a la recuperación de la información textualmente importante) para procesar globalmente la información seleccionada. Teniendo esto en cuenta, analizamos la información subrayada por el alumnado que leyó el texto en formato impreso, y en su caso, las notas que escribía en dicho texto; con el objetivo de vislumbrar su capacidad para gestionar recursos cognitivos a la hora de: localizar dónde se encuentra la información importante (a través del subrayado y la toma de notas) y sintetizar información y/o relacionar información de diferentes partes del texto (a través de la toma de notas).

- Borrador del resumen: situando el trabajo de Bereiter y Scarmadalia (1992) dentro del modelo MD-TRACE de Rouet y Britt (2011), el lector maduro, una vez leído el texto, redacta productos de tarea intermedios (borradores) antes de generar el producto de tarea definitivo. Estos borradores le permiten, por una parte, liberar recursos cognitivos para procesar en profundidad las ideas textualmente importantes; y por otra, mejorar la precisión de la metacomprensión (ya que favorecen la detección de dificultades en la compresión y facilitan la puesta en marcha de acciones reparadoras). Tomando esto como referencia, observamos si el alumnado realizaba borrador/es antes de redactar el resumen o si generaba el producto de tarea definitivo directamente del texto; y, en el caso de que sí lo/s realizara/n, comprobamos si el resumen final implicaba o no una transformación sustancial del borrador/es, es decir, si había habido o no un proceso reflexivo/correctivo que diera como resultado el producto de tarea final.

- Resumen del texto/hipertexto: el resumen nos permitió analizar la capacidad del alumnado para construir un texto escrito, cuya organización microestructural y 
superestructural recogiera, de forma breve y personal, la macroestructura del texto/ hipertexto leído. Teniendo esto en cuenta, analizamos las dificultades que mostraban los alumnos a la hora de realizar la tarea, y las agrupamos a través de tres subcategorías: a) el alumno copia literalmente grandes trazos de información que utiliza en el texto que escribe (lo cual, puede vincularse al uso de la estrategia copy-delete); b) el alumno construye un texto cuyo significado global no está claro (las dificultades de comprensión del lector suponen la puesta en marcha de estrategias de resumen ligadas al código de superficie del texto, que suelen venir acompañadas de dificultades de expresión escrita); y c) el alumno es capaz de organizar el texto que escribe en torno a una estructura global, pero malinterpreta información (estrategia off-the-subject), no la sintetiza suficientemente (aparece gran cantidad de información secundaria) y/o no la expresa de modo personal (mantiene el orden secuencial en el que aparecen las ideas en el texto original, limitándose a realizar paráfrasis cercanas a la copia y/o combinaciones enlazadas de la información del mismo). De esta manera, comprobamos si el alumnado tenía problemas para construir un texto breve y personal, para organizar el texto escrito microestructural y superestructuralmente y para identificar la macroestructura del texto leído.

Además de esto, a través del resumen, analizamos tanto la capacidad del alumnado para identificar los vínculos existentes entre la información textual secuenciada de forma no lineal (el pie de página que aparece en el texto impreso, y la información hipervinculada que aparece en el hipertexto), como su destreza para integrar dicha información de forma coherente a través del resumen escrito.

La variable operativa $\mathrm{VDTH}_{2}$ (Procedimientos que el alumno considera haber seguido para realizar la tarea) se analizó a través de los comentarios realizados por el alumnado en una actividad metacognitiva cumplimentada una vez finalizado el resumen. Observando los procedimientos que los alumnos decían utilizar conscientemente, pudimos establecer el grado de idoneidad de los procesos cognitivos que pusieron en marcha.

La revisión de los estudios de autores como Bereiter y Scarmadalia (1992), Flower (1990, 1993), Flower y Hayes (1980, 1981), Hernández y Quintero (2001, 2002), Quintero (1995, 1998), Salmerón y Gutiérrez-Brajos (2012) y Sánchez (1993,1998), nos permiten sostener que los procesos cognitivos implicados en la lectura y la escritura son similares, ya que ambas actividades implican procesos de: Planificación, Construcción progresiva de significado (lectura) o Elaboración progresiva significado (escritura), y Revisión. Esa similitud, favorece la fusión/solapamiento de dichos procesos cuando el lector se enfrenta a tareas de lectura orientadas a la escritura. En este sentido, Rouet y Britt (2011) destacan cinco procesos en su modelo MD-TRACE:

- Crear un modelo de tarea (incluyendo en él un conjunto de objetivos de lectura y plan de acción para cumplirlos); 
- Evaluar la necesidad informativa (el lector compara sus conocimientos sobre el tema con las demandas de la tarea);

- Procesar el texto/s (el lector evalúa la relevancia del texto/s y fragmento/s textual/es para la tarea que debe realizar, procesa en profundidad el contenido textual que considera relevante, y crea una representación mental del texto/s);

- Crear un producto de tarea (el lector, teniendo en cuenta el modelo de tarea creado y la información procesada en el documento/s leído/s, construye una respuesta para dicha tarea); y

- Evaluar el producto de tarea (si el resultado obtenido responde a lo establecido en el modelo de tarea, el producto se da por finalizado; si no satisface sus demandas, puede ser necesario revisar alguno de los procesos anteriores).

En el resumen, una forma básica de lectura orientada a tareas, el lector, partiendo del modelo de tarea creado, genera una representación mental del documento leído (para ello se apoya en técnicas como el subrayado o la toma de notas), que trata de expresar a través de sucesivos productos escritos (expresión de ideas claves, mapas conceptuales o borradores de resumen) que le permiten ir reflexionando en torno al nivel de comprensión alcanzado (mejorando la precisión de la metacomprensión) hasta conseguir un producto final que cumpla las demandas de la tarea (un resumen que refleje la macroestructura del texto leído).

En otro orden de cosas, cabe decir que, además de la variable dependiente Habilidades específicas de comprensión y expresión escrita para la síntesis de información, nos pareció interesante tener en cuenta otro tipo de variables, secundarias en nuestra investigación, que nos permitirían conocer: a) qué tipo de dificultades habían encontrado los alumnos a la hora de realizar la tarea; b) el grado en el que los alumnos utilizaron el glosario de términos como instrumento de ayuda para mejorar la comprensión lectora del texto; y c) qué opinaba el alumnado acerca de la importancia de la tarea realizada. (Se puede encontrar una definición operativa de estas variables en el Anexo II.1. Cuadros 2, 3 y 4). 


\begin{tabular}{|c|c|c|}
\hline $\begin{array}{c}\text { Variables Dependientes } \\
\text { Secundarias }\end{array}$ & Definición conceptual & $\begin{array}{c}\text { Variables Dependientes } \\
\text { Secundarias Operativas }\end{array}$ \\
\hline $\begin{array}{c}\text { VS1.Dificultades encontradas por el } \\
\text { alumnado para realizar la tarea }\end{array}$ & \multicolumn{1}{|c|}{ Ídem } & $\begin{array}{l}\text { VS1.1. Dificultades encontradas } \\
\text { por el alumnado que realizó la } \\
\text { tarea a partir de un texto }\end{array}$ \\
\cline { 2 - 4 } & $\begin{array}{l}\text { VS1.2. Dificultades encontradas } \\
\text { por el alumnado que hizo la } \\
\text { tarea a partir de hipertexto }\end{array}$ \\
\hline $\begin{array}{c}\text { VS2. Utilización de las ayudas a la } \\
\text { comprensión lectora (Glosario) }\end{array}$ & $\begin{array}{l}\text { Grado en el que el alumno utiliza } \\
\text { el glosario de términos para } \\
\text { mejorar la comprensión del } \\
\text { texto/hipertexto que lee }\end{array}$ \\
\hline VS3.Opinión del alumnado & $\begin{array}{l}\text { Opinión que tiene el alumnado } \\
\text { sobre el grado de importancia de } \\
\text { la tarea realizada }\end{array}$ \\
\hline
\end{tabular}

Cuadro 2.7. Variables Secundarias en el Diseño II

2.4.2.2. Variables Independientes en el Diseño II para la evaluación del efecto del formato textual sobre las estrategias de comprensión y expresión escrita

Para este segundo diseño establecimos dos variables independientes:

a) VI.1. Momento formativo. Medida a través de dos grupos: Educación Primaria y Psicopedagogía.

b) VI.2. Formato Textual. Medida a través de 2 formatos:

- Formato Impreso, que implicaba una forma lineal de lectura que permitía al lector acceder de forma progresiva y ordenada al contenido semántico que el autor pretendía transmitir; y

- Formato Hipertextual, que suponía una forma no lineal de lectura (lectura intertextual), en el sentido de que el lector debía saltar del texto principal a los textos hipervinculados (y viceversa).

Con respecto al formato textual, la investigación sobre comprensión lectora muestra diversas perspectivas.

En general, si comparamos estudios de lectura hipertextual, como los de Folz (1996), Juvina y Van Oostendorp (2008), Potelle y Rouet (2003), Madrid et al. (2009), Madrid y Cañas (2009), Salmerón et al. (2005), Salmerón et al. (2006 a, b) y Voros et al. (2011); con estudios sobre lectura texto impreso, como los de Kintsch (1988, 1998), 
McNamara y Kintsch (1996), O’Reilly y McNamara (2007) y Ozuru, et. al (2009); el proceso de comprensión lectora más que en relación al tipo de formato textual, parece variar en función de factores que estarían interviniendo en ambos formatos, como el conocimiento previo, las habilidades lectoras, la cohesión textual (determinada por el orden de lectura en hipertexto) y el tipo de tarea. En este sentido, un estudiante con bajo conocimiento previo sobre un tema puede comprender mejor un hipertexto bien estructurado (mediante organizadores previos), que le permita seguir un orden de lectura coherente; que un texto mal estructurado con muchos vacios semánticos.

Sin embargo, si tenemos en cuenta específicamente la carga cognitiva, estudios como los de Madrid et al. (2009), Madrid y Cañas (2009), Salmerón et al. (2005) y Salmerón et al. (2006 a, b) parecen indicar que la lectura hipertextual incrementa la carga mental con respecto a la lectura impreso, al exigir la elección de los nodos de lectura, y la selección del orden en el que se leen. De hecho, Salmerón (2006) afirma que la propia lectura intertextual (saltar de un nodo a otro) favorece el procesamiento activo de la información, y por tanto, supone un gasto de recursos cognitivos, que, como recogimos en el marco teórico, mejora o empeora la comprensión dependiendo de los factores que hemos mencionado en el párrafo anterior.

Tomando todo ello en consideración, uno de nuestros objetivos es comprobar la influencia que tiene el tipo de texto (impreso e hipervinculado) en la utilización de las estrategias de comprensión y expresión escrita. Concretamente, nos preguntamos si existen diferencias significativas (n.s.=.05) en la comprensión de un documento presentado en formato impreso y en formato hipertextual, cuando el orden de lectura de éste último viene predeterminado desde el diseño (reduciendo la toma de decisiones del lector a la lectura intertextual de nodos).

\subsubsection{Variables Control en el Diseño II para la evaluación del efecto del formato textual sobre las estrategias de comprensión y expresión escrita}

(Las variables de control son las mismas que las utilizadas para el Diseño I) 


\subsection{DESCRIPCIÓN DE LOS INSTRUMENTOS UTILIZADOS}

Utilizamos diferentes instrumentos de recogida de información para medir cada una de las variables dentro de los diseños de nuestro estudio.

\subsubsection{Instrumentos de recogida de información en el Diseño I para la evaluación de las habilidades básicas de comprensión y expresión escrita para la construcción de conocimiento}

La recogida de información para el Diseño I se realizó a través de dos instrumentos, que integramos dentro de una única prueba bajo el nombre de Evaluación de habilidades básicas para la comprensión y expresión escrita:

- un cuestionario identificativo de contexto para el estudiante; y

- una prueba de habilidades básicas de comprensión y expresión escrita (PHBCE).

\subsubsection{Cuestionario identificativo de contexto}

Elaboramos un instrumento en forma de encuesta de lápiz y papel, el cual se componía de dos partes claramente diferenciadas, que perseguían diferentes objetivos: recogida de información sobre datos demográficos, y recogida de información sobre hábitos lectores.

En la primera parte, información sobre datos demográficos, se recogió tanto información identificativa de los sujetos como datos académicos de la muestra. No obstante, aunque gran parte de los ítems aparecían en todos los cuestionarios, existían algunas cuestiones que estaban específicamente dirigidas al alumnado de un curso académico concreto (ver versión cuestionario para Educación Primaria en Anexo I.2; y versión cuestionario para Psicopedagogía en el Anexo I.3). De esta manera, mientras que los ítems vinculados a aspectos identificativos (nombre y apellidos, sexo, edad y correo electrónico) y algunos de los vinculados a aspectos académicos (centro de procedencia, calificación de entrada a la universidad y matrícula en otra carrera universitaria) aparecían en todos los cuestionarios; el resto de los ítems, vinculados a la experiencia académica, eran específicos para cada curso (a los alumnos de Educación Primaria se les solicitó la modalidad de bachillerato que habían cursado, mientras que al alumnado de Psicopedagogía se le requirió la titulación con la que accedió a segundo ciclo, así como la calificación obtenida en dicha carrera).

La segunda parte estaba compuesta por un conjunto de cuestiones que tenían como fin recoger información en torno a los hábitos lectores del alumnado. Gran parte 
de estos ítems fueron extraídos de los indicadores nacionales utilizados por el Ministerio de Cultura (2011) para establecer los hábitos lectores de la población infantil y juvenil. Concretamente seleccionamos aquellas cuestiones relacionadas con: el idioma habitual de lectura, motivos por los que leyó el último libro, materia del último libro leído, el número de libros leídos al año y las razones que llevaban al alumno a no leer con mayor frecuencia. Además, debido a que nuestros intereses de investigación estaban también vinculados a la lectura en soporte digital, construimos una cuestión que nos permitía recoger información en torno a la familiaridad que tenía el alumnado en relación a este formato de lectura.

De forma más general, cabe señalar que el cuestionario estaba compuesto por ítems de respuesta cerrada e ítems de respuesta abierta:

- Respuesta abierta: ítems cuya respuesta no estaba sujeta a la selección de una o varias opciones preestablecidas. Ya sea porque es difícil de categorizar (nombre y apellidos, correo electrónico) o porque interesa conocer la respuesta específica del alumno (edad y centro de procedencia).

- Respuesta cerrada limitada a la elección de una de las opciones disponibles: la formulación de algunos enunciados o la naturaleza de la realidad que se trataba en los mismos reducían las opciones de respuesta a unas pocas posibilidades, por lo que el alumno debía elegir una entre de dichas opciones (por ejemplo: el género; si ha estado matriculado en otra carrera, etc.)

- Respuesta cerrada con opción de respuesta abierta: algunos ítems posibilitaban un amplio abanico de posibles respuestas, que tratamos de enmarcar dentro de unas pocas categorías que se presentaron como opciones de respuesta. Entre esas opciones de respuesta, aparecía la categoría "Otros/ Otras razones", que venía acompañada por una opción de respuesta libre que permitía al alumnado especificar su respuesta en el caso de elegir esta categoría. Un ejemplo de esto son los ítems sobre: el idioma de lectura, la materia del último libro leído o las razones para no leer con mayor frecuencia.

- Respuesta cerrada que admitía la selección de más de una de las opciones disponibles: ítems que permitían al alumno seleccionar más de una de las opciones de respuestas disponibles si así lo estimaba oportuno. Un ejemplo de esto es el ítem "motivo por el que leyó su último libro". 


\subsubsection{Prueba de Habilidades Básicas de Comprensión y Expresión Escrita (PHBC-E)}

Con el objetivo de comprobar si los estudiantes universitarios poseían habilidades básicas de lectura, diseñamos una prueba de comprensión en la que los alumnos debían leer un texto (medio de evaluación) para realizar una serie de tareas, que exigían poner en práctica, de forma aislada o conjunta, dichas destrezas (la prueba se puede revisar en el Anexo I.2 o en el Anexo I.3). La evaluación de las tareas implicó la construcción de un instrumento de rúbrica.

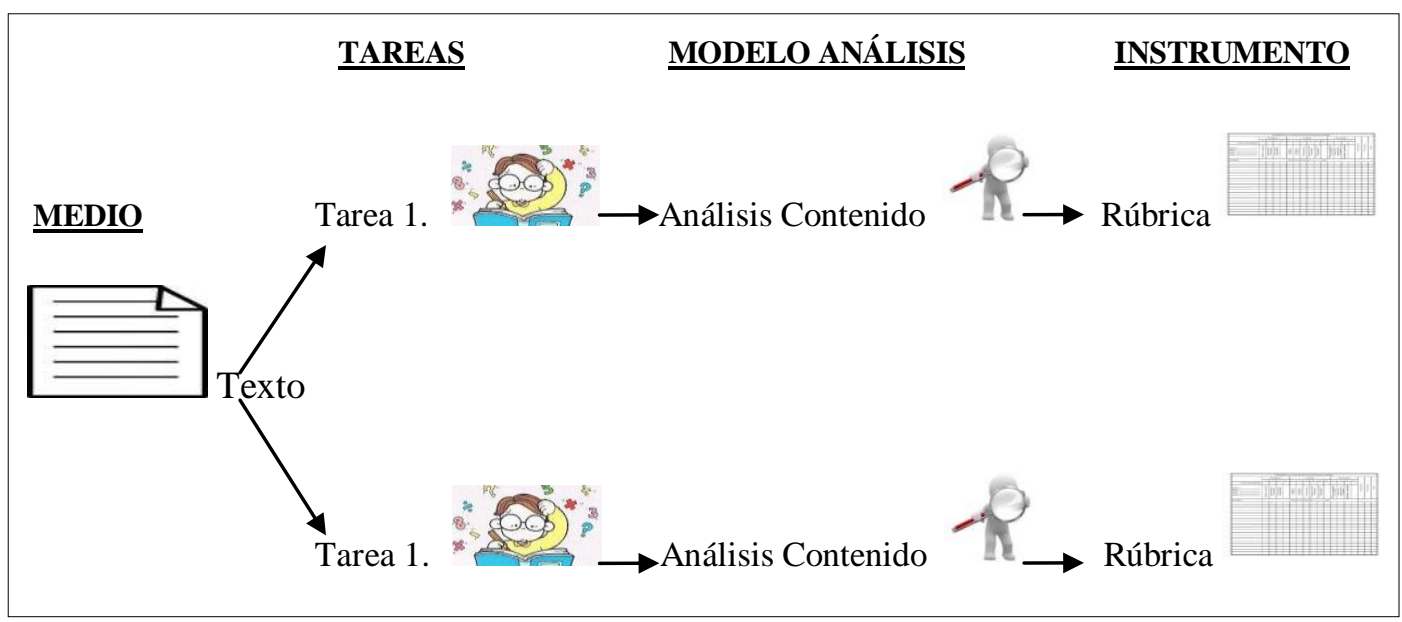

Cuadro 2.8. Esquema de evaluación de PHBC-E

Para la construcción de la prueba, debíamos tener en cuenta una serie de factores contextuales que podían incidir en la validez interna de la misma:

- Por un lado, la muestra estaba compuesta por alumnado que se encontraban en cursos universitarios diferentes.

- Y por otro, disponíamos de un tiempo limitado (1 hora) para la realización de un conjunto de tareas de carácter reflexivo.

Esto implicaba que debíamos buscar un texto lo suficientemente breve como para que el alumnado pudiera realizar todas las tareas en el tiempo establecido; y lo bastante divulgativo como para que sus conceptos fuesen comprensibles, tanto para los alumnos que accedieron a la universidad como para los que finalizaron sus estudios universitarios.

En este sentido, adaptamos un texto divulgativo, llamado "Marco Polo. En el corazón del Tíbet “(El País Dominical, 1994), que estaba compuesto por un total de 2112 palabras. Para ello, identificamos el hilo conductor del texto, estableciendo así sus dos ideas temáticas principales: por un lado Marco Polo y sus viajes por Asia, y por otro, el pasado y presente de la situación política del Tíbet. Hecho esto, omitimos la información 
relacionada con la primera idea temática y nos centramos en la relacionada con la segunda, eliminando aquellos párrafos que contenían información trivial o redundante, y manteniendo aquellos otros que permitían mantener la esencia del texto original. Finalmente, el texto quedó reducido a 490 palabras:

\begin{tabular}{|c|c|}
\hline Párrafo & Texto \\
\hline Párrafo 1 & $\begin{array}{l}\text { En el centro de Asia se levanta una plataforma árida y solitaria. Una meseta } \\
\text { montañosa escondida tras la barrera del Himalaya, el techo del mundo. El Tíbet. Un } \\
\text { país legendario que, anclado en la fe budista, permanece aislado por una naturaleza } \\
\text { gloriosa y desesperanzado por la invasión china que quebró su paz. Menos } \\
\text { conocido que la luna, el Tíbet se empeña en rozar las estrellas: la altitud media está } \\
\text { en } 5000 \text { metros. }\end{array}$ \\
\hline Párrafo 2 & $\begin{array}{l}\text { El Tíbet es sinónimo de supervivencia. Desde el principio de los tiempos todos han } \\
\text { querido acabar con su mágico aislamiento: misioneros, exploradores, místicos, } \\
\text { aventureros, comerciantes, guerreros... Jamás lo consiguieron. Sólo el estruendo de } \\
\text { los tanques y los cañones que llegaron de Pekín hicieron templar el silencio de sus } \\
\text { montañas. }\end{array}$ \\
\hline Párrafo 3 & $\begin{array}{l}\text { En 1949, el joven líder budista, el Dalai Lama, envió un mensaje urgente a los } \\
\text { gobiernos de Estados Unidos, la India y el Reino Unido y a la sede de las Naciones } \\
\text { Unidas. Era una desesperada petición de ayuda. El ejército de Liberación Popular } \\
\text { había cruzado sus fronteras, y la China comunista estaba invadiendo el país. } \\
\text { Entonces nadie acudió en ayuda del Tíbet. }\end{array}$ \\
\hline Párrafo4 & $\begin{array}{l}\text { El budismo tibetano se basa en la liberación del alma por medio de la compasión y } \\
\text { la práctica espiritual. El maoísmo, por el contrario, sostiene que la única manera de } \\
\text { alcanzar la liberación es mediante la batalla, lucha y revolución. Era difícil llegar a } \\
\text { un entendimiento, y fueron los carros blindados los que tuvieron la última palabra. }\end{array}$ \\
\hline Párrafo 5 & $\begin{array}{l}\text { Hoy, Lhasa, la capital del Tíbet, cuenta con alrededor de doscientos mil habitantes, } \\
\text { de los cuales más de la mitad son inmigrantes chinos. Sus calles recuerdan las de } \\
\text { cualquier capital china de provincias. Las tiendas venden productos chinos. Las } \\
\text { bicicletas son chinas. Los bares de los hoteles sirven cerveza china... }\end{array}$ \\
\hline Párrafo 6 & $\begin{array}{l}\text { Sólo la silueta del gran palacio de Potala, residencia del Dalai Lama durante cinco } \\
\text { siglos y centro del poder civil y religioso, se atreve a recordar que estamos en el } \\
\text { corazón del Tíbet. Potala, como el corazón de los habitantes de Lasha, está } \\
\text { dividida. El Palacio Blanco y el Palacio Rojo. La sumisión o el exilio. La paz } \\
\text { budista o la rebelión armada... }\end{array}$ \\
\hline Párrafo 7 & $\begin{array}{l}\text { Uno de esos exiliados afirma: "Los últimos enfrentamientos entre el Ejército y los } \\
\text { rebeldes en la ciudad se produjeron hace ya muchos años, y desde entonces los } \\
\text { invasores no han respetado los derechos humanos. Nos han encarcelado, torturado, } \\
\text { nos han quitado las tierras, han destruido nuestros templos, nos han robado la } \\
\text { paz.... No quieren que conservemos ni siquiera la dignidad" }\end{array}$ \\
\hline Párrafo 8 & $\begin{array}{l}\text { Algunos budistas tradicionales han arrinconado la compasión y quieren olvidar la } \\
\text { tradición de no violencia. Sueñan con empuñar un arma. Pero son muchos los que } \\
\text { piensan que en la situación actual un movimiento militar rebelde sería el suicidio. }\end{array}$ \\
\hline Párrafo 9 & $\begin{array}{l}\text { La sal, la turquesa, el oro, los libros sagrados y las armas. Las cinco riquezas del } \\
\text { Tíbet. "Hoy nuestros tesoros son la fortaleza y la confianza", asegura el Dalai } \\
\text { Lama. }\end{array}$ \\
\hline
\end{tabular}

Cuadro 2.9. Texto adaptado 
El texto resultante fue analizado en función del objetivo que perseguía cada una de las tareas que el alumno debía realizar.

\begin{tabular}{|c|l|l|}
\hline Tarea & \multicolumn{1}{|c|}{ Objetivo } & \multicolumn{1}{|c|}{ Tipo de análisis realizado } \\
\hline Tarea 1 & $\begin{array}{l}\text { Identificar la idea principal de cada } \\
\text { párrafo }\end{array}$ & $\begin{array}{l}\text { Determinamos el nivel de dificultad de } \\
\text { cada párrafo analizando tanto el grado } \\
\text { de cohesión de cada uno de ellos, como } \\
\text { el tipo de macroestrategia que se debía } \\
\text { utilizar para extraer cada idea. }\end{array}$ \\
\hline Tarea 2 & $\begin{array}{l}\text { Construcción de un mapa } \\
\text { conceptual que recoja las relaciones } \\
\text { que se dan entre las ideas más } \\
\text { importantes del texto }\end{array}$ & $\begin{array}{l}\text { Analizamos el texto considerándolo } \\
\text { como un todo, y partiendo de esto, } \\
\text { identificamos la estructura textual que } \\
\text { enmarca las relaciones que se dan entre } \\
\text { las fundamentales del texto. }\end{array}$ \\
\hline
\end{tabular}

Cuadro 2.10. Tareas y objetivos, y tipo de análisis realizado

Junto a los análisis mencionados, establecimos un conjunto de rúbricas de evaluación para valorar el grado de idoneidad de las respuestas de los alumnos en cada una de las tareas anteriores.

Describimos el análisis del contenido textual y las rúbricas de evaluación que establecimos para cada tarea:

\section{A) Tarea 1. Identificar la idea principal de cada párrafo}

\section{a.1. Análisis del contenido textual por párrafos}

Establecimos la progresión temática de cada párrafo realizando dos tipos de análisis de contenido:

- Análisis de las relaciones superficiales o temáticas que se establecían entre las proposiciones del párrafo, cuya finalidad era comprobar el grado de correferencia argumental explícita e implícita que se daban entre las proposiciones. Para realizar este tipo de análisis, consideramos oportuno: a) extraer proposiciones atómicas en mayor medida que proposiciones complejas, ya que las primeras reflejaban mejor el paso de información nueva a información dada; y b) presentar dichas proposiciones de modo similar a las unidades-idea propuestas por García Madruga et al. (1995) y García Madruga et al. (2002), para preservar los aspectos morfológicos del código de superficie, y así, clarificar aún más la progresión temática del párrafo.

- Análisis de las relaciones profundas o estructurales que se daban entre las proposiciones del párrafo, cuyo objetivo era comprobar el tipo de relaciones 
estructurales explícitas e implícitas que se establecían entre las ideas. Cabe destacar que, con el objetivo de visualizar las relaciones de subordinación que se daban entre las ideas, presentamos las relaciones profundas a través de un mapa conceptual que reflejaba los vínculos jerárquicos que se daban entre esas ideas.

Dichos análisis nos permitieron definir el grado de cohesión textual de cada párrafo, así como el tipo de macroestrategias que resultaban más adecuadas para extraer las ideas principales de cada uno de ellos. Partiendo de esto, pudimos extraer las ideas principales de los párrafos y evaluar el nivel de dificultad que entrañaba la identificación de cada macroproposición (los análisis realizados para cada párrafo se pueden ver en el Anexo I.4).

\begin{tabular}{|c|c|c|}
\hline Párrafo & Idea principal & $\begin{array}{l}\text { Nivel de dificultad extracción } \\
\text { idea principal }\end{array}$ \\
\hline Párrafo 1 & $\begin{array}{l}\text { El Tíbet es un país budista del centro de Asia, que } \\
\text { permanece aislado por su naturaleza y desesperanzado } \\
\text { por la invasión china }\end{array}$ & MEDIO \\
\hline Párrafo 2 & $\begin{array}{l}\text { Sólo el ejército chino pudo quebrar la capacidad de } \\
\text { supervivencia del Tíbet. (Otras opciones de respuesta en } \\
\text { Anexo I.4.Cuadro 20) }\end{array}$ & ALTO \\
\hline Párrafo 3 & $\begin{array}{l}\text { Nadie ayudó al Tíbet cuando fue invadido por China. } \\
\text { (Otras opciones de respuesta en Anexo I.4 Cuadro 35) }\end{array}$ & BAJO \\
\hline Párrafo4 & $\begin{array}{l}\text { Los chinos impusieron su ideología guerrera en el Tíbet } \\
\text { sin encontrar resistencia armada por parte de los } \\
\text { tibetanos. (Otras opciones de respuesta en Anexo I.4. } \\
\text { Cuadro 50) }\end{array}$ & ALTO \\
\hline Párrafo 5 & $\begin{array}{l}\text { El Tíbet ha adoptado la cultura china. (Otras opciones } \\
\text { de respuesta en Anexo I.4. Cuadro 63) }\end{array}$ & MEDIO \\
\hline Párrafo 6 & $\begin{array}{l}\text { La población tibetana se ve obligada a elegir entre la } \\
\text { sumisión o exilio; y entre paz o rebelión. (Otras opciones } \\
\text { de respuesta en Anexo I.4. Cuadro } 78 \text { ) }\end{array}$ & ALTO \\
\hline Párrafo 7 & $\begin{array}{l}\text { Los invasores no han respetado los derechos humanos. } \\
\text { (Otras opciones de respuesta en Anexo I.4. Cuadro 92) }\end{array}$ & BAJO \\
\hline Párrafo 8 & $\begin{array}{l}\text { Algunos budistas están comenzando a plantearse la } \\
\text { violencia, pero la mayoría considera que esto no es } \\
\text { posible situación actual. }\end{array}$ & BAJO \\
\hline Párrafo 9 & $\begin{array}{l}\text { El Dalai lama reclama fortaleza y confianza. (Otras } \\
\text { opciones de respuesta en Anexo I.4. Cuadro 121) }\end{array}$ & BAJO \\
\hline
\end{tabular}

Cuadro 2.11. Idea principal de cada párrafo y nivel de dificultad

Para clarificar los análisis realizados, hemos considerado oportuno introducir, a modo de ejemplo, el análisis de contenido de un párrafo de nivel de dificultad bajo. 
Ejemplo análisis de párrafo nivel de dificultad bajo

\section{Contenido del Párrafo 3}

En 1949, el joven líder budista, el Dalai Lama, envió un mensaje urgente a los gobiernos de Estados Unidos, la India y el Reino Unido y a la sede de las Naciones Unidas. Era una desesperada petición de ayuda. El ejército de Liberación Popular había cruzado sus fronteras, y la China comunista estaba invadiendo el país. Entonces nadie acudió en ayuda del Tíbet.

Cuadro 2.12. Contenido del párrafo 3

\section{Relaciones Superficiales de las Ideas del Párrafo 3}

43. El Dalai Lama envió un mensaje

44. El Dalai Lama era budista

45. El Dalai Lama era un líder

46. El Dalai Lama era joven

47. [Lo Anterior (49) FUE] en 1949

48. [Lo Anterior (49) ERA] urgente

49. [Lo Anterior (49)] a diferentes gobiernos

50. [Lo Anterior (49)]+ sede Naciones Unidas

51. Esos gobiernos eran EEUU

52. [Lo Anterior (51)]+ India

53. [Lo Anterior (51) (52)]+ Reino Unido

54. [Lo Anterior (43) (47) (48) (49) (50) ERA] una petición de ayuda

55. Esta petición era desesperada

56. [Lo Anterior (43) (47) (48) (49) (50) (51) (52) (53) (54) (55) PORQUE] Un ejército había cruzado las fronteras del Tíbet

57. [Lo Anterior (56)]Este ejercito era el ejército de liberación popular

58. [Lo Anterior (56) (57)] Este ejército pertenecía a China

59. [Lo Anterior (56) (57) (58)] Este ejército estaba invadiendo el Tíbet

60. [Lo Anterior (56) (57) (58) (59)] China estaba invadiendo el Tíbet

61. China era comunista

62. [Lo Anterior (56) (57) (58) (59) (60) ENTONCES] Nadie acudió en ayuda del Tíbet

63. [Lo Anterior (43) (47) (48) (49) (50) (51) (52) (53) (54) (55)PERO] Nadie acudió en ayuda del Tíbet

Cuadro 2.13. Relaciones superficiales de las ideas del párrafo 3

*Información en rojo entre corchetes: inferencia de una conexión estructural

* Información en rojo sin corchetes: necesidad de inferencia de idea implícita 


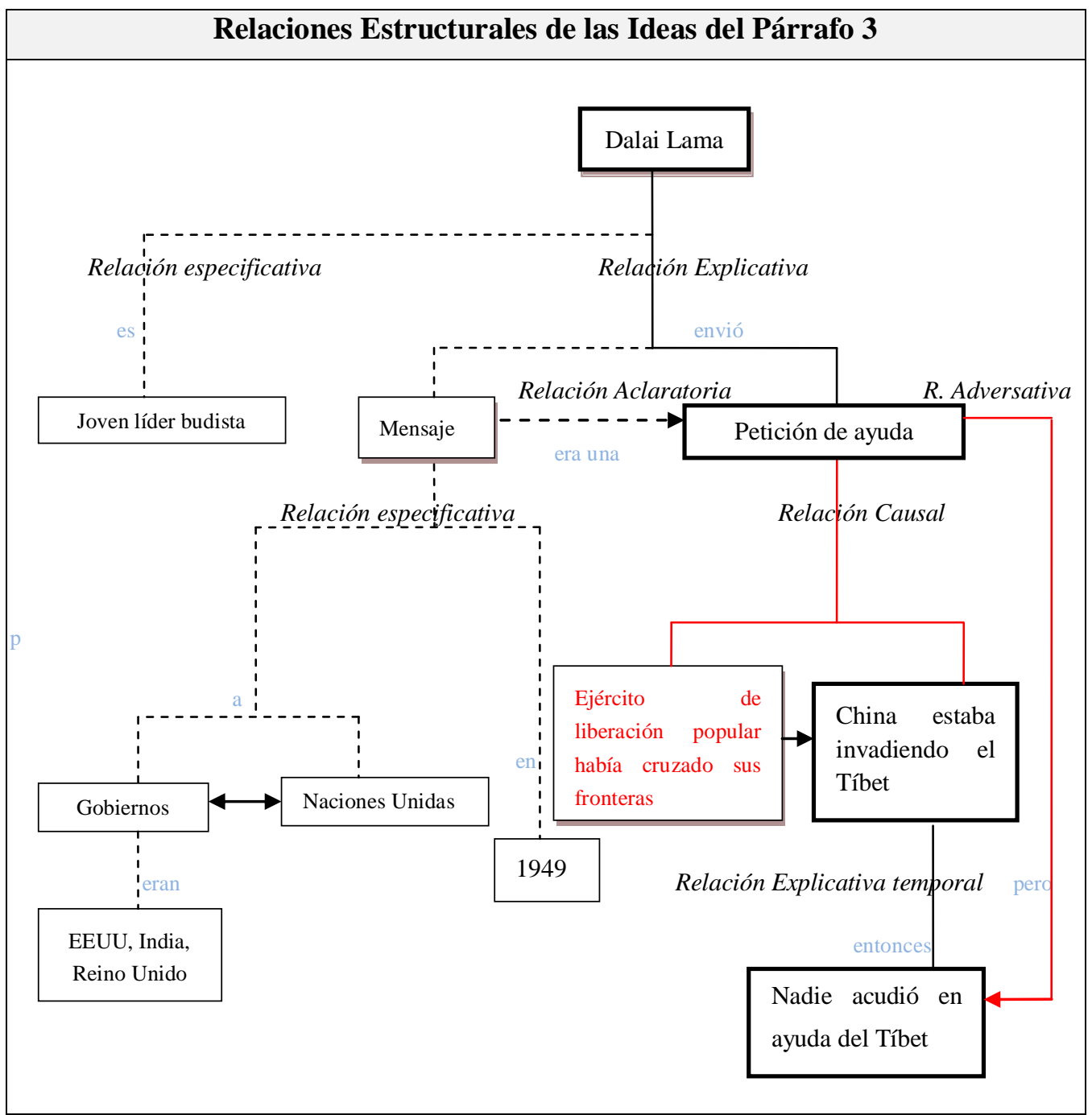

Cuadro 2.14. Relaciones estructurales de las ideas del párrafo 3

* Línea continua: relaciones estructurales predominantes dentro del párrafo

* Línea discontinua: relaciones estructurales subordinadas dentro del párrafo

* Línea roja: inferencia de una conexión estructural

* Información cuadro texto en letra roja: inferencia idea implícita

* Cuadros de texto destacados en negro: ideas importantes para construir la idea principal del párrafo 


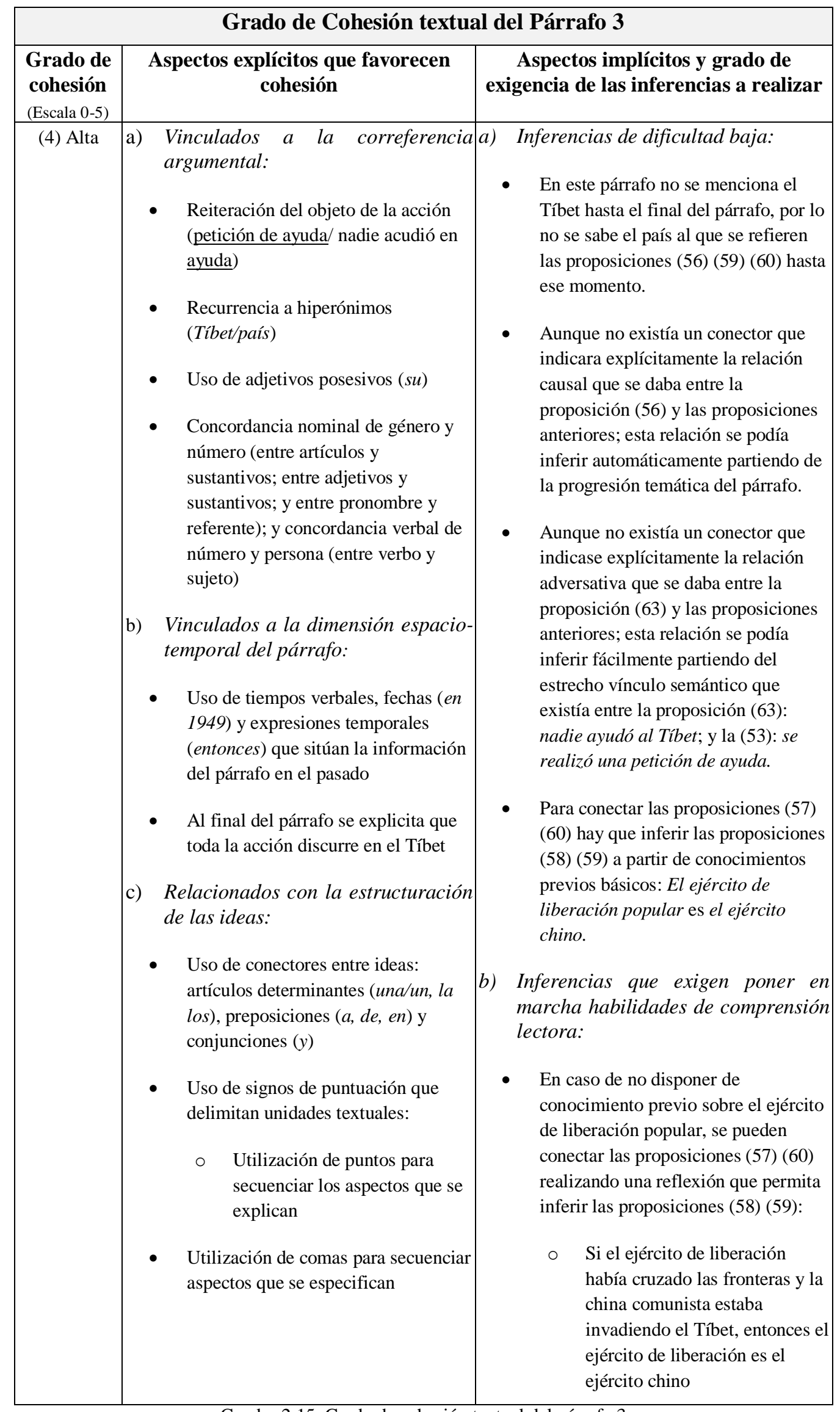

Cuadro 2.15. Grado de cohesión textual del párrafo 3 


\begin{tabular}{|c|c|c|c|}
\hline \multicolumn{4}{|c|}{ Idea Principal e Idea Temática del Párrafo 3} \\
\hline \multicolumn{2}{|c|}{ Idea temática } & \multicolumn{2}{|l|}{ Idea principal } \\
\hline Procedimiento extracción & Idea temática extraída & Procedimiento extracción & Idea extraída \\
\hline $\begin{array}{l}\text { 1. Teniendo en cuenta el } \\
\text { procedimiento de extracción de } \\
\text { la idea principal, el tema debía } \\
\text { mostrar de forma global el } \\
\text { aspecto adversativo "nadie } \\
\text { ayudó al Tíbet"; o bien } \\
\text { centrarse en el tema sobre el } \\
\text { que giraban todas las ideas, "la } \\
\text { petición de ayuda" }\end{array}$ & $\begin{array}{l}\text { "El desamparo del } \\
\text { Tíbet" } \\
\\
\\
\text { "La petición de } \\
\begin{array}{l}\text { ayuda del Dalai } \\
\text { Lama" }\end{array}\end{array}$ & $\begin{array}{l}\text { 1. En el párrafo existía una estructura adversativa implícita dominante que enmarcaba } \\
\text { una estructura causal implícita y una estructura explicativo-temporal explícita. } \\
\text { 2. Consideramos que la idea principal debía extraerse a partir de esta estructura } \\
\text { dominante, por lo que utilizamos la macroestrategia de omisión para omitir los } \\
\text { aspectos especificativos del párrafo: } \\
\text { - Por un lado, omitimos las proposiciones (44) (45) (46) puesto el conjunto de } \\
\text { adjetivos que se le atribuían al Dalai Lama no tienen gran importancia dentro del } \\
\text { hecho que se explica en el párrafo } \\
\text { - Por otro lado, omitimos la proposición (47), porque, tal y como se estructura el } \\
\text { párrafo, consideramos que para extraer la idea principal no es necesario explicitar } \\
\text { la fecha, ya que queda bastante claro que la estructura explicativa temporal trata un } \\
\text { hecho pasado que sucedió en un momento concreto: China invadió el Tíbet } \\
\text { entonces nadie ayudó al Tíbet } \\
\text { Finalmente, omitimos las proposiciones (49) (50) (51) (52) (53), puesto que } \\
\text { consideramos que, tal y como se estructura el párrafo, para extraer la idea principal } \\
\text { no es importante explicitar a quiénes se pidió ayuda, ya que en las proposiciones } \\
\text { (62) (63) se explicita que Nadie acudió en ayuda del Tíbet } \\
\text { Además, con el fin de sintetizar la idea extraída, utilizamos la macroestrategia de } \\
\text { 3. elección para seleccionar el aspecto de la estructura aclaratoria que más clarificaba } \\
\text { el modelo de la situación del párrafo: la petición de ayuda. } \\
\text { Establecimos varias opciones de idea principal. }\end{array}$ & $\begin{array}{l}\text { a) Se centra en la estructura } \\
\text { adversativa, y enmarca dentro de } \\
\text { ésta el momento en el que ocurrieron } \\
\text { los hechos: } \\
\text { "El Dalai Lama pidió ayuda cuando } \\
\text { el Tíbet fue invadido por China, pero } \\
\text { nadie le ayudó" } \\
\text { b) Se centra únicamente en qué ocurrió } \\
\text { y cuándo pasó: } \\
\text { "Nadie ayudó al Tíbet cuando fue } \\
\text { invadido por China" } \\
\text { c) Se centra en la causa de la petición } \\
\text { de ayuda y explica qué ocurrió en } \\
\text { ese momento: } \\
\text { "El Dalai Lama pidió ayuda ante } \\
\text { invasión china. Entonces nadie } \\
\text { acudió en ayuda del Tíbet" }\end{array}$ \\
\hline
\end{tabular}

Cuadro 2.16. Idea principal e idea temática del párrafo 3 


\begin{tabular}{|c|c|c|}
\hline \multicolumn{3}{|c|}{ Nivel de Dificultad del Párrafo 3} \\
\hline Cohesión/coherencia textual & Utilización macroestrategia & Nivel de dificultad \\
\hline $\begin{array}{l}\text { - La mayor parte de las ideas } \\
\text { aparecían explícitamente, y } \\
\text { aunque el alumno debía } \\
\text { realizar algunas inferencias } \\
\text { para explicitar las relación } \\
\text { causal y la relación } \\
\text { adversativa que aparecen } \\
\text { en el párrafo, ambas se } \\
\text { inferían fácilmente } \\
\text { partiendo de la progresión } \\
\text { temática del párrafo. } \\
\text { Debido a lo anterior, el } \\
\text { párrafo presentaba un } \\
\text { modelo de la situación } \\
\text { claro. }\end{array}$ & $\begin{array}{l}\text { El alumno debía utilizar una } \\
\text { estrategia de } \\
\text { selección/omisión de la } \\
\text { información para extraer la } \\
\text { idea principal. Ello, } \\
\text { únicamente, exige saber qué } \\
\text { aspectos utiliza el autor para } \\
\text { explicar lo que quiere decir, y } \\
\text { cuáles utiliza para especificar } \\
\text { o concretar algo de lo que } \\
\text { dice. }\end{array}$ & $\begin{array}{l}\text { BAJO } \\
\text { El modelo de la situación del texto } \\
\text { queda bastante claro, por lo que el } \\
\text { alumno únicamente debe } \\
\text { omitir/seleccionar información } \\
\text { partiendo de los criterios que } \\
\text { hemos explicitado. }\end{array}$ \\
\hline
\end{tabular}

Cuadro 2.17. Nivel de dificultad del párrafo 3

\section{a.2. Rúbricas de evaluación}

Se establecieron una serie de rúbricas de evaluación para cada párrafo, que nos permitieron valorar las ideas extraídas por los alumnos. De forma general, se establecieron cinco categorías de evaluación para todos los párrafos, que presentamos en el siguiente cuadro:

\begin{tabular}{|c|l|}
\hline \multicolumn{2}{|c|}{ Categorías Generales de Evaluación } \\
\hline Categorías & \multicolumn{1}{|c|}{ Definición Conceptual } \\
\hline$A$ & $\begin{array}{l}\text { El alumno extrae la idea principal del párrafo o se centra la mayor parte de los } \\
\text { aspectos vinculados a ella }\end{array}$ \\
\hline A tema & $\begin{array}{l}\text { El alumno extrae la idea temática del párrafo o se centra la mayor parte de los } \\
\text { aspectos vinculados a ella }\end{array}$ \\
\hline$B$ & El alumno extrae parcialmente la idea principal del párrafo \\
\hline$B$ tema & El alumno extrae parcialmente la idea temática del párrafo \\
\hline$C$ & $\begin{array}{l}\text { El alumno manifiesta dificultades para extraer total o parcialmente la idea } \\
\text { principal/temática del párrafo }\end{array}$ \\
\hline
\end{tabular}

Cuadro 2.18. Criterios generales de evaluación en la tarea 1

Como podemos observar en este cuadro, las cuatro primeras categorías indican, en mayor o menor medida, la identificación de la idea principal o temática del párrafo. Sin embargo, la última categoría refleja dificultades por parte del alumnado para 
identificar la idea principal o temática del párrafo. Con el fin de aclarar qué tipo de dificultades mostraban los alumnos a la hora de realizar la tarea, creamos tres subcategorías, tal y como muestra el siguiente cuadro.

\begin{tabular}{|c|l|}
\hline \multicolumn{2}{|c|}{ Dificultades generales extracción macroproposiciones } \\
\hline Subcategorías & \multicolumn{1}{|c|}{ Definición Conceptual } \\
\hline$C_{l}$ & $\begin{array}{l}\text { El alumno no tiene dificultades de expresión escrita, pero extrae una } \\
\text { idea/tema secundaria/o o construye una idea muy general }\end{array}$ \\
\hline$C_{2}$ & $\begin{array}{l}\text { El alumno no tiene dificultades para expresar la idea que extrae, pero la } \\
\text { construye basándose en una mala interpretación de la información del párrafo }\end{array}$ \\
\hline$C_{3}$ & El alumno tiene dificultades para expresar la idea que extrae \\
\hline
\end{tabular}

Cuadro 2.19. Dificultades generales en la extracción de macroproposiciones en la tarea 1

Para clarificar los criterios de evaluación específicos de cada párrafo, hemos considerado oportuno introducir, a modo de ejemplo, los que se tomaron para valorar las respuestas de los alumnos en el párrafo que analizamos anteriormente (los criterios de evaluación específicos para cada párrafo, así como la valoración a las respuestas dadas por los alumnos, se pueden ver en el Anexo I.4). Si bien antes de pasar al ejemplo, cabe mencionar que todos los análisis, tanto los criterios de evaluación como la valoración a las repuestas de los alumnos, fueron validados mediante la técnica de juicio de expertos (Cabero Almenara y Barroso, 2013) siguiendo el siguiente procedimiento:

a) El investigador principal construye los criterios de evaluación para cada párrafo, y valora las respuestas de los alumnos en función de dichos criterios.

b) Otro investigador, debido a su accesibilidad, pero sobre todo a su condición de experto en el estudio de las habilidades de comprensión y expresión escrita; revisa los criterios de evaluación y valora las respuestas de los alumnos en función a dichos criterios.

c) Ambos investigadores (investigador principal e investigador experto) comprueban las coincidencias y discuten las divergencias hasta llegar a un acuerdo.

d) Tras ello, seleccionamos un experto externo a la investigación, tomando de nuevo en consideración la facilidad de acceso, pero sobre todo, la condición experto en la materia; para valorar tanto los criterios de evaluación consituidos como las respuestas del alumnado.

e) Para finalizar, repetimos el procedimiento "c". 
Ejemplo criterios de evaluación específicos de párrafo con nivel de dificultad Bajo

\begin{tabular}{|c|c|c|}
\hline \multicolumn{3}{|c|}{ Categorías específicas de evaluación para el párrafo 3} \\
\hline $\begin{array}{l}\text { Categorías de } \\
\text { Evaluación }\end{array}$ & & Definición Conceptual \\
\hline \multirow[t]{3}{*}{$A$} & & $\begin{array}{l}\text { El alumno utiliza la macroestrategia de omisión para omitir la mayor } \\
\text { parte información secundaria que se transmite en el párrafo, y se centra en } \\
\text { la relación adversativa que se infiere del mismo: El Dalai Lama pidió } \\
\text { ayuda cuando el Tíbet fue invadido por China, pero nadie le ayudó. }\end{array}$ \\
\hline & & $\begin{array}{l}\text { El alumno utiliza la macroestrategia de omisión para omitir la mayor } \\
\text { parte de la información secundaria que se transmite en el párrafo, y se } \\
\text { centra en la relación causal que se infiere en el texto y en la relación } \\
\text { explicativa temporal que aparece explícitamente: El Dalai Lama pidió } \\
\text { ayuda a causa de la invasión china. Entonces nadie acudió en ayuda del } \\
\text { Tíbet. }\end{array}$ \\
\hline & c) & $\begin{array}{l}\text { El alumno, además de omitir la mayor parte de la información secundaria, } \\
\text { omite la petición de ayuda, centrándose en la ausencia de ayuda al Tíbet } \\
\text { en el momento en el que fue invadido por China: Nadie ayudó al Tíbet } \\
\text { cuando fue invadido por China. }\end{array}$ \\
\hline A tema & & $\begin{array}{l}\text { El alumno extrae la idea temática del párrafo construyendo una idea que } \\
\text { muestra de forma global la estructura adversativa dominante: El } \\
\text { desamparo del Tíbet. }\end{array}$ \\
\hline \multirow[t]{2}{*}{$B$} & a) & $\begin{array}{l}\text { El alumno construye parcialmente la idea principal del párrafo omitiendo, } \\
\text { además de la mayor parte de la información secundaria, la respuesta a la } \\
\text { petición de ayuda: El Tíbet pidió ayuda porque estaba siendo invadido } \\
\text { por China. }\end{array}$ \\
\hline & & $\begin{array}{l}\text { El alumno construye parcialmente la idea principal del párrafo omitiendo, } \\
\text { además de la mayor parte de la información secundaria, omite la razón de } \\
\text { la petición de ayuda: El Tíbet pidió ayuda pero nadie acudió en su ayuda. }\end{array}$ \\
\hline B tema & & $\begin{array}{l}\text { El alumno extrae parcialmente la idea temática del párrafo: La petición de } \\
\text { ayuda del Dalai Lama. }\end{array}$ \\
\hline
\end{tabular}

Cuadro 2.20. Categorías específicas de evaluación en el párrafo 3 


\begin{tabular}{|c|c|c|c|c|}
\hline \multicolumn{5}{|c|}{ Dificultades a la hora de extraer idea principal del párrafo 3} \\
\hline Categorías & Tipos de Dificultades & & Definición Conceptual Dificultades & Ejemplo \\
\hline \multirow[t]{3}{*}{$C_{l}$} & \multirow[t]{2}{*}{$\begin{array}{l}\text { Idea/tema } \\
\text { secundaria/o }\end{array}$} & a) & $\begin{array}{l}\text { Se centra principalmente en la invasión china, omitiendo } \\
\text { tanto la petición de ayuda del Dalai Lama como la } \\
\text { ausencia de ayuda }\end{array}$ & EDP141. "Tíbet es invadido por la China comunista” \\
\hline & & b) & $\begin{array}{l}\text { Se centra principalmente en temas secundarios (como la } \\
\text { invasión china) que se enmarcan dentro del tema } \\
\text { dominante del párrafo: el desamparo del Tíbet }\end{array}$ & $\begin{array}{l}\text { PSP 30. "Invasión China en el Tíbet" } \\
\text { PSP 26. "La invasión china al Tíbet", }\end{array}$ \\
\hline & Idea muy general & a) & $\begin{array}{l}\text { Extrae una idea que abarca una realidad mucho más } \\
\text { amplia que la temática del párrafo }\end{array}$ & PSP07. "Quién fue Dalai Lama y qué sucedió en el Tíbet" \\
\hline$C_{2}$ & $\begin{array}{l}\text { Malinterpreta la } \\
\text { información del } \\
\text { párrafo }\end{array}$ & a) & $\begin{array}{l}\text { La idea que construye el alumno genera un modelo de } \\
\text { la situación diferente al del párrafo }\end{array}$ & EDP.142. "Petición de ayuda del Tíbet para prevenir la invasión" \\
\hline \multirow[t]{5}{*}{$C_{3}$} & \multirow{2}{*}{$\begin{array}{l}\text { Dificultad para } \\
\text { mantener la } \\
\text { correferencia } \\
\text { argumental (no queda } \\
\text { claro a qué se refiere) }\end{array}$} & a) & $\begin{array}{l}\text { Escritura egocéntrica (el alumno habla como si el } \\
\text { lector supiese de qué o sobre quién está hablando) }\end{array}$ & $\begin{array}{l}\text { PSP39. "El líder budista Dalai lama reclama ayuda para salvar el Tíbet de esos ataques. Hubo } \\
\text { una gran destrucción" }\end{array}$ \\
\hline & & b) & No existe correferencia argumental entre ideas & EDP57. "Dalai Lama pide ayuda pero nadie acude. Consecuencias catastróficas" \\
\hline & \multirow[t]{3}{*}{$\begin{array}{l}\text { Dificultad para } \\
\text { estructurar } \\
\text { adecuadamente la } \\
\text { idea }\end{array}$} & a) & $\begin{array}{l}\text { Omite conectores (conjunción, preposición, sustantivo, } \\
\text { verbo) que es necesario explicitar teniendo en cuenta } \\
\text { cómo estructura la oración }\end{array}$ & $\begin{array}{l}\text { EDP104. "Dalai Lama pidió ayuda debido a que la China comunista estaba invadiendo el país, } \\
\text { pero la petición no fue aceptada y provocó graves problemas" } \\
\text { (Nota: Debería haber utilizado "y esto provocó") }\end{array}$ \\
\hline & & b) & $\begin{array}{l}\text { No integra bien las ideas (existe correferencia } \\
\text { argumental pero no secuencia bien la progresión } \\
\text { temática) }\end{array}$ & $\begin{array}{l}\text { PSP19. "Ocuparon el país. Pidieron ayuda pero nadie acudió. Hubieron muchas pérdidas" } \\
\text { PSP20. “Los chinos, finalmente lo conquistaron. El Tíbet pidió ayuda pero nadie la dio. Hubo } \\
\text { muchas pérdidas }\end{array}$ \\
\hline & & c) & $\begin{array}{l}\text { Usa conectores inadecuados (conjunción, preposición, } \\
\text { sustantivo, verbo) teniendo en cuenta el contenido } \\
\text { semántico de las proposiciones que utiliza }\end{array}$ & $\begin{array}{l}\text { EDP91. "Hecho bélico ocurrido en el país, que fundamentalmente el suceso más importantes la } \\
\text { petición de ayuda de Dalai" } \\
\text { EDP95. "Dada la invasión de la china comunista en el Tíbet, su líder budista solicitó ayuda a } \\
\text { distintos países y organizaciones sin ser recibida, lo que provocó terribles resultados". }\end{array}$ \\
\hline
\end{tabular}




\begin{tabular}{|c|c|c|c|c|}
\hline \multicolumn{5}{|c|}{ Dificultades a la hora de extraer idea principal del párrafo 3} \\
\hline Categorías & Tipos de Dificultades & & Definición Conceptual Dificultades & Ejemplo \\
\hline \multirow[t]{3}{*}{$C_{3}$} & $\begin{array}{l}\text { Dificultad para } \\
\text { estructurar } \\
\text { adecuadamente la idea }\end{array}$ & d) & $\begin{array}{l}\text { La forma de organizar la idea dificulta la comprensión de } \\
\text { la misma por parte del lector (bien habría que reorganizar } \\
\text { la información para clarificar su significado; o bien habría } \\
\text { que reducirla para que no corte la continuidad) }\end{array}$ & $\begin{array}{l}\text { EDP122. "El mensaje de Dalai Lama pidiendo ayuda a las potencias mundiales, aunque no } \\
\text { obtuvo ayuda, y la invasión del país con consecuencias para la población local" } \\
\text { EDP135. "El Tíbet estuvo en peligro cuando fue invadido por China, hubo muchos daños } \\
\text { personales y materiales, aunque el líder del Tíbet pidió mucha ayuda" }\end{array}$ \\
\hline & \multirow[t]{2}{*}{$\begin{array}{l}\text { Dificultad para generar } \\
\text { un Modelo de la } \\
\text { Situación claro }\end{array}$} & a) & $\begin{array}{l}\text { Uso de expresiones poco claras en el contexto en el que } \\
\text { se utilizan }\end{array}$ & $\begin{array}{l}\text { PSP09. "Aunque el Dalai lama pidió ayuda, no se hizo nada y destrozaron y mataron a millones } \\
\text { de personas" } \\
\text { PSP35. "Pedida de ayuda por parte de Dalai lama ante la invasión a la fuerza del Tíbet" }\end{array}$ \\
\hline & & & $\begin{array}{l}\text { Ausencia de información que clarifique el modelo de la } \\
\text { situación }\end{array}$ & $\begin{array}{l}\text { PSP02. "Dalai Lama ayuda, aun así murieron miles de personas en esa invasión" } \\
\text { PSP05. "Habla de la guerra que hubo en 1949, y la petición de ayuda no tuvo respuesta dando } \\
\text { lugar a una" }\end{array}$ \\
\hline
\end{tabular}


B) Tarea 2. Construcción de un mapa conceptual que recoja las relaciones jerárquicas que se dan entre las ideas del texto

\section{b.1. Análisis del contenido textual}

Para definir el nivel de dificultad que suponía la construcción del mapa conceptual del texto seguimos un conjunto de pasos:

- En primer lugar, definimos el grado de cohesión global que tenía el texto, teniendo en cuenta:

- El grado de cohesión que establecimos para cada párrafo durante el análisis de la tarea 1 (ver Anexo I.5. Cuadro 1)

- El grado de cohesión que existía en la transición de un párrafo a otro (para ver el análisis realizado ir al Anexo I.5. Cuadro 2)

Partiendo de ello, pudimos establecer que a nivel global el texto que leyeron los alumnos tenía un nivel de cohesión bajo.

- En segundo lugar, identificamos los referentes o señales textuales que indicaban la superestructura del texto (para ver el análisis realizado ir al Anexo I.5. Cuadro 3). En el texto existía una estructura explicativa-causal que se enmarcaba dentro una superestructura argumentativa/problema-solución. Teniendo en cuenta que se trataba de un texto divulgativo ${ }^{21}$ con un nivel de cohesión "bajo", llegamos a la conclusión de que los alumnos deberían poseer ciertas nociones sobre tipologías textuales, y ser capaces de utilizarlas estratégicamente para extraer la macroestructura textual.

- En tercer lugar construimos un mapa conceptual donde estructuramos las ideas principales extraídas de cada párrafo dentro de la estructura global del texto (ver Anexo I.5. Cuadro 4)

- Y en cuarto omitimos aquella información de las macroproposiciones que quedaban fuera de la superestructura del texto, tal y como se puede observar en el siguiente cuadro:

\footnotetext{
${ }^{21}$ El texto hablaba sobre un tema muy denunciado en los medios de comunicación (la invasión china del Tíbet); recogía términos y conceptos que deberían evocar modelos de la situación conocidos para el alumnado que había finalizado con éxito el Bachillerato; y tenía unas características estructurales muy familiares para alumnos de etapas educativas tan dispares como Educación Secundaria, Bachillerato y Universidad (las historias sobre invasiones presentan antecedentes, intervención de múltiples países, las causas del conflicto, consecuentes, etc.)
} 


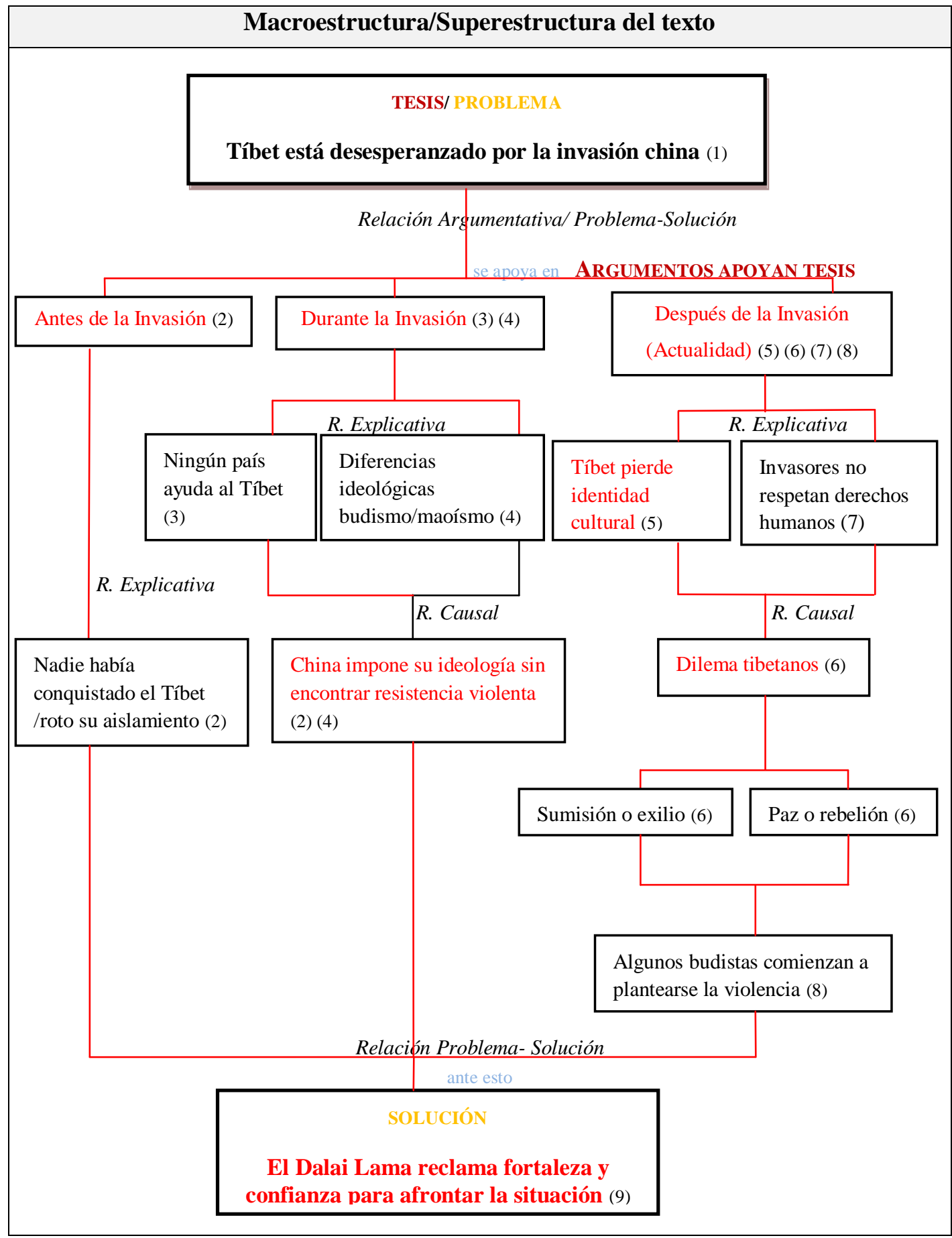

Cuadro 2 22. Macroestructura/Superestructura del texto

* Línea continua: relaciones estructurales predominantes dentro del texto

* Línea roja: inferencia de una conexión estructural

* Información cuadro texto en letra roja: inferencia idea implícita

* Cuadros de texto destacados en negro: macroproposiciones que componen la idea principal del texto

* Números entre paréntesis (): macroproposición correspondiente al párrafo textual que indica el número entre paréntesis

Partiendo de todos los pasos anteriores, generamos un conjunto de argumentos que nos permitieron establecer que la realización del mapa, suponía un nivel de dificultad medio para el alumno (ver Anexo I.5. Cuadro 6). 


\section{b.2. Rúbricas de evaluación}

Para esta segunda tarea se establecieron tres categorías de evaluación: A, B, y C. (Para ver una definición conceptual más exhaustiva ir al Anexo I.5. Cuadro 7; además se pueden ver ejemplificaciones de B en el Cuadro 9).

\begin{tabular}{|c|l|}
\hline \multicolumn{2}{|c|}{ Categorías de Evaluación para el mapa conceptual } \\
\hline Categorías & \multicolumn{1}{c|}{ Definición Conceptual } \\
\hline$A$ & $\begin{array}{l}\text { El alumno construye un mapa conceptual en el que estructura las ideas } \\
\text { importantes en torno a la superestructura dominante del texto }\end{array}$ \\
\hline$B$ & $\begin{array}{l}\text { El alumno construye un mapa conceptual en el que estructura las ideas } \\
\text { importantes en torno a una superestructura subordinada del texto }\end{array}$ \\
\hline$C$ & $\begin{array}{l}\text { El alumno tiene dificultades para establecer las relaciones estructurales } \\
\text { del texto en el mapa conceptual que construye }\end{array}$ \\
\hline
\end{tabular}

Cuadro 2.23. Criterios de evaluación en la tarea 2

Al igual que hicimos cuando hablábamos de las rúbricas de evaluación de la primera tarea, creamos tres subcategorías que clarificaban las dificultades que mostraba el alumno a la hora de construir el mapa conceptual del texto: $C_{1}, C_{2}, C_{3}$ (Para ver una definición conceptual más exhaustiva ir al Anexo I.5. Cuadro 8; además se pueden ver ejemplificaciones de $\mathrm{C}_{1}$ en el Cuadro 10, de $\mathrm{C}_{2}$ en el Cuadro 11, y de $\mathrm{C}_{3}$ en el Cuadro 12).

\begin{tabular}{|c|l|}
\hline \multicolumn{2}{|c|}{ Dificultades para la construcción del mapa conceptual } \\
\hline Subcategorías & \multicolumn{1}{c|}{ Definición Conceptual } \\
\hline$C_{1}$ & $\begin{array}{l}\text { el alumno construye un mapa conceptual que no se centra en las ideas } \\
\text { importantes del texto }\end{array}$ \\
\hline$C_{2}$ & $\begin{array}{l}\text { El alumno construye un mapa conceptual en el que no queda clara la } \\
\text { estructura global y/o significado global del mismo }\end{array}$ \\
\hline$C_{3}$ & $\begin{array}{l}\text { el alumno no sabe organizar en diferentes niveles jerárquicos el mapa } \\
\text { conceptual que trata de construir }\end{array}$ \\
\hline
\end{tabular}

Cuadro 2.24. Dificultades para la realización del mapa conceptual

(La valoración de las respuestas dadas por los alumnos se puede ver en el Anexo I.5. Cuadros $13,14,15$ y 16$)$

Cabe mencionar que todos los análisis realizados, tanto los criterios de evaluación como la valoración a las repuestas de los alumnos, fueron validados mediante la técnica de juicio de expertos (Cabero Almenara y Barroso, 2013) siguiendo el mismo procedimiento que especificamos para la tarea anterior (ver página 142), con la diferencia de que, en este caso, no tuvimos acceso a un investigador externo. 


\subsubsection{Instrumentos de recogida de información en el Diseño II para la evaluación del efecto del formato textual sobre las estrategias de comprensión y expresión escrita}

\subsubsection{Pre-test}

(Los mismos instrumentos que se utilizaron en el Diseño I: Cuestionario identificativo de contexto y PHBC-E)

\subsubsection{Post-test: Prueba resumen del texto impreso}

Para la construcción de la prueba, partimos de un artículo asociado a la disciplina de Tecnología Educativa o NNTT en Educación, cuyo título era "Usos y prácticas con medios y materiales en el contexto escolar: de la cultura impresa a la cultura digital (Area, 2001). (Ver artículo original en Anexo II.2). La razón que nos llevó a seleccionar este texto, fue que representaba un texto prototipo similar a los que se iban a enfrentar los alumnos que accedían a el Grado en Educación Primaria, y a los que se habían enfrentado el alumnado de Psicopedagogía durante la Diplomatura de Magisterio.

El artículo, que disponía de 4050 palabras, era demasiado extenso para que el alumnado pudiese realizar las dos tareas que componían la prueba (por una parte, resumir el texto; y por otra, explicar el procedimiento utilizado para la realización del resumen) en el tiempo establecido ( 2 horas). Por esta razón, tomamos como referencia la estructura del artículo, para omitir tanto información secundaria como información repetitiva o redundante.

Finalmente, obtuvimos un texto de 2848 palabras, que respetaba tanto la superestructura como la macroestructura del texto original (ver texto adaptado en Anexo II.3). A este texto se le adjunto un glosario de términos, dirigido sobre todo a aquellos alumnos que no estaban familiarizados con el tema (principalmente los alumnos que acababan de comenzar el grado en Educación Primaria), con el que tratamos de clarificar ciertos conceptos propios de la disciplina de Tecnología Educativa (ver glosario en Anexo II.4).

Una vez adaptado el texto, analizamos su contenido tanto a nivel de apartado como a nivel de texto, con el objetivo de determinar, por un lado, el nivel de dificultad que entrañaba extraer las ideas principales de cada apartado, y por otro, el nivel de dificultad que suponía identificar la macroestructura del texto. Partiendo de estos análisis, pudimos establecer un conjunto de rúbricas de evaluación que nos permitieron valorar las dos tareas que tuvieron que realizar los alumnos: un resumen y una actividad metacognitiva vinculada a dicha tarea. 


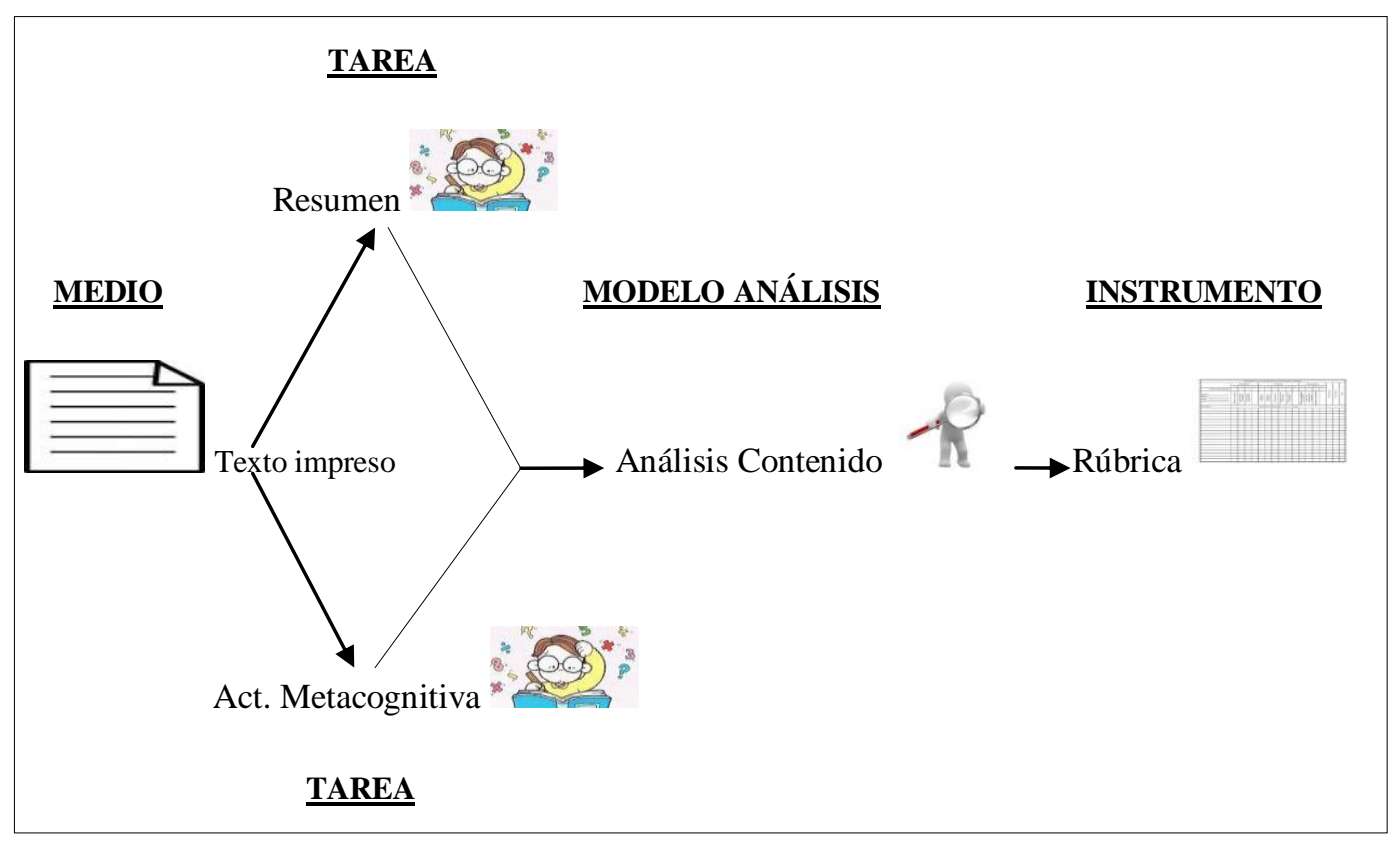

Cuadro 2.25. Esquema de evaluación del efecto del formato textual sobre las estrategias específicas de C y EE (texto impreso)

\section{A) Análisis de contenido texto impreso}

a.1. Análisis del contenido a nivel de apartado

Realizamos un análisis de contenido de la introducción, de las conclusiones y de cada uno de los cuatro apartados que componían el artículo. (Ver Anexo II.5)

Para clarificar los análisis realizados, a continuación, mostraremos los análisis de contenido realizados al apartado introductorio. 


\begin{tabular}{|l}
\hline Contenido del apartado introductorio \\
\hline USOS Y PRÁCTICAS CON MEDIOS Y MATERIALES EN EL CONTEX TO \\
ES COLAR. DE LA CULTURA IMPRESA A LA CULT URA DIGITAL \\
Manuel Area Moreira* \\
Los medios y materiales curriculares son un tipo particular de productos culturales cuya función \\
básica, como es bien conocido, consiste en facilitar el desarrollo de procesos de enseñanza y \\
aprendizaje. Son, en consecuencia, uno de los componentes sustantivos y presentes en todo proceso \\
de desarrollo o puesta en práctica del currículum en los centros y aulas. Esto significa que lo que \\
enseña el profesorado y lo que aprende el alumnado, entre otros factores, está regulado y \\
condicionado por el conjunto de medios y materiales utilizados. \\
En este artículo partiré del supuesto de que el uso de los medios y materiales en los procesos \\
educativos escolares están condicionados histórica y contextualmente por el origen y la naturaleza \\
específica de la cultura de la institución escolar. Esta cultura pertenece al canon de la cultura \\
impresa que ha sido hegemónica e incuestionable durante todo el siglo XIX y XX. Sin embargo, nos \\
encontramos en plena vorágine del cambio social y cultural provocado por el desarrollo y \\
generalización de las tecnologías de la información y comunicación lo que debe suponer reformular \\
esa cultura para dar entrada a formas culturales multimediadas e hipertextuales.
\end{tabular}

Cuadro 2.26. Contenido del apartado introductorio

\section{Progresión Temática en el apartado introductorio}

- La mayor parte de la información del apartado gira en torno a los medios y materiales curriculares, que es el tema principal del mismo. A su vez, este tema se divide en los siguientes subtemas:

- La primera parte del apartado trata de definir qué son los medios y materiales curriculares

- La segunda parte del apartado trata el uso de los medios y materiales curriculares en la escuela

Cuadro 2.27. Progresión temática en el apartado introductorio 


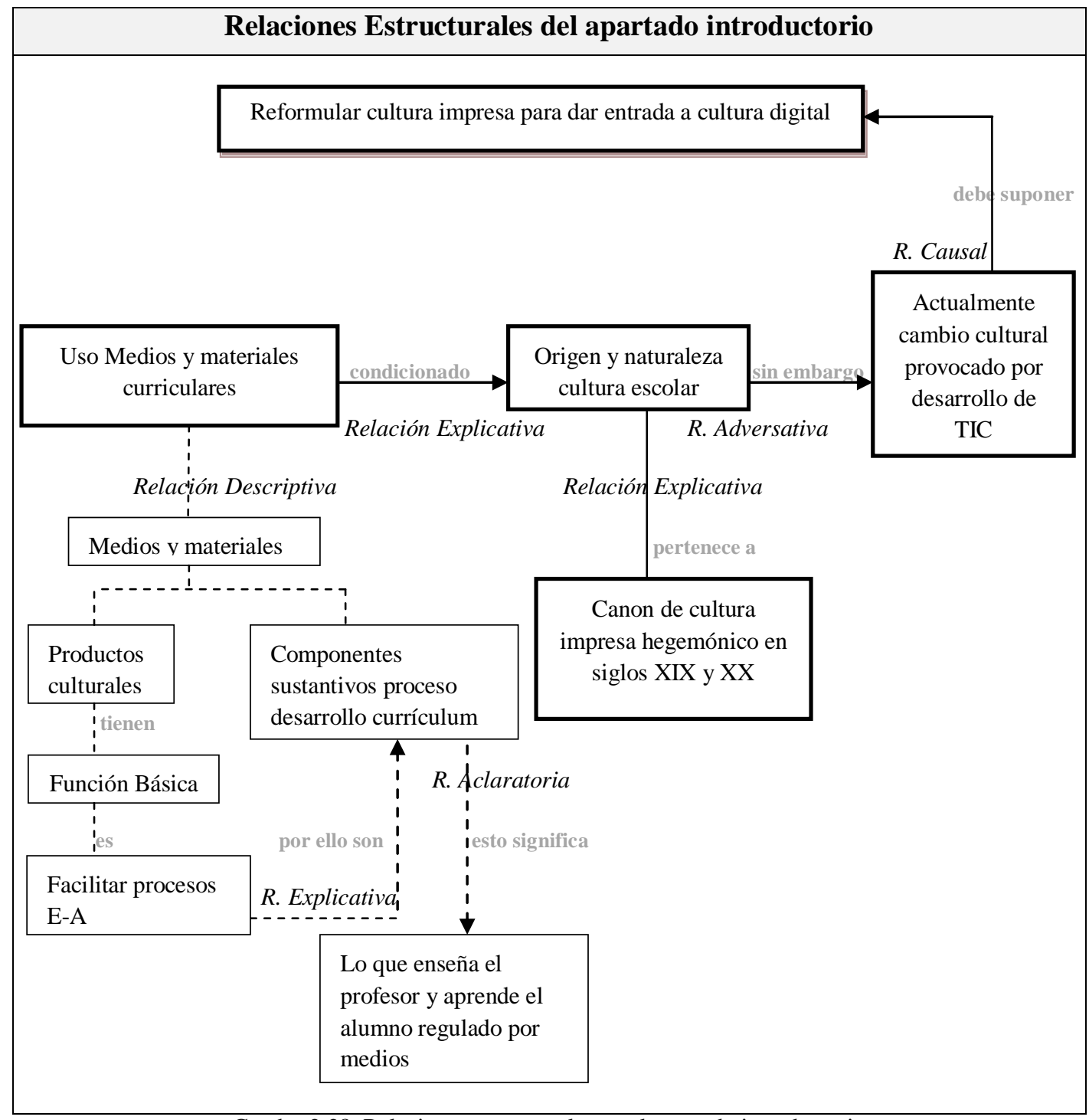

Cuadro 2.28. Relaciones estructurales en el apartado introductorio

* Línea continua: relaciones estructurales predominantes dentro del párrafo

* Línea discontinua: relaciones estructurales subordinadas dentro del párrafo

* Cuadros de texto destacados en negro: ideas importantes del apartado para construir macroestructura 


\begin{tabular}{|c|c|c|c|}
\hline \multicolumn{4}{|c|}{ Grado de cohesión textual del apartado introductorio } \\
\hline $\begin{array}{l}\text { Grado de } \\
\text { cohesión } \\
\text { (Escala 0-5) }\end{array}$ & & Aspectos explícitos que favorecen cohesión & $\begin{array}{l}\text { Aspectos implícitos y grado de } \\
\text { exigencia de las inferencias a realizar }\end{array}$ \\
\hline (5) Muy Alta & & $\begin{array}{l}\text { Vinculados a la correferencia argumental } \\
\text { Reiteración de medios y materiales, y de cultura. } \\
\text { Uso de pronombres (esto) y de adjetivos de relativo (cuya). } \\
\text { Concordancia nominal de género y número (entre artículos y sustantivos; entre adjetivos y sustantivos; y entre pronombre y } \\
\text { referente); y concordancia verbal de número y persona (entre verbo y sujeto). } \\
\text { Vinculados a la dimensión espacio-temporal: } \\
\text { Uso de tiempos verbales en futuro para señalar en qué aspectos se va apoyar el artículo. } \\
\text { Uso de tiempos verbales en presente, por una parte, para describir qué son los materiales curriculares; y por otra, para explicitar tanto } \\
\text { la tesis que se defiende en el apartado como los argumentos que apoyan dicha tesis. } \\
\text { Uso de tiempos verbales en pasado que comunican con el presente (uso del pretérito perfecto compuesto "ha sido" para especificar } \\
\text { la hegemonía de los medios impresos durante el S.XIX y XX). (Nota: hay que tener en cuenta que el artículo se publica en el año } \\
2000, \text { el primer año del S. XXI). } \\
\text { Relacionados con la estructuración de las ideas: } \\
\text { Uso de conectores entre ideas: artículos determinantes (una/un, este, esta...), de conjunciones (y, que...), preposiciones (en, entre, } \\
\text { de, por...). } \\
\text { Uso de signos de puntuación que delimitan unidades textuales: } \\
\text { u utilización de puntos para secuenciar descriptores. } \\
\text { uso de comas y dos puntos para especificar algo sobre los descriptores. }\end{array}$ & $\begin{array}{l}\text { a) Inferencias de dificultad baja: } \\
\text { - Se requieren conocimientos } \\
\text { previos que clarifiquen qué } \\
\text { quiere decir el autor cuando } \\
\text { habla de las culturas } \\
\text { multimediales e hipertextuales. } \\
\text { En este sentido, incluimos los } \\
\text { dos conceptos dentro de un } \\
\text { glosario de términos que se } \\
\text { facilitó a los alumnos a la hora } \\
\text { de leer el texto. }\end{array}$ \\
\hline
\end{tabular}




\begin{tabular}{|c|c|c|c|c|}
\hline \multicolumn{5}{|c|}{ Grado de cohesión textual del apartado introductorio } \\
\hline $\begin{array}{l}\text { Grado de } \\
\text { cohesión } \\
\text { (Escala 0-5) }\end{array}$ & & & Aspectos explícitos que favorecen cohesión & $\begin{array}{l}\text { Aspectos implícitos y grado de } \\
\text { exigencia de las inferencias a realizar }\end{array}$ \\
\hline (5) Muy Alta & & $\begin{array}{c}\text { Relaci } \\
\text { Uss } \\
0 \\
0 \\
0 \\
\text { Relaci } \\
\text { Títt } \\
\text { Uti } \\
\text { que }\end{array}$ & $\begin{array}{l}\text { nados con la estructuración de las ideas: } \\
\text { de señalizaciones estructurales: } \\
\text { Utilización de conectores consecutivos (en consecuencia) y de reformuladores explicativos (esto significa) que indican una } \\
\text { relación explicativa/ aclaratoria. } \\
\text { Uso de conectores contraargumentivos (sin embargo) que indican una relación adversativa. } \\
\text { Aparición de la forma verbal "debe suponer", que indica una consecuencia necesaria, y que por tanto sugiere una estructura } \\
\text { causal. } \\
\text { nados con la identificación de la macroestructura del texto } \\
\text { o del artículo: "Usos y prácticas con medios y materiales en el contexto escolar: de la cultura impresa a la cultura digital”. } \\
\text { zación de señales estructurales ("en este artículo partirée”) que indican que la información sucesiva sintetiza las ideas sobre las } \\
\text { a a girar globalmente el artículo. }\end{array}$ & \\
\hline
\end{tabular}

Cuadro 2.29. Grado de cohesión textual en el apartado introductorio 
a.2. Análisis del contenido a nivel de texto

Para definir el nivel de dificultad que suponía la realización del resumen del artículo, partimos de los siguientes análisis (para ver un análisis exhaustivo ir a Anexo II.6):

- Comenzamos observando que el artículo tenía unos referentes estructurales muy claros: los títulos del artículo y de los apartados; y las señales explícitas que aparecían en la introducción ("en este artículo partirê) y en las conclusiones ("En resumen", "En definitiva").

- Estos referentes indicaban la existencia de una estructura argumentativa/ problema-solución predominante.

- Una vez comprobado lo anterior, analizamos de forma más exhaustiva la información de cada apartado; y percibimos que el artículo tenía baja cohesión en su desarrollo (principalmente en los apartados 1 y 2).

- Debido a esto, consideramos que para realizar la tarea con éxito, los alumnos deberían usar estratégicamente los referentes que hemos mencionado; ya que éstos les permitirían extraer la macroestructura textual, que era lo que en definitiva demandaba la tarea.

- Teniendo en cuenta estos referentes, identificamos la macroestructura del artículo y la plasmamos en un resumen escrito que, a modo de ejemplo, expresaba dichas ideas de forma breve y personal. 


\section{Macroestructura del artículo}

\section{TEMA DEL ARTÍCULO}

Transición de la cultura impresa a la cultura digital

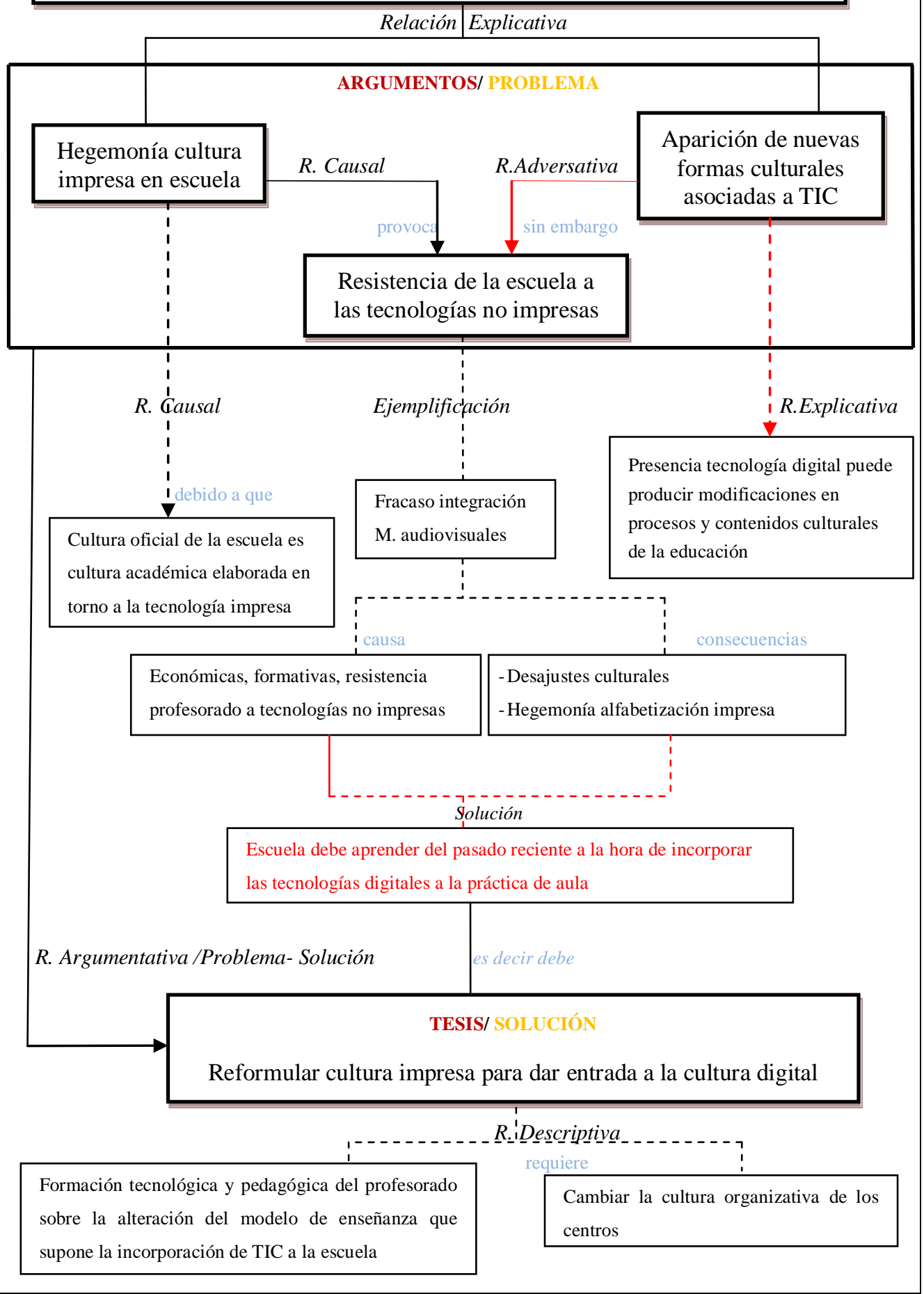

Cuadro 2.30. Macroestructura del artículo

* Línea continua: relaciones estructurales predominantes dentro del párrafo

* Línea discontinua: relaciones estructurales subordinadas dentro del párrafo

* Línea roja: inferencia de una conexión estructural

* Cuadros de texto destacados en negro: ideas importantes del apartado para construir macroestructura

* Información cuadro texto en letra roja: utilización macroestrategia (selección/construcción) 


\section{Ejemplificación de resumen (modelo)}

La hegemonía de la cultura impresa en el sistema educativo provoca una gran resistencia por parte de la institución escolar ante la incorporación de tecnologías no impresas dentro de los procesos de EnseñanzaAprendizaje.

Esto está provocando que cada vez existan mayores desajustes culturales, entre lo que el alumno aprende dentro (cultura impresa) y fuera de la escuela (formas culturales audiovisuales y digitales). Por lo que, para evitar una profunda crisis en el seno de la educación institucionalizada, la escuela debe renovar sus formas y contenidos culturales.

En este sentido, reformular la cultura impresa de la escuela para dar paso a la cultura digital implica dos factores: por un lado, una formación técnica y pedagógica del docente centrada en la alteración del modelo educativo que representa la incorporación de las TIC a la práctica de aula; por otro el cambio en la cultura organizativa de los centros, pasando de la individualidad, aislamiento y la ausencia de experiencias compartidas entre docentes, a la coordinación, el intercambio y la preparación conjunta de proyectos educativos.

Cuadro 2.31. Ejemplificación de resumen (modelo)

\section{B) Rúbricas de Evaluación para los resúmenes}

Para evaluar la variable Habilidades específicas de comprensión y expresión escrita para la síntesis de información, se establecieron un conjunto de variables operativas $\left(\mathrm{VDTH}_{1}\right.$.Uso de habilidades de comprensión y expresión escrita para realizar un resumen; y $\mathrm{VDTH}_{2}$. Procedimientos que el alumno considera haber llevado a cabo a la hora de realizar el resumen). A su vez, para cada variable operativa se establecieron una serie de sub-variables, que disponían de un conjunto de categorías de evaluación que nos permitieron valorar el desempeño del alumnado en la realización del resumen. 


\begin{tabular}{|c|c|}
\hline \multicolumn{2}{|r|}{ VDTH $_{1}$. Uso de habilidades de comprensión y expresión escrita para realizar el resumen de un texto } \\
\hline Sub-variables & Categorías de Evaluación y Definición Conceptual \\
\hline Tipo información subrayada (Texto impreso) & 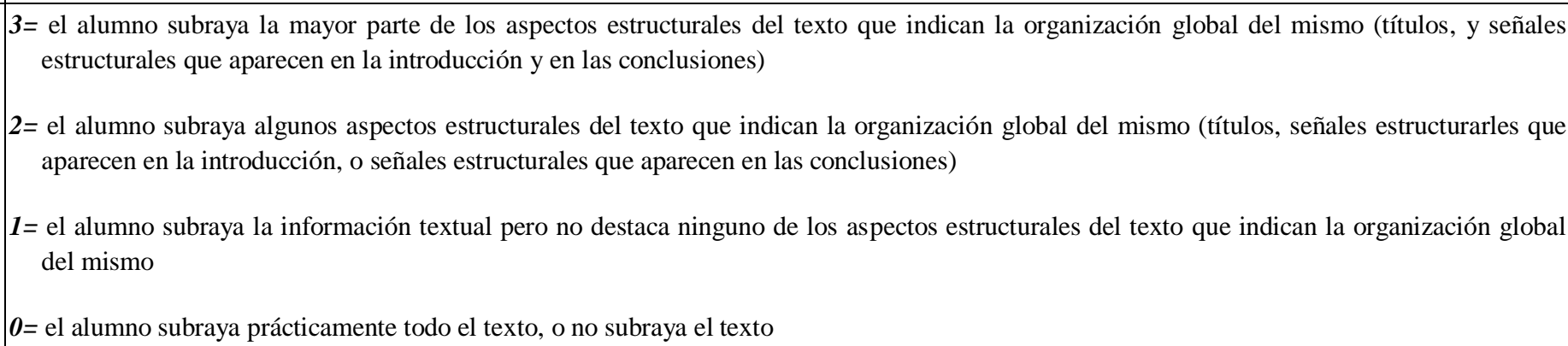 \\
\hline $\begin{array}{c}\text { Anotaciones realizadas en el artículo (Texto } \\
\text { impreso) }\end{array}$ & $\begin{array}{l}\mathbf{2}=\text { el alumno realiza anotaciones que asocian la información destacada con ideas que aparecen previamente, y/o realiza anotaciones en las que } \\
\text { reflexiona en torno a la información destacada } \\
\boldsymbol{1}=\text { el alumno realiza anotaciones que se limitan a copiar/parafrasear parte de la información destacada } \\
\boldsymbol{0}=\text { el alumno no hace anotaciones en el artículo o no queda claro lo que quiere decir en dichas anotaciones }\end{array}$ \\
\hline Integración Intertextual (Texto impreso) & $\begin{array}{l}3=\text { el alumno subraya en el texto información vinculada al pie de página, y la recoge en el resumen que construye integrándola adecuadamente } \\
2=\text { el alumno subraya en el texto información vinculada al pie de página, y aunque la recoge en el resumen que construye, no es capaz de } \\
\text { integrarla adecuadamente } \\
\boldsymbol{1}=\text { el alumno subraya en el texto información vinculada al pie de página, que no recoge en el resumen que construye } \\
\boldsymbol{0}=\text { el alumno no subraya en el texto, ni recoge en el resumen que construye información vinculada al pie de página }\end{array}$ \\
\hline Realización de Borrador & $\begin{array}{l}3=\text { el alumno utiliza el borrador (texto lineal o mapa conceptual) como guía estructurada para el resumen } \\
2=\text { el alumno utiliza el borrador (selecciona palabras clave del texto) como guía desestructurada para realizar el resumen } \\
\boldsymbol{1}=\text { el alumno utiliza el borrador, pero el texto que escribe es una copia literal o paráfrasis cercana la copia del texto original } \\
\boldsymbol{0}=\text { el alumno no utiliza un borrador }\end{array}$ \\
\hline
\end{tabular}




\begin{tabular}{|c|c|}
\hline \multicolumn{2}{|r|}{ VDTH $_{1}$. Uso de habilidades de comprensión y expresión escrita para realizar el resumen de un texto } \\
\hline Sub-variables & Categorías de Evaluación y Definición Conceptual \\
\hline Resumen de la información & 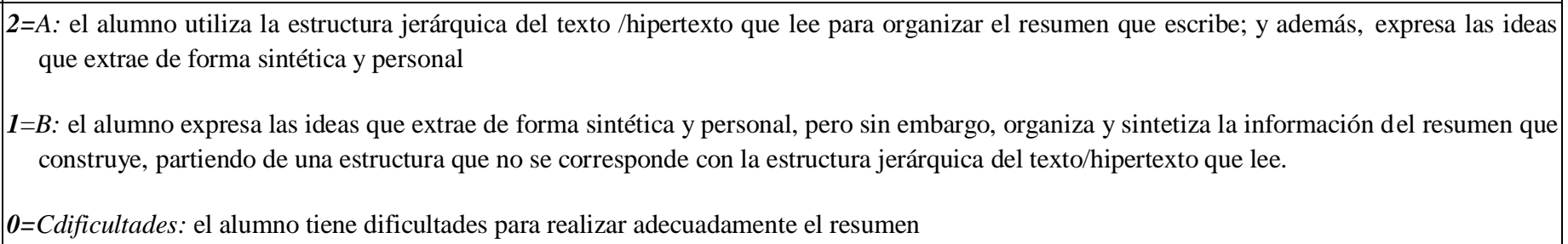 \\
\hline Dificultades en la realización del resumen & $\begin{array}{l}3=C_{1}: \text { el alumno es capaz de organizar el texto que escribe en torno a una estructura global, pero malinterpreta información, no la sintetiza } \\
\text { suficientemente, o no la presenta de modo personal } \\
2=C_{2}: \text { el alumno construye un texto cuyo significado global no está claro } \\
1=C_{3}: \text { el alumno copia literalmente del texto original la mayor parte de la información que utiliza en el texto que escribe }\end{array}$ \\
\hline
\end{tabular}

Cuadro 2.32. Uso de habilidades de comprensión y expresión escrita para realizar el resumen del texto $\left(\mathrm{VDTH}_{1}\right)$ 


\begin{tabular}{|c|c|}
\hline Sub-Variables & Categorías de Evaluación y Definición Conceptual \\
\hline $\begin{array}{c}\text { Procedimiento lectura (Texto } \\
\text { impreso) }\end{array}$ & $\begin{array}{l}\begin{array}{l}3=\text { el alumno hace dos o más lecturas y subraya el texto (durante la } \\
\text { primera o segunda lectura) }\end{array} \\
2=\text { el alumno hace una lectura, y va subrayando simultáneamente } \\
\boldsymbol{I}=\text { el alumno lee una o dos veces el texto sin subrayarlo } \\
\boldsymbol{0}=\mathrm{NS} / \mathrm{NC}\end{array}$ \\
\hline $\begin{array}{l}\text { Procedimiento escritura (Texto } \\
\text { impreso) }\end{array}$ & $\begin{array}{l}4=\text { el alumno realiza alguno de los tres pasos anteriores, y luego relee } \\
\text { el resumen y omite información } \\
3=\text { el alumno hace un borrador y/o anotaciones en el artículo, y } \\
\text { partiendo de esto hace el resumen } \\
2=\text { el alumno hace el resumen a partir de lo que ha subrayado } \\
\boldsymbol{1}=\text { el alumno hace el resumen directamente del texto } \\
\boldsymbol{0}=\mathrm{NS} / \mathrm{NC}\end{array}$ \\
\hline
\end{tabular}

Cuadro 2.33. Procedimiento que el alumnado considera haber seguido para realizar el resumen del texto $\left(\mathrm{VDTH}_{2}\right)$

En cuanto a la evaluación de las variables dependientes secundarias de este Diseño (VS1. Dificultades encontradas por el alumnado para realizar la tarea; VS2. Utilización de las ayudas a la comprensión lectora (Glosario); VS3. Opinión del alumnado), se establecieron los siguientes criterios de evaluación: 


\begin{tabular}{|c|c|c|}
\hline \multicolumn{3}{|c|}{ VS1.Dificultades encontradas, VS2.Utilización de ayudas y VS3.Opinión sobre la tarea } \\
\hline $\begin{array}{c}\text { Variables } \\
\text { Dependientes }\end{array}$ & $\begin{array}{c}\text { Variables dependientes } \\
\text { asociadas }\end{array}$ & Definición operativa \\
\hline $\begin{array}{l}\text { VS1. Dificultades } \\
\text { encontradas por el } \\
\text { alumnado para } \\
\text { realizar la tarea }\end{array}$ & $\begin{array}{l}\text { VS1.1.Dificultades } \\
\text { encontradas por alumnado } \\
\text { que realizó la tarea a partir } \\
\text { de texto impreso }\end{array}$ & $\begin{array}{l}\boldsymbol{6}=\text { el alumno dice no tener dificultad a la hora de } \\
\text { hacer la tarea } \\
5=\text { el alumno dice que el texto era demasiado } \\
\text { extenso } \\
4=\text { el alumno asegura que le faltó tiempo para } \\
\text { realizar la tarea } \\
3=\text { el alumno señala que el tema del texto le resultó } \\
\text { poco familiar o que el vocabulario que aparecía } \\
\text { en el texto era muy complejo } \\
2=\text { el alumno asegura haber tenido dificultades a la } \\
\text { hora de redactar el resumen } \\
1=\text { el alumno asegura haber tenido dificultades } \\
\text { durante el proceso de comprensión lectora } \\
\text { (selección de información, extracción de ideas } \\
\text { principales...) } \\
0=\text { NS/NC }\end{array}$ \\
\hline $\begin{array}{l}\text { VS2. Uso de ayudas a } \\
\text { la comprensión lectura } \\
\text { (Glosario de términos) }\end{array}$ & & $\begin{array}{l}\boldsymbol{L}=\text { el alumno utiliza Glosario } \\
\boldsymbol{I}=\text { el alumno no utiliza Glosario } \\
\boldsymbol{0}=\text { el alumno no utiliza Glosario a pesar de afirmar } \\
\text { tener problemas para entender algunos de los } \\
\text { términos del texto/hipertexto }\end{array}$ \\
\hline VS3.Opinión tarea & & $\begin{array}{l}2=\text { el alumno señala que este tipo de tareas es } \\
\text { importante para la construcción de conocimiento } \\
\boldsymbol{I =} \text { el alumno asegura que este tipo de tareas no es } \\
\text { importante para la construcción de conocimiento } \\
\boldsymbol{0}=\mathrm{NS} / \mathrm{NC}\end{array}$ \\
\hline
\end{tabular}

Cuadro 2.34. Dificultades encontradas (VS1), Utilización de ayudas (VS2), y Opinión sobre la tarea (VS3) (texto impreso)

\subsubsection{Post-test: Prueba resumen del texto hipervinculado}

El artículo impreso que habíamos adaptado, lo convertimos en un hipertexto que disponía de una página/nodo principal, cuyo contenido: a) respetaba la estructura de formato impreso (mantenía sus señales estructurales), y b) recogía un conjunto de enlaces que comunicaban con otros nodos, favoreciendo una secuencia de lectura similar 
a la del documento impreso. Con ello pretendíamos, por un lado, asegurar que el alumnado, independientemente del formato textual en el que leyera el artículo, dispusiera de un referente claro para interpretar globalmente la información del texto/hipertexto (y por consiguiente, para satisfacer las demandas de la tarea); y por otro, comprobar si estableciendo la misma secuencia/orden de lectura en ambos formatos, la lectura intertextual de los nodos del hipertexto implicaba estrategias de comprensión y expresión escrita diferenciales a la lectura lineal del texto impreso.

Para delimitar la secuencia de lectura, establecimos una organización topológica o estructuración espacial que determinaba casi por completo el orden de acceso a los nodos hipertextuales. Concretamente, dentro de la página principal del hipertexto se integraron palabras/oraciones enlaces (enlaces implicados) que comunicaban con el contenido hipervinculado de forma: bidireccional (cada enlace daba acceso a un nodo y desde ese nodo se podía volver al trazo de información del texto principal donde se encontraba el enlace), secuencial (no se podía ir desde un nodo hacia otro sin pasar previamente por la página principal), y jerárquica (cada enlace comunicaba con información que era subordinada al trazo de información donde se situaba el enlace). De esta manera, constituimos un hipertexto de tipo jerárquico sin ayudas a la navegación ${ }^{22}$, compuesto por un texto principal de 1859 palabras, en el que se integraban 4 palabras/oraciones enlace que conectaban con información hipervinculada (ver hipertexto adaptado en Anexo II.7):

- En el primer apartado existía un enlace, elaborada alrededor de la tecnología impresa, que llevaba a un nodo compuesto por 240 palabras; y a su vez, dentro este nodo se integraba otro hipervínculo, (1), que llevaba a otro nodo compuesto por 53 palabras (cuya información se correspondía con el pie de página del texto impreso).

- En el segundo apartado aparecían dos enlaces: lenguaje audiovisual, que llevaba a un tercer nodo compuesto por 86 palabras; e hipertextualidad, que conectaba con un cuarto nodo con 228 palabras.

- Para finalizar, en el cuarto apartado existía otro hipervínculo, preparación y cualificación de los agentes educativos, que conectaba con un quinto nodo compuesto por 543 palabras.

La navegación hipertextual se diseñó para reducir la carga cognitiva extraña o ineficaz y aumentar la carga eficaz. En primer lugar, los pocos enlaces que existían se podían identificar fácilmente, ya que, además de estar subrayados, estaban destacados con un color más claro (celeste) que el del texto en el que se integraban. En segundo

\footnotetext{
${ }^{22}$ Planteamos la posibilidad de utilizar un hipertexto de tipo jerárquico, en cuya página principal los enlaces hipertextuales se integraran dentro un esquema de navegación (que mostrara las relaciones jerárquicas existentes entre dichos enlaces). Pero pronto descartamos esta opción, ya que, por un lado, hubiera facilitado al lector de hipertexto un esquema organizativo previo a la lectura que no disponía el lector de texto impreso; y por otro, se alejaría de lo que entendemos por documento académico (un texto que no está específicamente adaptado para ser utilizado en procesos de enseñanza-aprendizaje).
} 
lugar, cuando el lector situaba el ratón sobre un enlace, el puntero se convertía en una flecha, lo que le indicaba la opción de acceder al contenido de ese enlace. En tercer lugar, cuando el lector clikeaba un enlace, se sustituía el nodo en el que se encontraban por el nodo con el que comunicaba dicho enlace (para evitar que la superposición de ventanas pudiese provocar la desorientación del lector dentro del hipertexto); y una vez visitado dicho nodo, el hipervínculo cambiaba a un color oscuro indicando que había sido consultado. Finalmente, el lector podía acceder desde la página/texto principal a la mayor parte de los nodos clickeando en sus respectivos enlaces (1: $N)$; al tiempo que podía volver a la página/texto principal (desde la mayor parte de los nodos) clickeando un icono que se encontraba en la parte superior izquierda de la pantalla $(N: 1)$. Solamente había un nodo, (1), al que no se podía acceder desde la página principal del hipertexto, y desde el que no se podía volver a la página principal; ya que era necesario pasar obligatoriamente por un nodo intermedio (donde se encontraba el enlace que comunicaba con dicho nodo).

Una vez construido el hipertexto, realizamos un análisis por apartados similar al que hicimos con el texto impreso, destacando en este caso, las inferencias que debía realizar el alumno a la hora de incluir la información de los hipervínculos dentro de la página principal del hipertexto (ver análisis en Anexo II.8). No obstante, no nos pareció necesario hacer un análisis a nivel global del hipertexto, ya que como hemos mencionado, tanto el texto impreso como la página principal del hipertexto compartían la misma estructura; y por tanto, las estrategias que los alumnos debían utilizar para satisfacer las demandas de la tarea de resumen eran similares en ambos formatos textuales.

Partiendo de esos análisis, establecimos un conjunto de rúbricas de evaluación que nos permitieron valorar los resúmenes que realizaron los alumnos a partir de hipertexto. La mayor parte de estas rúbricas eran las mismas que las del texto impreso, salvo algunas que incorporaban algunos ítems específicos al formato textual, tales como integración intertextual, procedimiento de lectura y dificultades tareas; y algunas subvariables que no se evaluaban para hipertexto, como anotaciones realizadas en artículo o tipo de información subrayada.

Para clarificar los análisis realizados con el hipertexto, a continuación, mostraremos los análisis de contenido realizados al apartado 2. Y una vez hecho esto explicitaremos las rúbricas de evaluación de hipertexto. 


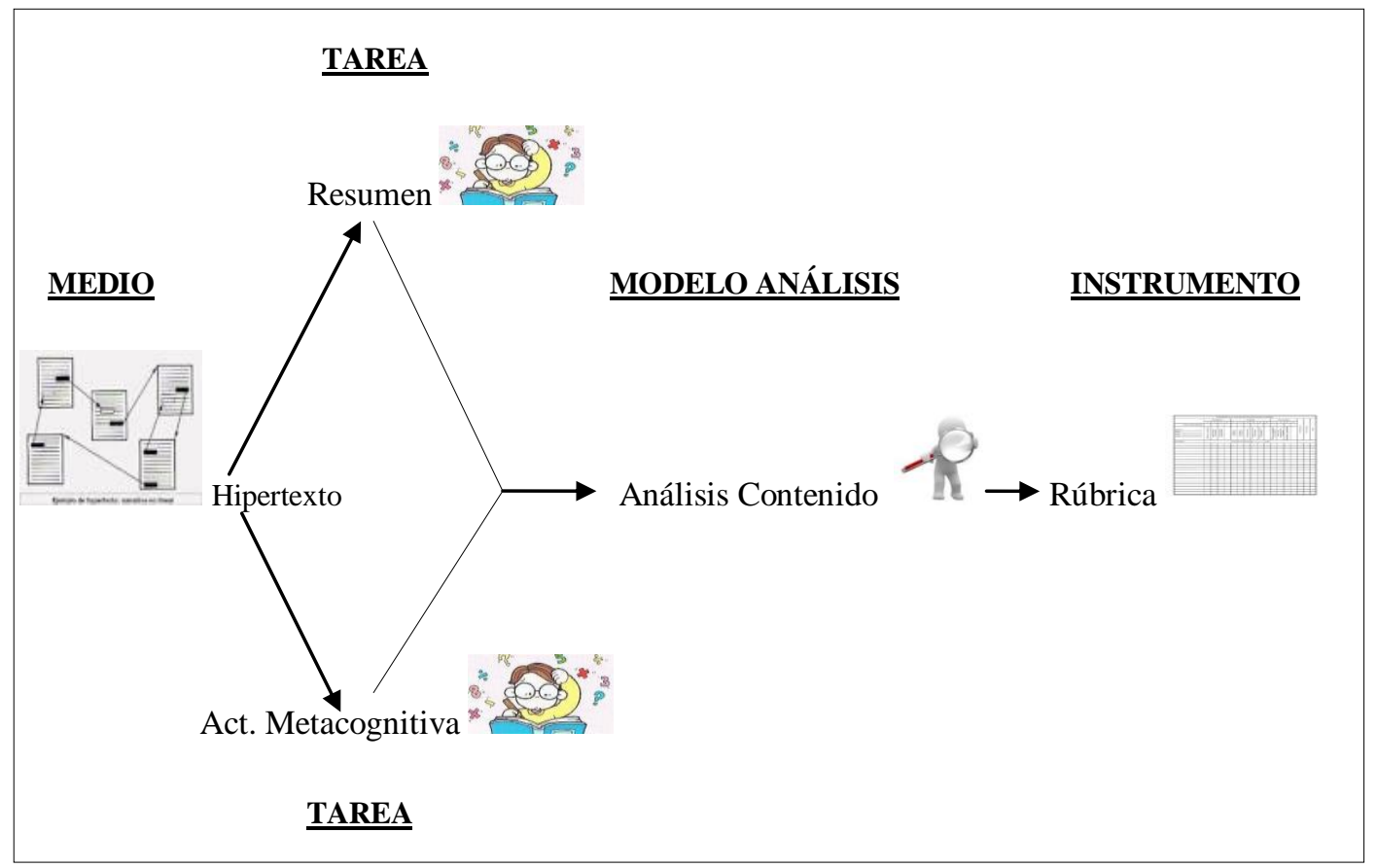

Cuadro 2.35. Esquema de evaluación del efecto del formato textual sobre las estrategias específicas de C y EE (Hipertexto)

\section{A) Análisis de contenido hipertexto}

Ejemplo de análisis del apartado 2 del hipertexto

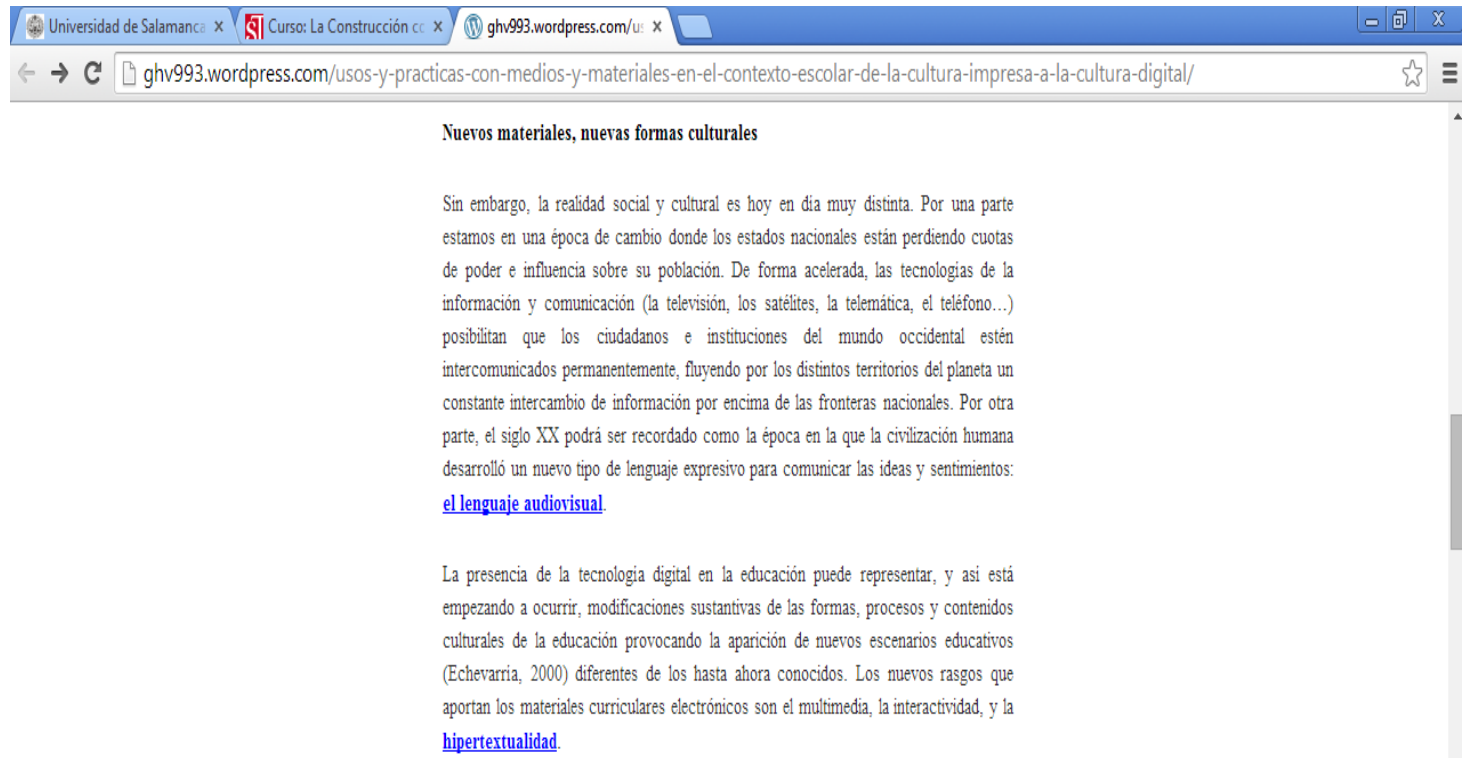

Imagen 2.1. Contenido del apartado 2 (página principal del hipertexto) 


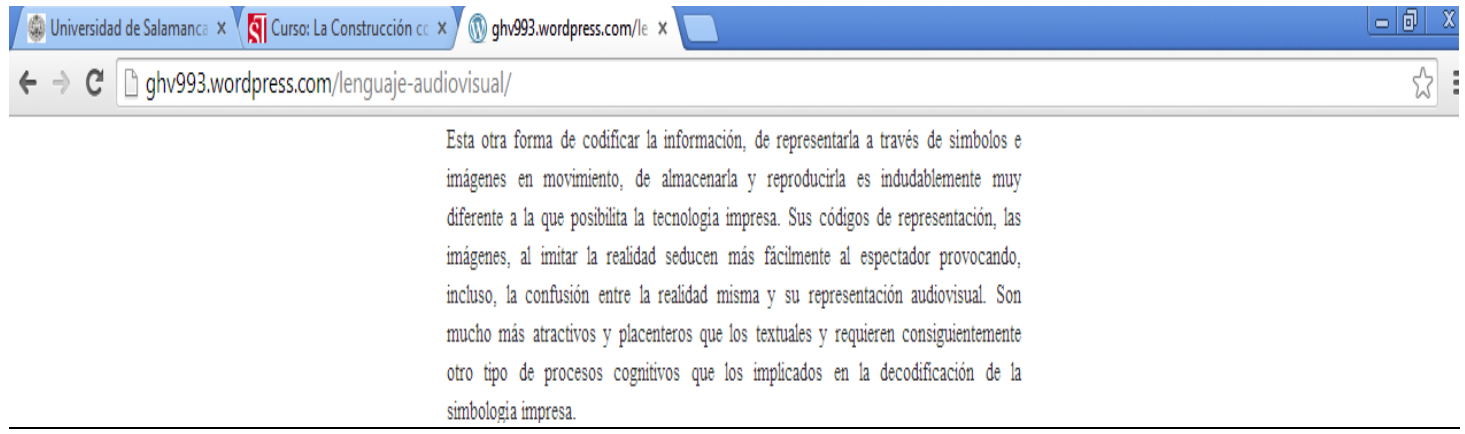

Imagen 2.2. Información asociada al hipervínculo el lenguaje audiovisual

\begin{tabular}{|c|c|c|}
\hline \multicolumn{3}{|c|}{ 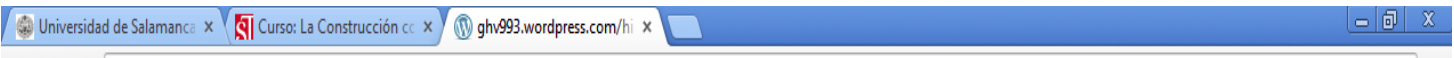 } \\
\hline$\leftarrow \Rightarrow$ C $\square$ ghv993.wordpress.com/hipertextualida & & $\xi \equiv$ \\
\hline & 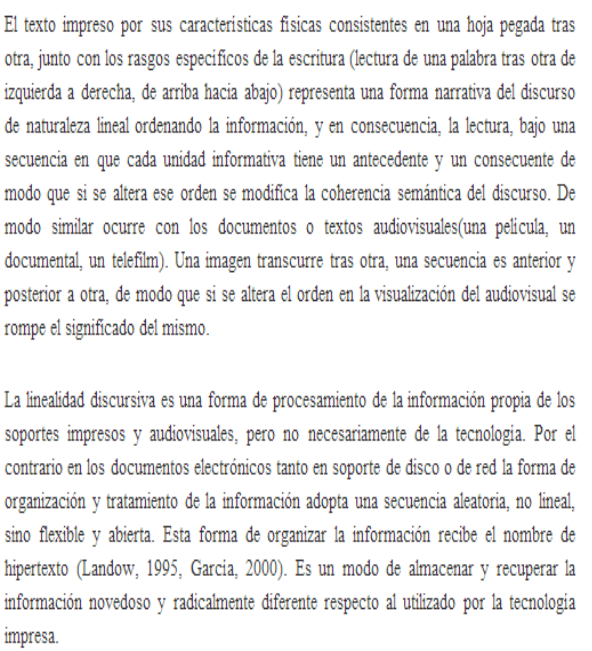 & \\
\hline
\end{tabular}

Imagen 2.3. Información asociada al hipervínculo hipertextualidad

\section{Progresión Temática en el apartado 2}

- La información del apartado gira en torno nuevas formas culturales que traen consigo las TIC. A su vez, este tema se divide en los siguientes subtemas:

- Cambios que provocan las TIC en la realidad social y cultural, con respecto a lo mencionado en el apartado 1.

- La presencia de la tecnología digital en la escuela puede suponer cambios en cultura escuela que provoquen la aparición de nuevos escenarios educativos.

Cuadro 2.36. Progresión temática en el apartado 2 del hipertexto 


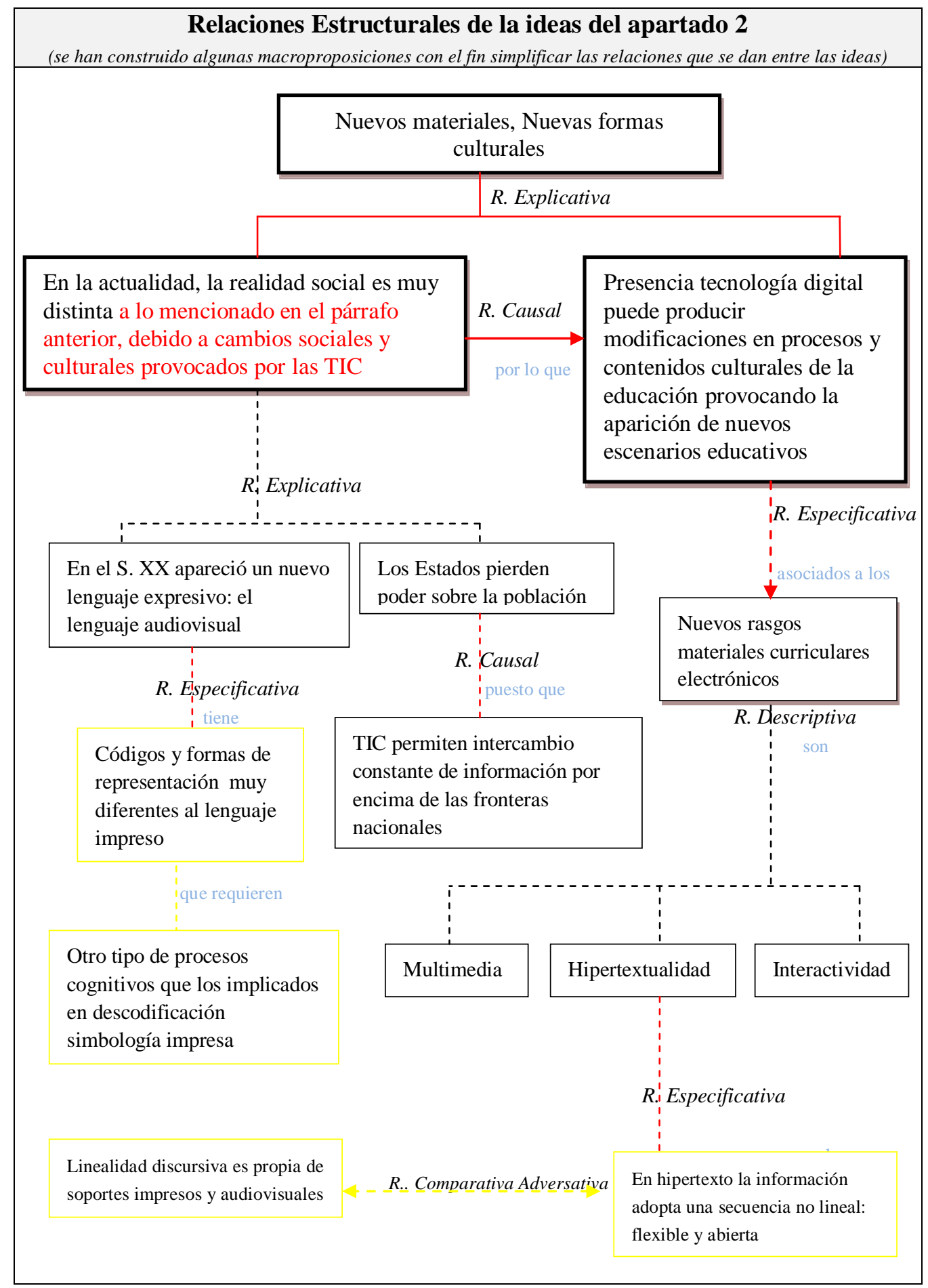

Cuadro 2.37. Relaciones estructurales en el apartado 2 del hipertexto

* Línea continua: relaciones estructurales predominantes dentro del párrafo

* Línea discontinua: relaciones estructurales subordinadas dentro del párrafo

* Línea roja: inferencia de una conexión estructural

* Cuadros de texto destacados en negro: ideas importantes del apartado para construir macroestructura

* Información cuadro texto en letra roja: macroproposiciones construidas a través de la macroestrategia de construcción

* Cuadros y líneas amarillas: ideas y relaciones estructurales que aparecen dentro de los hipervínculos 


\begin{tabular}{|c|c|c|}
\hline \multicolumn{3}{|c|}{ Grado de cohesión textual del apartado 2} \\
\hline $\begin{array}{l}\text { Grado de } \\
\text { cohesión } \\
\text { (Escala 0-5) }\end{array}$ & Aspectos explícitos que favorecen cohesión & Aspectos implícitos y grado de exigencia de las inferencias a realizar \\
\hline (2) Baja & $\begin{array}{l}\text { a) Vinculados a la correferencia argumental } \\
\text { - } \\
\text { - Reiteración de Hipertextualidad/Hipertexto } \\
\text { Recurrencia a sinónimos y antónimos (discurso lineal/linealidad discursiva, } \\
\text { posterior) } \\
\text { - Recurrencia a hiperónimos (TIC/ audivisual, digital) } \\
\text { - Uso de pronombres (esta) y de posesivos (sus) } \\
\text { - Concordancia nominal de género y número (entre artículos y sustantivos; entre } \\
\text { adjetivos y sustantivos; y entre pronombre y referente); y concordancia verbal de } \\
\text { número y persona (entre verbo y sujeto). } \\
\text { b) Vinculados a la dimensión espacio-temporal: } \\
\text { - Uso de tiempos verbales en presente, para reflejar que se están produciendo y se } \\
\text { pueden producir una serie de cambios asociados a las tecnologías de la } \\
\text { información y la comunicación } \\
\text { - Uso de tiempos verbales en pasado, para señalar que los cambios se están } \\
\text { produciendo desde el pasado (desde la aparición del lenguaje audiovisual) } \\
\text { c) Relacionados con señalizaciones entre ideas: } \\
\text { Uso de conectores entre ideas: artículos determinantes (la, una, el, los), de } \\
\text { conjunciones (y, e, que), preposiciones ( } \text {, de, por, con, bajo) }\end{array}$ & $\begin{array}{l}\text { a) Inferencias de dificultad baja: } \\
\text { - Aunque no existe ningún tipo de conector que indique la relación causal entre "los } \\
\text { estados pierden poder sobre su población" y "las TIC permiten intercambio de } \\
\text { información por encima de fronteras nacionales"; no es muy difícil inferirla } \\
\text { partiendo del contenido semántico de ambas ideas } \\
\text { - Aunque no existe ningún tipo de conector que indique la relación especificativa } \\
\text { entre "la presencia de la tecnología digital puede producir modificaciones en los } \\
\text { contenidos culturales de la educación" y "nuevos rasgos de los materiales } \\
\text { curriculares electrónicos"; no es muy difícil inferirla partiendo del contenido } \\
\text { semántico de ambas ideas } \\
\text { - Teniendo en cuenta que hipertextualidad e hipertexto son términos similares, y que } \\
\text { "hipertextualidad" es el concepto que sirve de enlace para acceder al hipervínculo } \\
\text { 4; el alumno no debería tener problemas para percibir que el hipervínculo } 4 \\
\text { describe la hipertextualidad } \\
\text { Teniendo en cuenta que "lenguaje audiovisual" es el concepto que sirve de enlace } \\
\text { para acceder al hipervínculo 3, y que dentro de éste ultimo existen señales que } \\
\text { indican que la información del hipervínculo describe el enlace; consideramos que } \\
\text { la integración de la información del vínculo dentro del texto principal, no debería } \\
\text { entrañar una gran dificultad para el alumno } \\
\text { Inferencias que exigen poner en marcha habilidades de comprensión lectora: } \\
\text { El alumno debe utilizar la macroestrategia de construcción para categorizar la } \\
\text { información que aparece en el párrafo 1. Para ello, debe tener en cuenta que el } \\
\text { lenguaje audiovisual es propio de las TIC (el glosario de términos muestra } \\
\text { claramente esta relación), y que, por tanto, el primer párrafo habla de los cambios } \\
\text { sociales y culturales provocados por las TIC }\end{array}$ \\
\hline
\end{tabular}




\begin{tabular}{|c|c|c|c|c|c|}
\hline \multicolumn{6}{|c|}{ Grado de cohesión textual del apartado 2} \\
\hline $\begin{array}{l}\text { Grado de } \\
\text { cohesión } \\
\text { (Escala 0-5) }\end{array}$ & & & Aspectos explícitos que favorecen cohesión & & Aspectos implícitos y grado de exigencia de las inferencia a realizar \\
\hline (2) Baja & & $\begin{array}{l}\text { Relacio } \\
\text { Uso } \\
\text { - } \\
\text { - Títul } \\
\text { Lelacio } \\
\text { La p } \\
\text { hoy } \\
\text { idea }\end{array}$ & $\begin{array}{l}\text { lados con señalizaciones entre ideas: } \\
\text { le señalizaciones estructurales: } \\
\text { Utilización de conectores enumerativos (por una parte...por otra parte) en el } \\
\text { primer apartado, que profundizan en las razones que llevan al autor enunciar la } \\
\text { primera oración del apartado } \\
\text { Uso de conector comparativo igualatorio (de modo similar) en el párrafo 3, que } \\
\text { permite igualar texto y documento audiovisual en cuanto a la linealidad de } \\
\text { ambos } \\
\text { zados con la identificación de la macroestructura del texto } \\
\text { del apartado: "Nuevos materiales, nuevas formas culturales" } \\
\text { imera oración de este apartado, "Sin embargo, la realidad social y cultural es } \\
\text { ndía muy distinta"; indica una relación estructural adversativa con respecto a la } \\
\text { expresadas en el apartado } 1\end{array}$ & b) & $\begin{array}{l}\text { Inferencias que exigen poner en marcha habilidades de comprensión lectora: } \\
\text { - Para inferir la relación causal dominante del apartado (ver cuadros de texto } \\
\text { destacados en el cuadro 2.37), el alumno, por un lado, debe tomar como } \\
\text { referencia el título del apartado; y por otro, debe saber que las tecnologías } \\
\text { digitales que se mencionan en el segundo párrafo, se incluyen dentro de las TIC } \\
\text { que se citan en el primer párrafo (el glosario de términos muestra claramente esta } \\
\text { relación) }\end{array}$ \\
\hline
\end{tabular}

Cuadro 2.38. Grado de cohesión textual en el apartado 2 del hipertexto 


\section{A) Rúbricas de evaluación hipertexto}

\begin{tabular}{|c|c|}
\hline \multicolumn{2}{|r|}{ VDTH $_{1}$. Uso de habilidades de comprensión y expresión escrita para realizar el resumen de un hipertexto } \\
\hline Sub-variables & Categorías de Evaluación y Definición Conceptual \\
\hline $\begin{array}{l}\text { Integración } \\
\text { intertextual } \\
\text { (Hipertexto) }\end{array}$ & $\begin{array}{l}\begin{array}{l}3=\text { el alumno recoge información de los hipervínculos en el resumen que construye, y toma como referencia la estructura jerárquica de la página principal del hipertexto a la hora de realizar inferencias } \\
\text { puente que permitan integrar la información dentro del resumen que escribe }\end{array} \\
\begin{array}{l}2=\text { el alumno recoge información de los hipervínculos en el resumen que construye, y aunque es capaz de establecer inferencias puente, no toma como referencia la estructura jerárquica de la página } \\
\text { principal del hipertexto a la hora de integrar la información dentro del resumen que escribe }\end{array} \\
\boldsymbol{I}=\text { el alumno recoge información de los hipervínculos en el resumen que construye, pero la mayor parte de las veces tiene problemas para integrar la información } \\
\boldsymbol{0}=\text { el alumno no recoge información de los hipervínculos en el resumen que construye }\end{array}$ \\
\hline $\begin{array}{c}\text { Realización de } \\
\text { borrador }\end{array}$ & $\begin{array}{l}3=\text { el alumno utiliza el borrador (texto lineal o mapa conceptual) como guía estructurada para el resumen } \\
2=\text { el alumno utiliza el borrador (selecciona palabras clave del texto) como guía desestructurada para realizar el resumen } \\
\boldsymbol{I}=\text { el alumno utiliza el borrador, pero el texto que escribe es una copia literal o una paráfrasis cercana la copia del texto original } \\
\boldsymbol{0}=\text { el alumno no utiliza un borrador }\end{array}$ \\
\hline $\begin{array}{l}\text { Resumen de la } \\
\text { información }\end{array}$ & $\begin{array}{l}2=A: \text { el alumno utiliza la estructura jerárquica del texto /hipertexto que lee para organizar el resumen que escribe; y además, expresa las ideas que extrae de forma sintética y personal } \\
\begin{array}{l}\boldsymbol{I}=B \text { : el alumno expresa las ideas que extrae de forma sintética y personal, pero sin embargo, organiza y sintetiza la información del resumen que construye, partiendo de una estructura que no se } \\
\text { corresponde con la estructura jerárquica del texto/hipertexto que lee }\end{array} \\
\boldsymbol{0}=\text { Cdificultades: el alumno tiene dificultades para realizar adecuadamente el resumen }\end{array}$ \\
\hline $\begin{array}{l}\text { Dificultades en la } \\
\text { realización del } \\
\text { resumen }\end{array}$ & $\begin{array}{l}3=C_{l}: \text { el alumno es capaz de organizar el texto que escribe en torno a una estructura global, pero malinterpreta información , no la sintetiza suficientemente, o no la presenta de modo personal } \\
2=C_{2}: \text { el alumno construye un texto cuyo significado global no está claro } \\
\boldsymbol{I}=C_{3}: \text { el alumno copia literalmente del texto original la mayor parte de la información que utiliza en el texto que escribe }\end{array}$ \\
\hline
\end{tabular}

Cuadro 2.39. Uso de habilidades de comprensión y expresión escrita para realizar el resumen de hipertexto 


\begin{tabular}{|c|c|}
\hline \multicolumn{2}{|c|}{ REALIZAR EL RESUMEN DE HIPERTEXTO } \\
\hline Sub-Variables & Categorías de Evaluación y Definición Conceptual \\
\hline $\begin{array}{l}\text { Procedimiento lectura } \\
\text { (Hipertexto })\end{array}$ & 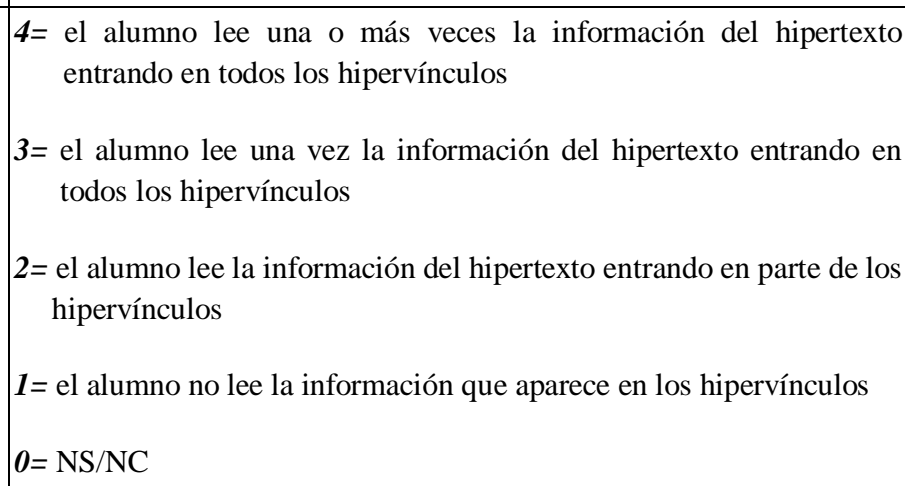 \\
\hline $\begin{array}{l}\text { Procedimiento escritura } \\
\text { (Hipertexto })\end{array}$ & 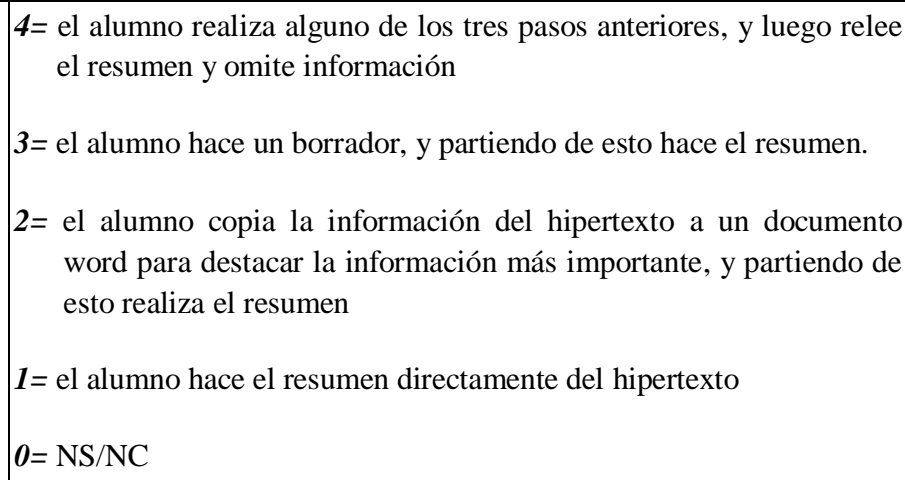 \\
\hline
\end{tabular}

Cuadro 2.40. Procedimientos que el alumnado considera haber seguido para realizar el resumen de hipertexto 


\begin{tabular}{|c|c|c|}
\hline \multicolumn{3}{|c|}{ VS1.Dificultades encontradas, VS2.utilización de ayudas y VS3.Opinión sobre la tarea } \\
\hline $\begin{array}{c}\text { Variables Dependientes } \\
\text { Secundarias }\end{array}$ & $\begin{array}{l}\text { Variables dependientes } \\
\text { secundarias asociadas }\end{array}$ & Definición operativa \\
\hline $\begin{array}{c}\text { VS1. Dificultades } \\
\text { encontradas por el } \\
\text { alumnado para realizar } \\
\text { la tarea }\end{array}$ & $\begin{array}{l}\text { VDS1.2.Dificultades } \\
\text { encontradas por el } \\
\text { alumnado que realizó la } \\
\text { tarea a partir de } \\
\text { hipertexto }\end{array}$ & $\begin{aligned} \boldsymbol{7}= & \text { el alumno dice no tener dificultad a la hora de } \\
& \text { hacer la tarea } \\
& \text { extenso }\end{aligned}$ \\
\hline $\begin{array}{l}\text { VS2. Uso de ayudas a la } \\
\text { comprensión lectura } \\
\text { (Glosario de términos) }\end{array}$ & & $\begin{aligned} \boldsymbol{L}= & \text { el alumno utiliza Glosario } \\
\boldsymbol{I}= & \text { el alumno no utiliza Glosario } \\
\boldsymbol{O}= & \text { el alumno no utiliza Glosario a pesar de afirmar } \\
& \text { tener problemas para entender algunos de los } \\
& \text { términos del texto/hipertexto }\end{aligned}$ \\
\hline VS3. Opinión tarea & & $\begin{aligned} 2= & \text { el alumno señala que este tipo de tareas es } \\
& \text { importante para la construcción de conocimiento } \\
\boldsymbol{1}= & \text { el alumno asegura que este tipo de tareas no es } \\
& \text { importante para la construcción de conocimiento } \\
\boldsymbol{0}= & \mathrm{NS} / \mathrm{NC}\end{aligned}$ \\
\hline
\end{tabular}

Cuadro 2.41. Dificultades encontradas (VS1), Utilización de ayudas (VS2), y Opinión sobre la tarea (VS3) (Hipertexto)

(Los resúmenes realizados por los alumnos que leyeron el texto en formato impreso, y por los que lo leyeron en formato hipertextual, se pueden consultar en el Anexo II.9. Por su parte, la valoración de los mismos se encuentra en el Anexo II.10) 
Cabe destacar que, igual que en el Diseño I (Pre-test de este segundo diseño), tanto los criterios de evaluación como la valoración de las tareas realizadas por los alumnos fueron validadas mediante la técnica de juicio de expertos (Cabero Almenara y Barroso, 2013). Si bien, en este caso, variamos el procedimiento por dos razones: a) no pudimos contar con el juicio de un experto externo a la investigación, y b) nuestro investigador experto tenía una disponibilidad limitada. Debido a ello, los productos de tarea del alumnado fueron evaluados por dos investigadores (el investigador principal y el investigador experto) hasta que hubo un alto grado de consenso en las valoraciones (esto ocurrió cuando, al evaluar de manera consecutiva las tareas realizadas por al menos seis alumnos, las divergencias entre investigadores se limitaban a uno o dos aspectos puntuales). Una vez logrado ese grado de acuerdo, únicamente el investigador principal continuó valorando los productos de tarea restantes.

\subsection{POBLACIÓN Y MUESTRA}

Para la realización de esta investigación, partimos de una población compuesta por los siguientes sujetos:

1. Alumnos de nuevo ingreso de la Universidad de Salamanca que comenzaban los estudios de Grado de Maestro durante el curso académico 2012/2013; y

2. Alumnos matriculados en la Licenciatura de Psicopedagogía en el curso 2012/2013 titulados en alguna de las Diplomaturas de Maestro que se impartían en la Universidad de Salamanca.

\begin{tabular}{|c|c|c|c|c|c|c|c|c|}
\hline \multicolumn{9}{|c|}{$\begin{array}{c}\text { Alumnado matriculados en } 1^{\circ} \text { curso en los Grados de Maestro y en la Licenciatura en Psicopedagogía } \\
\text { durante el curso académico 2012/2013 }\end{array}$} \\
\hline & \multicolumn{6}{|c|}{ GRADOS DE MAESTRO } & \multirow{3}{*}{$\begin{array}{c}\text { LICENCIATURA } \\
\text { PSICOPEDAGOGÍA } \\
\end{array}$} & \multirow{3}{*}{ Tota } \\
\hline & \multicolumn{3}{|c|}{ Educación Primaria } & \multicolumn{3}{|c|}{ Educación Infantil } & & \\
\hline & $\begin{array}{c}\text { Facultad } \\
\text { Educación } \\
\text { Salamanca }\end{array}$ & $\begin{array}{c}\text { E.U. } \\
\text { Zamora }\end{array}$ & $\begin{array}{l}\text { E.U. } \\
\text { Ávila }\end{array}$ & $\begin{array}{c}\text { Facultad } \\
\text { Educación } \\
\text { Salamanca }\end{array}$ & $\begin{array}{c}\text { E.U. } \\
\text { Zamora }\end{array}$ & $\begin{array}{l}\text { E.U. } \\
\text { Ávila }\end{array}$ & & \\
\hline Frecuencia & 477 & 295 & 363 & 295 & 258 & 251 & 62 & 1706 \\
\hline
\end{tabular}

Tabla 2.1. Alumnado que accedió a los títulos de maestro en la Universidad de Salamanca en el curso $2012 / 2013$

*Datos recuperados de la web de la USAL de estadísticas:

http://campus.usal.es/ estadisticasgenerales/contenido/2-1-3.html

\subsubsection{Características de la muestra}

Debido a las dificultades que encontramos para extraer de forma aleatoria una muestra de la población de estudio, tomamos como muestra inicial tres grupos 
incidentales (dos de Educación Primaria y uno de Psicopedagogía) a los que tuvimos acceso durante las tres primeras semanas del curso académico 2012/2013.

\subsubsection{Muestra en el Diseño I :Tamaño y selección}

Para el Diseño I, partimos de una muestra inicial total de 155 alumnos, de los cuales, 105 estaban matriculados en $1^{\circ}$ de Educación Primaria (en adelante EDP) y 50 en $1^{\circ}$ curso de Psicopedagogía (en adelante PSP).

Una vez realizadas las pruebas correspondientes a este diseño, analizamos las respuestas dadas por el alumnado a algunos ítems del cuestionario, con el fin de seleccionar aquellos elementos de la muestra inicial total que estarían dentro de la muestra definitiva. Estos ítems son:

- Ítem 3: ¿Has estado matriculado en alguna otra carrera universitaria?

- Ítem 4: Universidad o centro de procedencia

- Ítem 5: Carrera que da acceso a los estudios de segundo ciclo (Nota: este ítem sólo se presentó en el cuestionario que realizaron los alumnos de Psicopedagogía)

Partiendo de las respuestas dadas por los alumnos a estos ítems, comprobamos que 16 alumnos de EDP (un alumno que había estado matriculado en EDP en un curso académico anterior y 15 alumnos que habían estado matriculados previamente en otra carrera universitaria) y 9 alumnos de PSP (5 alumnos titulados en otra universidad española, 2 alumnos que habían accedido al segundo ciclo a través de una titulación que no era el título de maestro y 2 alumnos que provenían de una universidad extranjera) quedaban fuera de la muestra.

Teniendo en cuenta lo anterior, la muestra definitiva de este primer diseño quedó finalmente compuesta por 130 alumnos.

\begin{tabular}{c|c|c|c}
\hline \multicolumn{3}{c|}{ Muestra final Diseño I } & \\
\hline & \multicolumn{3}{c}{$\begin{array}{c}\text { GRUPO DE ESTUDIO } \\
\text { (carrera universitaria) }\end{array}$} \\
\cline { 2 - 4 } & $P S P$ & $E D P$ & Total alumnos \\
\hline Frecuencia & $\mathbf{4 1}$ & $\mathbf{8 9}$ & $\mathbf{1 3 0}$ \\
$\%$ & 31,5 & 68,5 & 100.0 \\
\hline
\end{tabular}

Tabla 2.2. Muestra final para el Diseño I 


\subsubsection{Muestra en el Diseño II: Tamaño y selección}

De los 130 alumnos del Diseño I, 24 no realizaron las pruebas que exclusivamente correspondían al Diseño II. Teniendo en cuenta que el Diseño I es la fase Pre-test del Diseño II, la muestra inicial para este segundo diseño se redujo a los 106 que realizaron todas las pruebas (tanto el Pres-test como el Pos-test).

Estos 106 alumnos fueron divididos en cuatro grupos en función del momento formativo en el que se encontraban y del formato textual (asignado al azar) en el que habían realizado la tarea académica de la fase Pos-test.

De esta forma, la muestra inicial quedó definida de la siguiente manera:

- Grupo 1. EDP Texto: compuesto por 33 alumnos de Educación Primaria de los turnos de mañana y tarde, que habían realizado la tarea a partir de la lectura de un texto impreso.

- Grupo 2. EDP Hipertexto: compuesto 34 alumnos de Educación Primaria de los turnos de mañana y tarde, que habían realizado la tarea a partir de la lectura de un hipertexto.

- Grupo 3. PSP Texto: compuesto por 17 alumnos de Psicopedagogía, que habían realizado la tarea a partir de la lectura de un texto impreso.

- Grupo 4. PSP Hipertexto: compuesto por 22 alumnos de Psicopedagogía, que habían realizado la tarea a partir de la lectura de un hipertexto.

Una vez realizadas las pruebas correspondientes a este diseño, analizamos las respuestas del alumnado utilizando los mismos ítems del cuestionario que señalamos para Diseño I; con el fin de seleccionar aquellos elementos de la muestra inicial que estarían dentro de la población de estudio.

Partiendo de las respuestas dadas por los alumnos a estos ítems, comprobamos que 2 alumnos de EDP texto, 3 alumnos EDP hipertexto, 4 alumnos de PSP texto y 1 alumno de PSP hipertexto quedaban fuera de la muestra. Los de EDP texto e hipertexto porque habían estado matriculados previamente en otra carrera universitaria; y los de PSP texto e hipertexto porque habían obtenido el título de maestro en otra universidad española.

Tomando en consideración todo lo anterior, la muestra de este segundo diseño quedó finalmente compuesta por 96 alumnos. 


\begin{tabular}{c|c|c|c|c|c}
\hline \multicolumn{5}{c|}{ Muestra Final Diseño II } \\
\hline & \multicolumn{4}{|c}{$\begin{array}{c}\text { GRUPO DE ESTUDIO } \\
\text { (carrera universitaria y formato textual tarea) }\end{array}$} \\
\cline { 2 - 6 } & PSP Hipertexto & EDP Hipertexto & PSP Texto & EDP Texto & Total alumnos \\
\hline \multirow{2}{*}{ Frecuencia } & $\mathbf{2 1}$ & $\mathbf{3 1}$ & $\mathbf{1 3}$ & $\mathbf{3 1}$ & $\mathbf{9 6}$ \\
\hline$\%$ & 21,9 & 32,3 & 13,5 & 32,3 & 100.0 \\
\hline
\end{tabular}

Tabla 2.3. Muestra final para el Diseño II

\subsection{TRABAJO DE CAMPO: APLICACIÓN DE LAS PRUEBAS Y TEMPORALIZACIÓN}

\subsubsection{Aplicación de pruebas del Diseño I (fase Pre-test Diseño II) y temporalización}

Todos los instrumentos de recogida de información vinculados a este diseño o fase (cuestionario identificativo de contexto y prueba de habilidades básicas de comprensión y expresión escrita PHBC-E) se unificaron bajo el nombre de "Evaluación de habilidades básicas para la comprensión y expresión escrita", dentro de una batería de pruebas que se presentó en formato impreso (ver Anexos I.2 y I.3).

Esta batería disponía de una página inicial donde, en primer lugar, se informaba al alumnado sobre cuál era el objetivo de las pruebas que iba a realizar; en segundo lugar, se solicitaba a dichos alumnos que realizaran tales pruebas lo mejor que supiesen; y tercer lugar, se agradecía a todos los participantes su colaboración. Tras esta página, aparecía un cuestionario que, dependiendo del momento formativo, variaba levemente en algunas de sus preguntas (ver versiones del cuestionario para Primaria y Psicopedagogía en los Anexos I.2 y I.3 respectivamente). Para finalizar, las últimas dos páginas recogían una prueba de habilidades básicas de comprensión y expresión escrita:

- en la primera página aparecía una tabla que presentaba dos columnas y nueve filas, mientras la primera columna mostraba los nueve párrafos que componían el texto que los alumnos debían leer, la segunda descubría nueve espacios en blanco reservados para que escribieran las ideas principales que elaboraban a partir de la lectura de cada párrafo. Encima de la tabla se guardó un espacio destinado a recoger los datos identificativos del alumnado (nombre y apellidos) y a explicar brevemente la primera tarea (extraer las ideas principales de cada párrafo).

- en la segunda página aparecía un gran cuadro de texto, y encima del mismo se explicaba la segunda tarea (realizar un mapa conceptual del texto leído). 
A la hora de aplicar esta batería de pruebas debimos tener en cuenta dos aspectos fundamentales: el tiempo y el espacio.

En lo que respecta al tiempo, estimamos que la realización de todas las pruebas entrañaría un máximo de una hora (incluidos 10 minutos para explicar al alumnado las tareas que debían hacer); por lo que solicitamos a un profesor de cada grupo-clase una hora dentro del horario académico. Finalmente, la aplicación de las pruebas quedó establecida para el día 4 de octubre de 2012, comenzando a las 11:00 los grupos-clase que tenían turno de mañana (Psicopedagogía y Educación Primaria turno de mañana) y a las 16:00 el de Educación Primaria turno tarde.

En cuanto al espacio, realizamos la aplicación de la batería de pruebas en el aula habitual de cada grupo-clase.

\begin{tabular}{|c|c|c|c|c|c|c|c|}
\hline & \multicolumn{7}{|c|}{ TEMPORALIZACIÓN } \\
\hline $\begin{array}{c}\text { Grupo- } \\
\text { clase }\end{array}$ & Fecha & Aula & $\begin{array}{l}\text { Grupo } \\
\text { estudio }\end{array}$ & Inicio & Final & $\begin{array}{l}\text { Tiempo } \\
\text { empleado } \\
\text { primer alumno } \\
\text { acaba prueba }\end{array}$ & $\begin{array}{l}\text { Tiempo empleado } \\
\text { último alumno } \\
\text { acaba prueba }\end{array}$ \\
\hline $\begin{array}{c}1^{\circ} \\
\text { Psicoped }\end{array}$ & $4 / 10 / 2012$ & 20 & PSP & $11: 06$ & $11: 58$ & $28^{\prime}$ & $52^{\prime}$ \\
\hline $\begin{array}{c}\text { Ed. } \\
\text { Primaria } \\
\text { (mañana) }\end{array}$ & $4 / 10 / 2012$ & 21 & EDP & $11: 07$ & $12: 05$ & $25^{\prime}$ & $58^{\prime}$ \\
\hline $\begin{array}{c}\text { Ed. } \\
\text { Primaria } \\
\text { tarde) }\end{array}$ & $4 / 10 / 2012$ & 21 & EDP & $16: 05$ & $17: 12$ & $22^{\prime}$ & $47^{\prime}$ \\
\hline
\end{tabular}

Cuadro 2.42. Temporalización de las pruebas del Diseño I (Pre-test Diseño II)

Como se puede visualizar en el cuadro anterior, dos de los grupos comenzaban las pruebas a la misma hora pero en aulas distintas (Psicopedagogía y Educación Primaria turno mañana), mientras que el tercer grupo realizaba las pruebas en el mismo aula que uno de los grupos anteriores pero a una hora diferente (Educación Primaria turno tarde). Debido a esto, las sesiones que coincidían en el tiempo debían supervisarlas dos investigadores diferentes; mientras que las sesiones que se realizaron en el mismo espacio las podía aplicar un mismo investigador pero en diferentes horarios. Todo ello podía hacer que cada uno de los grupos-clase tuviese una experiencia intersensorial diferente a la hora de realizar las pruebas, por lo que para minimizar dicho efecto, y a su vez, disminuir la carga cognitiva ineficaz y aumentar la eficaz asociadas a las instrucciones para realizar las tareas; construimos una plantilla base, que utilizaron los investigadores para tratar de explicar, de la forma más similar posible a todos los grupos, las tareas que debían realizar: 
- Presentación (quiénes somos, cuál es nuestro objetivo de investigación)

- Descripción breve de las pruebas a realizar (cuestionario y prueba de habilidades básicas de comprensión y expresión escrita):

- leer los enunciados de cada una de las tareas;

- explicar brevemente cuáles eran los espacios reservados para realizar dichas tareas; e

- indicar el tiempo máximo disponible para la realización de las pruebas (1 hora).

- Incidir a los alumnos en que se identifiquen con nombres y apellidos en el lugar destinado para eso, explicando la razón que nos lleva a pedirles dichos datos (es imprescindible saber quién ha hecho cada prueba para poder triangular los resultados obtenidos con los resultados de las pruebas que harían la semana siguiente en otra sesión).

- Garantizar el anonimato de las identidades de los alumnos a la hora de difundir los resultados de la investigación.

- Solicitar al alumnado que realice las pruebas tal y como las suelen realizar.

Durante la aplicación de la prueba, para verificar si el tiempo destinado para la realización de la tarea era suficiente, anotamos lo que tardaron el alumno que finalizó el primero y el alumno que finalizó el último en cada uno de los grupos-clase. De forma que, como se aprecia en el cuadro 2.42, el alumno que más tiempo empleó en la realización de las tareas fue un alumno del grupo EDP (58') que pertenecía al grupoclase de Educación Primaria turno mañana, siendo también el que menos tardó un alumno del mismo grupo de estudio (22) aunque de diferente grupo-clase (Educación Primaria turno tarde).

\subsubsection{Aplicación de pruebas Pos-test del Diseño II y temporalización}

Para recoger información en torno a esta fase Pos-test construimos un curso dentro de la plataforma Moodle (Studium) de la Universidad de Salamanca, que llamamos "La construcción del conocimiento a través de fuentes digitales e impresas".

La página principal del curso estaba dividida en tres bloques: Diagrama de temas, Grupo A y Grupo B. 
El primer bloque era una breve introducción donde: se explicitaba el objetivo de la prueba, se solicitaba que ésta se realizase de la mejor forma posible y, finalmente, se agradecía a todos los participantes su colaboración (imagen 2.4).

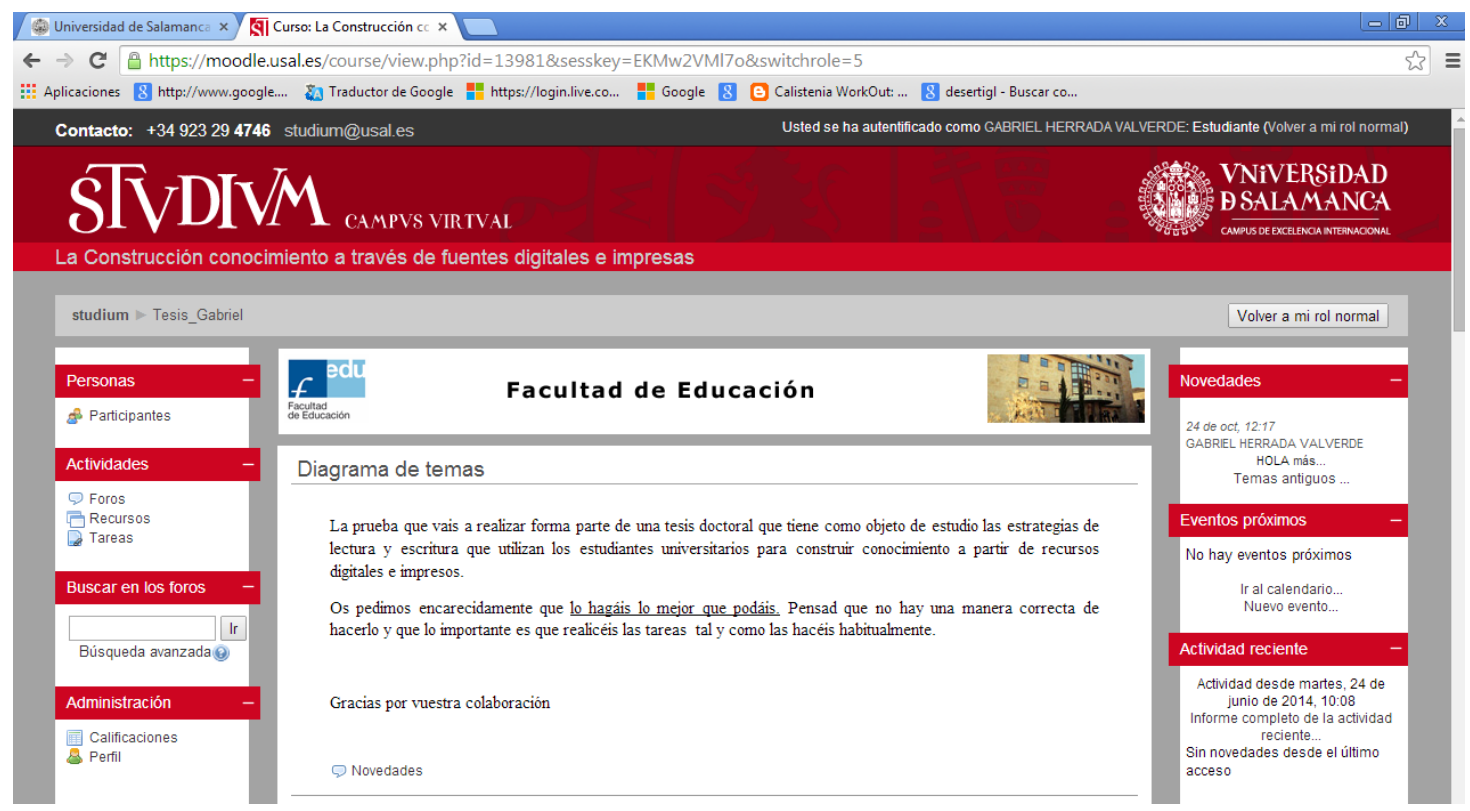

Imagen 2.4. Diagrama de temas

El segundo bloque, llamado grupo A, estaba destinado a describir/remitir los recursos que necesitarían para acometer las tareas, los alumnos que realizaban el resumen a partir de un texto impreso (imagen 2.5):

- por un lado, se les explicaba que dispondría de dos recursos impresos (un texto y un glosario de términos) y de un folio en blanco; y se les mencionaba la posibilidad de subrayar o tomar notas en el texto impreso o de tomar notas en el folio blanco, si así lo estimaban oportuno.

- por otro lado, se les remitía a tres enlaces (indicaciones para realizar la tarea, subir resumen, subir descripción pasos resumen) poniendo espacial hincapié en el primero de ellos, donde encontrarían las instrucciones precisas para realizar las tareas que les serían encomendadas. 


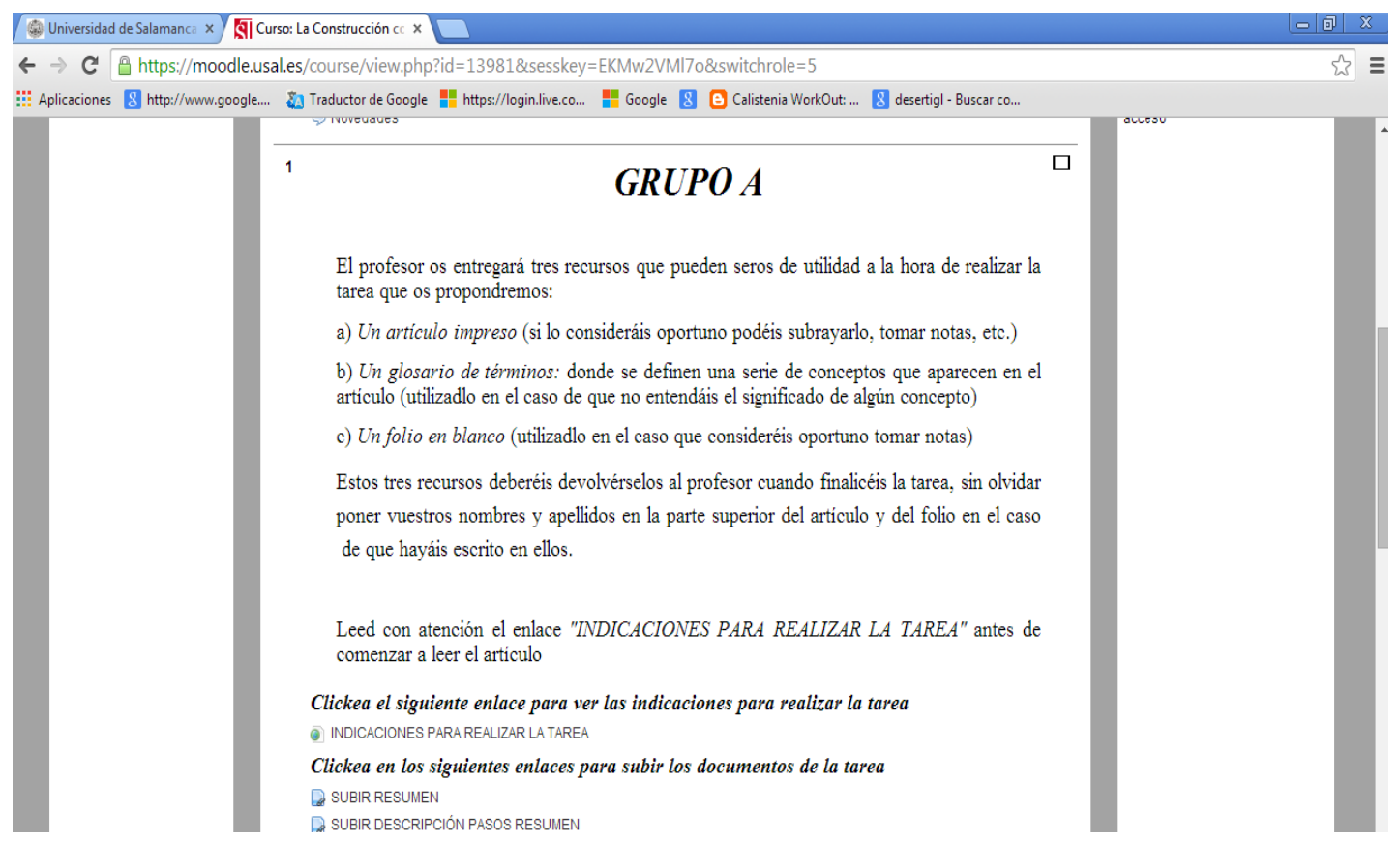

Imagen 2.5. Grupo A (alumnos que realizaron la tarea a partir de texto impreso)

Clickeando el primer enlace de este segundo bloque (Indicaciones para realizar la tarea) el alumno accedía a un nodo que recogía los pasos que debía seguir para realizar la tarea (imagen 2.6). Concretamente, indicaba:

- qué tenían que hacer: por un lado, resumir el artículo en un documento word utilizando 650 palabras máximo; y por otro, registrar los pasos dados a la hora hacer el resumen en otro documento word; realizando ambas tareas en un tiempo limitado a 2 horas.

- cómo debían de hacerlo: cómo abrir un documento word, qué tenían que escribir en cada documento, cómo debían llamar a cada archivo y cómo podían subir los archivos realizados a la plataforma Studium. 


\begin{tabular}{|c|c|}
\hline 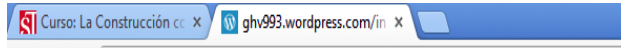 & 드. 回 $x$ \\
\hline$\leftarrow \Rightarrow$ C $\square$ ghv993.wordpress.com/indicaciones-para-realizar-la-prueba-a-1/ & $\xi \equiv$ \\
\hline
\end{tabular}

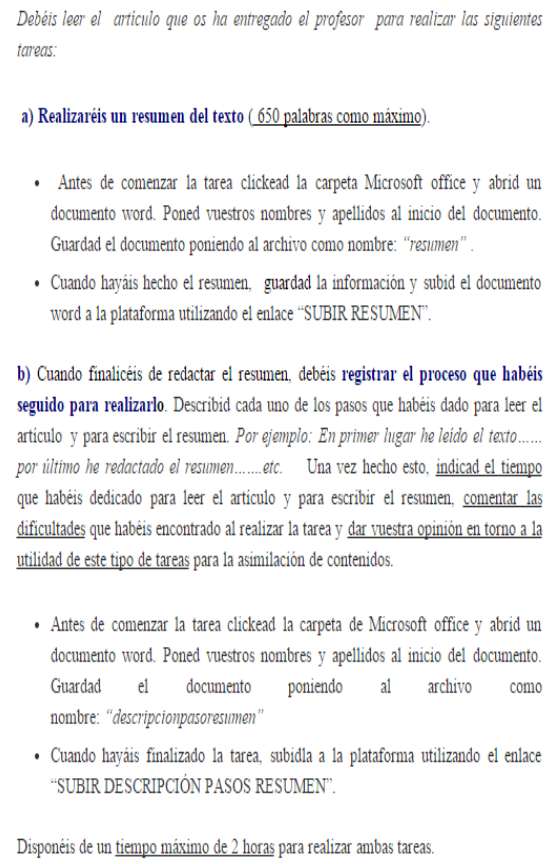

Imagen 2.6. Contenido del enlace "Indicaciones para realizar la tarea Grupo A"

En lo que se refiere al segundo enlace de este segundo bloque, contenía una breve explicación sobre cómo subir el resumen a la plataforma, así como un enlace que permitía subir el resumen (imagen 2.7).

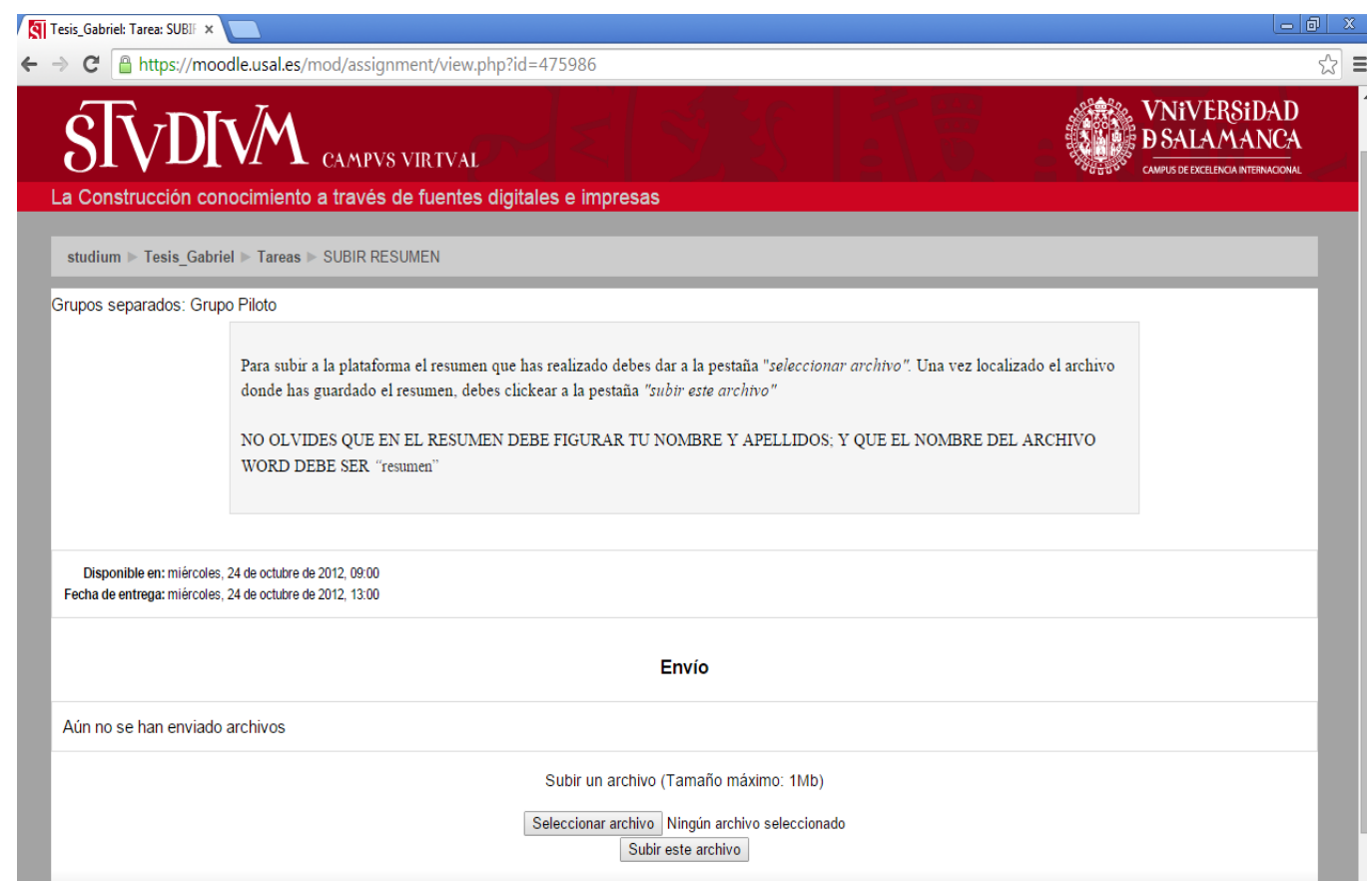

Imagen 2.7. Contenido del enlace "Subir resumen Grupo A" 
En cuanto al contenido del tercer enlace, cabe señalar que, por una parte, ofrecía una escueta información acerca de cómo subir el documento word en el alumno había registrado el procedimiento que había utilizado a la hora de realizar resumen; y por otra, aportaba un enlace para subir dicho documento a la plataforma (imagen 2.8).

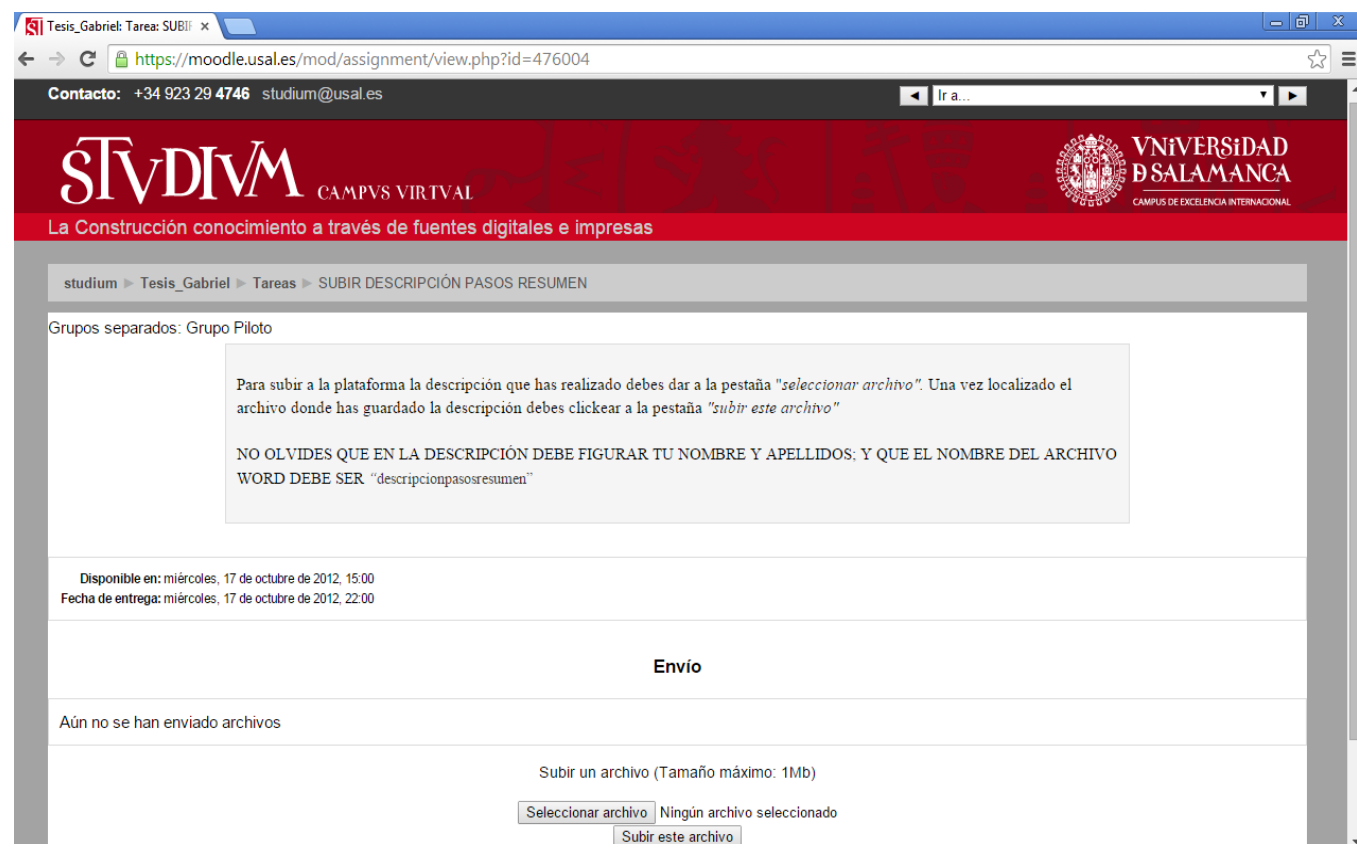

Imagen 2.8. Contenido del enlace "Subir descripción pasos resumen Grupo A"

El tercer bloque, llamado grupo $\mathrm{B}$, estaba destinado a describir/remitir los recursos que necesitarían para acometer las tareas, los alumnos que realizaban el resumen a partir de un hipertexto (imagen 2.9):

- por un lado, se les explicaba que dispondrían de un recurso impreso (glosario de términos) y de un folio en blanco, mencionándoles la posibilidad de tomar notas en este último, si así lo estimaban oportuno.

- por otro lado, se les remitía a cuatro enlaces (indicaciones para realizar la tarea, acceder al artículo (hipertexto), subir resumen, subir descripción pasos resumen) poniendo espacial hincapié en el primero de ellos. 


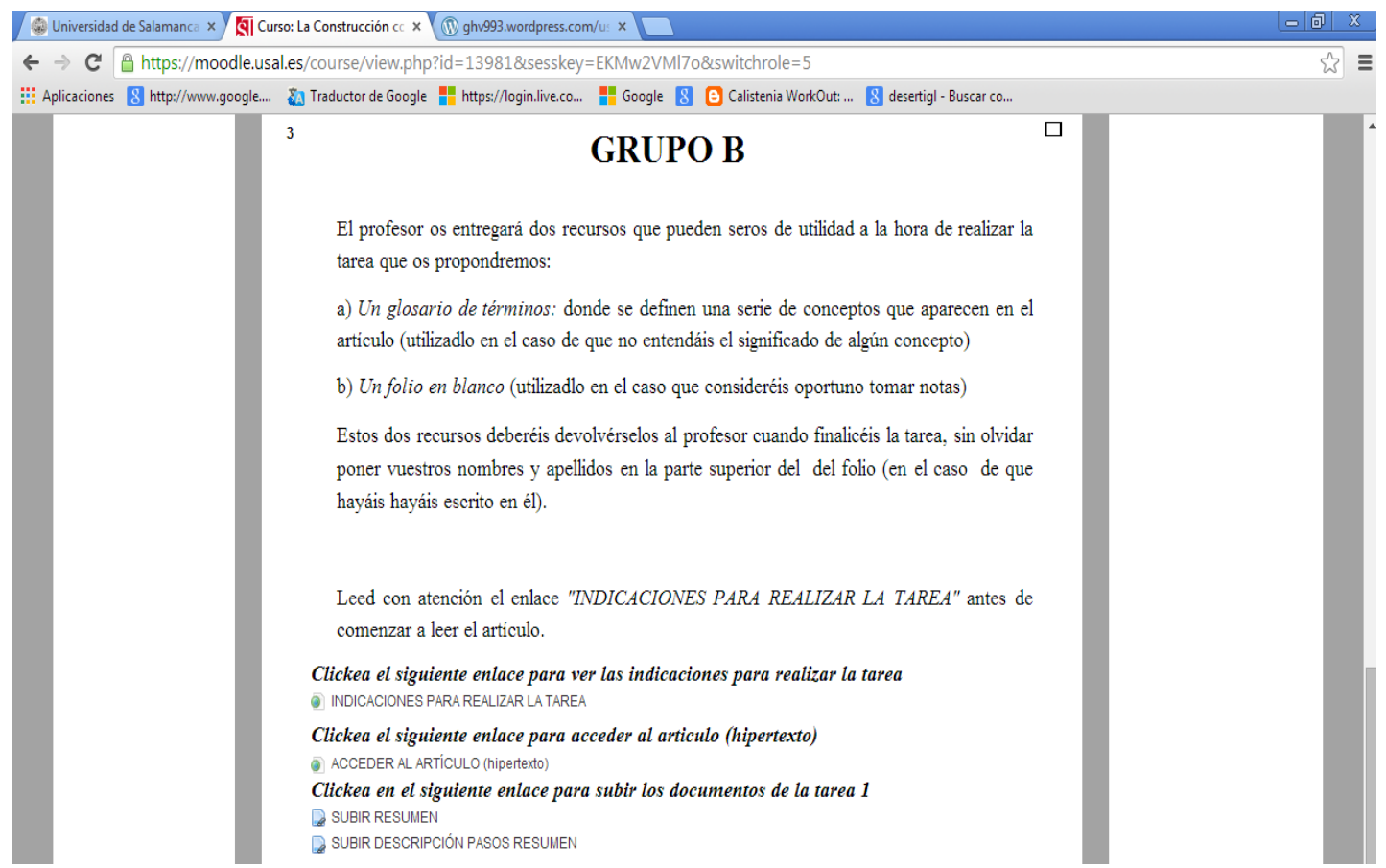

Imagen 2.9. Grupo B (alumnos que realizaron la tarea a partir de hipertexto)

Clickeando el primer enlace de este tercer bloque (indicaciones para realizar la tarea) el alumno accedía a un conjunto de pasos que debe seguir para realizar la tarea (imagen 2.10). Estas indicaciones eran similares a las del grupo A, y únicamente se diferenciaba en que, en este caso, en lugar de hablar de texto se habla de hipertexto.

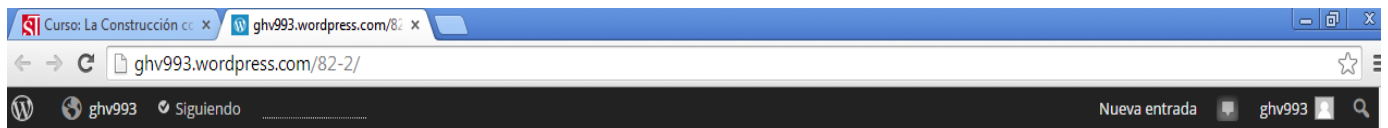

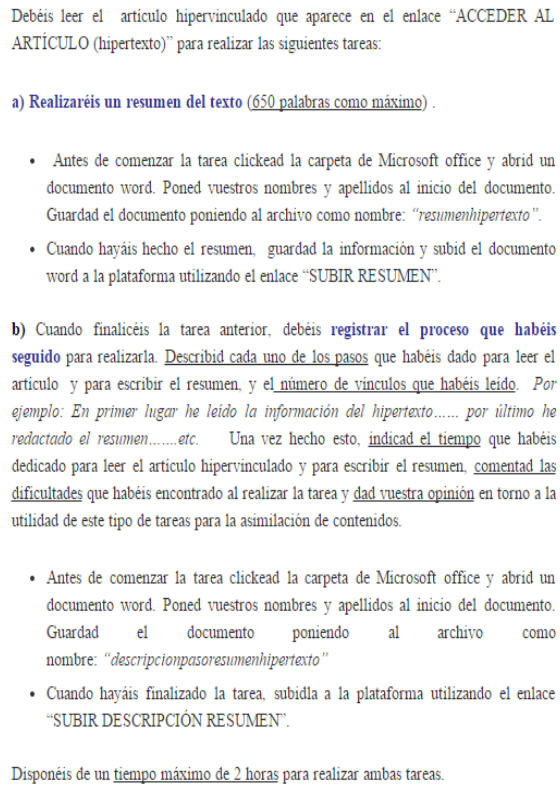

Imagen 2.10. Contenido del enlace "Indicaciones para realizar la tarea Grupo B" 
De la misma manera que señalamos para el grupo A, en este tercer bloque, el segundo enlace (subir resumen) se utilizaba para subir el resumen una vez finalizado (imagen 2.11); mientras que el tercer enlace (subir descripción pasos resumen) servía para subir el documento donde los alumnos recogen los pasos dados para realizar resumen (imagen 2.12).

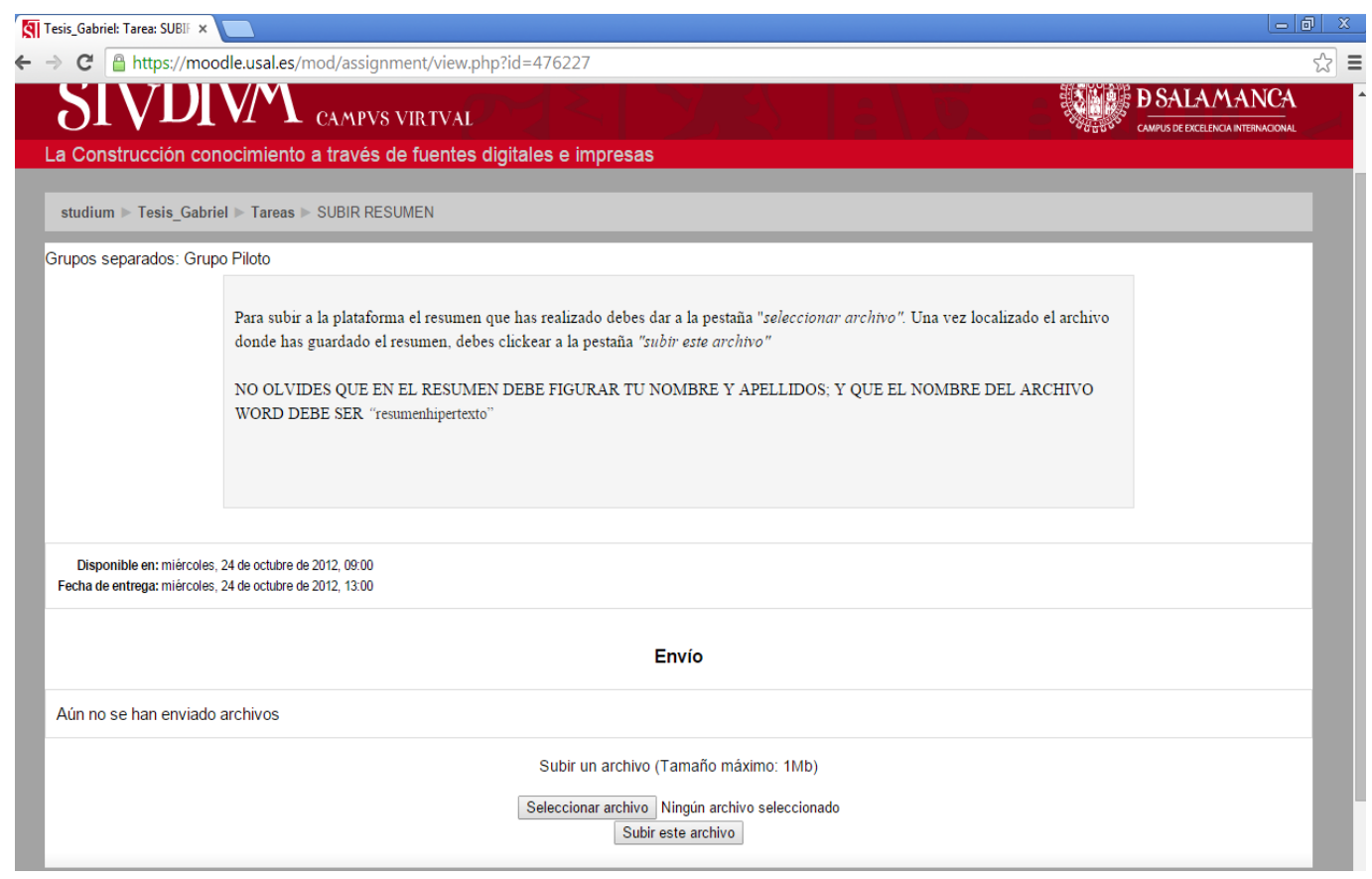

Imagen 2.11. Contenido del enlace "Subir resumen Grupo B"

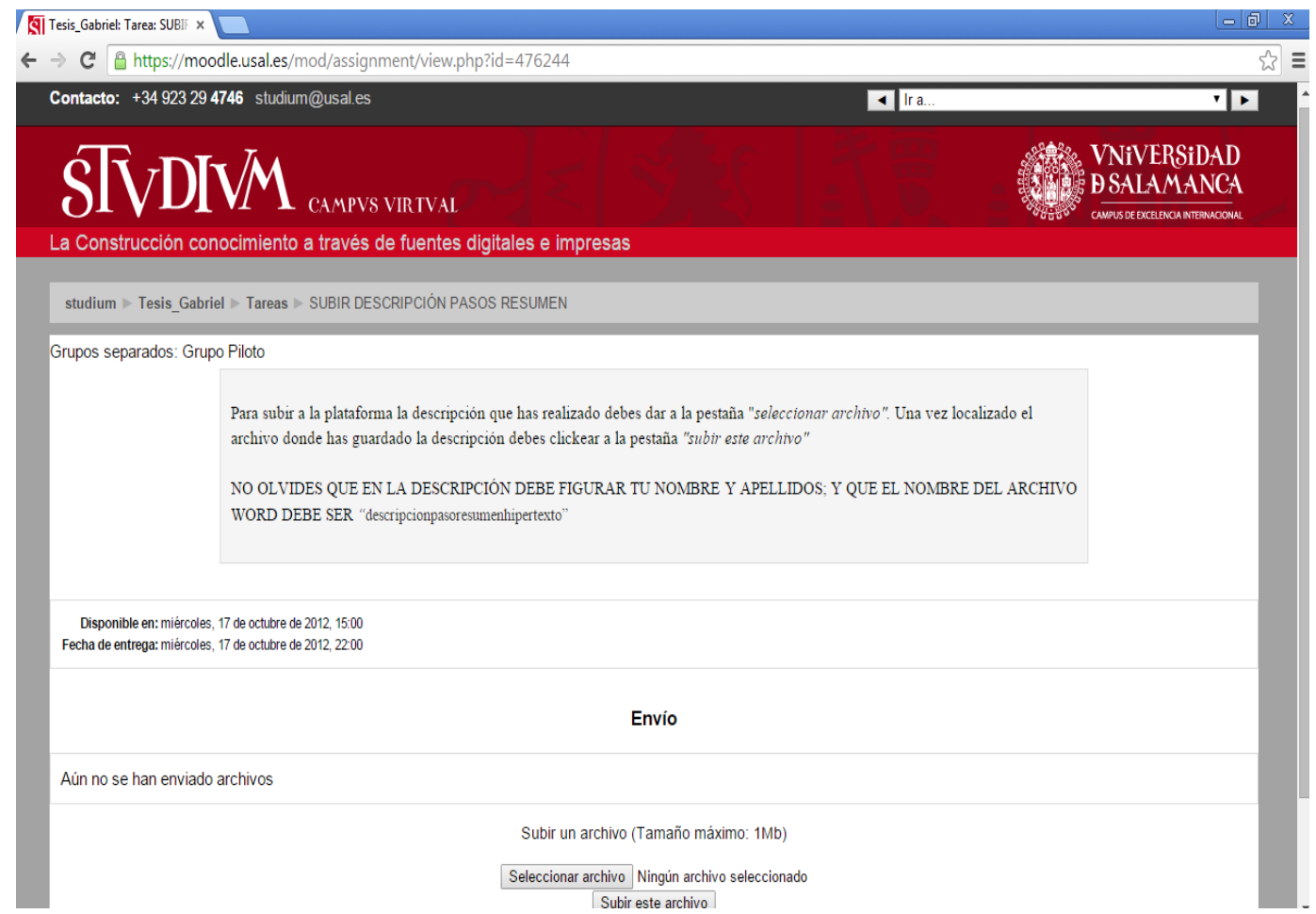

Imagen 2.12. Contenido del enlace "Subir descripción pasos resumen Grupo B" 
Una vez ubicado el curso dentro de la plataforma Studium, para aplicar la prueba debimos tener en cuenta el factor espacio-temporal, como ya hicimos en el Diseño I.

En cuanto al tiempo, consideramos oportuno realizar un ensayo previo con un grupo piloto formado por alumnos de $2^{\circ}$ curso de la Licenciatura en Psicopedagogía, para determinar el número de horas que necesitaría el alumnado para la realización de las tareas. En este estudio preliminar observamos que el investigador encargado de dar la información sobre las tareas tardó 5 minutos, que el primer alumno que finalizó la tarea lo hizo en 87 minutos, y que el último la hizo en 1 hora y 43 minutos; por lo que estimamos que sería necesario disponer de 2 horas por sesión: 10 minutos para trasladar al alumnado desde su aula de referencia al aula de informática (donde realizarían la prueba), 5 minutos para explicar las tareas que debían realizar, y 1 hora y 45 minutos para realizar las tareas que se les solicitaban. Tomando esto en consideración, pedimos a un profesor de cada uno de los grupos-clase ( $1^{\circ}$ Psicopedagogía, $1^{\circ}$ Educación Primaria mañana, $1^{\circ}$ Educación Primaria tarde) dos horas dentro del horario académico. Finalmente, la aplicación de la prueba quedó establecida el 10/10/2012 a las 10:00, para Psicopedagogía, el 17/10/2012 a las 18:00, para Educación Primaria turno tarde, y el 24/10/2012 a las 10:00, para Educación Primaria turno mañana.

En lo que se refiere al espacio, hemos de recordar que aunque los alumnos de los grupos PSP texto y EDP texto realizaron la prueba partiendo de la lectura de un texto impreso, éstos debían redactar tanto el resumen del texto como el procedimiento realizado para hacer el resumen en unos documentos word, que debían subir a la plataforma Studium a través de los enlaces destinados para ello. Teniendo en cuenta que la prueba de habilidades básicas de comprensión y expresión escrita la realizaron 50 alumnos de Psicopedagogía, 56 de Educación Primaria del turno de mañana y 49 de Educación Primaria del turno de tarde (incluyendo los alumnos que quedarían fuera de la muestra); consideramos necesario reservar tres aulas de informática para cada una de las sesiones. Concretamente, las aulas de informática 1 y 2 disponían de 15 equipos informáticos cada una, se encontraban una junto a otra y se comunicaban a través de una puerta; mientras que el aula de informática 3 disponía de 32 ordenadores y se localizaba en otro edificio de la Facultad de Educación de la Universidad de Salamanca.

Partiendo de los aspectos espacio-temporales descritos, nos encontramos con varios problemas:

a) Debido a la cantidad de alumnos que estimábamos que iban a realizar la prueba en cada sesión, se reservaron tres aulas diferentes, y por tanto, se necesitaron tres investigadores distintos que introdujeran al alumnado en las tareas que debían realizar.

b) Debido a que las sesiones no se realizaban por grupos de estudio, sino por grupos-clase, hubo grupos de estudio, como el grupo EDP texto y el EDP 
hipertexto, en los que parte de los alumnos realizaron la prueba el día 17/10/2012 a las 18:00, y parte la hicieron el día 24/10/2012 a las 10:00.

Ello podía provocar que entre los grupos de estudio, y dentro de cada uno de los grupos, se diese una historia intersensorial diferente a la hora de realizar la prueba. Por lo que, para tratar de minimizar dicho efecto, así como, para disminuir la carga cognitiva ineficaz y aumentar la eficaz asociadas a las instrucciones de las tareas; construimos una plantilla base, que utilizaron los investigadores con el fin de explicar a todos los grupos de estudio, de la forma más similar posible, las tareas que debían realizar, garantizando así, la fiabilidad en la aplicación:

- Ir al aula de referencia del grupo dos de los tres investigadores que pasan la prueba (no era necesario que fuese el tercer investigador, ya que los alumnos que iban a realizar la prueba en formato hipertextual lo harían en dos aulas contiguas).

- Presentación de la sesión-prueba (quiénes somos, cuál es nuestro objetivo de investigación).

- Asignar los alumnos de cada grupo-clase a un grupo estudio, tomando como criterio de asignación aleatoria la disposición espacial de los alumnos en el momento en el que llegamos a su aula. De esta forma, los que están sentados a la derecha del aula se integran en el grupo que leería en formato impreso el artículo que debían resumir (Grupo A), mientras que los que se encuentran a la izquierda de la misma conforman el grupo que lo leería en formato hipervinculado (Grupo B).

- Indicar a cada grupo de estudio qué investigador les va a llevar a su aula de destino, y hacer hincapié en la necesidad de ir directamente a dicha aula con el fin de comenzar la prueba lo antes posible.

- Durante el traslado de los alumnos, un investigador se dirige junto a los alumnos del grupo B a la planta baja del edificio, donde se encuentran las dos salas de informáticas contiguas en las que realizarán la prueba (en una de las salas se encuentra el tercer investigador); mientras que el otro lleva a los alumnos del grupo A a una sala de informática situada en otro edificio.

- Al llegar al aula de destino, los alumnos irán ocupando equipos informáticos conforme van entrando al aula (en el caso de los alumnos del grupo B, se realizó el mismo procedimiento ya que las dos aulas de informática en las que se realizaba la prueba estaban comunicadas por una puerta). 
- Una vez finalizado el traslado, el investigador dispone de un ordenador, un proyector y una pizarra digital para realizar un modelado sobre el uso de la plataforma, al tiempo que describe todo lo relacionado con las tareas que el alumnado debe acometer:

- En primer lugar, explica la función que tienen los recursos impresos que se encuentran junto a cada equipo informático (glosario de términos, folio en blanco, y, en el caso de los alumnos del grupo A, el texto en formato impreso)

- En segundo lugar, accede a la plataforma Studium, donde se encuentra toda la información necesaria para realizar las tareas, y resuelve los problemas de los alumnos que tienen alguna dificultad para acceder.

- En tercer lugar, lee en voz alta la información que encuentran los alumnos en el menú principal de Studium, así como en el contenido de los enlaces: indicaciones para realizar la tarea, subir resumen y subir descripción pasos resumen (en el caso de los alumnos del grupo B, el investigador accede al hipertexto y clickea en todos los hipervínculos, con el fin de que el alumnado no tenga dificultades durante el proceso de navegación).

- En cuarto lugar, abre dos documentos word e indica a los alumnos que deben escribir sus nombres y apellidos en cada uno de ellos; hecho esto, señala cómo deben llamar a cada uno de los archivos (resumen y descripción pasos resumen).

- Para finalizar, explica la razón por la que se les pide dichos datos (es imprescindible saber quién ha hecho cada prueba para poder triangular los resultados obtenidos con los resultados de las pruebas que harían la semana siguiente en otra sesión) y les garantiza el anonimato de sus identidades a la hora de difundir los resultados de la investigación.

A pesar de todas estas medidas, cabe destacar que encontramos ciertos imprevistos durante una de las sesiones. Concretamente, el día en el que realizamos la prueba con el grupo-clase Educación Primaria turno tarde, se convocó una huelga de estudiantes que provocó que únicamente asistiesen un total de 19 alumnos, de los cuales, 12 fueron asignados al grupo EDP hipertexto y 7 al grupo EDP texto. Esto, aunque redujo el número de alumnos que un primer momento estimamos que asistirían a la prueba en este grupo-clase, no supuso una gran pérdida en lo que se refiere a los grupos de estudio, puesto que, dichas bajas se compensaron con los alumnos del grupo-clase de Educación Primaria turno mañana que realizaron la prueba (24 para el grupo EDP texto y 19 para el grupo EDP hipertexto). 
En el cuadro 2.43 se muestra de forma sintética todo lo que hemos señalado, y además, se recoge el tiempo que empleó para finalizar la prueba el alumno que acabó el primero y el que terminó el último en cada uno de los grupos. Como podemos apreciar todos los alumnos acabaron la prueba antes de las dos horas, siendo un alumno del grupo PSP texto (109`) y uno del grupo PSP hipertexto (108`) los que más tardaron. Mientras que los alumnos que menos tardaron en realizar la prueba fueron dos alumnos del grupo EDP texto (42', y 58').

\begin{tabular}{|c|c|c|c|c|c|c|c|c|}
\hline & \multicolumn{8}{|c|}{ TEMPORALIZACIÓN } \\
\hline & $\begin{array}{l}\text { Grupo- } \\
\text { clase }\end{array}$ & Fecha & Aula & $\begin{array}{l}\text { Grupo } \\
\text { estudio }\end{array}$ & Inicio & Final & $\begin{array}{l}\text { Tiempo } \\
\text { primer } \\
\text { alumno } \\
\text { acaba } \\
\text { prueba }\end{array}$ & $\begin{array}{l}\text { Tiempo } \\
\text { último } \\
\text { alumno } \\
\text { acaba } \\
\text { prueba }\end{array}$ \\
\hline $\begin{array}{l}\text { Prueba } \\
\text { Piloto }\end{array}$ & $\begin{array}{c}2^{\circ} \\
\text { Psicoped }\end{array}$ & $2 / 10 / 2012$ & 23 & - & 11:00 & $12: 43$ & $\begin{array}{c}87^{\prime} \\
\text { hipertxt }\end{array}$ & $\begin{array}{r}103^{\prime} \\
\text { hipertxt }\end{array}$ \\
\hline \multirow{6}{*}{$\begin{array}{c}\text { Prueba } \\
\text { Pos-test } \\
\text { Diseño II }\end{array}$} & \multirow[t]{2}{*}{$\begin{array}{c}1^{\circ} \\
\text { Psicoped }\end{array}$} & \multirow[t]{2}{*}{$10 / 10 / 2012$} & $\begin{array}{c}\text { Inform } \\
3\end{array}$ & PSP texto & 10:06 & $11: 55$ & $\begin{array}{l}79^{\prime} \\
\text { texto }\end{array}$ & $\begin{array}{l}109^{\prime} \\
\text { texto }\end{array}$ \\
\hline & & & $\begin{array}{c}\text { Inform } \\
1 \text { y } 2\end{array}$ & $\begin{array}{c}\text { PSP } \\
\text { Hipertxt }\end{array}$ & 10:04 & $11: 54$ & $\begin{array}{c}71^{\prime} \\
\text { hipertxt }\end{array}$ & $\begin{array}{r}108^{\prime} \\
\text { hipertxt }\end{array}$ \\
\hline & \multirow[t]{2}{*}{$\begin{array}{c}\text { Ed. } \\
\text { Primaria } \\
\text { (mañana) }\end{array}$} & \multirow[t]{2}{*}{$24 / 10 / 2012$} & $\begin{array}{c}\text { Inform } \\
3\end{array}$ & $\begin{array}{l}\text { EDP } \\
\text { texto }\end{array}$ & 10: 05 & 11:40 & $\begin{array}{l}42^{\prime} \\
\text { texto }\end{array}$ & $\begin{array}{r}95^{\prime} \\
\text { texto }\end{array}$ \\
\hline & & & $\begin{array}{c}\text { Inform } \\
1 \text { y } 2\end{array}$ & $\begin{array}{c}\text { EDP } \\
\text { Hipertxt }\end{array}$ & 10: 07 & $11: 50$ & $\begin{array}{c}61^{\prime} \\
\text { hipertxt }\end{array}$ & $\begin{array}{r}103^{\prime} \\
\text { hipertxt }\end{array}$ \\
\hline & \multirow{2}{*}{$\begin{array}{c}\text { Ed. } \\
\text { Primaria } \\
\text { (tarde) }\end{array}$} & \multirow[t]{2}{*}{$17 / 10 / 2012$} & $\begin{array}{c}\text { Inform } \\
1\end{array}$ & $\begin{array}{l}\text { EDP } \\
\text { texto }\end{array}$ & 18:05 & $19: 30$ & $\begin{array}{c}58^{\prime} \\
\text { texto }\end{array}$ & $\begin{array}{l}85^{\prime} \\
\text { texto }\end{array}$ \\
\hline & & & $\begin{array}{c}\text { Inform } \\
2\end{array}$ & $\begin{array}{c}\text { EDP } \\
\text { Hipertxt }\end{array}$ & 18:05 & 19:34 & $\begin{array}{c}63^{\prime} \\
\text { hipertxt }\end{array}$ & $\begin{array}{r}89^{\prime} \\
\text { hipertxt }\end{array}$ \\
\hline
\end{tabular}

Cuadro 2.43. Temporalización de la prueba Pos-test del Diseño II

*Inform= Sala de informática 


\subsection{INFORMATIZACIÓN Y TIPO DE ANÁLISIS DE DATOS}

Los datos recogidos durante el trabajo de campo, una vez categorizados, se informatizaron a través del paquete estadístico PASW Stadistics 18 (SPSS) ${ }^{23}$. No obstante, antes de introducir la información en el programa, tuvimos que considerar las características de los diseños de nuestra investigación, con el fin de determinar qué número de ficheros debíamos generar para agilizar la informatización de los datos y facilitar su posterior análisis.

La creación de un fichero de datos para los dos diseños dificultaba enormemente el proceso de análisis, por lo que descartamos esa opción. Recordemos que el Diseño I y la fase Pre-test del Diseño II, aunque compartían tanto las variables control como las variables dependientes; diferían en lo que respecta al número de variables independientes (en el primer diseño el momento formativo, mientras que en el segundo el momento formativo y el formato textual) y de sujetos (el primer diseño disponía de una muestra de 130 sujetos, mientras que el segundo disponía de 96 sujetos). Partiendo de esto, consideramos imprescindible diferenciar la información correspondiente a un diseño de la vinculada al otro; y por ello, decidimos generar las dos matrices de datos: una para el Diseño I (ver Anexo I.8) y otra para el Diseño II (ver Anexo II.14).

En lo que respecta a la matriz del primer diseño (ver Anexo I.8), cabe señalar que permitió evaluar los 130 sujetos de la muestra en 44 variables:

- La variable independiente momento formativo;

- Las variables de control, que se recogen en el Anexo I.1. Cuadro 2; y

- La variable dependiente VD. Habilidades básicas de comprensión y expresión escrita para la construcción de conocimiento, concretamente, las variables dependientes operativas que se recogen en el Anexo I.1. Cuadro 1.

Considerando la naturaleza pre-experimental del Diseño I, se aplicaron, en función de los objetivos planteados y del tipo de las variables estudiadas, técnicas estadísticas de carácter descriptivo (tablas de contingencia) e inferencial (estadístico $\chi^{2}$, y prueba $t$ de diferencia de medias).

Por su parte, la matriz del segundo diseño (ver Anexo II.14) permite evaluar a los 96 sujetos de la muestra a través de 61 variables:

- Las variables independientes momento formativo y formato textual.

\footnotetext{
${ }^{23}$ Licencia de campus de la Universidad de Salamanca
} 
- $\quad$ Las variables de control que se recogen en el Anexo I.1. Cuadro 2.

- La variable dependiente VDTH. Habilidades de comprensión y expresión escrita para la síntesis de información, concretamente, las variables dependientes operativas que recogemos en el Anexo II.1. Cuadro 1.

- Las variables secundarias que se recogen en el Anexo II.1. Cuadros 2, 3 y 4.

Teniendo en cuenta la naturaleza cuasi-experimental del Diseño II, se aplicaron, en función de los objetivos planteados y del tipo de las variables estudiadas, técnicas estadísticas de carácter descriptivo (tablas de contingencia) e inferencial (estadístico $\chi^{2} \mathrm{y}$ ANOVA de un factor). 


\subsection{ESQUEMA DE INVESTIGACIÓN}

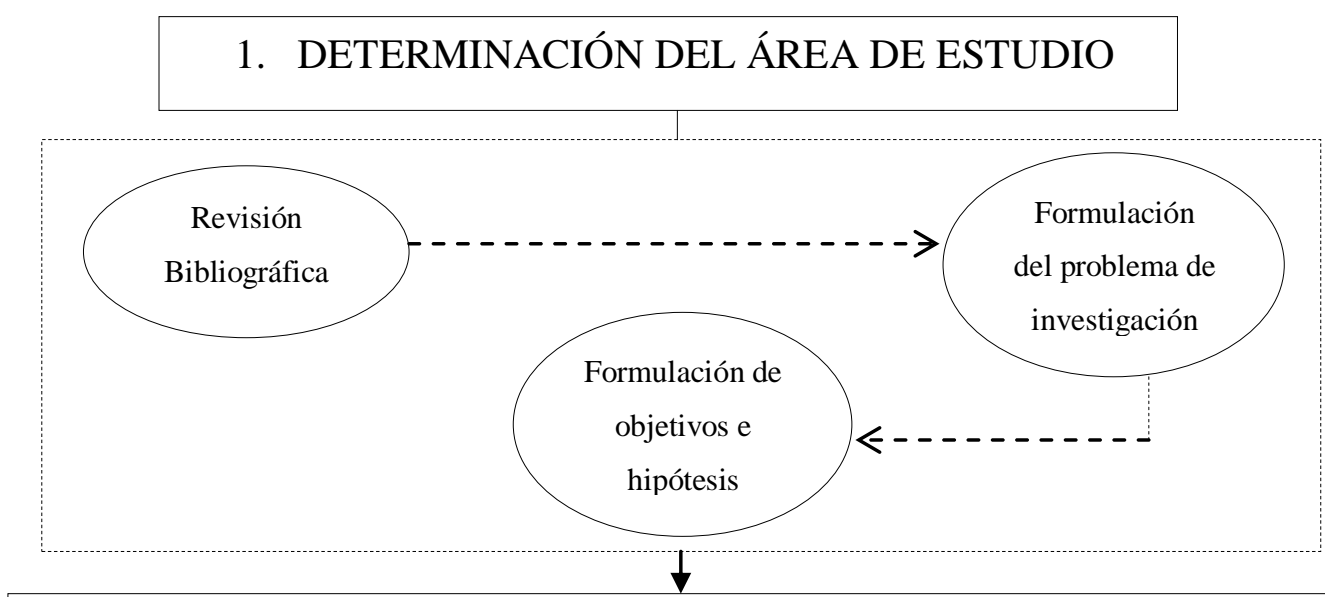

2. PLANIFICACIÓN DE LA INVESTIGACIÓN DESDE EL ENFOQUE EMPÍRICO ANALÍTICO (LaTorre, Del Rincón y Arnal, 1996)

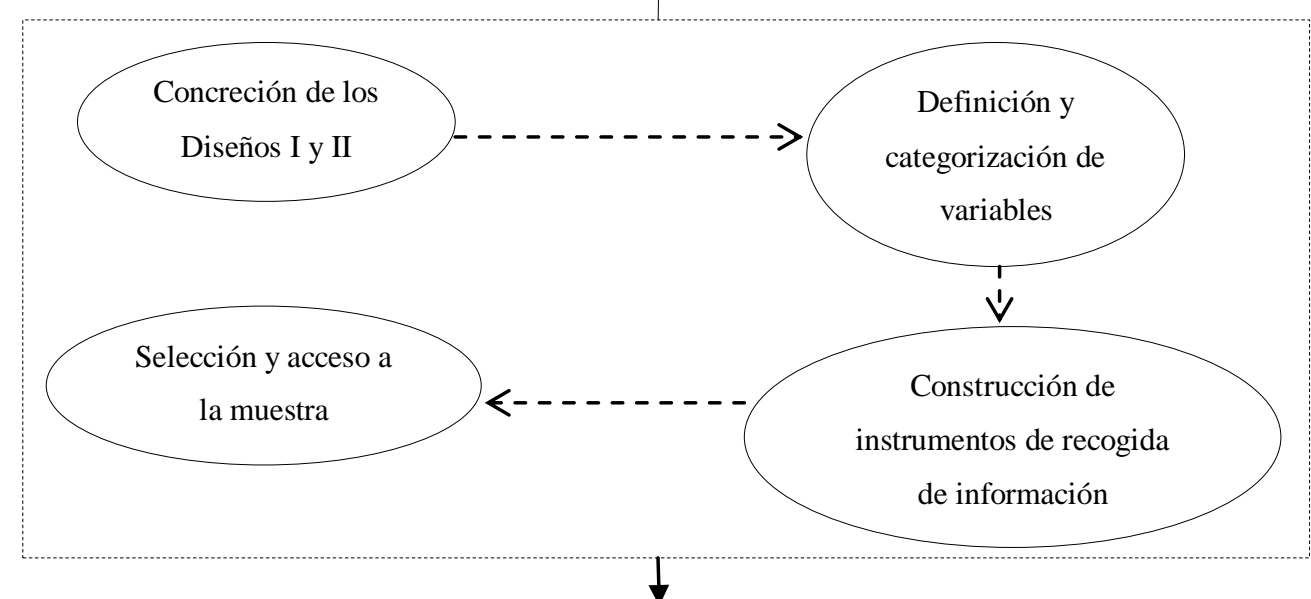

\section{TRABAJO DE CAMPO}

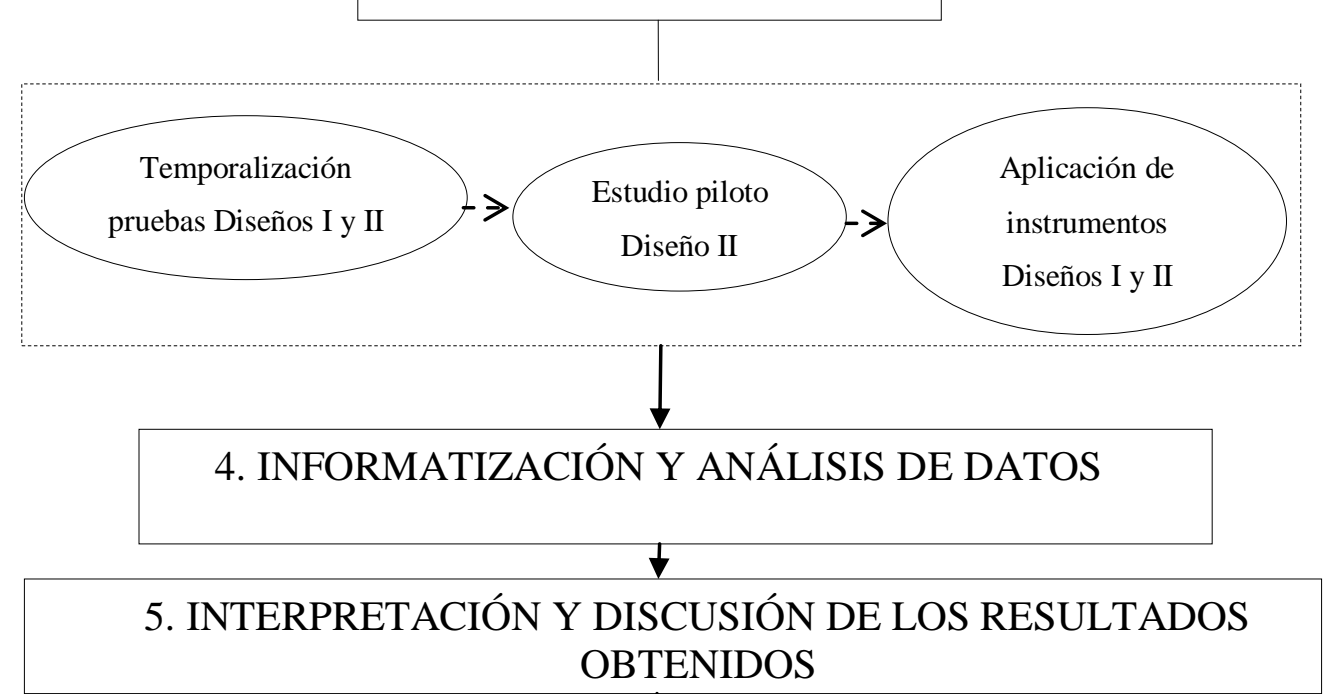

6. CONCLUSIONES Y PROSPECTIVA 


\section{CAPÍTULO III. RESULTADOS}

En este tercer capítulo, vamos a analizar los resultados obtenidos para cada uno de los dos diseños que conforman nuestra investigación. Para el primer diseño, de carácter pre-experimental, evaluamos las habilidades básicas y expresión escrita tanto de los alumnos que comienzan el Grado en Educación Primaria, como de los alumnos de Psicopedagogía que habían finalizado la carrera de maestro; mientras que para el segundo, de carácter cuasi-experimental, evaluamos el efecto del formato textual sobre las estrategias de comprensión y expresión escrita de los que comienzan y han finalizado la carrera de maestro. Conviene recordar que, para el Diseño II, se tomó como fase Pretest las pruebas que realizaron en el primer diseño los alumnos que asistieron a las pruebas Pos-test, estableciendo, en este caso, el momento formativo y el formato textual como variables independientes.

\subsection{RESULTADOS SOBRE EL DISEÑO I: EVALUACIÓN DE LAS HABILIDADES BÁSICAS DE Cy E ESCRITA EN EDUCACIÓN PRIMARIA Y PSICOPEDAGOGÍA}

\subsubsection{Características de las muestras y contraste de homogeneidad: Educación Primaria vs Psicopedagogía}

Como hemos señalado con anterioridad, para este primer diseño, establecimos un conjunto de medidas con el fin de comprobar si existían diferencias significativas (n.s.=.05) intergrupos (Educación Primaria y Psicopedagogía) que pudieran ofrecer una explicación alternativa a la variable independiente momento formativo para los resultados obtenidos. Concretamente, constituimos tres tipos de variables de control: 


\begin{tabular}{|c|c|}
\hline \multicolumn{2}{|r|}{ VARIABLES DE CONTROL } \\
\hline Variable Control & Variables Control Operativas \\
\hline $\begin{array}{l}\text { VC1. Variables de } \\
\text { Identificación }\end{array}$ & $\begin{array}{l}\text { VC1.1. Género } \\
\text { VC1.2. Edad }\end{array}$ \\
\hline $\begin{array}{l}\text { VC2. Variables } \\
\text { Pedagógicas }\end{array}$ & $\begin{array}{l}\text { VC2.1. Centro de procedencia } \\
\text { VC2.2. Modalidad de bachillerato (Primaria) } \\
\text { VC2.3. Calificación de entrada a la universidad } \\
\text { VC2.4. Primer ciclo cursado (Psicopedagogía) } \\
\text { VC2.5. Calificación obtenida en el Primer ciclo cursado (Psicopedagogía) } \\
\text { VC2.6. Matrícula en otra carrera universitaria }\end{array}$ \\
\hline $\begin{array}{l}\text { VC3. Variables Hábitos } \\
\text { Lectores }\end{array}$ & $\begin{array}{l}\text { VC3.1. Idioma de lectura } \\
\text { VC3.2. Causa lectura último libro } \\
\text { VC3.3. Materia del último libro leído } \\
\text { VC3.4. Cantidad libros leídos al año } \\
\text { VC3.5. Razones para no leer con mayor frecuencia } \\
\text { VC3.6. Lectura en soporte digital } \\
\text { - VC3.6.1. Lectura en soporte digital. Webs, blogs, foros } \\
\text { - VC3.6.2. Lectura en soporte digital. Prensa } \\
\text { - VC3.6.3. Lectura en soporte digital. Revistas } \\
\text { - VC3.6.4. Lectura en soporte digital. Libros } \\
\text { - VC3.6.5. Lectura en soporte digital. Otros }\end{array}$ \\
\hline
\end{tabular}

Cuadro 3.1. Variables de control constituidas (Diseño I)

\subsubsection{Contraste para las variables de Identificación (VC1) para el Diseño I}

Se analizaron dos tipos de variables de identificación. En lo que respecta al Género, no existían diferencias significativas (n.s.=.05) entre los dos grupos de la muestra, ya que, como indica la siguiente tabla, predominaban las mujeres con respecto a los hombres en ambos grupos. 


\begin{tabular}{c|c|c|c}
\hline \multirow{2}{*}{ Hombre } & \multicolumn{3}{c}{ VC1.1 Género } \\
\cline { 2 - 3 } & CARRERA UNIVERSITARIA & $\begin{array}{c}\text { Total alumnos } \\
\text { según tipo de } \\
\text { respuesta }\end{array}$ \\
\hline \multirow{2}{*}{ Mujer } & 8 & Primaria & 35 \\
& $19.5 \%$ & 27 & $26.9 \%$ \\
\hline \multirow{2}{*}{ Total alumnos de cada carrera } & 33 & $30.3 \%$ & 95 \\
& $80.5 \%$ & 62 & $73.1 \%$ \\
\hline $\boldsymbol{p}$ & 41 & $69.7 \%$ & 130 \\
\hline$\chi^{2}(\mathrm{gl})$ & $100.0 \%$ & $100.0 \%$ & $100.0 \%$ \\
\hline $\boldsymbol{y}$ & \multicolumn{3}{|c}{$1.672(1)$} \\
\hline
\end{tabular}

Tabla 3.1. Género (VC1.1) (Diseño I)

(la salida completa de este procedimiento se encuentra en el Anexo I. 6 tabla 2)

Sin embargo, sí encontramos diferencias significativas en lo que se refiere a la variable Edad, como se observa en la tabla 3.2 (para el estadístico de contraste $\chi^{2}=35.178$ con 2 grados de libertad, corresponde una probabilidad $\mathrm{p}<.001$ ). Estas diferencias están muy relacionadas con la variable independiente momento formativo, principalmente porque, por una parte, Educación Primaria era una carrera de primer ciclo en la que la edad del alumnado de $1^{\circ}$ curso se encontraban principalmente entre 17 y 18 años; y por otra, Psicopedagogía era una carrera de segundo ciclo (se accedía a ella tras un primer ciclo de tres años) en la que ningún alumno se encontraba en la franja de edad entre 17 y 18 años.

\begin{tabular}{|c|c|c|c|}
\hline \multicolumn{4}{|c|}{ VC1.2. Edad } \\
\hline & \multicolumn{2}{|c|}{ CARRERA UNIVERSITARIA } & \multirow{2}{*}{$\begin{array}{l}\text { Total alumnos } \\
\text { según tipo de } \\
\text { respuesta }\end{array}$} \\
\hline & Psicopedagogía & Primaria & \\
\hline \multirow[t]{2}{*}{ Entre 17 y 18 años } & 0 & 48 & 48 \\
\hline & $.0 \%$ & $53.9 \%$ & $36.9 \%$ \\
\hline \multirow[t]{2}{*}{ Entre 19 y 23 años } & 36 & 35 & 71 \\
\hline & $87.8 \%$ & $39.3 \%$ & $54.6 \%$ \\
\hline \multirow[t]{2}{*}{ Más de 23 años } & 5 & 6 & 11 \\
\hline & $12.2 \%$ & $6.7 \%$ & $8.5 \%$ \\
\hline \multirow[t]{2}{*}{ Total alumnos de cada carrera } & 41 & 89 & 130 \\
\hline & $100.0 \%$ & $100.0 \%$ & $100.0 \%$ \\
\hline$\chi^{2}(\mathrm{gl})$ & \multicolumn{3}{|c|}{$35.178(2)$} \\
\hline$p$ & \multicolumn{3}{|c|}{.000} \\
\hline
\end{tabular}

Tabla 3.2. Edad (VC1.2) (Diseño I)

(la salida completa de este procedimiento se encuentra en el Anexo I. 6 tabla 4) 


\subsubsection{Contraste para las variables Pedagógicas (VC2) para el Diseño I}

Las variables pedagógicas se dividieron en dos bloques. El primer bloque de variables tenía por finalidad conocer la existencia o no de diferencias significativas entre los grupos en cuanto a determinados aspectos académicos: Centro de procedencia (VC2. 1), Calificación de entrada en la universidad (VC2.3) y Matriculación en otra carrera universitaria (VC2.6). El objetivo del segundo bloque era profundizar en algunos datos académicos propios de cada grupo: para el grupo de Educación Primaria se analizó la Modalidad de bachillerato (VC2.2), y para el grupo de Psicopedagogía se analizaron el Primer ciclo cursado (Psicopedagogía) (VC2.4) y la Calificación obtenida en el primer ciclo cursado (Psicopedagogía) (VC2.5).

Comenzando por la variable Calificación de entrada a la universidad, hemos de señalar que, como se observa en la tabla 3.3, no se encontraron diferencias significativas intergrupales (n.s.=.05). La mayoría de los alumnos accedieron a la universidad con una calificación de Aprobado (el 70.7\% en Psicopedagogía y el 49,4\% en Primaria), siendo minoría los que lo hicieron con una nota de Sobresaliente (el 2.2\% en Primaria).

\begin{tabular}{|c|c|c|c|}
\hline \multicolumn{4}{|c|}{ VC2.3. Calificación de entrada a la universidad } \\
\hline & \multicolumn{2}{|c|}{ CARRERA UNIVERSITARIA } & \multirow{2}{*}{$\begin{array}{l}\text { Total alumnos } \\
\text { según tipo de } \\
\text { respuesta }\end{array}$} \\
\hline & Psicopedagogía & Primaria & \\
\hline \multirow[t]{2}{*}{ Sobresaliente } & 0 & 2 & 2 \\
\hline & $.0 \%$ & $2.2 \%$ & $1.5 \%$ \\
\hline \multirow[t]{2}{*}{ Notable } & 10 & 30 & 40 \\
\hline & $24.4 \%$ & $33.7 \%$ & $30.8 \%$ \\
\hline \multirow[t]{2}{*}{ Aprobado } & 29 & 44 & 73 \\
\hline & $70.7 \%$ & $49.4 \%$ & $56.2 \%$ \\
\hline \multirow[t]{2}{*}{$N S / N C$} & 2 & 13 & 15 \\
\hline & $4.9 \%$ & $14.6 \%$ & $11.5 \%$ \\
\hline \multirow[t]{2}{*}{ Total alumnos de cada carrera } & 41 & 89 & 130 \\
\hline & $100.0 \%$ & $100.0 \%$ & $100.0 \%$ \\
\hline$\chi^{2}(\mathrm{gl})$ & & $6.282(3)$ & \\
\hline$p$ & & .099 & \\
\hline
\end{tabular}

Tabla 3.3. Calificación de entrada a la universidad (VC2.3) (Diseño I)

(la salida completa de este procedimiento se encuentra en el Anexo I. 6 tabla 9)

Continuando con las demás variables del primer bloque, cabe mencionar la existencia de diferencias significativas en Centro de Procedencia y Matrícula en otra carrera universitaria. Estas diferencias volvían a estar muy vinculadas con la variable independiente momento formativo; ya que el grupo Educación Primaria estaba compuesto por alumnos que acaban de entrar en la universidad (era su primera experiencia universitaria), mientras que el grupo de Psicopedagogía, al estar cursando 
una carrera de segundo ciclo, estaba compuesto por alumnos que ya habían cursado una carrera universitaria.

En cuanto al segundo bloque de variables (tal como puede apreciarse en los gráficos 3.1 y 3.2), el 50.6\% de los alumnos de Educación Primaria eligieron Ciencias Sociales como Modalidad de bachillerato (primaria) (VC2.2), y la mayor parte de los alumnos de Psicopedagogía cursaron Educación Infantil (48.8\%) o Educación Primaria (34.1\%) como carrera de primer ciclo.

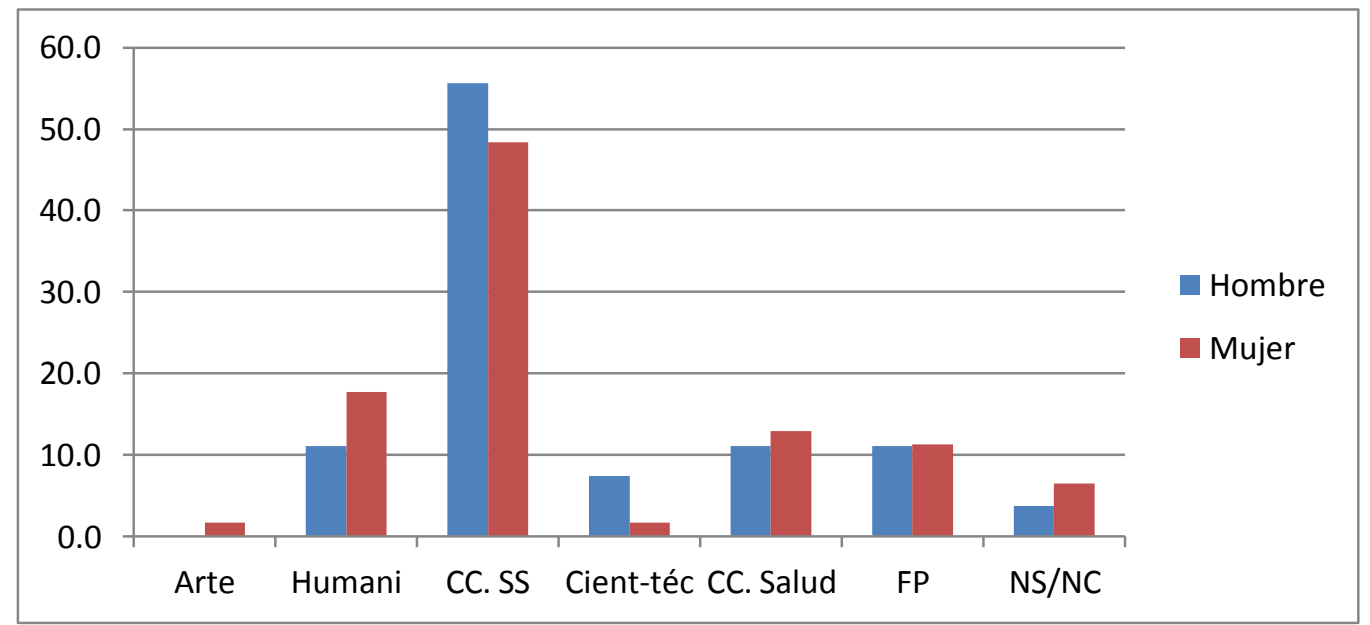

Gráfico 3.1. Distribución de la muestra de Ed. Primaria para Modalidad de bachillerato y Sexo (porcentaje sobre la modalidad de bachillerato) (Diseño I)

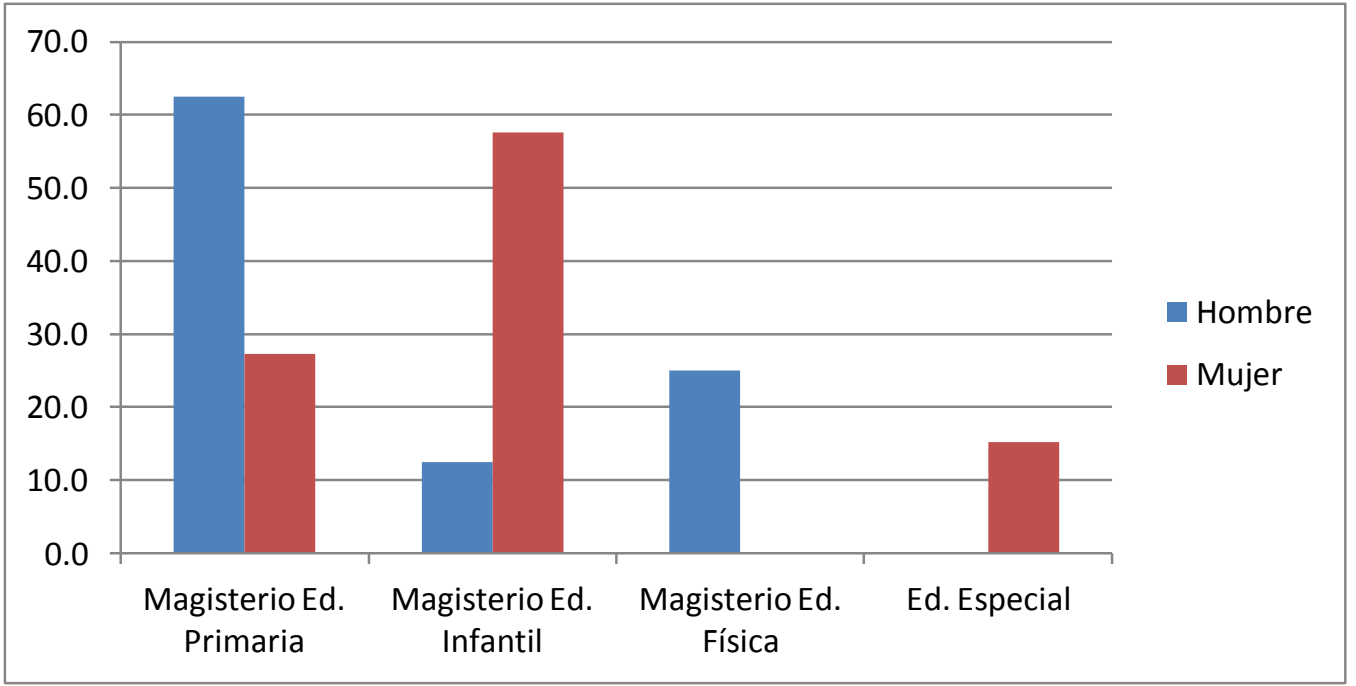

Gráfico 3.2. Distribución de la muestra de Psicopedagogía para Primer ciclo cursado y Sexo (porcentaje por primer ciclo cursado) (Diseño I)

Nos llama la atención que la mayor parte de los alumnos de Psicopedagogía (80,5\%) obtuvieran como calificación del primer ciclo cursado un Notable, cuando, como veíamos anteriormente (tabla 3.3), la mayor parte de ellos accedieron a la universidad con una calificación de Aprobado (el 70.7\%). 


\subsubsection{Contraste para las variables Hábitos Lectores (VC3) para el Diseño I}

Para analizar los hábitos de lectura del alumnado, se establecieron una serie de variables asociadas: Idioma de lectura (VC3.1), Causa de la lectura del último libro (VC3.2), Materia del último libro leído (VC3.3), Cantidad de libros leído al año (VC3.4), Razones para no leer con mayor frecuencia (VC3.5) y Lectura en soporte digital (VC3.6).

Los resultados obtenidos, mostraron que:

En primer lugar, los alumnos, como es obvio, leían predominantemente en Castellano (98.5\%) (tabla 3.4).

\begin{tabular}{|c|c|c|c|}
\hline \multicolumn{4}{|c|}{ VC3.1. Idioma de lectura } \\
\hline & \multicolumn{2}{|c|}{ CARRERA UNIVERSITARIA } & \multirow{2}{*}{$\begin{array}{c}\text { Total alumnos } \\
\text { según tipo de } \\
\text { respuesta }\end{array}$} \\
\hline & Psicopedagogía & Primaria & \\
\hline \multirow[t]{2}{*}{ Castellano } & 41 & 87 & 128 \\
\hline & $100.0 \%$ & $97.8 \%$ & $98.5 \%$ \\
\hline \multirow[t]{2}{*}{ Otro Idioma } & 0 & 2 & 2 \\
\hline & $.0 \%$ & $2.2 \%$ & $1.5 \%$ \\
\hline \multirow{2}{*}{$\begin{array}{l}\text { Total errores alumnos de cada } \\
\text { carrera }\end{array}$} & 41 & 89 & 130 \\
\hline & $100.0 \%$ & $100.0 \%$ & $100.0 \%$ \\
\hline$\chi^{2}(\mathrm{gl})$ & \multicolumn{3}{|c|}{$.936(1)$} \\
\hline$p$ & \multicolumn{3}{|c|}{.333} \\
\hline
\end{tabular}

Tabla 3.4. Idioma de lectura (VC3.1) (Diseño I)

(la salida completa de este procedimiento se encuentra en el Anexo I. 6 tabla 15)

En segundo lugar, la causa por la que los alumnos leyeron el último libro era el entretenimiento (54.3\%) o los estudios (39.5\%) (gráfico 3.3). 


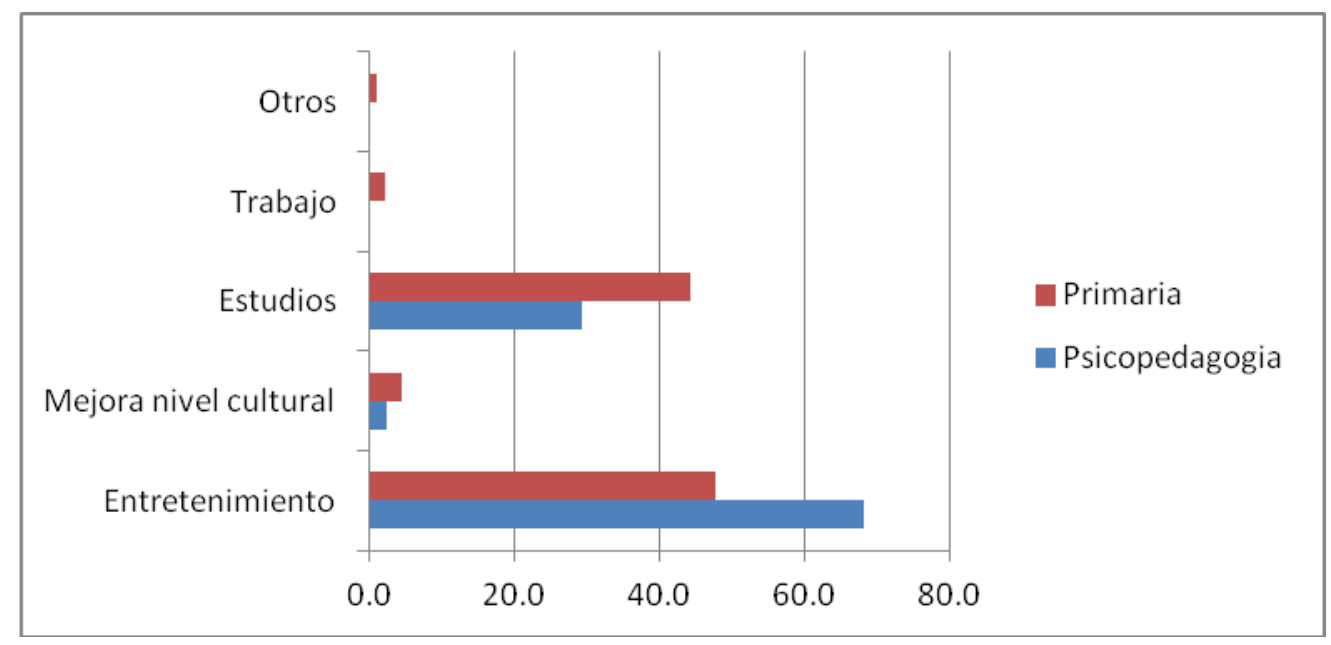

Gráfico 3.3. Distribución de las muestras de Ed. Primaria y Psicopedagogía para Causa de la lectura del último libro (VC3.2) (porcentaje causa de lectura del último libro) (Diseño I)

En tercer lugar, el último libro leído por gran parte de los alumnos era un libro de literatura (41.4\%) (tabla 3.5).

\begin{tabular}{|c|c|c|c|}
\hline \multicolumn{4}{|c|}{ VC3.3. Materia del último libro leído } \\
\hline & \multicolumn{2}{|c|}{ CARRERA UNIVERSITARIA } & \multirow{2}{*}{$\begin{array}{l}\text { Total alumnos } \\
\text { según tipo de } \\
\text { respuesta }\end{array}$} \\
\hline & Psicopedagogía & Primaria & \\
\hline \multirow[t]{2}{*}{ Literatura } & 14 & 39 & 53 \\
\hline & $35.0 \%$ & $44.3 \%$ & $41.4 \%$ \\
\hline \multirow[t]{2}{*}{ Humanidades y CC. Sociales } & 6 & 17 & 23 \\
\hline & $15.0 \%$ & $19.3 \%$ & $18.0 \%$ \\
\hline \multirow{2}{*}{$\begin{array}{l}\text { Científico-técnico, Medicina, } \\
\text { Biología }\end{array}$} & 1 & 3 & 4 \\
\hline & $2.5 \%$ & $3.4 \%$ & $3.1 \%$ \\
\hline \multirow[t]{2}{*}{ Infantil y juvenil } & 6 & 18 & 24 \\
\hline & $15.0 \%$ & $20.5 \%$ & $18.8 \%$ \\
\hline \multirow[t]{2}{*}{ Otros } & 13 & 11 & 24 \\
\hline & $32.5 \%$ & $12.5 \%$ & $18.8 \%$ \\
\hline \multirow[t]{2}{*}{ Total alumnos de cada carrera } & 40 & 88 & 128 \\
\hline & $100.0 \%$ & $100.0 \%$ & $100.0 \%$ \\
\hline$\chi^{2}(\mathrm{gl})$ & & $7.238(4)$ & \\
\hline$p$ & & .124 & \\
\hline
\end{tabular}

Tabla 3.5. Materia del último libro leído (VC3.3) (Diseño I)

(la salida completa de este procedimiento se encuentra en el Anexo I. 6 tabla 19)

En cuarto lugar, los alumnos leían entre 2 y 4 (40.8\%) o entre 5 y 9 (31.5\%) libros al año (gráfico 3.4). 


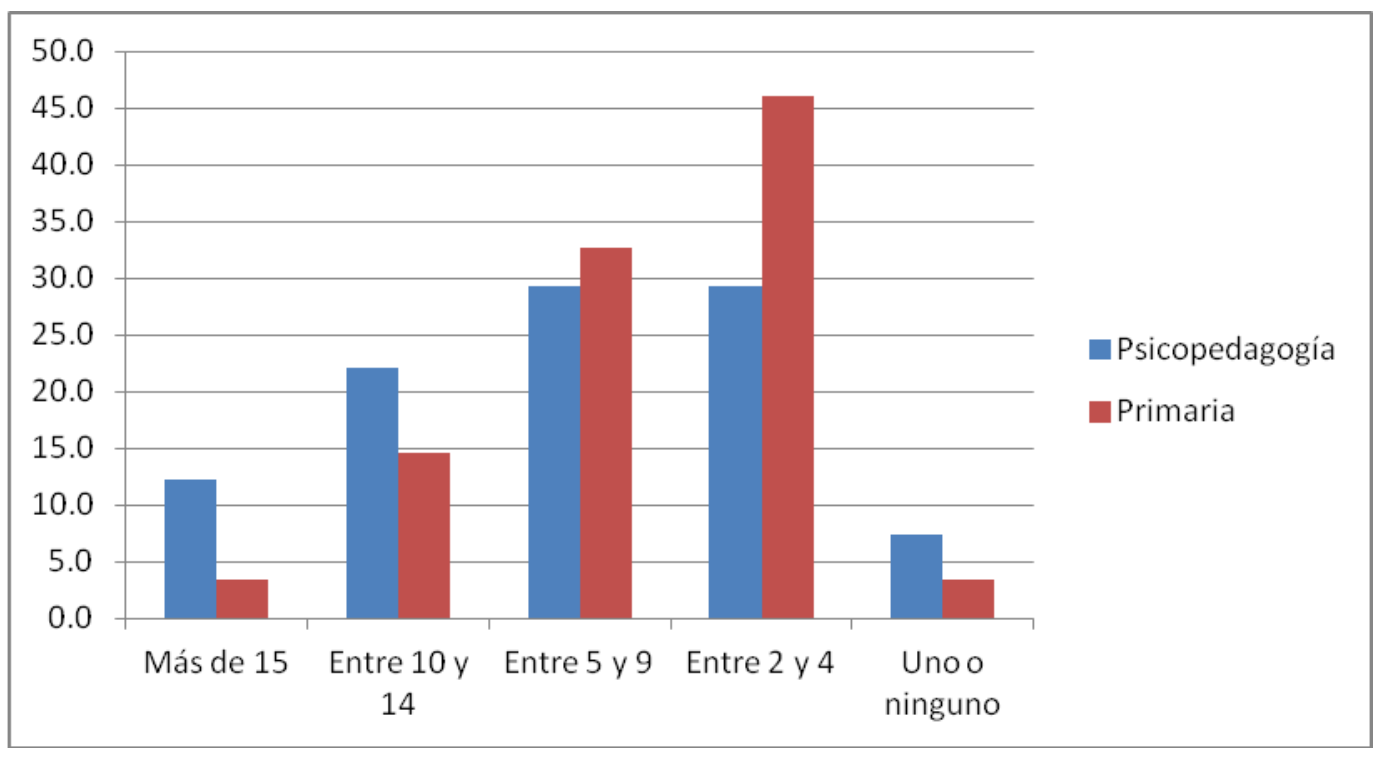

Gráfico 3.4. Cantidad de libros leídos al año (VC3.4) (porcentaje Cantidad libros leídos al año) (Diseño I)

En quinto lugar, cabe señalar que existían diferencias significativas intergrupales (n.s.=.05) para la variable Razones para no leer con mayor frecuencia. Estas diferencias se pueden apreciar con claridad en la tabla 3.6; donde se observa, por un lado, que la gran mayoría de los alumnos de Psicopedagogía (el 90\%) no leían más, porque no disponían de tiempo; y por otro, que la mayor parte de los alumnos de Primaria no lo hacían, bien por falta de tiempo (53.9\%), o bien porque preferían dedicar su tiempo libre a otras $\operatorname{cosas}(33.7 \%)$.

\begin{tabular}{|c|c|c|c|}
\hline \multicolumn{4}{|c|}{ VC3.5. Razones para no leer con mayor frecuencia } \\
\hline & \multicolumn{2}{|c|}{ CARRERA UNIVERSITARIA } & \multirow{2}{*}{$\begin{array}{l}\text { Total alumnos } \\
\text { según tipo de } \\
\text { respuesta } \\
\end{array}$} \\
\hline & Psicopedagogía & Primaria & \\
\hline \multirow[t]{2}{*}{ No dispongo de tiempo } & 36 & 48 & 84 \\
\hline & $90.0 \%$ & $53.9 \%$ & $65.1 \%$ \\
\hline \multirow{2}{*}{$\begin{array}{l}\text { No me gustal no me interesa } \\
\text { leer }\end{array}$} & 0 & 6 & 6 \\
\hline & $.0 \%$ & $6.7 \%$ & $4.7 \%$ \\
\hline \multirow{2}{*}{$\begin{array}{l}\text { Prefiero dedicar mi tiempo a } \\
\text { otras cosas }\end{array}$} & 4 & 30 & 34 \\
\hline & $10.0 \%$ & $33.7 \%$ & $26.4 \%$ \\
\hline \multirow[t]{2}{*}{ Otros motivos } & 0 & 5 & 5 \\
\hline & $.0 \%$ & $5.6 \%$ & $3.9 \%$ \\
\hline \multirow[t]{2}{*}{ Total alumnos de cada carrera } & 40 & 89 & 129 \\
\hline & $100.0 \%$ & $100.0 \%$ & $100.0 \%$ \\
\hline$\chi^{2}(\mathrm{gl})$ & \multicolumn{3}{|c|}{$16.342(3)$} \\
\hline$p$ & \multicolumn{3}{|c|}{.001} \\
\hline
\end{tabular}

Tabla 3.6. Razones para no leer con mayor frecuencia (VC3.5) (Diseño I)

(la salida completa de este procedimiento se encuentra en el Anexo I. 6 tabla 23) 
Para finalizar, hemos de señalar que más de la mitad del alumnado leía habitualmente en soporte digital 56.9\% (tabla 3.7). (El análisis concreto que se ha hecho de la lectura en diferentes soportes digitales se puede revisar en el Anexo I.6 desde la tabla 26 a la tabla 35$)$.

\begin{tabular}{|c|c|c|c|}
\hline \multicolumn{4}{|c|}{ VC3.6. Lectura en soporte digital } \\
\hline & \multicolumn{2}{|c|}{ CARRERA UNIVERSITARIA } & \multirow{2}{*}{$\begin{array}{l}\text { Total alumnos } \\
\text { según tipo de } \\
\text { respuesta }\end{array}$} \\
\hline & Psicopedagogía & Primaria & \\
\hline \multirow[t]{2}{*}{$S I$} & 25 & 49 & 74 \\
\hline & $61.0 \%$ & $55.1 \%$ & $56.9 \%$ \\
\hline \multirow[t]{2}{*}{ NO } & 16 & 40 & 56 \\
\hline & $39.0 \%$ & $44.9 \%$ & $43.1 \%$ \\
\hline \multirow{2}{*}{$\begin{array}{l}\text { Total errores alumnos de cada } \\
\text { carrera }\end{array}$} & 41 & 89 & 130 \\
\hline & $100.0 \%$ & $100.0 \%$ & $100.0 \%$ \\
\hline$\chi^{2}(\mathrm{gl})$ & \multicolumn{3}{|c|}{$.527(1)$} \\
\hline$p$ & \multicolumn{3}{|c|}{.421} \\
\hline
\end{tabular}

Tabla 3.7. Lectura en soporte digital (VC3.6) (Diseño I)

(la salida completa de este procedimiento se encuentra en el Anexo I. 6 tabla 25)

Teniendo en cuenta los resultados obtenidos para las variables de control establecidas, podemos sostener que no existían diferencias significativas entre grupos a nivel global, que pudiesen ofrecer una explicación alternativa a la variable independiente momento formativo para los resultados obtenidos. Como hemos señalado, las diferencias que aparecen en las variables Edad (VC1.2), Centro de Procedencia (VC2.1), y Matrícula en otra carrera universitaria (VC2.6); responden claramente al momento formativo en el que se encontraba cada alumno. Además, las diferencias en Razones para no leer con mayor frecuencia (VC3.5), aunque no se asocian directamente con el momento formativo, se puede relacionar indirectamente al mismo. Por ejemplo, el hecho de que la mayoría del grupo de Psicopedagogía no dispusiera de tiempo para leer más, puede que esté relacionado con que estos alumnos debían dedicar un gran número de horas a otras tareas académicas, como el estudio del temario, la redacción de trabajos académicos, etc.

\subsubsection{Resultados de las hipótesis en el Diseño I: Habilidades básicas de comprensión y expresión escrita en Educación Primaria y Psicopedagogía}

En este primer diseño, analizamos la incidencia de la variable independiente momento formativo sobre una variable dependiente general (Habilidades básicas de comprensión y expresión escrita) formada por cuatro variables dependientes asociadas: 
Formación de la idea principal de cada párrafo (VD1); Dificultades para formar la idea principal de cada párrafo (VD2); Construcción de un mapa conceptual donde se recoja la macroestructura del texto leído (VD3); Dificultades en la construcción del mapa conceptual (VD4).

\begin{tabular}{|c|c|c|}
\hline $\begin{array}{l}\text { Variable } \\
\text { Dependiente }\end{array}$ & Definición Conceptual & Variables Dependientes Operativas \\
\hline \multirow{4}{*}{$\begin{array}{l}\text { Habilidades básicas de } \\
\text { comprensión y } \\
\text { expresión escrita para } \\
\text { la construcción } \\
\text { conocimiento }\end{array}$} & \multirow{4}{*}{$\begin{array}{l}\text { Capacidad para usar } \\
\text { estratégicamente tanto la } \\
\text { microestructura del texto } \\
\text { (con el fin de extraer } \\
\text { macropoposiciones), como la } \\
\text { superestructura textual (con } \\
\text { el objetivo de identificar la } \\
\text { macroestructura); y Habilidad } \\
\text { para mejorar la comprensión } \\
\text { y la precisión de la } \\
\text { metacomprensión a través de } \\
\text { la expresión escrita }\end{array}$} & $\begin{array}{l}\text { VD1. Formación de la idea principal de } \\
\text { cada párrafo }\end{array}$ \\
\hline & & $\begin{array}{l}\text { VD2. Dificultades para formar la idea } \\
\text { principal de cada párrafo }\end{array}$ \\
\hline & & $\begin{array}{l}\text { VD3. Construcción de un mapa conceptual } \\
\text { donde se recoja la macroestructura del texto } \\
\text { leído }\end{array}$ \\
\hline & & $\begin{array}{l}\text { VD4. Dificultades en la construcción del } \\
\text { mapa conceptual }\end{array}$ \\
\hline
\end{tabular}

Cuadro 3.2. Variables Dependientes en el Diseño I (definición operativa)

Recordemos que las hipótesis a contrastar en este diseño son:

1. Los alumnos de nuevo ingreso en la Universidad de Salamanca, matriculados en el primer curso del Grado de Maestro en Educación Primaria, presentan dificultades en el dominio de habilidades básicas de comprensión y expresión escrita para la construcción de conocimiento.

2. Los alumnos que acceden a $1^{\circ}$ curso de la Licenciatura en Psicopedagogía desde alguna de las Diplomaturas de Maestro que se imparten en la Universidad de Salamanca tienen dificultades para realizar adecuadamente una prueba de lectura, que requiere la disposición de habilidades básicas de comprensión y expresión escrita para la construcción de conocimiento.

3. Existen diferencias en el nivel de habilidades básicas en comprensión y expresión escrita entre los alumnos de nuevo ingreso en la Universidad de Salamanca y los que han finalizado alguna de las Diplomaturas de Maestro en dicha Universidad.

Los resultados obtenidos se muestran a continuación.

\subsubsection{Resultados en la Formación de la idea principal de cada párrafo (VD1)}

Los alumnos realizaron una primera tarea en la que debían extraer la idea principal de cada uno de los párrafos que conformaban un texto breve (el nivel de 
dificultad de cada párrafo, así como las puntuaciones otorgadas al alumnado por la extracción de las ideas principales de dichos párrafos, se pueden ver en el Anexo I.7 tabla 1). Una vez recogidos los datos, realizamos un análisis exhaustivo de las ideas extraídas por los alumnos, que hemos sintetizado en la siguiente tabla-resumen (para ver los resultados de forma pormenorizada ir a Anexo I.7).

\begin{tabular}{|c|c|c|c|c|c|c|c|c|c|c|}
\hline & \multicolumn{10}{|c|}{ Resumen de VD1. Formación de la idea principal de cada párrafo } \\
\hline & & $P 1$ & $P 2$ & $P 3$ & $P 4$ & $P 5$ & $P 6$ & $P 7$ & $P 8$ & $P 9$ \\
\hline & $A$ & $3.8 \%$ & $2.3 \%$ & $15.4 \%$ & $0 \%$ & $19.2 \%$ & $0 \%$ & $19.2 \%$ & $6.2 \%$ & $13.8 \%$ \\
\hline & Atema & $3.8 \%$ & $3.1 \%$ & $2.3 \%$ & $.8 \%$ & $2.3 \%$ & $.8 \%$ & $6.2 \%$ & $2.3 \%$ & $1.5 \%$ \\
\hline & $B$ & $3.8 \%$ & $7.7 \%$ & $10.8 \%$ & $3.1 \%$ & $6.2 \%$ & $6.9 \%$ & $10.0 \%$ & $11.5 \%$ & $6.9 \%$ \\
\hline & Btema & $3.1 \%$ & $2.3 \%$ & $4.6 \%$ & $0 \%$ & $6.2 \%$ & $2.3 \%$ & $11.5 \%$ & $0 \%$ & $1.5 \%$ \\
\hline & C & $85.4 \%$ & $84.6 \%$ & $66.9 \%$ & $96.2 \%$ & $66.2 \%$ & $90.0 \%$ & $53.1 \%$ & $80.0 \%$ & $76.2 \%$ \\
\hline & $\begin{array}{c}\text { Total } \\
\text { alumns }\end{array}$ & $\begin{array}{c}130 \\
(100 \%)\end{array}$ & $\begin{array}{c}130 \\
(100 \%)\end{array}$ & $\begin{array}{c}130 \\
(100 \%)\end{array}$ & $\begin{array}{c}130 \\
(100 \%)\end{array}$ & $\begin{array}{c}130 \\
(100 \%)\end{array}$ & $\begin{array}{c}130 \\
(100 \%)\end{array}$ & $\begin{array}{c}130 \\
(100 \%)\end{array}$ & $\begin{array}{c}130 \\
(100 \%)\end{array}$ & $\begin{array}{c}130 \\
(100 \%)\end{array}$ \\
\hline \multirow{3}{*}{$\begin{array}{c}\text { Ed. } \\
\text { Primaria } \\
\text { y } \\
\text { Psicoped. }\end{array}$} & $\chi^{2}(\mathrm{gl})$ & $\begin{array}{c}8.924 \\
(4)\end{array}$ & $\begin{array}{c}2.307 \\
(4)\end{array}$ & $\begin{array}{c}0.828 \\
(4)\end{array}$ & $\begin{array}{c}0.552 \\
(2)\end{array}$ & $\begin{array}{c}3.497 \\
(4)\end{array}$ & $\begin{array}{c}3.962 \\
(3)\end{array}$ & $\begin{array}{c}1.209 \\
(4)\end{array}$ & $\begin{array}{c}2.075 \\
(3)\end{array}$ & $\begin{array}{c}2.122 \\
(4)\end{array}$ \\
\hline & $P$ & .063 & .680 & .654 & .759 & .478 & .266 & .877 & .557 & .713 \\
\hline & $\begin{array}{c}\text { Nivel } \\
\text { Dificult }\end{array}$ & MEDIO & ALTO & BAJO & ALTO & MEDIO & ALTO & BAJO & BAJO & BAJO \\
\hline
\end{tabular}

Tabla 3.8. Resumen de los resultados en el Diseño I para Formación de la idea principal de cada párrafo (VD1) (\% de respuesta por categoría), y análisis inferencial entre Psicopedagogía y Educación Primaria

La proporción de $\chi^{2}$ indica que no existían diferencias significativas intergrupales (n.s.=.05) en Formación de la idea principal de cada párrafo (VD1). Como era de esperar, los alumnos, independientemente del curso en el que se encontraban, tenían mayores dificultades para extraer las ideas principales de los párrafos de nivel alto (P2, P4 y P6) que para hacer lo propio con las ideas del resto de los párrafos. Si bien, cabe señalar que, a pesar de que el porcentaje de los alumnos que tenían dificultades era similar en los párrafos categorizados bajo un mismo nivel (bien medio o bien bajo), los resultados muestran que:

a) En los párrafos P1 y P5, categorizados con un nivel medio de dificultad, sólo un $3.8 \%$ de los alumnos extrajeron la idea principal de P1, mientras que un $19.2 \%$ lo consiguió para P5. Teniendo en cuenta los análisis realizados al contenido semántico de estos dos párrafos (ver Anexo I.4 desde el cuadro 1 al 14, y desde el cuadro 59 al 73), podemos señalar que la organización de las proposiciones en 
el párrafo 1 planteó al alumnado mayores dificultades a la hora de extraer su idea principal; quizá debido a que la idea general aparece en el centro del párrafo 1, mientras que las ejemplificaciones de dicha idea se presentan al principio y al final del mismo.

b) En los párrafos P3, P7, P8 y P9, categorizados con un nivel de dificultad bajo, los alumnos tuvieron mayores dificultades para extraer la idea principal de P8 (sólo un 6.2\% lo consiguió) que para identificar las ideas principales de los párrafos P3 (15.4\%), P7 (19.2\%) y P9 (13.8\%). Revisando los análisis realizados al párrafo 8 (ver Anexo I.4 desde el cuadro 103 al 116), podríamos afirmar que gran parte de los alumnos manifestaban ciertos problemas a la hora de seguir la correferencia argumental de este párrafo, y esto pudo conllevar una cierta confusión a la hora de extraer la idea principal.

Una vez obtenidas las puntuaciones del alumnado para cada párrafo en Formación de la idea principal de cada párrafo (VD1); analizamos el nivel de desempeño general del alumnado en dicha variable, y determinamos si existían diferencias significativas (n.s.=.05) entre los grupos de estudios en cuanto al nivel mostrado. Para ello, sumamos las puntuaciones obtenidas por cada alumno en los nueve párrafos que componían el texto:

$$
V D 1=p_{1}+p_{2}+p_{3}+p_{4}+p_{5}+p_{6}+p_{7}+p_{8}+p_{9}
$$

$\mathrm{P}_{i}$ se obtiene a partir de la puntuación obtenida en cada párrafo según la rúbrica establecida para dichos párrafos

A continuación determinamos el nivel que mostraban los alumnos mediante los siguientes criterios:

- Nivel muy Bajo: la puntuación del alumno oscilaría entre 0 puntos y la puntuación que se obtiene identificando la idea principal de un párrafo de nivel bajo $(\mathrm{A}=0.75)$ y la idea temática de otro párrafo del mismo nivel $(\mathrm{B}=0.25)$. Siendo la oscilación entre 0 y 1 punto.

- Nivel Bajo: la puntuación del alumno oscilaría entre 1.01 puntos y la puntuación que se obtiene identificando las ideas principales de los 4 párrafos de nivel bajo $(0.75$ x $4=3)$. Siendo la oscilación entre 1.01 y 3 puntos.

- Nivel Medio: la puntuación del alumno oscilaría entre 3.01 puntos y la puntuación que se obtiene identificando las ideas principales de los 4 párrafos de nivel bajo $(0.75 \times 4=3)$ y las ideas principales de los dos párrafos de nivel medio $(A=1$, por lo que $1+1=2)$. Siendo la oscilación entre 3.01 y 5 puntos. 
- Nivel Alto: la puntuación del alumno oscilaría entre 5.01 puntos y la puntuación que se obtiene identificando las ideas principales de los 4 párrafos de nivel bajo $(0.75 \times 4=3)$, las ideas principales de los dos párrafos de nivel medio $(\mathrm{A}=1$, por lo que $1+1=2)$ y la idea principal de uno de los párrafos categorizados con un nivel alto $(\mathrm{A}=1.25)$. Siendo la oscilación entre $5.01 \mathrm{y}$ 6.25 .

- Nivel muy Alto: la puntuación del alumno oscilaría entre 6.26 puntos y la puntuación que se obtiene identificando las ideas principales de los 4 párrafos de nivel bajo $(0.75 \times 4=3)$, las ideas principales de los dos párrafos de nivel medio $(\mathrm{A}=1$, por lo que $1+1=2)$ y las ideas principales de los tres párrafos categorizado con un nivel alto $(\mathrm{A}=1.25$ por lo que $1.25+1.25+1.25=3.75)$. Siendo la oscilación entre 6.26 y 8.75 .

\begin{tabular}{|c|c|}
\hline \multicolumn{2}{|c|}{ Intervalo de puntuación para identificar nivel del alumnado en VD1. Formación de } \\
la idea principal de cada párrafo (Diseño I)
\end{tabular}

Cuadro 3.3. Intervalo de puntación para identificar el nivel del alumnado en: Formación de la idea principal de cada párrafo (VD1) (Diseño I)

Partiendo de estos intervalos, comprobamos que el alumnado tenía un nivel entre bajo y muy bajo en Formación de la idea principal de cada párrafo (VD1). El siguiente gráfico muestra claramente que la mayoría de los alumnos de ambos grupos se encontraban entre estos dos niveles. 


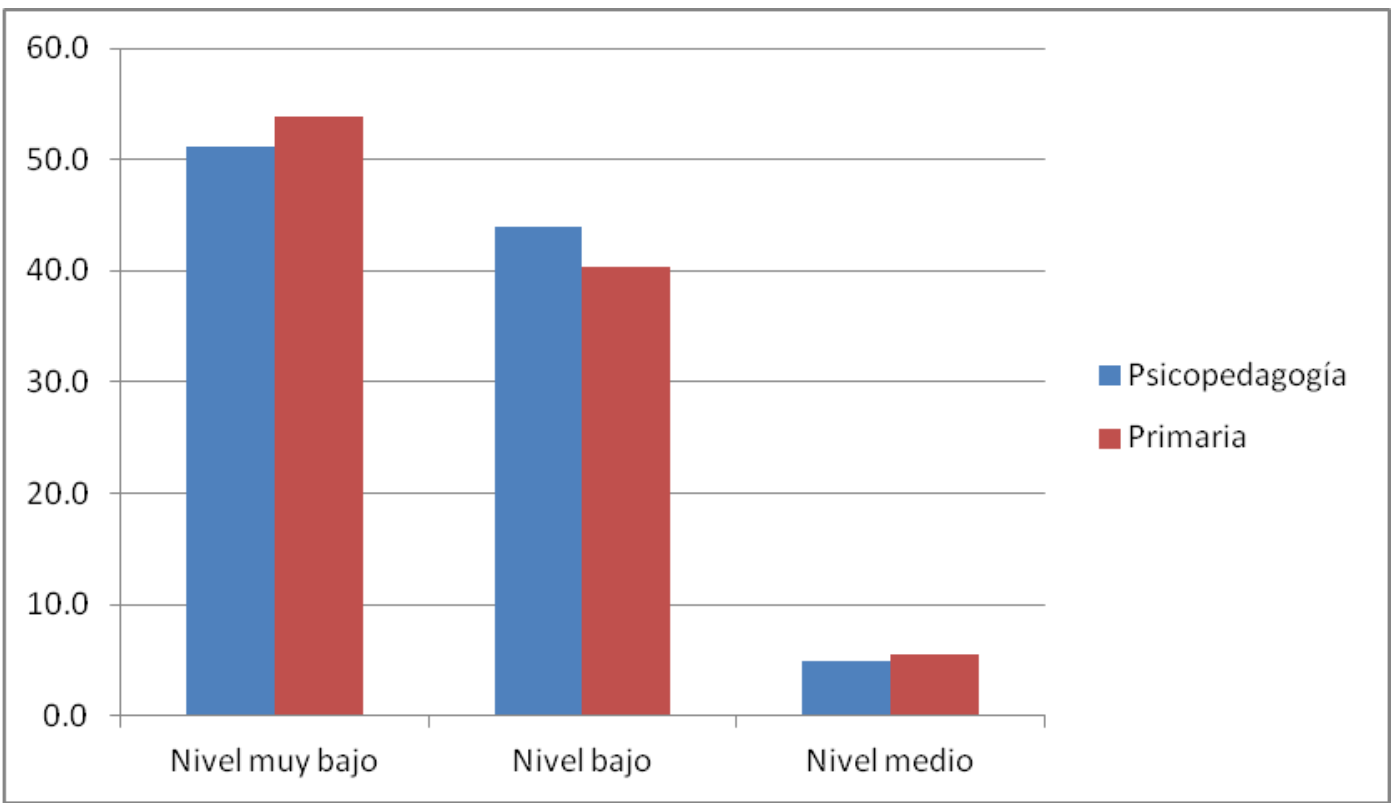

Gráfico 3.5. Nivel del alumnado en: Formación de la idea principal de cada párrafo (VD1) (Diseño I)

(porcentajes)

No obstante, para cerciorarnos de que no existían diferencias estadísticas entre grupos (n.s.=.05), realizamos una prueba t para muestras independientes; la cual, como vemos en la siguiente tabla, indica que no existían diferencias significativas intergrupales (al estadístico de contraste $\mathrm{t}=0.174$, corresponde una $\mathrm{p}=.862$ ).

\begin{tabular}{c|c|c|c|c|c|c}
\hline \multicolumn{7}{c}{ Prueba t de diferencia de medias para muestras independientes } \\
\hline VD & $\bar{x}$ psico & $\mathrm{SD}_{\text {Psico }}$ & $\overline{\mathrm{x}}$ primaria & $\mathrm{SD}_{\text {Primaria }}$ & $\mathrm{t}$ & \multicolumn{1}{c}{} \\
\hline $\begin{array}{c}\text { VD1. Formación de la } \\
\text { idea principal de cada } \\
\text { párrafo }\end{array}$ & .5366 & .59572 & .5169 & .60514 & 0,174 & .862 \\
\hline
\end{tabular}

Tabla 3.9. Prueba t de diferencia de medias en cuanto a: Formación de la idea principal de cada párrafo (VD1) (Diseño I)

Teniendo en cuenta los resultados obtenidos, parece que la variable independiente momento formativo no fue determinante a la hora de que los alumnos obtuviesen mejor o peor nivel de desempeño en Formación de la idea principal de cada párrafo (VD1). 


\subsubsection{Resultados en las Dificultades para formar la idea principal de cada párrafo (VD2)}

Con el fin de profundizar en el tipo de dificultades que tenían los alumnos a la hora de extraer las ideas principales de cada párrafo, realizamos un análisis de los resultados que obtuvieron en la variable Dificultades para formar la idea principal de cada párrafo (VD2), que hemos sintetizado en la siguiente tabla-resumen (para ver los resultados de forma pormenorizada ir Anexo I.7).

\begin{tabular}{|c|c|c|c|c|c|c|c|c|c|c|}
\hline & \multicolumn{10}{|c|}{ Resumen de VD2. Dificultades para formar la idea principal de cada párrafo } \\
\hline & & $P 1$ & $P 2$ & $P 3$ & $P 4$ & $P 5$ & P6 & $P 7$ & P8 & $P 9$ \\
\hline & $C_{l}$ & $54.1 \%$ & $36.4 \%$ & $21.8 \%$ & $39.2 \%$ & $36.0 \%$ & $9.4 \%$ & $23.2 \%$ & $3.8 \%$ & $32.3 \%$ \\
\hline & $C_{2}$ & $8.1 \%$ & $16.4 \%$ & $3.4 \%$ & $14.4 \%$ & $4.7 \%$ & $41.0 \%$ & $29.0 \%$ & $51.9 \%$ & $19.2 \%$ \\
\hline & $C_{3}$ & $37.8 \%$ & $47.3 \%$ & $74.7 \%$ & $46.4 \%$ & $59.3 \%$ & $49.6 \%$ & $47.8 \%$ & $44.2 \%$ & $48.5 \%$ \\
\hline & $\begin{array}{c}\text { Total } \\
\text { errores }\end{array}$ & $\begin{array}{c}111 \\
(100 \%)\end{array}$ & $\begin{array}{c}110 \\
(100 \%)\end{array}$ & $\begin{array}{c}87 \\
(100 \%)\end{array}$ & $\begin{array}{c}125 \\
(100 \%)\end{array}$ & $\begin{array}{c}86 \\
(100 \%)\end{array}$ & $\begin{array}{c}117 \\
(100 \%)\end{array}$ & $\begin{array}{c}69 \\
(100 \%)\end{array}$ & $\begin{array}{c}104 \\
(100 \%)\end{array}$ & $\begin{array}{c}99 \\
(100 \%)\end{array}$ \\
\hline \multirow{4}{*}{$\begin{array}{c}\text { Ed. } \\
\text { Primaria } \\
\mathbf{y} \\
\text { Psicoped }\end{array}$} & $\chi^{2}(\mathrm{gl})$ & 1.898 & 4.164 & .850 & 4.764 & 1.614 & 1.080 & 6.335 & 4.807 & 1.752 \\
\hline & & & (2) & & & & & & & \\
\hline & $P$ & .387 & .125 & .654 & .092 & .446 & .583 & .042 & .090 & .417 \\
\hline & $\begin{array}{c}\text { Nivel } \\
\text { Dificult }\end{array}$ & MEDIO & ALTO & BAJO & ALTO & MEDIO & ALTO & BAJO & BAJO & BAJO \\
\hline
\end{tabular}

Tabla 3.10. Resumen de los resultados en el Diseño I para Dificultades para formar la idea principal de cada párrafo (VD2) (\% de respuesta por subcategoría), y análisis inferencial entre Psicopedagogía y Educación Primaria

Como podemos observar, no existían diferencias significativas intergrupales en la mayor parte de los párrafos. Únicamente aparecen diferencias en el párrafo 7, las cuales, como vemos en la tabla 3.11, se debían principalmente a que mientras la mayor parte de los alumnos de Psicopedagogía que habían tenido dificultades malinterpretaban la información del párrafo (45.5\%), la mayor parte de los alumnos de Primaria que habían tenido dificultades no expresaban adecuadamente la información extraída $(57.8 \%)$. 


\begin{tabular}{|c|c|c|c|}
\hline \multicolumn{4}{|c|}{ Dificultades para formar la idea principal del párrafo 7} \\
\hline & \multicolumn{2}{|c|}{ CARRERA UNIVERSITARIA } & \multirow{2}{*}{$\begin{array}{l}\text { Total alumnos } \\
\text { según tipo de } \\
\text { respuesta }\end{array}$} \\
\hline & Psicopedagogía & Primaria & \\
\hline \multirow[t]{2}{*}{$\begin{array}{ll}C_{\boldsymbol{I}} & \begin{array}{l}\text { Extrae una ideas/temas secundarios o idea muy } \\
\text { general }\end{array}\end{array}$} & 6 & 10 & 16 \\
\hline & $25.0 \%$ & $22.2 \%$ & $23.2 \%$ \\
\hline \multirow[t]{2}{*}{$C_{2} \quad$ Malinterpreta información del párrafo } & 11 & 9 & 20 \\
\hline & $45.8 \%$ & $20.0 \%$ & $29.0 \%$ \\
\hline \multirow[t]{2}{*}{$\begin{array}{llll}\boldsymbol{C}_{3} & \begin{array}{l}\text { No expresa adecuadamente la información } \\
\text { extraída }\end{array} & & \end{array}$} & 7 & 26 & 33 \\
\hline & $29.2 \%$ & $57.8 \%$ & $47.8 \%$ \\
\hline \multirow[t]{2}{*}{ Total errores alumnos de cada carrera } & 24 & 45 & 69 \\
\hline & $100.0 \%$ & $100.0 \%$ & $100.0 \%$ \\
\hline
\end{tabular}

Tabla 3.11. Dificultades para formar la idea principal del párrafo 7 (Diseño I)

En lo que se refiere al resto de los párrafos, el alumnado mostraba dificultades, principalmente, a la hora de expresar adecuadamente la información extraída $\left(\mathrm{C}_{3}\right)$. Solamente existían dos párrafos en los que predominaban otro tipo de dificultades; en concreto, nos refirimos al párrafo 1 (P1), donde la mayor parte del alumnado extraía ideas secundarias, y al párrafo 8 (P8), donde la mayor parte del alumnado malinterpretaba la información. En este sentido, las características de estos dos párrafos pudieron ser determinantes:

- Por una parte, en el párrafo 1 (ver Anexo I.4, desde cuadro 1 a cuadro 14) había que poner en marcha la macroestrategia de generalización, teniendo en cuenta que la idea general aparece en el centro del párrafo y que las ejemplificaciones de dicha idea aparecen al principio y al final del párrafo. Esto pudo hacer que los alumnos tuviesen dificultades a la hora de extraer la idea principal, y en consecuencia, se acabaran centrando en ideas secundarias.

- Por otra parte, en el párrafo 8 (ver Anexo I.4 desde cuadro 103 a cuadro 116) parece que gran parte de los alumnos manifestaban ciertos problemas a la hora de seguir la correferencia argumental de este párrafo, y esto pudo conllevar una cierta confusión a la hora de interpretar el mismo.

\subsubsection{Resultados para Construcción de un mapa conceptual donde se recoja la macroestructura del texto leído (VD3)}

Los alumnos realizaron una segunda tarea en la que debían construir un mapa conceptual que expresara las relaciones que se establecían entre las ideas importantes del texto. Los resultados obtenidos se recogen en la siguiente tabla: 


\begin{tabular}{|c|c|c|c|}
\hline \multicolumn{4}{|c|}{ VD3. Construcción de un mapa conceptual donde se recoja la macroestructura del texto leído } \\
\hline & \multicolumn{2}{|c|}{ CARRERA UNIVERSITARIA } & \multirow{2}{*}{$\begin{array}{l}\text { Total alumnos según } \\
\text { tipo de respuesta }\end{array}$} \\
\hline & Psicopedagogía & Primaria & \\
\hline $\begin{array}{l}\text { Construye un mapa en el que } \\
\text { estructura las ideas importantes } \\
\text { en torno a una estructura } \\
\text { organizativa subordinada del } \\
\text { texto }\end{array}$ & $4.9 \%$ & $2.2 \%$ & $3.1 \%$ \\
\hline $\begin{array}{ll}\boldsymbol{C} & \text { Dificultades para establecer } \\
& \text { las relaciones estructurales del } \\
\text { texto en el mapa conceptual } & \\
\text { que construye }\end{array}$ & $\begin{array}{c}39 \\
95.1 \%\end{array}$ & $\begin{array}{c}87 \\
97.8 \%\end{array}$ & $\begin{array}{c}126 \\
96.9 \%\end{array}$ \\
\hline $\begin{array}{l}\text { Total errores alumnos de cada } \\
\text { carrera }\end{array}$ & $\begin{array}{c}41 \\
100.0 \%\end{array}$ & $\begin{array}{c}89 \\
100.0 \%\end{array}$ & $\begin{array}{c}130 \\
100.0 \%\end{array}$ \\
\hline $\begin{array}{l}\chi^{2}(\mathrm{gl}) \\
p\end{array}$ & & $\begin{array}{c}0.651(1) \\
.420\end{array}$ & \\
\hline
\end{tabular}

Tabla 3.12. Construcción de un mapa conceptual donde se recoja la macroestructura del texto leído (VD3) (Diseño I)

(la salida completa de este procedimiento se encuentra en el Anexo I. 7 tabla 44)

No rechazamos la hipótesis nula, y por consiguiente, no existen diferencias significativas (n.s.=.05) en la variable Construcción de un mapa conceptual donde se recoja la macroestructura del texto leído (VD3) entre alumnos que inician la carrera de maestro y alumnos que la han finalizado $\left(\chi^{2}=0.651 ; \mathrm{p}=.420\right)$. Cabe destacar que ningún alumno fue capaz de reflejar en su mapa conceptual las relaciones estructurales que se daban entre las ideas más importantes del texto, y que únicamente un 3.1\% de los alumnos estructuró las ideas principales del texto en torno a una estructura o forma organizativa subordinada del mismo. Esto hizo que prácticamente la totalidad del alumnado tuviese dificultades a la hora de realizar la tarea (un 96.9\%).

A continuación analizaremos estas dificultades a través de los resultados obtenidos para la variable Dificultades en la construcción del mapa conceptual (VD4).

\subsubsection{Resultados para Dificultades en la construcción del mapa conceptual (VD4)}

La siguiente tabla muestra que no existían diferencias significativas entre los dos grupos de la muestra en la variable Dificultades en la construcción del mapa conceptual $\left(\chi^{2}=3.447 ; \mathrm{p}=.178\right)$. 


\begin{tabular}{|c|c|c|c|}
\hline \multicolumn{4}{|c|}{ VD4. Dificultades en la construcción del mapa conceptual } \\
\hline & \multicolumn{2}{|c|}{ CARRERA UNIVERSITARIA } & \multirow{2}{*}{$\begin{array}{l}\text { Total alumnos } \\
\text { según tipo de } \\
\text { respuesta }\end{array}$} \\
\hline & Psicopedagogía & Primaria & \\
\hline $\begin{array}{ll}\boldsymbol{C}_{I} & \text { Construye un mapa conceptual que no } \\
& \text { se centra en la ideas importantes del } \\
& \text { texto }\end{array}$ & $\begin{array}{c}12 \\
30.8 \%\end{array}$ & $\begin{array}{c}21 \\
24.1 \%\end{array}$ & $\begin{array}{c}33 \\
26.2 \%\end{array}$ \\
\hline $\begin{array}{ll}\boldsymbol{C}_{2} & \begin{array}{l}\text { Construye un mapa conceptual en el } \\
\text { que no queda clara la estructura global } \\
\text { y/o significado global del mismo }\end{array} \\
\end{array}$ & $\begin{array}{c}21 \\
53.8 \% \\
\end{array}$ & $\begin{array}{c}60 \\
69.0 \% \\
\end{array}$ & $\begin{array}{c}81 \\
64.3 \% \\
\end{array}$ \\
\hline $\begin{array}{ll}\boldsymbol{C}_{3} & \begin{array}{l}\text { No sabe organizar en diferentes } \\
\text { niveles jerárquicos el mapa } \\
\text { conceptual que trata de construir }\end{array}\end{array}$ & $\begin{array}{c}6 \\
15.4 \% \\
\end{array}$ & $\begin{array}{r}6 \\
6.9 \% \\
\end{array}$ & $\begin{array}{r}12 \\
9.5 \% \\
\end{array}$ \\
\hline Total errores alumnos de cada carrera & $\begin{array}{c}39 \\
100.0 \%\end{array}$ & $\begin{array}{c}87 \\
100.0 \%\end{array}$ & $\begin{array}{c}126 \\
100.0 \%\end{array}$ \\
\hline $\begin{array}{l}\chi^{2}(\mathrm{gl}) \\
p\end{array}$ & & $\begin{array}{c}3.447(2) \\
.178\end{array}$ & \\
\hline
\end{tabular}

Tabla 3.13. Dificultades en la construcción del mapa conceptual (VD4) (Diseño I)

(la salida completa de este procedimiento se encuentra en el Anexo I. 7 tabla 46)

Observando con detenimiento la tabla, se percibe que la mayor parte de los alumnos (un 64.3\%) tenían problemas de la categoría $\mathrm{C}_{2}$ (Construye un mapa conceptual en el que no queda clara la estructura global y/o significado global). Además, un 26.2\% del alumnado, aunque era capaz de construir un mapa conceptual cuyos conceptos se relacionaban a nivel global de forma clara, recogía relaciones que no eran las que se establecían en el texto. Para finalizar, sólo un $9.5 \%$ tenía problemas a la hora de organizar en diferentes niveles jerárquicos el mapa conceptual.

\subsubsection{Contraste de las hipótesis relativas a la variable dependiente Habilidades básicas de comprensión y expresión escrita en los grupos de Educación Primaria y Psicopedagogía}

Partiendo de los resultados obtenidos podemos señalar que:

a) No rechazamos la primera hipótesis: Los alumnos de nuevo ingreso en la Universidad de Salamanca, matriculados en el primer curso del Grado de Maestro en Educación Primaria, presentan dificultades en el dominio de habilidades básicas de comprensión y expresión escrita para la construcción de conocimiento.

b) No rechazamos la segunda hipótesis: Los alumnos que acceden a $1^{\circ}$ curso de la Licenciatura en Psicopedagogía desde alguna de las Diplomaturas de Maestro que se imparten en la Universidad de Salamanca tienen dificultades para realizar adecuadamente una prueba de lectura, que requiere la disposición de habilidades básicas de comprensión y expresión escrita para la construcción de conocimiento. 
c) No parece existir diferencia entre alumnos que inician la carrera de maestro y alumnos que han finalizado dicha carrera en la variable general habilidades básicas de comprensión y expresión escrita. Como hemos visto, no existían diferencias significativas (n.s.=.05) en las sub-variables Formación de la idea principal de cada párrafo (VD1); Construcción de un mapa conceptual donde se recoja la macroestructura del texto leído (VD3); y Dificultades en la construcción del mapa conceptual (VD4). Y aunque en el párrafo P7 aparecían diferencias para la variable Dificultades para formar la idea principal de cada párrafo (VD2), en el resto de los párrafos no existían diferencias intergrupos. En consecuencia, rechazamos la tercera hipótesis: Existen diferencias en el nivel de habilidades básicas en comprensión y expresión escrita entre los alumnos de nuevo ingreso en la Universidad de Salamanca y los que han finalizado alguna de las Diplomaturas de Maestro en dicha Universidad.

Además, para la mayoría del alumnado se observa un nivel bastante bajo en cuanto a esta variable general, ya que, por una parte, el nivel de desempeño de los alumnos para la variable Formación de la idea principal de cada párrafo se encuentra entre Bajo y muy Bajo; y por otra, la gran mayoría de los alumnos (un 96.9\%) mostraron dificultades para la variable Construcción de un mapa conceptual donde se recoja la macroestructura del texto leído.

\subsection{RESULTADOS SOBRE EL DISEÑO II: EVALUACIÓN DEL EFECTO DEL FORMATO TEXTUAL SOBRE LAS ESTRATEGIAS DE C y E ESCRITA EN EDUCACIÓN PRIMARIA Y PSICOPEDAGOGÍA}

Antes de mostrar los resultados obtenidos para este segundo diseño, conviene recordar tres de los aspectos que tratamos durante el capítulo de metodología.

En primer lugar la muestra de utilizada:

\begin{tabular}{|c|c|c|c|c|c|}
\hline \multicolumn{6}{|c|}{ Muestra Final Diseño II } \\
\hline & \multicolumn{4}{|c|}{$\begin{array}{c}\text { GRUPO DE ESTUDIO } \\
\text { (carrera universitaria y formato textual tarea) }\end{array}$} & \multirow[b]{2}{*}{ Total alumnos } \\
\hline & PSP Hipertexto & EDP Hipertexto & PSP Texto & EDP Texto & \\
\hline Frecuencia & 21 & 31 & 13 & 31 & 96 \\
\hline$\%$ & 21,9 & 32,3 & 13,5 & 32,3 & 100.0 \\
\hline
\end{tabular}

Tabla 2.3. Muestra Final para el Diseño II

En segundo lugar la hipótesis a contrastar: 
4. El tipo de texto (impreso e hipertexto) implica la puesta en práctica de tareas de comprensión y expresión escrita diferenciales en ambos grupos.

Y en tercer lugar el diseño utilizado:

\begin{tabular}{|l|c|c|c|}
\hline \multicolumn{1}{|c|}{ Grupos } & Pre-test & $\begin{array}{c}\text { Tratamiento } \\
\text { (tipo de texto) }\end{array}$ & Pos-test \\
\hline Grupo1. EDP Texto & $O_{1}$ & $X_{1}$ & $O_{2}$ \\
\hline Grupo2. EDP Hipertexto & $O_{1}$ & $X_{2}$ & $O_{2}$ \\
\hline Grupo3. PSP Texto & $O_{1}$ & $X_{1}$ & $O_{2}$ \\
\hline Grupo 4. PSP Hipertexto & $O_{1}$ & $X_{2}$ & $O_{2}$ \\
\hline
\end{tabular}

Cuadro 2.2. Diseño II

$O_{I}=$ Primera observación/ medición de la variable dependiente (resultados obtenidos en prueba Diseño I)

$X_{I}=$ Estímulo formato texto

$X_{2}=$ Estímulo formato hipertexto

$\mathrm{O}_{2}=$ Segunda observación/ medición de la variable dependiente (resultados obtenidos en tarea académica propuesta para el Diseño II)

\subsubsection{Resultados del Pre-test en el Diseño II}

El objetivo de esta fase (Pre-test) es comprobar estadísticamente que los 4 grupos (constituidos al azar) son homogéneos en las variables de control y con la variable general habilidades básicas de comprensión y expresión escrita; para, posteriormente, poder comprobar (en la fase Pos-test) si existen diferencias o no entre ellos en función de la variable específica habilidades específicas para la síntesis de información.

\subsubsection{Características de las muestras y contraste de homogeneidad: EDP texto, EDP hipertexto, PSP texto, PSP hipertexto}

Como señalamos en el apartado población y muestra, en este segundo diseño se constituyeron cuatro grupos (EDP texto, EDP hipertexto, PSP texto, PSP hipertexto) partiendo de las dos variables independientes que fueron objeto de análisis (el momento formativo y el formato textual). Con el fin de comprobar si existían diferencias significativas entre estos grupos (n.s.=.05) que nos pudieran ofrecer una explicación alternativa a dichas variables independientes, partimos de las mismas variables de control que en el Diseño I. 


\begin{tabular}{|c|c|}
\hline \multicolumn{2}{|r|}{ VARIABLES DE CONTROL } \\
\hline Variable Control & Variables Control Operativas \\
\hline VC1. Variables de Identificación & $\begin{array}{l}\text { VC1.1. Género } \\
\text { VC1.2. Edad }\end{array}$ \\
\hline VC2. Variables Pedagógicas & $\begin{array}{l}\text { VC2.1. Centro de procedencia } \\
\text { VC2.2. Modalidad de bachillerato (Primaria) } \\
\text { VC2.3. Calificación de entrada a la universidad } \\
\text { VC2.4. Primer ciclo cursado (Psicopedagogía) } \\
\text { VC2.5. Calificación obtenida en el Primer ciclo (Psicopedagogía) } \\
\text { VC2.6. Matrícula en otra carrera universitaria }\end{array}$ \\
\hline VC3 Variables Hábitos Lectores & $\begin{array}{l}\text { VC3.1. Idioma de lectura } \\
\text { VC3.2. Causa lectura último libro } \\
\text { VC3.3. Materia del último libro leído } \\
\text { VC3.4. Cantidad libros leídos al año } \\
\text { VC3.5. Razones para no leer con mayor frecuencia } \\
\text { VC3.6. Lectura en soporte digital } \\
\text { - VC3.6.1. Lectura en soporte digital. Webs, blogs, foros } \\
\text { - VC3.6.2. Lectura en soporte digital. Prensa } \\
\text { - VC3.6.3. Lectura en soporte digital. Revistas } \\
\text { - VC3.6.4. Lectura en soporte digital. Libros } \\
\text { - VC3.6.5. Lectura en soporte digital. Otros }\end{array}$ \\
\hline
\end{tabular}

Cuadro 3.4. Variables de control constituidas (Diseño II)

\section{A. Contraste para Variables de Identificación (VC1) para el Diseño II}

En cuanto a la variable Género (VC1.1), no encontramos diferencias significativas entre los grupos (n.s.=.05). Si bien, existía un claro predominio de mujeres (un 76.0\%) sobre hombres (un 24.0\%). 


\begin{tabular}{|c|c|c|c|c|c|}
\hline \multicolumn{6}{|c|}{ VC1.1 Género } \\
\hline & \multicolumn{4}{|c|}{ GRUPO ESTUDIO } & \multirow{2}{*}{$\begin{array}{l}\text { Total } \\
\text { alumnos } \\
\text { según tipo de } \\
\text { respuesta }\end{array}$} \\
\hline & $\begin{array}{c}\text { PSP } \\
\text { Hipertexto }\end{array}$ & $\begin{array}{c}\text { EDP } \\
\text { Hipertexto }\end{array}$ & PSP Texto & EDP Texto & \\
\hline \multirow[t]{2}{*}{ Hombre } & 2 & 10 & 3 & 8 & 23 \\
\hline & $9.5 \%$ & $32.3 \%$ & $23.1 \%$ & $25.8 \%$ & $24.0 \%$ \\
\hline \multirow[t]{2}{*}{ Mujer } & 19 & 21 & 10 & 23 & 73 \\
\hline & $90.5 \%$ & $67.7 \%$ & $76.9 \%$ & $74.2 \%$ & $76.0 \%$ \\
\hline \multirow{2}{*}{$\begin{array}{l}\text { Total errores alumnos de } \\
\text { cada carrera }\end{array}$} & 21 & 31 & 13 & 31 & 96 \\
\hline & $100.0 \%$ & $100.0 \%$ & $100.0 \%$ & $100.0 \%$ & $100.0 \%$ \\
\hline$\chi^{2}(\mathrm{gl})$ & \multicolumn{5}{|c|}{$3.637(3)$} \\
\hline$p$ & \multicolumn{5}{|c|}{.303} \\
\hline
\end{tabular}

(la salida completa de este procedimiento se encuentra en el Anexo II. 11 tabla 2)

Por el contrario, sí existen diferencias significativas (n.s.=.05) en la variable Edad $\left(\chi^{2}=40.191 ; \mathrm{p}<.01\right)$. Estas diferencias, al igual que en el Diseño I, estaban muy relacionadas con la variable independiente momento formativo. Recordemos que un grupo-clase es de Educación Primaria y otro de Psicopedagogía (cursos académicos distintos).

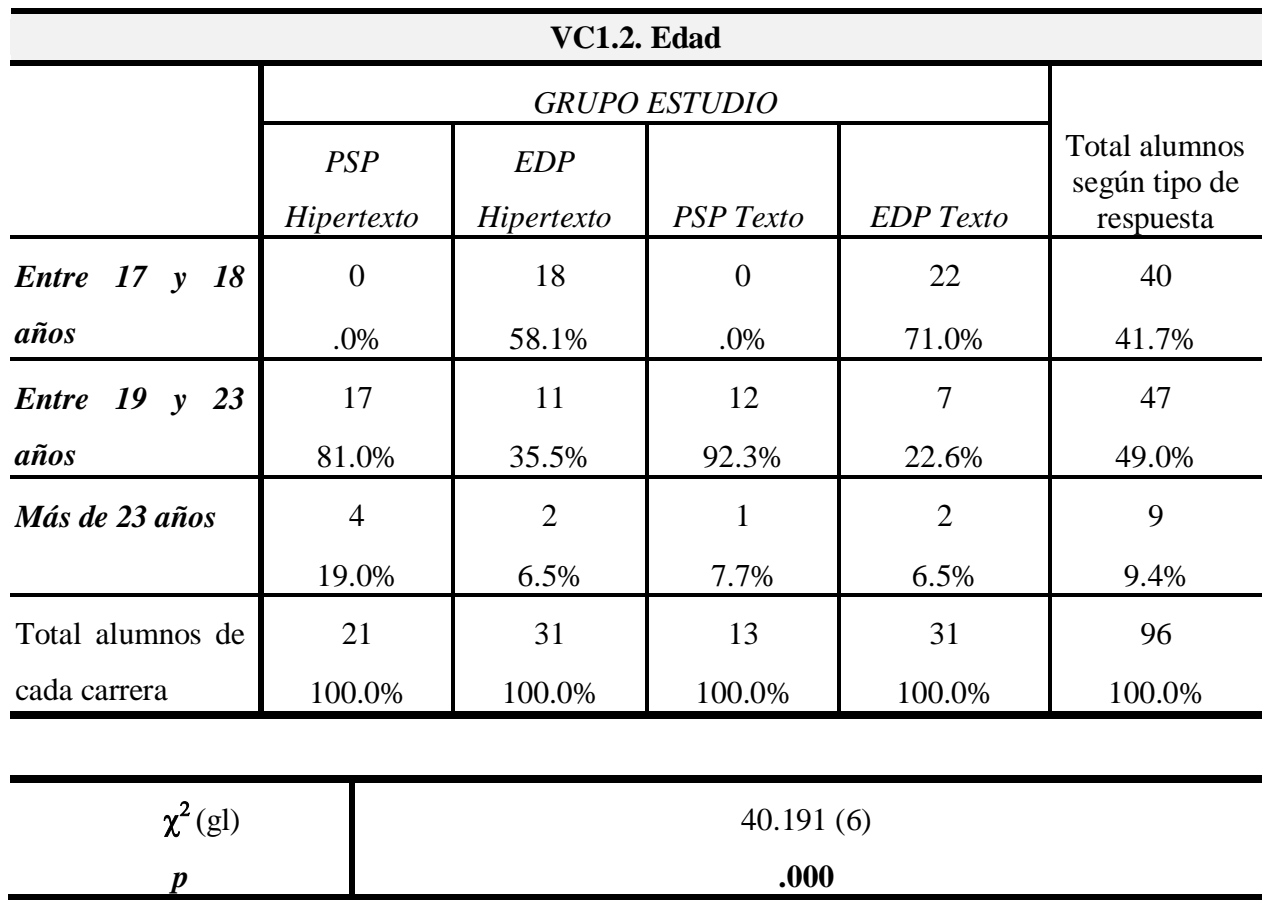

Tabla 3.15. Edad (VC1.2) (Diseño II)

(la salida completa de este procedimiento se encuentra en el Anexo II. 11 tabla 4) 


\section{B. Contraste para Variables Pedagógicas (VC2) para el Diseño II}

Las variables pedagógicas, al igual que para el Diseño I, se dividieron en dos bloques. El primer bloque de variables tenía por finalidad conocer la existencia o no de diferencias significativas entre los grupos (n.s.=.05) en cuanto a determinados aspectos académicos: Centro de procedencia (VC2.1), Calificación de entrada en la universidad (VC2.3) y matricula en otra carrera universitaria (VC2.6). Mientras que el objetivo del segundo bloque, era profundizar en algunos datos académicos propios de cada grupo: para el grupo de Educación Primaria se analizó Modalidad de bachillerato (VC2.2), y para el grupo de Psicopedagogía se analizaron el Primer ciclo cursado (VC2.4) y la Calificación obtenida en el primer ciclo (VC2.5).

Comenzando por la variable Calificación de entrada a la universidad (VC2.3), hemos de señalar que, como vemos en la tabla 3.16, no se encuentran diferencias significativas intergrupos (n.s.=.05). Más de la mitad de los alumnos accedieron a la universidad con una calificación de Aprobado (el 54.2\%), siendo muy pocos los que lo hicieron con una nota de Sobresaliente (el 2.1\%). Concretamente, la mayor parte de los alumnos obtuvieron una calificación de Aprobado en los grupos PSP hipertexto (un 61.9\%), EDP hipertexto (un 58.1\%) y PSP texto (un 76.9\%); mientras que en el grupo EDP texto, el porcentaje de Notables (un 45.2\%) superaba ligeramente al de Aprobados (un $35.5 \%$ ).

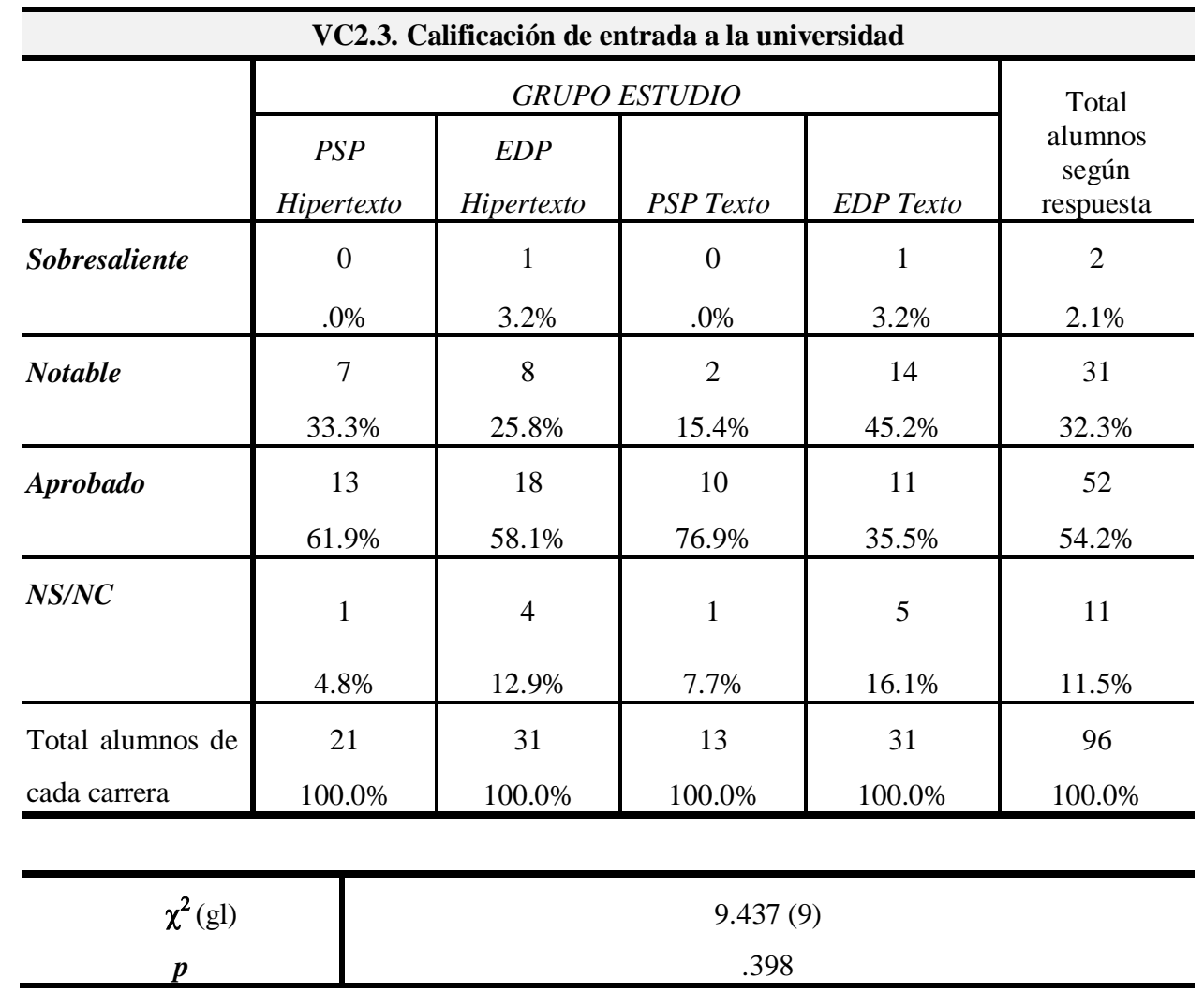

Tabla 3.16. Calificación de entrada a la universidad (VC2.3) (Diseño II) (la salida completa de este procedimiento se encuentra en el Anexo II. 11 tabla 10) 
Continuando con las demás variables del primer bloque, cabe mencionar que se observan diferencias significativas entre grupos en cuanto a las variables Centro de Procedencia (VC2.1) (ver Anexo II tabla 6), y Matrícula en otra carrera universitaria (VC2.6) (ver Anexo II tabla 16). La causa de estas diferencias, al igual que en el Diseño I, estaba relacionada con la variable independiente momento formativo.

En cuanto al segundo conjunto de variables, no existían diferencias significativas (n.s.=.05) entre los grupos de Primaria (EDP texto y EDP hipertexto) en Modalidad de bachillerato (VC2.2) (gráfico 3.6); ni tampoco entre los grupos de Psicopedagogía (PSP texto y PSP hipertexto) en Primer ciclo cursado (VC2.4) (Gráfico 3.7). Prácticamente la mitad de los alumnos de Educación Primaria (48.4\%) realizaron la modalidad de bachillerato de Ciencias Sociales, mientras que la mayor parte de los alumnos matriculados en Psicopedagogía cursaron el primer ciclo en Educación Infantil (47.1\%) o en Educación Primaria (35.3\%).

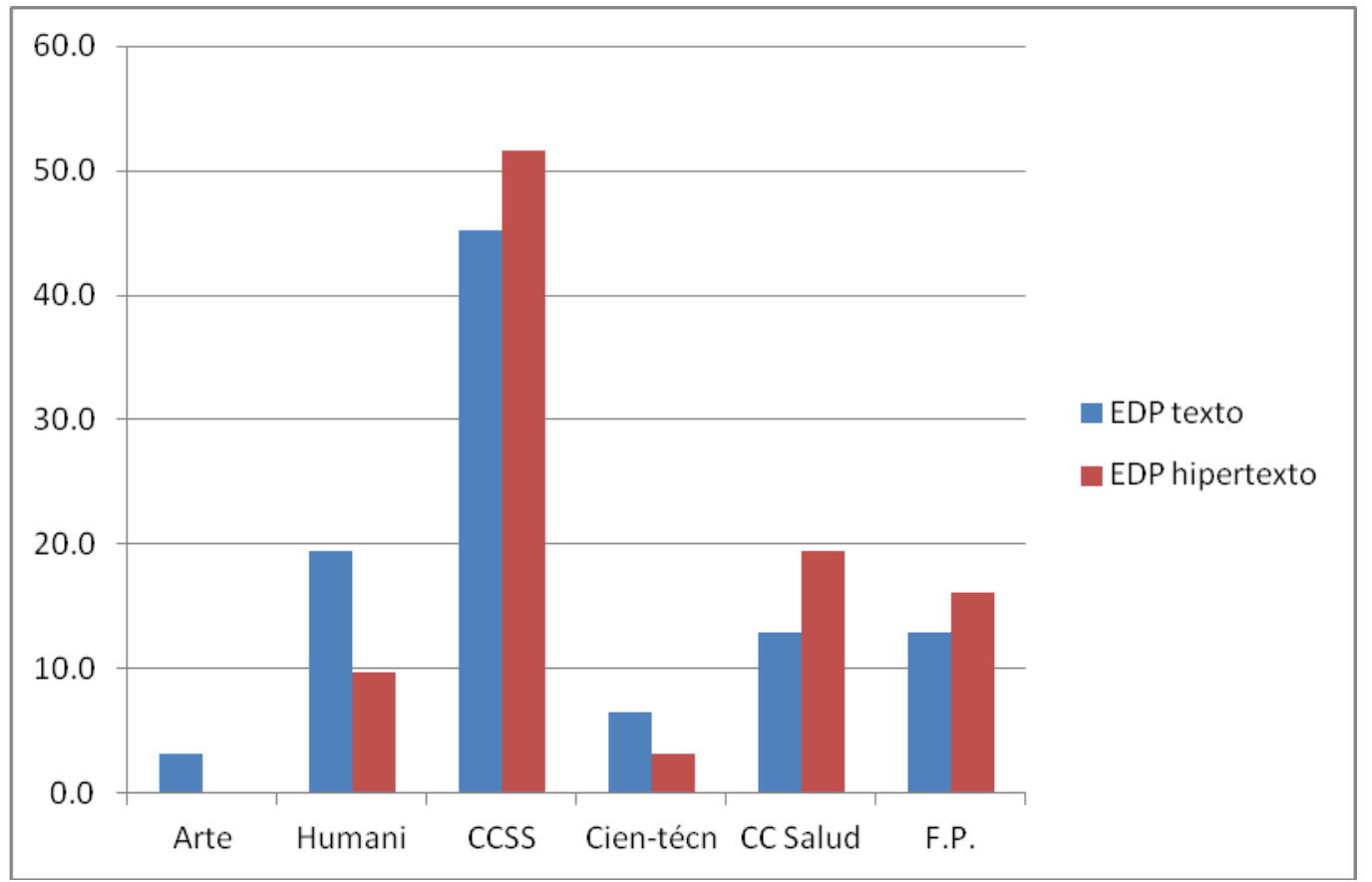

Gráfico 3.6. Modalidad de bachillerato (EDP texto vs EDP hipertexto) y Sexo (porcentajes sobre la modalidad de bachillerato) (Diseño II) 


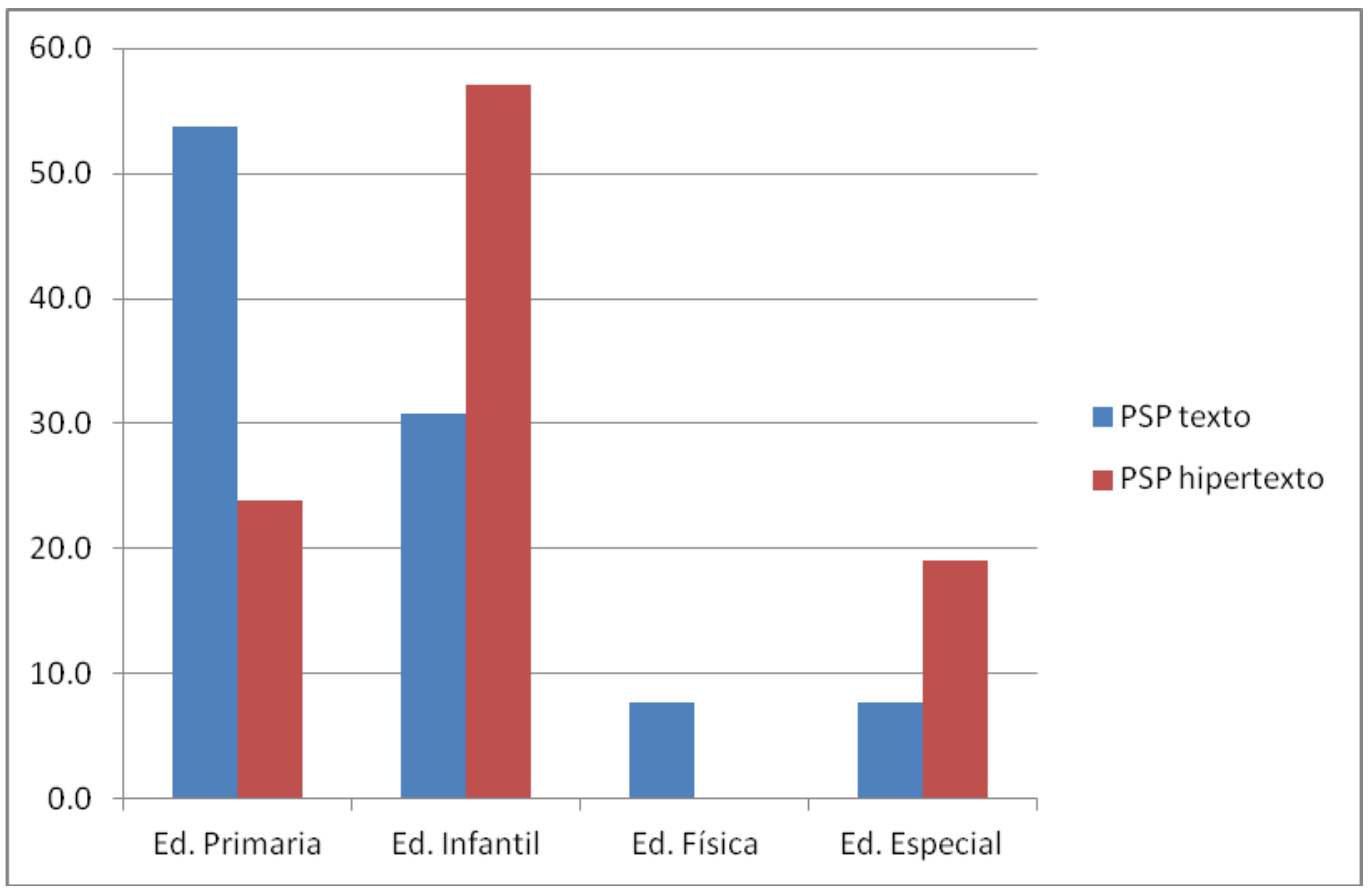

Gráfico 3.7. Primer ciclo cursado (PSP texto vs PSP hipertexto) y Sexo (porcentajes por ciclo cursado) (Diseño II)

Cabe destacar que, al igual que afirmábamos para el primer diseño, llama la atención que la mayor de los alumnos PSP texto y PSP hipertexto obtuvieran como Calificación del primer ciclo un Notable, cuando, como veíamos anteriormente (tabla 3.16), la mayor parte de ellos accedieron a la universidad con una calificación de Aprobado (el 76.9\% para PSP texto y el 61.9\% para PSP hipertexto).

\section{Contraste para Variables Hábitos Lectores (VC3) para el Diseño II}

Del mismo modo que en el primer diseño, se establecieron una serie de variables asociadas a los hábitos lectores del alumnado: Idioma de lectura (VC3.1), Causa de la lectura del último libro (VC3.2), Materia del último libro leído (VC3.3), Cantidad de libros leído al año (VC3.4), Razones para no leer con mayor frecuencia (VC3.5) y Lectura en soporte digital (VC3.6).

Los resultados obtenidos mostraron que:

En primer lugar, los alumnos leían predominantemente en Castellano (99.0\%) (tabla 3.17). 


\begin{tabular}{|c|c|c|c|c|c|}
\hline \multicolumn{6}{|c|}{ VC3.1. Idioma de lectura } \\
\hline & \multicolumn{4}{|c|}{ GRUPO ESTUDIO } & \multirow{2}{*}{$\begin{array}{c}\text { Total } \\
\text { alumnos } \\
\text { según tipo de } \\
\text { respuesta } \\
\end{array}$} \\
\hline & $\begin{array}{c}\text { PSP } \\
\text { Hipertexto } \\
\end{array}$ & $\begin{array}{c}\text { EDP } \\
\text { Hipertexto } \\
\end{array}$ & PSP Texto & EDP Texto & \\
\hline \multirow[t]{2}{*}{ Castellano } & 21 & 31 & 13 & 30 & 95 \\
\hline & $100.0 \%$ & $100.0 \%$ & $100.0 \%$ & $96.8 \%$ & $99.0 \%$ \\
\hline \multirow[t]{2}{*}{ Otro Idioma } & 0 & 0 & 0 & 1 & 1 \\
\hline & $.0 \%$ & $.0 \%$ & $.0 \%$ & $3.2 \%$ & $1.0 \%$ \\
\hline \multirow{2}{*}{$\begin{array}{l}\text { Total errores alumnos de } \\
\text { cada carrera }\end{array}$} & 21 & 31 & 13 & 31 & 96 \\
\hline & $100.0 \%$ & $100.0 \%$ & $100.0 \%$ & $100.0 \%$ & $100.0 \%$ \\
\hline$\chi^{2}(\mathrm{gl})$ & \multicolumn{5}{|c|}{$2.119(3)$} \\
\hline$p$ & \multicolumn{5}{|c|}{.548} \\
\hline
\end{tabular}

(la salida completa de este procedimiento se encuentra en el Anexo II. 11 tabla 18)

En segundo lugar, la causa por la que los alumnos leyeron el último libro era el entretenimiento (54.2\%) o los estudios (38.5\%) (gráfico 3.8).

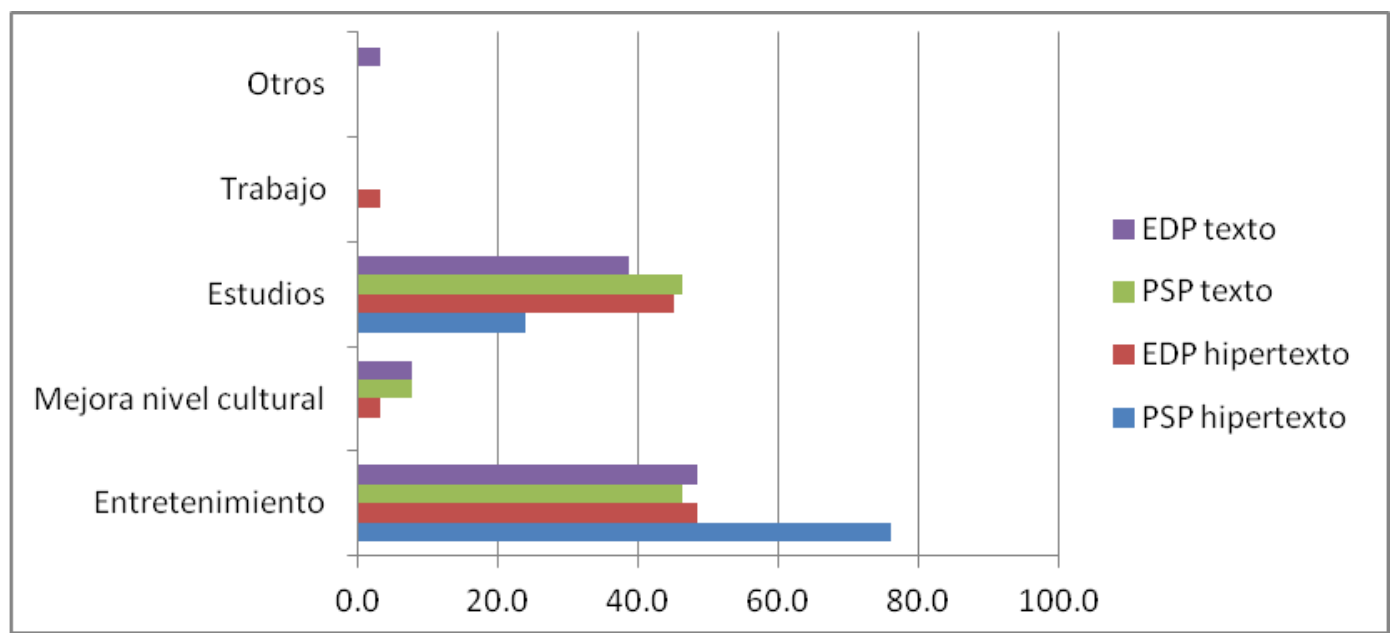

Gráfico 3.8. Causa de la lectura del último libro (VC3.2) (porcentajes sobre causa del último libro leído) (Diseño II)

En tercer lugar, el último libro leído por gran parte de los alumnos era un libro de literatura (39.6\%) (tabla 3.18). 


\begin{tabular}{|c|c|c|c|c|c|}
\hline \multicolumn{6}{|c|}{ VC3.3. Materia del último libro leído } \\
\hline & \multicolumn{4}{|c|}{ GRUPO ESTUDIO } & \multirow{2}{*}{$\begin{array}{c}\text { Total } \\
\text { alumnos } \\
\text { según tipo de } \\
\text { respuesta }\end{array}$} \\
\hline & $\begin{array}{c}\text { PSP } \\
\text { Hipertexto } \\
\end{array}$ & $\begin{array}{c}\text { EDP } \\
\text { Hipertexto } \\
\end{array}$ & PSP Texto & EDP Texto & \\
\hline \multirow[t]{2}{*}{ Literatura } & 8 & 15 & 5 & 10 & 38 \\
\hline & $38.1 \%$ & $48.4 \%$ & $38.5 \%$ & $32.3 \%$ & $39.6 \%$ \\
\hline \multirow{2}{*}{$\begin{array}{l}\text { Humanidades y CC. } \\
\text { Sociales }\end{array}$} & 2 & 5 & 2 & 8 & 17 \\
\hline & $9.5 \%$ & $16.1 \%$ & $15.4 \%$ & $25.8 \%$ & $17.7 \%$ \\
\hline \multirow{2}{*}{$\begin{array}{l}\text { Científico-técnico, } \\
\text { medicina, biología }\end{array}$} & 0 & 2 & 1 & 1 & 4 \\
\hline & $.0 \%$ & $6.5 \%$ & $7.7 \%$ & $3.2 \%$ & $4.2 \%$ \\
\hline \multirow[t]{2}{*}{ Infantil y juvenil } & 4 & 9 & 2 & 4 & 19 \\
\hline & $19.0 \%$ & $29.0 \%$ & $15.4 \%$ & $12.9 \%$ & $19.8 \%$ \\
\hline \multirow[t]{2}{*}{ Otros } & 7 & 0 & 3 & 8 & 18 \\
\hline & $33.3 \%$ & $.0 \%$ & $23.1 \%$ & $25.8 \%$ & $18.8 \%$ \\
\hline \multirow{2}{*}{$\begin{array}{l}\text { Total alumnos de cada } \\
\text { carrera }\end{array}$} & 21 & 31 & 13 & 31 & 96 \\
\hline & $100.0 \%$ & $100.0 \%$ & $100.0 \%$ & $100.0 \%$ & $100.0 \%$ \\
\hline$\chi^{2}(\mathrm{gl})$ & \multicolumn{5}{|c|}{$16.148(12)$} \\
\hline$p$ & \multicolumn{5}{|c|}{.185} \\
\hline
\end{tabular}

En cuarto lugar, cabe señalar que existían diferencias significativas intergrupales (n.s.=.05) para la variable Cantidad de libros leídos al año (VC3.3). Estas diferencias, como vemos en el gráfico 3.9, se daban principalmente porque en el grupo PSP texto se concentraba la mayor parte de los alumnos que leían uno o ningún libro al año (el 15.4 $\%$ ), en el grupo PSP hipertexto se concentraban la mayoría de los alumnos que leían más de 15 libros al año (el 19.0\%) y en los grupos PSP texto y EDP texto se concentraban la mayor parte de los alumnos que leían entre 10 y 14 libros al año. 


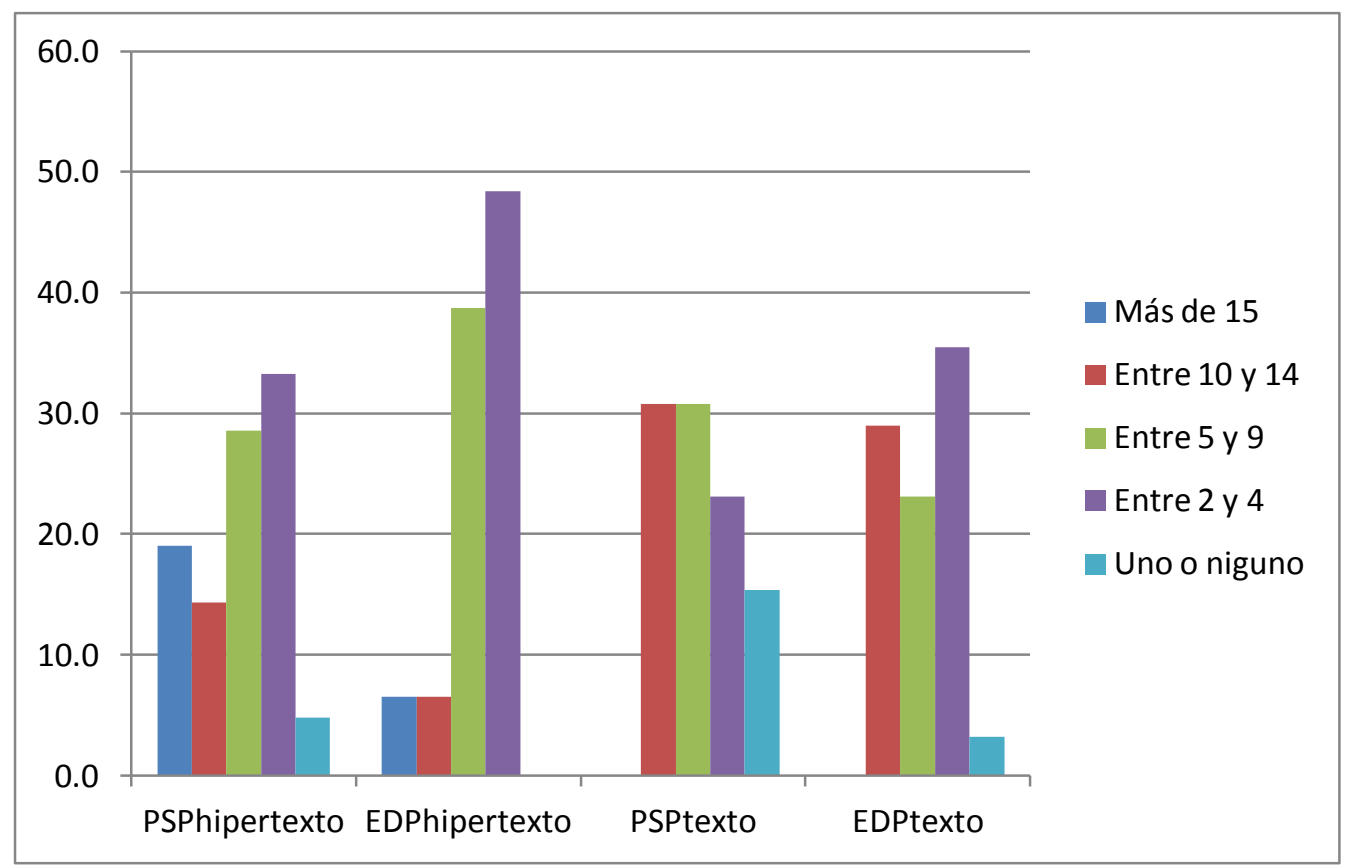

Gráfico 3.9. Cantidad de libros leídos al año (VC3.4) (porcentajes por cantidad de libros leídos al año) (Diseño II)

(la salida completa de este procedimiento se encuentra en el Anexo II.11 tabla 24)

En quinto lugar, los alumnos no leía con mayor asiduidad principalmente por la falta de tiempo (69.8\%) (tabla 3.19). No existiendo diferencias estadísticas entre grupos (n.s.=.05).

\begin{tabular}{|c|c|c|c|c|c|}
\hline \multicolumn{6}{|c|}{ VC3.5. Razones para no leer con mayor frecuencia } \\
\hline & \multicolumn{4}{|c|}{ GRUPO ESTUDIO } & \multirow[b]{2}{*}{$\begin{array}{c}\text { Total } \\
\text { alumnos } \\
\text { según nivel } \\
\end{array}$} \\
\hline & $\begin{array}{c}\text { PSP } \\
\text { Hipertexto } \\
\end{array}$ & $\begin{array}{c}\text { EDP } \\
\text { Hipertexto }\end{array}$ & PSP Texto & EDP Texto & \\
\hline \multirow{2}{*}{$\begin{array}{l}\text { No dispongo de } \\
\text { tiempo }\end{array}$} & 20 & 21 & 10 & 16 & 67 \\
\hline & $95.2 \%$ & $67.7 \%$ & $76.9 \%$ & $51.6 \%$ & $69.8 \%$ \\
\hline \multirow{2}{*}{$\begin{array}{l}\text { No me gustal no me } \\
\text { interesa leer }\end{array}$} & 0 & 1 & 0 & 1 & 2 \\
\hline & $.0 \%$ & $3.2 \%$ & $.0 \%$ & $3.2 \%$ & $2.1 \%$ \\
\hline \multirow{2}{*}{$\begin{array}{l}\text { Prefiero dedicar mi } \\
\text { tiempo a otras cosas }\end{array}$} & 1 & 8 & 3 & 11 & 23 \\
\hline & $4.8 \%$ & $25.8 \%$ & $23.1 \%$ & $35.5 \%$ & $24.0 \%$ \\
\hline \multirow[t]{2}{*}{ Otros motivos } & 0 & 1 & 0 & 3 & 4 \\
\hline & $.0 \%$ & $3.2 \%$ & $.0 \%$ & $9.7 \%$ & $4.2 \%$ \\
\hline \multirow{2}{*}{$\begin{array}{l}\text { Total alumnos de cada } \\
\text { carrera }\end{array}$} & 21 & 31 & 13 & 31 & 96 \\
\hline & $100.0 \%$ & $100.0 \%$ & $100.0 \%$ & $100.0 \%$ & $100.0 \%$ \\
\hline$\chi^{2}(\mathrm{gl})$ & \multicolumn{5}{|c|}{$13.366(9)$} \\
\hline$p$ & \multicolumn{5}{|c|}{.147} \\
\hline
\end{tabular}

Tabla 3.19. Razones para no leer con mayor frecuencia (VC3.5) (Diseño II)

(la salida completa de este procedimiento se encuentra en el Anexo II. 11 tabla 26) 
Para finalizar, hemos de señalar que más de la mitad del alumnado ha declarado que leía habitualmente en soporte digital 57.3\% (tabla 3.20) (para ver el análisis concreto que se ha hecho de la lectura en diferentes soportes digitales revisar el Anexo II.11 desde la tabla 27 a la tabla 37 ).

\begin{tabular}{|c|c|c|c|c|c|}
\hline \multicolumn{6}{|c|}{ VC3.6. Lectura en soporte digital } \\
\hline & \multicolumn{4}{|c|}{ GRUPO ESTUDIO } & \multirow{2}{*}{$\begin{array}{c}\text { Total } \\
\text { alumnos } \\
\text { según tipo de } \\
\text { respuesta }\end{array}$} \\
\hline & $\begin{array}{c}\text { PSP } \\
\text { Hipertexto } \\
\end{array}$ & $\begin{array}{c}\text { EDP } \\
\text { Hipertexto }\end{array}$ & PSP Texto & EDP Texto & \\
\hline \multirow[t]{2}{*}{$S I$} & 12 & 17 & 8 & 18 & 55 \\
\hline & $57.1 \%$ & $54.8 \%$ & $61.5 \%$ & $58.1 \%$ & $57.3 \%$ \\
\hline \multirow[t]{2}{*}{ NO } & 9 & 14 & 5 & 13 & 41 \\
\hline & $42.9 \%$ & $45.2 \%$ & $38.5 \%$ & $41.9 \%$ & $42.7 \%$ \\
\hline \multirow{2}{*}{$\begin{array}{l}\text { Total errores alumnos de } \\
\text { cada carrera }\end{array}$} & 21 & 31 & 13 & 31 & 96 \\
\hline & $100.0 \%$ & $100.0 \%$ & $100.0 \%$ & $100.0 \%$ & $100.0 \%$ \\
\hline$\chi^{2}(\mathrm{gl})$ & \multicolumn{5}{|c|}{$0.180(3)$} \\
\hline$p$ & \multicolumn{5}{|c|}{.981} \\
\hline
\end{tabular}

Tabla 3.20. Lectura en soporte digital (VC3.6) en los grupos del Diseño II

(la salida completa de este procedimiento se encuentra en el Anexo II. 11 tabla 28)

Partiendo de los resultados obtenidos para las variables de control establecidas, podemos sostener que no existían diferencias significativas (n.s.=.05) entre grupos a nivel global, que pudiesen ofrecer una explicación para los resultados obtenidos que fuese alternativa a las variables independientes momento formativo y formato textual. No obstante, cabe apuntar que existen diferencias en la variable Cantidad de libros leído al año (VC3.4) que pudiera tener relación sobre los resultados del pos-test (el porcentaje de alumnos que leía un libro o ninguno al año se concentraban principalmente en el grupo PSP texto, el de alumnos que leían más de 15 libros al año se concentraban en grupo PSP hipertexto; y el de alumnos que leían entre 10 y 14 libros al año se concentraba en EDP texto y PSP texto).

\subsubsection{Resultados de las hipótesis en el Diseño II: Habilidades básicas de comprensión y expresión escrita en EDP texto, EDP hipertexto, PSP texto y PSP hipertexto}

En esta fase Pre-test analizamos la incidencia de las variables independientes momento formativo y formato textual, sobre la variable dependiente Habilidades básicas de comprensión y expresión escrita, formada por cuatro sub-variables asociadas: Formación de la idea principal de cada párrafo (VD1); Dificultades para formar la idea principal de cada párrafo (VD2); Construcción de un mapa conceptual donde se recoja 
la macroestructura del texto leído (VD3); Dificultades en la construcción del mapa conceptual (VD4). Los resultados obtenidos se muestran a continuación.

\section{A. Resultados en el Diseño II para la Formación de la idea principal de cada párrafo (VD1)}

El análisis que realizamos para el Diseño I, lo utilizamos en este segundo diseño teniendo en cuenta dos aspectos: a) que trabajamos con cuatro grupos, y b) que algunos de los alumnos que formaron parte de la muestra definitiva del Diseño I no estaban dentro de la muestra del Diseño II (ya que no realizaron las tareas específicas vinculadas con este diseño). Para clarificar los resultados obtenidos, como ya hicimos con el diseño anterior, presentamos la siguiente tabla-resumen (estos análisis se pueden encontrar pormenorizados en el Anexo II.12 desde tabla 2 hasta tabla 37).

\begin{tabular}{|c|c|c|c|c|c|c|c|c|c|c|}
\hline & \multicolumn{10}{|c|}{ Resumen de VD1. Formación de la idea principal de cada párrafo } \\
\hline & & $P 1$ & $P 2$ & $P 3$ & $P 4$ & $P 5$ & $P 6$ & $P 7$ & $P 8$ & $P 9$ \\
\hline & $A$ & $5.2 \%$ & $3.1 \%$ & $16.7 \%$ & $.0 \%$ & $19.8 \%$ & $.0 \%$ & $21.9 \%$ & $7.3 \%$ & $15.6 \%$ \\
\hline & Atema & $2.1 \%$ & $1.0 \%$ & $2.1 \%$ & $2.1 \%$ & $1.0 \%$ & $1.0 \%$ & $4.2 \%$ & $2.1 \%$ & $2.1 \%$ \\
\hline & $B$ & $5.2 \%$ & $7.3 \%$ & $9.4 \%$ & $2.1 \%$ & $5.2 \%$ & $6.3 \%$ & $10.4 \%$ & $14.6 \%$ & $6.3 \%$ \\
\hline & Btema & $3.1 \%$ & $3.1 \%$ & $4.2 \%$ & $.0 \%$ & $7.3 \%$ & $2.1 \%$ & $7.3 \%$ & $.0 \%$ & $1.0 \%$ \\
\hline & $C$ & $84.4 \%$ & $85.4 \%$ & $67.7 \%$ & $95.8 \%$ & $66.7 \%$ & $90.6 \%$ & $56.3 \%$ & $76.0 \%$ & $75.0 \%$ \\
\hline & $\begin{array}{c}\text { Total } \\
\text { alumns }\end{array}$ & 96 & 96 & 96 & 96 & 96 & 96 & 96 & 96 & 96 \\
\hline \multirow{3}{*}{$\begin{array}{l}\text { EDPtext, } \\
\text { EDPhipe } \\
\text { PSP texto } \\
\text { PSPhiper }\end{array}$} & $\chi^{2}(\mathrm{gl})$ & $\begin{array}{r}11.862 \\
(12)\end{array}$ & $\begin{array}{c}13.143 \\
(12)\end{array}$ & $\begin{array}{l}9.759 \\
(12)\end{array}$ & $\begin{array}{c}2.975 \\
(6)\end{array}$ & $\begin{array}{c}16.177 \\
(12)\end{array}$ & $\begin{array}{c}6.027 \\
(9)\end{array}$ & $\begin{array}{c}12.771 \\
(12)\end{array}$ & $\begin{array}{c}6.309 \\
(9)\end{array}$ & $\begin{array}{c}9.628 \\
(12)\end{array}$ \\
\hline & $P$ & .457 & .359 & .637 & .812 & .183 & .737 & .386 & .709 & .649 \\
\hline & $\begin{array}{c}\text { Nivel } \\
\text { Dificult }\end{array}$ & MEDIO & ALTO & BAJO & ALTO & MEDIO & ALTO & BAJO & BAJO & BAJO \\
\hline
\end{tabular}

Tabla 3.21. Resumen de los resultados en el Diseño II para Formación de la idea principal de cada párrafo (VD1) (\% de respuesta por categoría), y análisis inferencial entre PSP texto, PSP hipertexto, EDP texto y EDP hipertexto

La tabla muestra que no existían diferencias significativas intergrupales (n.s.=.05) en Formación de la idea principal de cada párrafo (VD1). Al igual que pasaba en el Diseño I:

a) Los alumnos, independientemente del grupo de estudio, tenían mayores dificultades para extraer las ideas principales de los párrafos de nivel alto (P2, P4 y P6) que para hacer lo propio con el resto de los párrafos. 
b) Los párrafos P1 y P5, con un nivel de dificultad medio, mostraban diferentes niveles de desempeño por parte del alumnado (un 5.2\% extrajo la idea principal de P1, mientras que un $19.8 \%$ consiguió identificar la idea principal de P5).

c) Los alumnos tuvieron mayores dificultades para extraer la idea principal del P8 (sólo un 7.3\% lo consiguió) que para identificar las ideas principales de los párrafos P3 (el $16.7 \%$ lo logró), P7 (el $21.9 \%$ lo consiguió) y P9 (el 15.6 \% lo logró); a pesar que todos estos párrafos estaban categorizados con un nivel de dificultad bajo.

Una vez obtenidas las puntuaciones por párrafo en Formación de la idea principal de cada párrafo (VD1), analizamos el nivel de desempeño general del alumnado en dicha variable, y determinamos si existían diferencias significativas entre los grupos de estudio (n.s.=.05) en cuanto al nivel mostrado por el alumnado en esta variable. Para ello, sumamos las puntuaciones obtenidas por cada alumno en los nueve párrafos que componían el texto, y categorizamos el nivel de los alumnos como explicamos en el apartado de resultados del Diseño I.

$$
V D 1=p_{1}+p_{2}+p_{3}+p_{4}+p_{5}+p_{6}+p_{7}+p_{8}+p_{9}
$$

$\mathrm{P}_{i}$ se obtiene a partir de la puntuación obtenida en cada párrafo según la rúbrica establecida para dichos párrafos

A continuación determinamos el nivel que mostraban los alumnos, tomando como referencia los mismos criterios que explicitamos cuando hablamos de los resultados del Diseño I:

\begin{tabular}{|c|c|}
\hline \multicolumn{2}{|c|}{$\begin{array}{c}\text { Intervalo de puntuación para identificar nivel del alumnado en VD1. Formación de } \\
\text { la idea principal de cada párrafo (Diseño II) }\end{array}$} \\
\hline Nivel del alumno & Intervalo puntuación total obtenida por el alumno \\
\hline MUY ALTO & {$[6.26-8.75]$} \\
\hline ALTO & {$[5.01-6.25]$} \\
\hline MEDIO & {$[3.01-5]$} \\
\hline BAJO & {$[1.01-3]$} \\
\hline MUY BAJO & {$[0-1]$} \\
\hline
\end{tabular}

Cuadro 3.5. Intervalo de puntuación para identificar el nivel del alumnado en: Formación de la idea principal de cada párrafo (VD1) (Diseño II)

Partiendo de esto, comprobamos que, como muestra el gráfico 3.10, el alumnado de los cuatro grupos de estudio tenía un nivel en Formación de la idea principal de cada párrafo (VD1) entre bajo y muy bajo. 


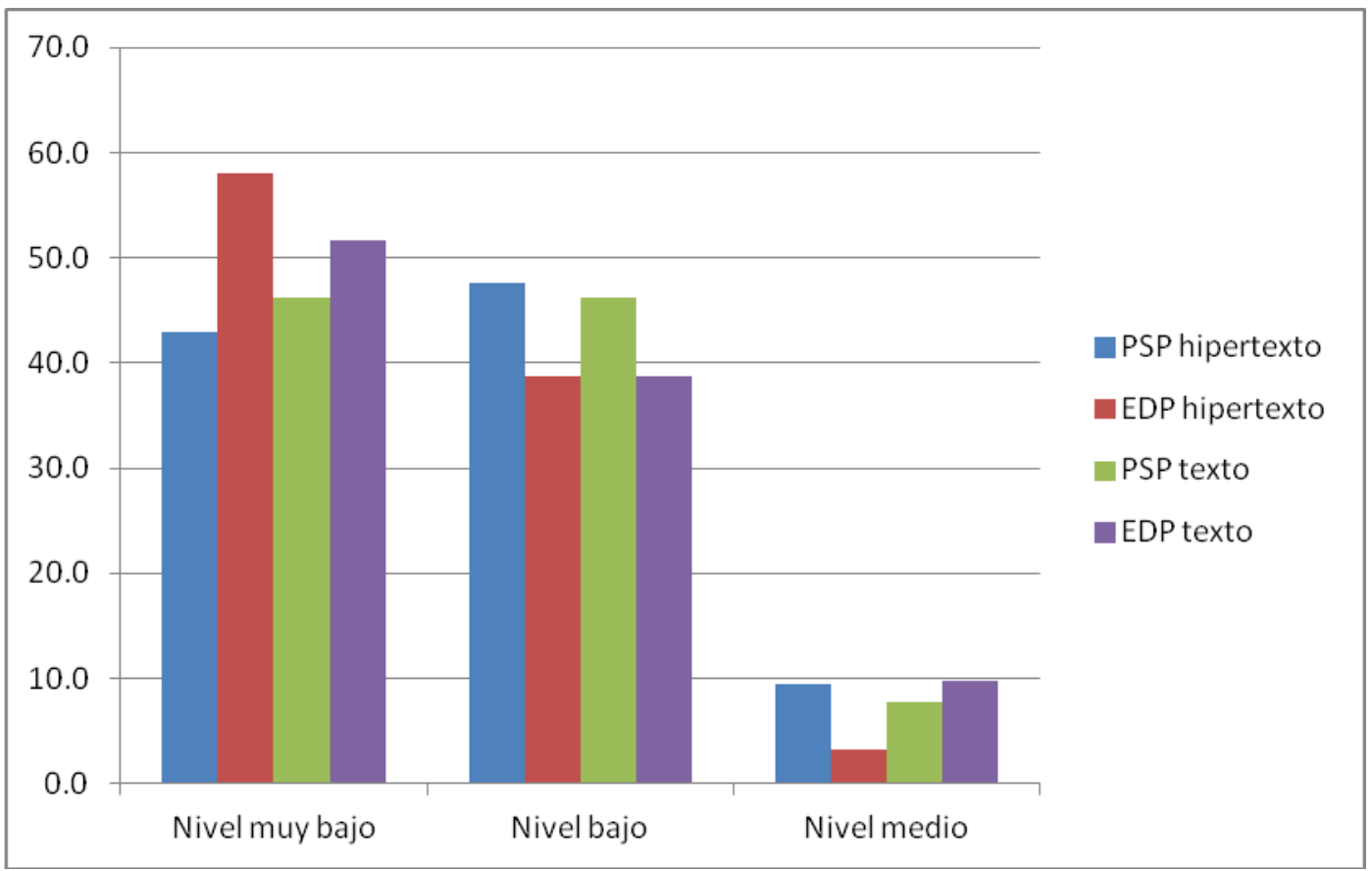

Gráfico 3.10. Nivel del alumnado en: Formación de la idea principal de cada párrafo (VD1) (Diseño II) (Porcentajes)

No obstante, para cerciorarnos de que no existían diferencias entre grupos, realizamos la prueba ANOVA de un factor; la cual, como vemos en la siguiente tabla, indicaba que no existían diferencias significativas intergrupales $(\mathrm{F}=.174 ; \mathrm{p}=.654)$.

\begin{tabular}{c|c|c|c|c|c|c|c}
\hline \multicolumn{1}{|c|}{ ANOVA } \\
\hline VD & $\overline{\mathrm{X}}_{\text {PSPhip }}$ & $\overline{\mathrm{X}}_{\mathrm{PSP} \mathrm{Xt}}$ & $\overline{\mathrm{X}}_{\text {EDPhip }}$ & $\overline{\mathrm{X}}_{\mathrm{EDPtxt}}$ & $\mathrm{F}^{(*)}$ & $\mathrm{p}$ & $\begin{array}{c}\text { Diferencias } \\
\text { entre grupos }\end{array}$ \\
\hline $\begin{array}{c}\text { VD1. Formación de } \\
\text { la idea principal de } \\
\text { cada párrafo }\end{array}$ & .6667 & .6154 & .4516 & .5806 & .544 & .654 & .434 \\
\hline
\end{tabular}

Tabla 3.22. Pruebas ANOVA para determinar las diferencias entre alumnos de diferentes grupos en cuanto al nivel en Formación de la idea principal de cada párrafo (VD1)

(*) Valores F< 1 indican algún problema en las distribuciones; en este caso un alto grado de homogeneidad en la respuestas (bajo- muy bajo)

\section{B. Resultados en el Diseño II para Dificultades para formar la idea principal de cada párrafo (VD2)}

La siguiente tabla-resumen muestra que no existían diferencias significativas entre grupos (n.s.=.05) en cuanto a Dificultades para formar la idea principal de cada párrafo (VD2) (se pueden encontrar los resultados de forma pormenorizada en el Anexo II.12 desde tabla 2 hasta tabla 37$)$. 


\begin{tabular}{|c|c|c|c|c|c|c|c|c|c|c|}
\hline & \multicolumn{10}{|c|}{ Resumen de VD2. Dificultades para formar la idea principal de cada párrafo } \\
\hline & & $P 1$ & $P 2$ & $P 3$ & $P 4$ & $P 5$ & P6 & $P 7$ & $P 8$ & $P 9$ \\
\hline & $C_{1}$ & $56.8 \%$ & $35.4 \%$ & $20.0 \%$ & $42.4 \%$ & $32.8 \%$ & $9.2 \%$ & $20.4 \%$ & $4.1 \%$ & $33.3 \%$ \\
\hline & $C_{2}$ & $8.6 \%$ & $18.3 \%$ & $3.1 \%$ & $13.0 \%$ & $4.7 \%$ & $39.1 \%$ & $29.6 \%$ & $50.7 \%$ & $19.4 \%$ \\
\hline & $C_{3}$ & $34.6 \%$ & $46.3 \%$ & $76.9 \%$ & $44.6 \%$ & $62.5 \%$ & $51.7 \%$ & $50.0 \%$ & $45.2 \%$ & $47.2 \%$ \\
\hline & $\begin{array}{c}\text { Total } \\
\text { errores }\end{array}$ & 81 & 82 & 65 & 92 & 64 & 87 & 54 & 73 & 72 \\
\hline \multirow{3}{*}{$\begin{array}{l}\text { EDPtext } \\
\text { EDPhipe } \\
\text { PSP text } \\
\text { PSPhipe }\end{array}$} & $\chi^{2}(\mathrm{gl})$ & $\begin{array}{c}5.142 \\
(6)\end{array}$ & $\begin{array}{c}6.188 \\
(6)\end{array}$ & $\begin{array}{c}5.085 \\
(6)\end{array}$ & $\begin{array}{c}9.617 \\
(6)\end{array}$ & $\begin{array}{c}2.311 \\
(6)\end{array}$ & $\begin{array}{c}6.164 \\
(6)\end{array}$ & $\begin{array}{c}4.387 \\
(6)\end{array}$ & $\begin{array}{c}4.183 \\
(6)\end{array}$ & $\begin{array}{c}4773 \\
(6)\end{array}$ \\
\hline & $P$ & .526 & .402 & .533 & .142 & .889 & .405 & .624 & .652 & .573 \\
\hline & $\begin{array}{c}\text { Nivel } \\
\text { Dificult }\end{array}$ & MEDIO & ALTO & BAJO & ALTO & MEDIO & ALTO & BAJO & BAJO & BAJO \\
\hline
\end{tabular}

Tabla 3.23. Resumen de los resultados del Diseño II para Dificultades para formar la idea principal del párrafo (VD2) (\% de respuesta por subcategoría), y análisis inferencial entre PSP texto, PSP hipertexto, EDP texto y EDP hipertexto

Como podemos observar en la tabla, de la misma manera que ocurría en el Diseño I:

a) Las dificultades mostradas estaban vinculadas principalmente a la categoría $\mathrm{C}_{3}$, que indicaba problemas para expresar adecuadamente la información extraída (P2 con un $46.3 \%$, P3 con un $76.9 \%$, P4 con un 46.6\%, P5 con un $62.5 \%$, P6 con un 51.7\%, P7 con un 50.0\% y P9 con un $47.2 \%)$.

b) Únicamente en los párrafos P1 (un $56.8 \%$ extrae ideas/temas secundarios o $\mathrm{C}_{1}$ ) y P8 (un $50.7 \%$ malinterpreta la información o $\mathrm{C}_{2}$ ) destacaban otro tipo de dificultades.

\section{Resultados en el Diseño II para Construcción de un mapa conceptual sobre la macroestructura del texto leído (VD3)}

En cuanto a la Construcción de un mapa conceptual que recoja la macroestructura del texto leído (VD3), no existían diferencias significativas entre los alumnos de los cuatro grupos de la muestra $\left(\chi^{2}=.651 ; \mathrm{p}=.420\right)$, como se puede observar en la siguiente tabla. 


\begin{tabular}{|c|c|c|c|c|c|}
\hline \multicolumn{6}{|c|}{ VD3. Construcción de un mapa conceptual donde se recoja la macroestructura del texto leído } \\
\hline & \multicolumn{4}{|c|}{ GRUPO DE ESTUDIO } & \multirow{2}{*}{$\begin{array}{c}\text { Total } \\
\text { alumnos } \\
\text { según tipo de } \\
\text { respuesta }\end{array}$} \\
\hline & $\begin{array}{c}\text { PSP } \\
\text { Hipertexto }\end{array}$ & $\begin{array}{c}\text { EDP } \\
\text { Hipertexto }\end{array}$ & PSP Texto & EDP Texto & \\
\hline $\begin{array}{ll}\boldsymbol{B} & \begin{array}{l}\text { Construye un mapa en } \\
\text { el que estructura las }\end{array} \\
& \text { ideas importantes en } \\
\text { torno a una estructura } & \\
\text { organizativa } \\
\text { subordinada del texto }\end{array}$ & $9.5 \%$ & $.0 \%$ & $.0 \%$ & $6.5 \%$ & $4.2 \%$ \\
\hline $\begin{array}{ll}\boldsymbol{C} & \begin{array}{l}\text { Dificultades para } \\
\text { establecer las }\end{array} \\
& \text { relaciones estructurales } \\
& \text { del texto en el mapa } \\
& \text { conceptual que } \\
\text { construye }\end{array}$ & $90.5 \%$ & $100.0 \%$ & $100.0 \%$ & $93.5 \%$ & $\begin{array}{c}92 \\
95.8 \%\end{array}$ \\
\hline $\begin{array}{l}\text { Total errores alumnos de } \\
\text { cada carrera }\end{array}$ & $\begin{array}{c}21 \\
100.0 \%\end{array}$ & $\begin{array}{c}31 \\
100.0 \%\end{array}$ & $\begin{array}{c}13 \\
100.0 \%\end{array}$ & $\begin{array}{c}31 \\
100.0 \%\end{array}$ & $\begin{array}{c}96 \\
100.0 \%\end{array}$ \\
\hline $\begin{array}{l}\chi^{2}(\mathrm{gl}) \\
p\end{array}$ & & & $\begin{array}{l}28(3) \\
281\end{array}$ & & \\
\hline
\end{tabular}

Tabla 3.24. Construcción de un mapa conceptual donde se recoja la macroestructura del texto leído (VD3) en los grupos del Diseño II

(la salida completa de este procedimiento se encuentra en el Anexo II. 12 tabla 43)

Como muestra la tabla, por un lado, ningún alumno fue capaz de reflejar en su mapa conceptual las relaciones estructurales que se daban entre las ideas más importantes del texto, y por otro, únicamente un $4.2 \%$ de los alumnos estructuró las ideas principales en torno a una estructura organizativa subordinada dentro del texto. Lo que suponía que la mayor parte del alumnado tenía dificultades a la hora de realizar la tarea (un $95.8 \%$ ).

El tipo de dificultades fueron revisadas a través de la variable Dificultades en la construcción del mapa conceptual (VD4), cuyos resultados veremos a continuación.

\section{Resultados en el Diseño II para Dificultades en la construcción del mapa conceptual (VD4)}

En lo que respecta a esta variable, existían diferencias significativas (n.s.=.05) entre los cuatro grupos de la muestra $\left(\chi^{2}=14.208 ; \mathrm{p}=\mathbf{. 0 2 7}\right)$. 


\section{VD4. Dificultades en la construcción del mapa conceptual}

\begin{tabular}{|c|c|c|c|c|c|}
\hline & \multicolumn{4}{|c|}{ GRUPO DE ESTUDIO } & \multirow{2}{*}{$\begin{array}{c}\text { Total } \\
\text { alumnos } \\
\text { según tipo } \\
\text { de } \\
\text { respuesta }\end{array}$} \\
\hline & $\begin{array}{c}\text { PSP } \\
\text { Hipertexto }\end{array}$ & $\begin{array}{c}\text { EDP } \\
\text { Hipertexto }\end{array}$ & PSP Texto & $\begin{array}{l}\text { EDP } \\
\text { Texto }\end{array}$ & \\
\hline $\begin{array}{ll}\boldsymbol{C}_{\boldsymbol{I}} & \begin{array}{l}\text { Construye un mapa conceptual que } \\
\text { no se centra en las ideas importantes }\end{array} \\
\text { del texto }\end{array}$ & $\begin{array}{r}4 \\
21.1 \% \\
\end{array}$ & $\begin{array}{r}5 \\
16.1 \% \\
\end{array}$ & $\begin{array}{c}4 \\
30.8 \% \\
\end{array}$ & $\begin{array}{c}11 \\
37.9 \%\end{array}$ & $\begin{array}{c}24 \\
26.1 \%\end{array}$ \\
\hline $\begin{array}{ll}\boldsymbol{C}_{2} & \begin{array}{l}\text { Construye un mapa conceptual en el } \\
\text { que no queda clara la estructura global }\end{array} \\
\text { y/o significado global del mismo }\end{array}$ & $\begin{array}{c}14 \\
73.7 \%\end{array}$ & $\begin{array}{c}24 \\
77.4 \%\end{array}$ & $\begin{array}{c}5 \\
38.5 \%\end{array}$ & $\begin{array}{c}17 \\
58.6 \%\end{array}$ & $\begin{array}{c}60 \\
65.2 \%\end{array}$ \\
\hline 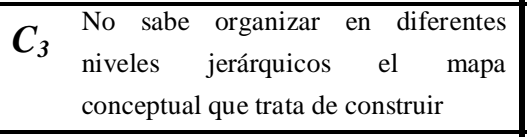 & $\begin{array}{c}1 \\
5.3 \% \\
\end{array}$ & $\begin{array}{r}2 \\
6.5 \% \\
\end{array}$ & $\begin{array}{c}4 \\
30.8 \% \\
\end{array}$ & $\begin{array}{c}1 \\
3.4 \% \\
\end{array}$ & $\begin{array}{r}8 \\
8.7 \% \\
\end{array}$ \\
\hline Total errores alumnos de cada carrera & $\begin{array}{c}19 \\
100.0 \%\end{array}$ & $\begin{array}{c}31 \\
100.0 \%\end{array}$ & $\begin{array}{c}13 \\
100.0 \%\end{array}$ & $\begin{array}{c}29 \\
100.0 \%\end{array}$ & $\begin{array}{c}92 \\
100.0 \%\end{array}$ \\
\hline $\begin{array}{l}\chi^{2}(\mathrm{gl}) \\
p\end{array}$ & & & $\begin{array}{r}14.208 \\
\mathbf{. 0 2 7}\end{array}$ & & \\
\hline
\end{tabular}

Tabla 3.25. Dificultades en la construcción del mapa conceptual (VD4) (Diseño II)

(la salida completa de este procedimiento se encuentra en el Anexo II. 12 tabla 45)

Estas diferencias se observan principalmente entre el grupo PSP texto y el resto de grupos; concretamente, mientras en el grupo PSP texto se manifestaban los tres tipos de dificultades en una proporción similar $\left(\mathrm{C}_{1}=30.8 \%, \mathrm{C}_{2}=38.5 \%, \mathrm{C}_{3}=30.8 \%\right)$; en los grupos PSP hipertexto (73.7\%), EDP hipertexto (77.4\%) y EDP texto (58.6\%), las dificultades del alumnado se concentraban principalmente en $\mathrm{C}_{2}$ (Construye un mapa conceptual en el que no queda clara la estructura global y/o significado global).

\section{E. Contraste de la hipótesis relativa a la variable dependiente Habilidades básicas de comprensión y expresión escrita para el Diseño II}

Partiendo de los resultados obtenidos, podemos señalar que no parecían existir diferencias entre los cuatro grupos de estudio en la variable dependiente general habilidades básicas de comprensión y expresión escrita. Puesto que:

a) no existían diferencias significativas en Formación de la idea principal de cada párrafo (VD1); Dificultades para formar la idea principal de cada párrafo (VD2); Construcción de un mapa conceptual donde se recoja la macroestructura del texto leído (VD3); y

b) las diferencias entre grupos aparecían en Dificultades en la construcción del mapa conceptual (VD4), una variable que únicamente utilizamos para concretar el tipo de dificultades que mostraban los alumnos. 
Merece la pena destacar, desde nuestro punto de vista, el bajo nivel que presentan los alumnos en cuanto a las habilidades básicas de comprensión y expresión escrita. Ya que por una parte, el nivel de desempeño de los alumnos para la variable Formación de la idea principal de cada párrafo (VD1) se encuentra entre bajo y muy bajo; y por otra parte, la gran mayoría de los alumnos (un 95.8\%) mostraron dificultades en Construcción de un mapa conceptual donde se recoja la macroestructura del texto leído (VD3).

\subsubsection{Resultados del Pos-test para el Diseño II}

Una vez comprobada la homogeneidad de las muestras (4 grupos) pasamos a verificar la Hipótesis 4.

4. El tipo de texto (impreso e hipertexto) implica la puesta en práctica de tareas de comprensión y expresión escrita diferenciales en ambos grupos.

\subsubsection{Resultados en Habilidades específicas de comprensión y expresión escrita para la síntesis de información}

En este segundo diseño, analizamos la incidencia de las variables independientes, Momento formativo y Formato textual, sobre una variable dependiente específica (Habilidades específicas de comprensión y expresión escrita para la síntesis de información) formada fundamentalmente por dos variables asociadas: Uso de habilidades de comprensión y expresión escrita para realizar la tarea $\left(\mathrm{VDTH}_{1}\right)$; y Procedimientos que el alumno considera haber seguido para realizar la tarea $\left(\mathrm{VDTH}_{2}\right)$.

\begin{tabular}{|c|c|c|}
\hline Variable Dependiente & Definición conceptual & $\begin{array}{c}\text { Variables Dependientes } \\
\text { Operativas }\end{array}$ \\
\hline \multirow[t]{2}{*}{$\begin{array}{c}\text { Habilidades específicas de } \\
\text { comprensión y expresión } \\
\text { escrita para la síntesis de } \\
\text { información }\end{array}$} & \multirow{2}{*}{$\begin{array}{l}\text { Capacidad del alumnado para usar } \\
\text { estratégicamente habilidades de } \\
\text { comprensión y expresión escrita con el } \\
\text { fin de realizar el resumen de un } \\
\text { texto/hipertexto; y Grado de } \\
\text { consciencia que tiene el alumnado de } \\
\text { los procedimientos utilizados a la hora } \\
\text { de realizar dicha tarea }\end{array}$} & $\begin{array}{l}\mathrm{VDTH}_{1} \text {. Uso de habilidades de } \\
\text { comprensión y expresión escrita } \\
\text { para realizar la tarea }\end{array}$ \\
\hline & & $\begin{array}{l}\mathrm{VDTH}_{2} \text {. Procedimientos que el } \\
\text { alumno considera haber seguido } \\
\text { para realizar la tarea }\end{array}$ \\
\hline
\end{tabular}

Cuadro 2.6. Variables Dependientes en el Diseño II

*VDTH: Variable dependiente texto/hipertexto

Los resultados obtenidos se muestran a continuación. 


\section{A. Resultados para Uso de habilidades de comprensión y expresión escrita para realizar la tarea $\left(\mathrm{VDTH}_{1}\right)$}

La variable dependiente asociada Uso de habilidades de comprensión y expresión escrita para realizar la tarea $\left(\mathrm{VDTH}_{1}\right)$, se analizó a través de 7 sub-variables:

- Tipo información subrayada (Texto impreso) $\left(\mathrm{VDTH}_{1.1}\right)$

- Anotaciones realizadas en el artículo (Texto impreso) $\left(\mathrm{VDTH}_{1.2}\right)$

- Integración intertextual (Hipertexto) $\left(\mathrm{VDTH}_{1.3}\right)$

- Integración intertextual (Texto impreso) $\left(\mathrm{VDTH}_{1.4}\right)$

- Realización de borrador $\left(\mathrm{VDTH}_{1.5}\right)$

- Resumen de la información de texto/hipertexto $\left(\mathrm{VDTH}_{1.6}\right)$

- Dificultades en la realización del resumen $\left(\mathrm{VDTH}_{1.7}\right)$

En lo que se refiere a Tipo información subrayada (Texto impreso) $\left(\mathrm{VDTH}_{1.1}\right)$, las pruebas $\chi^{2}$ indican que no existían diferencias significativas intergrupales $\left(\chi^{2}=\right.$ 4.243; $\mathrm{p}=.236$ ). Observando los porcentajes que aparecen en la tabla 3.26, cabe señalar que más de la mitad de los alumnos del grupo PSP texto (53.8\%) y una parte considerable de los alumnos del grupo EDP texto (35.5\%), subrayaban algunos aspectos estructurales del texto; mientras que un porcentaje considerable alumnos del grupo EDP texto $(38.7 \%)$ subrayaban todo el texto o no lo subrayaban. 


\begin{tabular}{l|c|c|c}
\hline \multicolumn{4}{c}{ VDTH $_{1.1}$. Tipo información subrayada (Texto impreso) } \\
\hline & GRUPO DE ESTUDIO & $\begin{array}{c}\text { Total alumnos } \\
\text { según tipo de } \\
\text { respuesta }\end{array}$ \\
\cline { 2 - 5 } Subraya la mayor parte de aspectos estructurales del texto & 2 & 3 & 5 \\
\hline Subraya algunos aspectos estructurales del texto & $15.4 \%$ & $9.7 \%$ & $11.4 \%$ \\
\hline No subraya aspectos estructurales del texto & 7 & 11 & 18 \\
\hline Subraya todo texto o no lo subraya & $53.8 \%$ & $35.5 \%$ & $40.9 \%$ \\
\hline Total de alumnos de cada carrera & 3 & 5 & 8 \\
& $23.1 \%$ & $16.1 \%$ & $18.2 \%$ \\
\hline$\chi^{2}(\mathrm{gl})$ & 1 & 12 & 13 \\
$\boldsymbol{p}$ & $7.7 \%$ & $38.7 \%$ & $29.5 \%$ \\
\hline
\end{tabular}

Tabla 3.26. Tipo de información subrayada (Texto impreso) $\left(\mathrm{VDTH}_{1.1}\right)$

(la salida completa de este procedimiento se encuentra en el Anexo II. 13 tabla 2)

Con respecto a la segunda sub-variable, Anotaciones realizadas en el artículo (Texto impreso) $\left(\mathrm{VDTH}_{1.2}\right)$, tampoco existían diferencias significativas intergrupales. Como se percibe en la tabla que aparece a continuación, la gran mayoría del alumnado (el 93.2\%) no hizo anotaciones en el texto que leyó.

\begin{tabular}{|c|c|c|c|}
\hline \multicolumn{4}{|c|}{ VDTH $_{1.2}$. Anotaciones realizadas en el artículo (Texto impreso) } \\
\hline & \multicolumn{2}{|c|}{ GRUPO DE ESTUDIO } & \multirow{2}{*}{$\begin{array}{l}\text { Total alumnos } \\
\text { según tipo de } \\
\text { respuesta }\end{array}$} \\
\hline & PSP Texto & EDP Texto & \\
\hline $\begin{array}{l}\text { Realiza anotaciones para realizar una reflexión o } \\
\text { para asociar ideas }\end{array}$ & $\begin{array}{c}1 \\
7.7 \% \\
\end{array}$ & $\begin{array}{c}1 \\
3.2 \% \\
\end{array}$ & $\begin{array}{c}2 \\
4.5 \% \\
\end{array}$ \\
\hline $\begin{array}{l}\text { Realiza anotaciones para copiar/ parafrasear } \\
\text { información }\end{array}$ & $\begin{array}{c}1 \\
7.7 \% \\
\end{array}$ & $\begin{array}{c}0 \\
.0 \% \\
\end{array}$ & $\begin{array}{c}1 \\
2.3 \% \\
\end{array}$ \\
\hline No hace anotaciones o no queda clara la anotación & $\begin{array}{c}11 \\
84.6 \% \\
\end{array}$ & $\begin{array}{c}30 \\
96.8 \% \\
\end{array}$ & $\begin{array}{c}41 \\
93.2 \% \\
\end{array}$ \\
\hline Total de alumnos de cada carrera & $\begin{array}{c}13 \\
100.0 \%\end{array}$ & $\begin{array}{c}31 \\
100.0 \%\end{array}$ & $\begin{array}{c}44 \\
100.0 \%\end{array}$ \\
\hline $\begin{array}{l}\chi^{2}(\mathrm{gl}) \\
p\end{array}$ & & $\begin{array}{c}2.932(2) \\
.231\end{array}$ & \\
\hline
\end{tabular}

Tabla 3.27. Anotaciones realizadas en el artículo (Texto impreso) $\left(\mathrm{VDTH}_{1.2}\right)$

(la salida completa de este procedimiento se encuentra en el Anexo II. 13 tabla 4) 
Sin embargo, en la variable Integración intertextual (Hipertexto) $\left(\mathrm{VDTH}_{1.3}\right)$ sí existían diferencias significativas (n.s.=.05; $\chi^{2}=10.012 ; \mathrm{p}=.007$ ). Estas diferencias se perciben claramente visualizando la tabla 3.28 , donde se observa que, a pesar de que la mayoría los alumnos (88.5\%) no utilizaban información de los hipervínculos en el resumen, existían diferencias intergrupales entre el grupo EDP hipertexto, en el que el $100 \%$ de los alumnos no utilizaba información de vínculos; y el grupo PSP hipertexto, en el que aparece un pequeño porcentaje de alumnos que: a) tienen problemas a la hora de integrar la información del hipertexto dentro del resumen (19.0\%), y b) no toman como referencia la estructura de la página principal del hipertexto a la hora integrar la información en el resumen $(9.5 \%)$.

\begin{tabular}{|c|c|c|c|}
\hline \multicolumn{4}{|c|}{$\mathrm{VDTH}_{1.3 .}$ Integración intertextual (Hipertexto) } \\
\hline & \multicolumn{2}{|c|}{ GRUPO DE ESTUDIO } & \multirow[b]{2}{*}{$\begin{array}{l}\text { Total alumnos } \\
\text { según tipo de } \\
\text { respuesta }\end{array}$} \\
\hline & $\begin{array}{c}\text { PSP } \\
\text { Hipertexto } \\
\end{array}$ & $\begin{array}{c}E D P \\
\text { Hipertexto } \\
\end{array}$ & \\
\hline $\begin{array}{l}\text { No toma como referencia estructura de la página } \\
\text { principal del hipertexto, a la hora de integrar la } \\
\text { información de los hipervínculos dentro del resumen } \\
\text { que escribe }\end{array}$ & $\begin{array}{c}2 \\
9.5 \%\end{array}$ & $\begin{array}{c}0 \\
.0 \%\end{array}$ & $\begin{array}{c}2 \\
3.8 \%\end{array}$ \\
\hline $\begin{array}{l}\text { Tiene problemas para integrar la información de los } \\
\text { hipervínculos dentro del resumen que escribe }\end{array}$ & $\begin{array}{c}4 \\
19.0 \%\end{array}$ & $\begin{array}{c}0 \\
.0 \%\end{array}$ & $\begin{array}{c}4 \\
7.7 \%\end{array}$ \\
\hline $\begin{array}{l}\text { No recoge información de los hipervínculos en el } \\
\text { resumen que escribe }\end{array}$ & $\begin{array}{c}15 \\
71.4 \% \\
\end{array}$ & $\begin{array}{c}31 \\
100.0 \% \\
\end{array}$ & $\begin{array}{c}46 \\
88.5 \% \\
\end{array}$ \\
\hline Total de alumnos de cada carrera & $\begin{array}{c}21 \\
100.0 \% \\
\end{array}$ & $\begin{array}{c}31 \\
100.0 \% \\
\end{array}$ & $\begin{array}{c}52 \\
100.0 \% \\
\end{array}$ \\
\hline $\begin{array}{l}\chi^{2}(\mathrm{gl}) \\
p \\
\end{array}$ & & $\begin{array}{c}10.012(2) \\
.007\end{array}$ & \\
\hline
\end{tabular}

Tabla 3.28. Integración intertextual (Hipertexto) $\left(\mathrm{VDTH}_{1.3}\right)$

(la salida completa de este procedimiento se encuentra en el Anexo II. 13 tabla 6)

Por su parte, ni en la cuarta (Integración intertextual (Texto impreso) $\left(\mathrm{VDTH}_{1.4}\right)$ ) ni en la quinta sub-variable (Realización de borrador $\left(\mathrm{VDTH}_{1.5}\right)$ ) existían diferencias significativas entre grupos (n.s.=.05), puesto que, por un lado, el 97.7\% del alumnado no utilizó la información del pie de página en el resumen que escribió (tabla 3.29); y por otro, el $94.8 \%$ no utilizó borrador para realizar el resumen (tabla 3.30). 


\begin{tabular}{|c|c|c|c|}
\hline \multicolumn{4}{|c|}{ VDTH $_{1.4}$ Integración intertextual (Texto impreso) } \\
\hline & \multicolumn{2}{|c|}{ GRUPO DE ESTUDIO } & \multirow{2}{*}{$\begin{array}{l}\text { Total alumnos } \\
\text { según tipo de } \\
\text { respuesta }\end{array}$} \\
\hline & PSP Texto & EDP Texto & \\
\hline $\begin{array}{l}\text { Subraya en el texto información vinculada al pie de } \\
\text { página, y aunque la recoge en el resumen que } \\
\text { construye, no es capaz de integrarla adecuadamente }\end{array}$ & $\begin{array}{c}0 \\
.0 \%\end{array}$ & $\begin{array}{c}1 \\
3.2 \%\end{array}$ & $\begin{array}{c}1 \\
2.3 \%\end{array}$ \\
\hline $\begin{array}{l}\text { No subraya en el texto ni recoge en el resumen } \\
\text { información vinculada al pie de página }\end{array}$ & $\begin{array}{c}13 \\
100.0 \% \\
\end{array}$ & $\begin{array}{c}30 \\
96.8 \% \\
\end{array}$ & $\begin{array}{r}43 \\
97.7 \% \\
\end{array}$ \\
\hline Total de alumnos de cada carrera & $\begin{array}{c}13 \\
100.0 \%\end{array}$ & $\begin{array}{c}31 \\
100.0 \%\end{array}$ & $\begin{array}{c}44 \\
100.0 \%\end{array}$ \\
\hline$\chi^{2}(\mathrm{gl})$ & & $\begin{array}{c}0.429(1) \\
.512\end{array}$ & \\
\hline
\end{tabular}

Tabla 3.29. Integración intertextual (Texto impreso) $\left(\mathrm{VDTH}_{1.4}\right)$

(la salida completa de este procedimiento se encuentra en el Anexo II.13 tabla 8)

\begin{tabular}{|c|c|c|c|c|c|}
\hline \multicolumn{6}{|c|}{ VDTH $_{1.5 .}$ Realización de borrador } \\
\hline & \multicolumn{4}{|c|}{ GRUPO DE ESTUDIO } & \multirow{2}{*}{$\begin{array}{l}\text { Total } \\
\text { alumnos } \\
\text { según tipo } \\
\text { de respuesta }\end{array}$} \\
\hline & $\begin{array}{c}\text { PSP } \\
\text { Hipertexto }\end{array}$ & $\begin{array}{c}E D P \\
\text { Hipertexto }\end{array}$ & PSP Texto & EDP Texto & \\
\hline $\begin{array}{l}\text { Utiliza Borrador como una guía } \\
\text { estructurada (texto lineal o mapa } \\
\text { conceptual) del resumen que escribe }\end{array}$ & $\begin{array}{c}0 \\
.0 \% \\
\end{array}$ & $\begin{array}{c}0 \\
.0 \% \\
\end{array}$ & $\begin{array}{c}1 \\
7.7 \% \\
\end{array}$ & $.0 \%$ & $\begin{array}{c}1 \\
1.0 \% \\
\end{array}$ \\
\hline $\begin{array}{l}\text { Utiliza Borrador como una guía } \\
\text { desestructurada (selecciona palabras } \\
\text { clave texto) del resumen que escribe }\end{array}$ & $\begin{array}{c}2 \\
9.5 \%\end{array}$ & $\begin{array}{c}0 \\
.0 \%\end{array}$ & $\begin{array}{c}1 \\
7.7 \%\end{array}$ & $\begin{array}{c}0 \\
.0 \%\end{array}$ & $\begin{array}{c}3 \\
3.1 \%\end{array}$ \\
\hline $\begin{array}{l}\text { Utiliza Borrador, pero el texto que } \\
\text { escribe es una copia literal o } \\
\text { paráfrasis cercana la copia del mismo }\end{array}$ & $\begin{array}{c}1 \\
4.8 \% \\
\end{array}$ & $\begin{array}{c}0 \\
.0 \%\end{array}$ & $.0 \%$ & $\begin{array}{l}0 \\
.0 \%\end{array}$ & $\begin{array}{c}1 \\
1.0 \%\end{array}$ \\
\hline No utiliza Borrador & $\begin{array}{c}18 \\
85.7 \% \\
\end{array}$ & $\begin{array}{c}31 \\
100.0 \% \\
\end{array}$ & $\begin{array}{c}11 \\
84.6 \% \\
\end{array}$ & $\begin{array}{c}31 \\
100.0 \% \\
\end{array}$ & $\begin{array}{c}91 \\
94.8 \% \\
\end{array}$ \\
\hline Total de alumnos de cada carrera & $\begin{array}{c}21 \\
100.0 \%\end{array}$ & $\begin{array}{c}31 \\
100.0 \%\end{array}$ & $\begin{array}{c}13 \\
100.0 \%\end{array}$ & $\begin{array}{c}31 \\
100.0 \%\end{array}$ & $\begin{array}{c}96 \\
100.0 \%\end{array}$ \\
\hline $\begin{array}{l}\chi^{2}(\mathrm{gl}) \\
p\end{array}$ & & & $\begin{array}{c}16.015(9) \\
.067\end{array}$ & & \\
\hline
\end{tabular}

Tabla 3.30. Realización de borrador $\left(\mathrm{VDTH}_{1.5}\right)$

(la salida completa de este procedimiento se encuentra en el Anexo II.13 tabla 10)

Para finalizar, cabe señalar que el $100 \%$ del alumnado mostraba dificultades vinculadas a la sub-variable $\mathrm{VDTH}_{1.6}$ : Resumen de la información de texto/hipertexto (tabla 3.31); y que esas dificultades, como muestra $\mathrm{VDTH}_{1.7}$ : Dificultades en la realización del resumen (tabla 3.32), se centraba principalmente en la categoría $\mathrm{C}_{2}$ (Construye un texto cuyo significado global no está claro). 


\begin{tabular}{|c|c|c|c|c|c|c|}
\hline \multicolumn{7}{|c|}{ VDTH $_{1.6 .}$ Resumen de la información de texto/hipertexto } \\
\hline & & \multicolumn{4}{|c|}{ GRUPO DE ESTUDIO } & \multirow[b]{2}{*}{$\begin{array}{l}\text { Total alumnos } \\
\text { según tipo de } \\
\text { respuesta }\end{array}$} \\
\hline & & $\begin{array}{c}\text { PSP } \\
\text { Hipertexto } \\
\end{array}$ & $\begin{array}{c}E D P \\
\text { Hipertexto } \\
\end{array}$ & PSP Texto & EDP Texto & \\
\hline \multirow{2}{*}{$C$} & Dificultades para realizar & 21 & 31 & 13 & 31 & 96 \\
\hline & adecuadamente el resumen & $100 \%$ & $100 \%$ & $100 \%$ & $100 \%$ & $100 \%$ \\
\hline \multirow{2}{*}{\multicolumn{2}{|c|}{ Total de alumnos de cada carrera }} & 21 & 31 & 13 & 31 & 96 \\
\hline & & $100 \%$ & $100 \%$ & $100 \%$ & $100 \%$ & $100 \%$ \\
\hline
\end{tabular}

Tabla 3.31. Resumen de la información de texto/hipertexto $\left(\mathrm{VDTH}_{1.6}\right)$

\begin{tabular}{|c|c|c|c|c|c|c|}
\hline \multicolumn{7}{|c|}{ VDTH $_{1.7 .}$ Dificultades en la realización del resumen } \\
\hline & & \multicolumn{4}{|c|}{ GRUPO DE ESTUDIO } & \multirow[b]{2}{*}{$\begin{array}{l}\text { Total alumnos } \\
\text { según tipo de } \\
\text { respuesta }\end{array}$} \\
\hline & & $\begin{array}{c}\text { PSP } \\
\text { Hipertexto }\end{array}$ & $\begin{array}{c}\text { EDP } \\
\text { Hipertexto }\end{array}$ & $\begin{array}{l}\text { PSP } \\
\text { Texto }\end{array}$ & $\begin{array}{l}\text { EDP } \\
\text { Texto }\end{array}$ & \\
\hline$C_{1}$ & $\begin{array}{l}\text { Organiza texto en torno a una } \\
\text { estructura global, pero malinterpreta, } \\
\text { no sintetiza suficientemente o no } \\
\text { expresa personalmente la información }\end{array}$ & $\begin{array}{c}2 \\
9.5 \%\end{array}$ & $\begin{array}{c}0 \\
.0 \%\end{array}$ & $\begin{array}{c}0 \\
.0 \%\end{array}$ & $\begin{array}{c}0 \\
.0 \%\end{array}$ & $\begin{array}{c}2 \\
2.1 \%\end{array}$ \\
\hline$C_{2}$ & $\begin{array}{l}\text { Construye un texto cuyo significado } \\
\text { global no está claro }\end{array}$ & $\begin{array}{c}17 \\
81.0 \% \\
\end{array}$ & $\begin{array}{c}30 \\
96.8 \% \\
\end{array}$ & $\begin{array}{c}10 \\
76.9 \% \\
\end{array}$ & $\begin{array}{c}26 \\
83.9 \% \\
\end{array}$ & $\begin{array}{r}83 \\
86.5 \% \\
\end{array}$ \\
\hline & $\begin{array}{l}\text { Copia literalmente la mayor parte de } \\
\text { información que utiliza en el texto } \\
\text { que escribe }\end{array}$ & $\begin{array}{r}2 \\
9.5 \% \\
\end{array}$ & $\begin{array}{c}1 \\
3.2 \% \\
\end{array}$ & $\begin{array}{c}3 \\
23.1 \% \\
\end{array}$ & $\begin{array}{c}5 \\
16.1 \% \\
\end{array}$ & $\begin{array}{c}11 \\
11.5 \%\end{array}$ \\
\hline \multicolumn{2}{|c|}{ Total de alumnos de cada carrera } & $\begin{array}{c}21 \\
100.0 \%\end{array}$ & $\begin{array}{c}31 \\
100.0 \%\end{array}$ & $\begin{array}{c}13 \\
100.0 \%\end{array}$ & $\begin{array}{c}31 \\
100.0 \%\end{array}$ & $\begin{array}{c}96 \\
100.0 \%\end{array}$ \\
\hline & $\chi^{2}(\mathrm{gl})$ & & \multicolumn{4}{|c|}{$\begin{array}{c}11.783(6) \\
.067\end{array}$} \\
\hline
\end{tabular}

Tabla 3.32. Dificultades en la realización del resumen $\left(\mathrm{VDTH}_{1.7}\right)$

(la salida completa de este procedimiento se encuentra en el Anexo II. 13 tabla 13)

En síntesis, no existían diferencias significativas intergrupales (n.s.=.05) en la mayor parte de las sub-variables vinculadas a $\mathrm{VDTH}_{1}$ : Uso de habilidades de comprensión y expresión escrita para realizar la tarea. Tan solo en Integración Intertextual (Hipertexto) $\left(\mathrm{VDTH}_{1.3}\right)$ aparecían diferencias significativas entre el grupo EDP hipertexto y el grupo PSP hipertexto, que se basaban en el hecho de que: en el primer grupo ningún alumno utilizaba información de los vínculos, mientras que en el segundo hay algunos alumnos que sí lo hacían.

Teniendo esto en cuenta, los resultados parecen mostrar que el momento formativo y el formato textual no eran factores determinantes en lo que respecta a Uso de habilidades de comprensión y expresión escrita para realizar la tarea $\left(\mathrm{VDTH}_{1}\right)$. 


\section{B. Resultados para Procedimientos que el alumno considera haber seguido para realizar la tarea $\left(\mathrm{VDTH}_{2} 2\right.$}

La variable dependiente asociada Procedimientos que el alumno considera haber seguido para realizar la tarea $\left(\mathrm{VDTH}_{2}\right)$, se analizó a través de las siguientes subvariables:

- $\quad$ Procedimiento lectura (Texto impreso) $\left(\mathrm{VDTH}_{2.1}\right)$

- Procedimiento escritura (Texto impreso) $\left(\mathrm{VDTH}_{2.2}\right)$

- Procedimiento lectura (Hipertexto) $\left(\mathrm{VDTH}_{2.3}\right)$

- Procedimiento escritura (Hipertexto) $\left(\mathrm{VDTH}_{2.4}\right)$

En cuanto a Procedimiento lectura (Texto impreso) $\left(\mathrm{VDTH}_{2.1}\right)$, aparecen diferencias significativas (n.s.=.05) entre los grupos PSP texto y EDP texto. Estas diferencias se observan claramente en la tabla 3.33, donde se percibe, por una parte, que todos los alumnos del grupo PSP texto subrayaban el texto que leían (un 46.2\% leen dos o más veces el texto y un $53.8 \%$ leen una vez el texto), y por otra, que en el grupo EDP texto aparecían alumnos que afirmaban leer el texto sin subrayarlo (22.6\%) o que no decían nada al respecto (12.9\%). Además, se aprecia una gran diferencia de porcentaje entre los alumnos de PSP texto que leían una vez el texto y lo subrayan (53.8\%) y los del grupo EDP texto que utilizaron el mismo procedimiento (19.4\%).

\begin{tabular}{|c|c|c|c|}
\hline \multicolumn{4}{|c|}{ VDTH $_{2.1}$. Procedimiento lectura (Texto impreso) } \\
\hline & \multicolumn{2}{|c|}{ GRUPO DE ESTUDIO } & \multirow{2}{*}{$\begin{array}{l}\text { Total alumnos } \\
\text { según tipo de } \\
\text { respuesta }\end{array}$} \\
\hline & PSP Texto & EDP Texto & \\
\hline \multirow{2}{*}{$\begin{array}{l}\text { Lee dos o más veces el texto y lo } \\
\text { subraya }\end{array}$} & 6 & 14 & 20 \\
\hline & $46.2 \%$ & $45.2 \%$ & $45.5 \%$ \\
\hline \multirow{2}{*}{ Lee una vez el texto y lo subraya } & 7 & 6 & 13 \\
\hline & $53.8 \%$ & $19.4 \%$ & $29.5 \%$ \\
\hline \multirow{2}{*}{ Lee el texto sin subrayarlo } & 0 & 7 & 7 \\
\hline & $.0 \%$ & $22.6 \%$ & $15.9 \%$ \\
\hline \multirow{2}{*}{$N S / N C$} & 0 & 4 & 4 \\
\hline & $.0 \%$ & $12.9 \%$ & $9.1 \%$ \\
\hline \multirow[t]{2}{*}{ Total de alumnos de cada carrera } & 13 & 31 & 44 \\
\hline & $100.0 \%$ & $100.0 \%$ & $100.0 \%$ \\
\hline$\chi^{2}(\mathrm{gl})$ & \multicolumn{3}{|c|}{$8.303(3)$} \\
\hline$p$ & \multicolumn{3}{|c|}{.040} \\
\hline
\end{tabular}

Tabla 3.33. Procedimiento lectura (Texto impreso) $\left(\mathrm{VDTH}_{2.1}\right)$

(la salida completa de este procedimiento se encuentra en el Anexo II. 13 tabla 15) 
En lo que respecta a Procedimiento escritura (Texto impreso) $\left(\mathrm{VDTH}_{2.2}\right)$, también existen diferencias significativas entre los grupos PSP texto y EDP texto, puesto que, como se aprecia en la tabla 3.34 , para $\chi^{2}$ con un valor de 38.235 corresponde una probabilidad <.001. En este sentido, la principal diferencia entre los grupos era que la mayor parte del grupo EDP texto realizaba el resumen partiendo directamente del texto (74.2\%), mientras que gran parte del grupo PSP texto hacía el resumen a partir de lo subrayado $(61.5 \%)$.

\begin{tabular}{|c|c|c|c|}
\hline \multicolumn{4}{|c|}{ VDTH $_{2.2 \cdot}$ Procedimiento escritura (Texto impreso) } \\
\hline & \multicolumn{2}{|c|}{ GRUPO DE ESTUDIO } & \multirow{2}{*}{\begin{tabular}{|c|} 
Total \\
alumnos \\
según tipo de \\
respuesta \\
\end{tabular}} \\
\hline & PSP Texto & EDP Texto & \\
\hline \multirow{2}{*}{$\begin{array}{l}\text { Realiza alguno de los tres pasos anteriores, y luego } \\
\text { relee el resumen y omite información }\end{array}$} & 3 & 2 & 5 \\
\hline & $23.1 \%$ & $6.5 \%$ & $11.4 \%$ \\
\hline \multirow[t]{2}{*}{ Hace el resumen a partir de anotaciones/borrador } & 2 & 0 & 2 \\
\hline & $15.4 \%$ & $.0 \%$ & $4.5 \%$ \\
\hline \multirow[t]{2}{*}{ Hace el resumen a partir de lo subrayado } & 8 & 0 & 8 \\
\hline & $61.5 \%$ & $.0 \%$ & $18.2 \%$ \\
\hline \multirow[t]{2}{*}{ Hace resumen directamente del texto } & 0 & 23 & 23 \\
\hline & $.0 \%$ & $74.2 \%$ & $52.3 \%$ \\
\hline \multirow[t]{2}{*}{$N S / N C$} & 0 & 6 & 6 \\
\hline & $.0 \%$ & $19.4 \%$ & $13.6 \%$ \\
\hline \multirow[t]{2}{*}{ Total de alumnos de cada carrera } & 13 & 31 & 44 \\
\hline & $100.0 \%$ & $100.0 \%$ & $100.0 \%$ \\
\hline$\chi^{2}(\mathrm{gl})$ & & $38.235(4)$ & \\
\hline$p$ & & .000 & \\
\hline
\end{tabular}

Tabla 3.34. Procedimiento escritura (Texto impreso) $\left(\mathrm{VDTH}_{2.2}\right)$

(la salida completa de este procedimiento se encuentra en el Anexo II.13 tabla 17)

Para finalizar, en las sub-variables Procedimiento lectura (Hipertexto) $\left(\mathrm{VDTH}_{2.3}\right)$ y Procedimiento escritura (Hipertexto) $\left(\mathrm{VDTH}_{2.4}\right)$, aparecen de nuevo diferencias significativas intergrupos (n.s.=.05) (tabla 3.35 y 3.36 respectivamente).

En el caso de la primera, la tabla 3.35 muestra que, por un lado, gran parte del grupo EDP hipertexto expresa que no lee los hipervínculos; y por otro, los alumnos del grupo PSP hipertexto se reparten entre los manifiestan que no leen los vínculos (28.5\%), los que dicen entrar en parte de los vínculos (23.8\%) y los que afirman entrar en todos los vínculos leyéndolos una (14.3\%) o más veces (33.3\%). 


\begin{tabular}{|c|c|c|c|}
\hline \multicolumn{4}{|c|}{ VDTH $_{2.3 .}$ Procedimiento lectura (Hipertexto) } \\
\hline & \multicolumn{2}{|c|}{ GRUPO DE ESTUDIO } & \multirow[b]{2}{*}{$\begin{array}{l}\text { Total alumnos } \\
\text { según tipo de } \\
\text { respuesta }\end{array}$} \\
\hline & $\begin{array}{c}P S P \\
\text { Hipertexto } \\
\end{array}$ & $\begin{array}{c}\text { EDP } \\
\text { Hipertexto } \\
\end{array}$ & \\
\hline Lee el hipertexto dos o más veces entrando en todos los & 7 & 2 & 9 \\
\hline hipervínculos & $33.3 \%$ & $6.5 \%$ & $17.3 \%$ \\
\hline Lee el hipertexto una vez entrando en todos los & 3 & 4 & 7 \\
\hline hipervínculos & $14.3 \%$ & $12.9 \%$ & $13.5 \%$ \\
\hline \multirow[t]{2}{*}{ Lee el hipertexto entrando en parte de los hipervínculos } & 5 & 2 & 7 \\
\hline & $23.8 \%$ & $6.5 \%$ & $13.5 \%$ \\
\hline \multirow[t]{2}{*}{ No lee hipervínculos } & 6 & 20 & 26 \\
\hline & $28.6 \%$ & $64.5 \%$ & $50.0 \%$ \\
\hline \multirow[t]{2}{*}{$N S / N C$} & 0 & 3 & 3 \\
\hline & $.0 \%$ & $9.7 \%$ & $5.8 \%$ \\
\hline \multirow[t]{2}{*}{ Total de alumnos de cada carrera } & 21 & 31 & 52 \\
\hline & $100.0 \%$ & $100.0 \%$ & $100.0 \%$ \\
\hline$\chi^{2}(\mathrm{gl})$ & & $13.314(4)$ & \\
\hline$p$ & & .010 & \\
\hline
\end{tabular}

Tabla 3.35. Procedimiento lectura (Hipertexto) $\left(\mathrm{VDTH}_{2.3}\right)$

(la salida completa de este procedimiento se encuentra en el Anexo II. 13 tabla 19)

Con respecto a Procedimiento escritura (Hipertexto) $\left(\mathrm{VDTH}_{2.4}\right)$, en la tabla 3.36 vemos que, aunque la mayoría de alumnos de ambos grupos han declarado hacer el resumen directamente del texto (un $52.4 \%$ en el grupo PSP hipertexto y un $77.4 \%$ en el grupo EDP hipertexto), existen diferencias entre grupos en cuanto al porcentaje de alumnos que releen el resumen y luego omiten información (un 23.8\% del grupo PSP hipertexto, por ninguno del grupo EDP hipertexto). 


\begin{tabular}{|c|c|c|c|}
\hline \multicolumn{4}{|c|}{ VDTH $_{2.4} \cdot$ Procedimiento escritura (Hipertexto) } \\
\hline & \multicolumn{2}{|c|}{ GRUPO DE ESTUDIO } & \multirow[b]{2}{*}{$\begin{array}{c}\text { Total alumnos } \\
\text { según tipo } \\
\text { respuesta } \\
\end{array}$} \\
\hline & $\begin{array}{c}\text { PSP } \\
\text { Hipertexto }\end{array}$ & $\begin{array}{c}\text { EDP } \\
\text { Hipertexto }\end{array}$ & \\
\hline $\begin{array}{l}\text { Realiza alguno de los tres pasos anteriores, y luego relee el } \\
\text { resumen y omite información }\end{array}$ & $\begin{array}{c}5 \\
23.8 \% \\
\end{array}$ & $\begin{array}{c}0 \\
.0 \% \\
\end{array}$ & $\begin{array}{c}5 \\
9.6 \% \\
\end{array}$ \\
\hline Hace el resumen a partir de borrador & $\begin{array}{c}3 \\
14.3 \% \\
\end{array}$ & $\begin{array}{c}4 \\
12.9 \% \\
\end{array}$ & $\begin{array}{c}7 \\
13.5 \% \\
\end{array}$ \\
\hline $\begin{array}{l}\text { Copia información del hipertexto en un documento word, } \\
\text { destaca información que considera importante, y hace el } \\
\text { resumen }\end{array}$ & $9.5 \%$ & 0 & $3.8 \%$ \\
\hline Hace el resumen directamente del texto & $\begin{array}{c}11 \\
52.4 \% \\
\end{array}$ & $\begin{array}{c}24 \\
77.4 \% \\
\end{array}$ & $\begin{array}{r}35 \\
67.3 \% \\
\end{array}$ \\
\hline$N S / N C$ & $\begin{array}{c}0 \\
.0 \% \\
\end{array}$ & $\begin{array}{r}3 \\
9.7 \% \\
\end{array}$ & $\begin{array}{r}3 \\
5.8 \% \\
\end{array}$ \\
\hline Total de alumnos de cada carrera & $\begin{array}{c}21 \\
100.0 \% \\
\end{array}$ & $\begin{array}{c}31 \\
100.0 \% \\
\end{array}$ & $\begin{array}{c}52 \\
100.0 \% \\
\end{array}$ \\
\hline$\chi^{2}(\mathrm{gl})$ & & $\begin{array}{c}3.549(4) \\
.009\end{array}$ & \\
\hline
\end{tabular}

Tabla 3.36. Procedimiento escritura (Hipertexto) $\left(\mathrm{VDTH}_{2.4}\right)$

(la salida completa de este procedimiento se encuentra en el Anexo II.13 tabla 21)

Resumiendo, existían diferencias significativas intergrupales en todas las subvariables asociadas a Procedimientos que el alumno considera haber seguido para realizar la tarea $\left(\mathrm{VDTH}_{2}\right)$. Concretamente, los resultados parecen mostrar que el alumnado de Psicopedagogía, independientemente del formato textual en el que realizará la prueba, utilizaba procedimientos más adecuados que el de Educación Primaria.

En lo que se refiere a los grupos de Educación Primaria, cabe señalar que los aseguraban haber realizado el resumen directamente del texto (sin apoyarse en anotaciones o borradores) y no haberlo releído una vez escrito. En particular, hemos de decir que: a) la mayoría del grupo EDP texto, a pesar de haber subrayado el artículo, decía no haberse apoyado en dicha información a la hora de realizar el resumen (lo que significa que no aprovechaban la técnica del subrayado); y b) gran parte del grupo EDP hipertexto afirmó no haber accedido a ninguno de los vínculos del hipertexto.

Por el contrario, en lo que respecta a los grupos de Psicopedagogía, la mayoría de los alumnos del grupo PSP texto hacían el resumen partiendo de la información que habían subrayado (por lo que la técnica tenía una finalidad definida), y gran parte del alumnado del grupo PSP hipertexto accedía a todos los hipervínculos del hipertexto (aunque, al igual que los alumnos del grupo EDP hipertexto, realizaban el resumen 
directamente del hipertexto; probablemente, porque no podían subrayar la información como hicieron los del grupo PSP texto).

Teniendo esto en cuenta, parece que el momento formativo sí era un factor determinante en lo que respecta a Procedimientos que el alumno considera haber seguido para realizar la tarea $\left(\mathrm{VDTH}_{2}\right)$.

\section{Contraste de hipótesis relativa a la variable dependiente Habilidades específicas de comprensión y expresión escrita para la síntesis de información}

Los resultados muestran que existían diferencias significativas (n.s.=.05) en todas las sub-variables vinculadas a Procedimientos que el alumno considera haber seguido para realizar la tarea $\left(\mathrm{VDTH}_{2}\right)$; pero no diferencias intergrupales en la mayor parte de las sub-variables vinculadas a Uso de habilidades de comprensión y expresión escrita para realizar la tarea $\left(\mathrm{VDTH}_{1}\right)$ (solamente aparecía diferencias en Integración Intertextual (Hipertexto) $\left.\left(\mathrm{VDTH}_{1.3}\right)\right)$. Estas diferencias respondían más al momento formativo que al formato textual, de forma que los alumnos de los grupos PSP texto y PSP hipertexto, aunque utilizaban procedimientos diferentes a los que usaban los alumnos de EDP texto y EDP hipertexto; mostraban similares deficiencias en cuanto al uso de habilidades de comprensión y expresión escrita a la hora de realizar la tarea.

Por lo que partiendo de los resultados obtenidos podemos rechazar la cuarta hipótesis que formulamos para nuestra investigación: El tipo de texto (impreso e hipertexto) implica la puesta en práctica de tareas de comprensión y expresión escrita diferenciales en ambos grupos.

\subsubsection{Evaluación de otras variables (secundarias)}

Además de la variable dependiente específica Habilidades específicas de comprensión y expresión escrita para la síntesis de información, analizamos otras variables que, siendo secundarias en nuestra investigación, nos pareció interesante tener en cuenta: Dificultades encontradas por el alumnado para realizar la tarea (VS1), Utilización de las ayudas a la comprensión lectora (glosario) (VS2) y Opinión del alumnado (VS3).

\section{A. Resultados para Dificultades encontradas por el alumnado para realizar la tarea (VS1)}

La variable Dificultades encontradas por el alumnado para realizar la tarea (VS1) se dividió en dos sub-variables: Dificultades encontradas por el alumnado que 
realizó la tarea a partir de un texto (VS1.1) y Dificultades encontradas por el alumnado que hizo la tarea a partir de hipertexto (VS1.2).

En cuanto a Dificultades encontradas por el alumnado que realizó la tarea a partir de un texto (VS1.1), como vemos en la tabla 3.37, no existían diferencias significativas entre grupos (n.s.=.05). Concretamente casi la mitad del alumnado no dice nada en torno a las dificultades encontradas (47.7\%), y un $27.3 \%$ de los alumnos afirman no haber tenido dificultades. De forma más particular, hemos destacar que en el grupo PSP texto un $23.1 \%$ de los alumnos indicaron que la falta de tiempo fue la mayor dificultad que encontraron a la hora de realizar la tarea.

\begin{tabular}{|c|c|c|c|}
\hline & \multicolumn{2}{|c|}{ GRUPO DE ESTUDIO } & \multirow{2}{*}{$\begin{array}{l}\text { Total alumnos según } \\
\text { tipo de respuesta }\end{array}$} \\
\hline & PSP Texto & EDP Texto & \\
\hline No tiene dificultades & $\begin{array}{c}3 \\
23.1 \%\end{array}$ & $\begin{array}{c}9 \\
29.0 \%\end{array}$ & $\begin{array}{c}12 \\
27.3 \%\end{array}$ \\
\hline Extensión del texto & $\begin{array}{c}0 \\
.0 \%\end{array}$ & $\begin{array}{c}3 \\
9.7 \%\end{array}$ & $\begin{array}{c}3 \\
6.8 \%\end{array}$ \\
\hline $\begin{array}{l}\text { Falta de tiempo para realizar la } \\
\text { tarea }\end{array}$ & $\begin{array}{c}3 \\
23.1 \%\end{array}$ & $\begin{array}{c}0 \\
.0 \%\end{array}$ & $\begin{array}{c}3 \\
6.8 \%\end{array}$ \\
\hline $\begin{array}{l}\text { Tema poco familiar o vocabulario } \\
\text { complejo }\end{array}$ & $\begin{array}{c}0 \\
.0 \%\end{array}$ & $\begin{array}{c}2 \\
6.5 \% \\
\end{array}$ & $\begin{array}{c}2 \\
4.5 \% \\
\end{array}$ \\
\hline $\begin{array}{l}\text { Dificultades en redacción del } \\
\text { resumen }\end{array}$ & $\begin{array}{c}0 \\
.0 \%\end{array}$ & $\begin{array}{c}1 \\
3.2 \%\end{array}$ & $\begin{array}{c}1 \\
2.3 \%\end{array}$ \\
\hline $\begin{array}{l}\text { Dificultades en la comprensión } \\
\text { lectora }\end{array}$ & $\begin{array}{c}1 \\
7.7 \% \\
\end{array}$ & $\begin{array}{c}1 \\
3.2 \% \\
\end{array}$ & $\begin{array}{c}2 \\
4.5 \% \\
\end{array}$ \\
\hline$N S / N C$ & $\begin{array}{c}6 \\
46.2 \% \\
\end{array}$ & $\begin{array}{c}15 \\
48.4 \% \\
\end{array}$ & $\begin{array}{c}21 \\
47.7 \% \\
\end{array}$ \\
\hline Total de alumnos de cada carrera & $\begin{array}{c}13 \\
100.0 \% \\
\end{array}$ & $\begin{array}{c}31 \\
100.0 \% \\
\end{array}$ & $\begin{array}{c}44 \\
100.0 \% \\
\end{array}$ \\
\hline $\begin{array}{l}\chi^{2}(\mathrm{gl}) \\
p\end{array}$ & & $\begin{array}{c}10.201(6) \\
.116\end{array}$ & \\
\hline
\end{tabular}

Tabla 3.37. Dificultades encontradas por el alumnado que realizó la tarea a partir de texto impreso (VS1.1) (la salida completa de este procedimiento se encuentra en el Anexo II. 13 tabla 23)

En lo que se refiere a la segunda sub-variable (Dificultades encontradas por el alumnado que hizo la tarea a partir de hipertexto (VS1.2)), tampoco hay diferencias significativas entre grupos (n.s.=.05). Como muestra la tabla 3.38, para el estadístico de contraste $\chi^{2}$ con un valor de 13.976, corresponde una probabilidad de .052. Dicha tabla muestra claramente que la mayor parte de los alumnos dicen no tener dificultades a la hora de realizar la tarea $(42.3 \%)$, mientras que el resto del alumnado se distribuye entre 
otras opciones de respuesta (destacamos los que tienen dificultades de comprensión lectora $(19.2 \%)$ y los que consideran que el artículo era muy extenso $(11.5 \%)$. Además cabe señalar, que sólo unos pocos alumnos del grupo PSP hipertexto manifestaron tener problemas de navegación (el 14.3\% de los alumnos de este grupo).

\begin{tabular}{|c|c|c|c|}
\hline \multicolumn{4}{|c|}{ VS1.2. Dificultades encontradas por el alumnado que hizo la tarea a partir de hipertexto } \\
\hline & \multicolumn{2}{|c|}{ GRUPO DE ESTUDIO } & \multirow[b]{2}{*}{$\begin{array}{l}\text { Total alumnos } \\
\text { según tipo de } \\
\text { respuesta }\end{array}$} \\
\hline & $\begin{array}{c}\text { PSP } \\
\text { Hipertexto }\end{array}$ & $\begin{array}{c}E D P \\
\text { Hipertexto }\end{array}$ & \\
\hline \multirow[t]{2}{*}{ No tiene dificultades } & 10 & 12 & 22 \\
\hline & $47.6 \%$ & $38.7 \%$ & $42.3 \%$ \\
\hline \multirow[t]{2}{*}{ Extensión del hipertexto } & 0 & 6 & 6 \\
\hline & $.0 \%$ & $19.4 \%$ & $11.5 \%$ \\
\hline \multirow[t]{2}{*}{ Falta de tiempo para realizar la tarea } & 0 & 1 & 1 \\
\hline & $.0 \%$ & $3.2 \%$ & $1.9 \%$ \\
\hline \multirow[t]{2}{*}{ Tema poco familiar o vocabulario complejo } & 2 & 3 & 5 \\
\hline & $9.5 \%$ & $9.7 \%$ & $9.6 \%$ \\
\hline \multirow[t]{2}{*}{ Problemas de navegación } & 3 & 0 & 3 \\
\hline & $14.3 \%$ & $.0 \%$ & $5.8 \%$ \\
\hline \multirow[t]{2}{*}{ Dificultades en redacción del resumen } & 1 & 0 & 1 \\
\hline & $4.8 \%$ & $.0 \%$ & $1.9 \%$ \\
\hline \multirow[t]{2}{*}{ Dificultades en la comprensión lectora } & 5 & 5 & 10 \\
\hline & $23.8 \%$ & $16.1 \%$ & $19.2 \%$ \\
\hline \multirow[t]{2}{*}{$N S / N C$} & 0 & 4 & 4 \\
\hline & $.0 \%$ & $12.9 \%$ & $7.7 \%$ \\
\hline \multirow[t]{2}{*}{ Total de alumnos de cada carrera } & 21 & 31 & 52 \\
\hline & $100.0 \%$ & $100.0 \%$ & $100.0 \%$ \\
\hline$\chi^{2}(\mathrm{gl})$ & & $13.976(7)$ & \\
\hline$p$ & & .052 & \\
\hline
\end{tabular}

Tabla 3.38. Dificultades encontradas por el alumnado que hizo la tarea a partir de hipertexto (VS1.2) (la salida completa de este procedimiento se encuentra en el Anexo II. 13 tabla 25)

\section{B. Resultados para Utilización de las ayudas a la comprensión lectora (glosario) (VS2)}

Como se observa en la tabla 3.39 , para el estadístico de contraste $\chi^{2}=26.346$ corresponde una $\mathrm{p}<\mathbf{. 0 0 1}$, por lo que interpretamos existían diferencias significativas entre los grupos (n.s.=.05) en la variable Utilización de las ayudas a la comprensión lectora (glosario) (VS2). El momento formativo del alumnado parece incidir en estas diferencias, puesto que mientras gran parte de los alumnos de los grupos PSP hipertexto 
y PSP texto utilizaban el glosario, la mayoría de los alumnos de los grupos EDP hipertexto y EDP texto no lo hacían.

\begin{tabular}{|c|c|c|c|c|c|}
\hline \multicolumn{6}{|c|}{ VS2. Utilización de las ayudas a la comprensión lectora (Glosario) } \\
\hline & \multicolumn{4}{|c|}{ GRUPO DE ESTUDIO } & \multirow[b]{2}{*}{$\begin{array}{l}\text { Total alumnos } \\
\text { según tipo de } \\
\text { respuesta }\end{array}$} \\
\hline & $\begin{array}{c}\text { PSP } \\
\text { Hipertexto }\end{array}$ & $\begin{array}{c}E D P \\
\text { Hipertexto }\end{array}$ & PSP Texto & EDP Texto & \\
\hline Utiliza glosario & $\begin{array}{c}9 \\
42.9 \%\end{array}$ & $\begin{array}{c}3 \\
9.7 \%\end{array}$ & $\begin{array}{c}9 \\
69.2 \%\end{array}$ & $\begin{array}{c}5 \\
16.1 \%\end{array}$ & $\begin{array}{c}26 \\
27.1 \%\end{array}$ \\
\hline No utiliza glosario & $\begin{array}{c}10 \\
47.6 \%\end{array}$ & $\begin{array}{c}27 \\
87.1 \%\end{array}$ & $\begin{array}{c}3 \\
23.1 \%\end{array}$ & $\begin{array}{c}26 \\
83.9 \%\end{array}$ & $\begin{array}{c}66 \\
68.8 \%\end{array}$ \\
\hline $\begin{array}{l}\text { No utiliza glosario a pesar de no } \\
\text { comprender el vocabulario } \\
\text { artículo }\end{array}$ & $\begin{array}{r}2 \\
9.5 \% \\
\end{array}$ & $\begin{array}{c}1 \\
3.2 \% \\
\end{array}$ & $\begin{array}{c}1 \\
7.7 \% \\
\end{array}$ & $\begin{array}{c}0 \\
.0 \% \\
\end{array}$ & $\begin{array}{c}4 \\
4.2 \% \\
\end{array}$ \\
\hline Total de alumnos de cada carrera & $\begin{array}{c}21 \\
100.0 \%\end{array}$ & $\begin{array}{c}31 \\
100.0 \%\end{array}$ & $\begin{array}{c}13 \\
100.0 \%\end{array}$ & $\begin{array}{c}31 \\
100.0 \%\end{array}$ & $\begin{array}{c}96 \\
100.0 \%\end{array}$ \\
\hline $\begin{array}{l}\chi^{2}(\mathrm{gl}) \\
p\end{array}$ & & & $\begin{array}{r}26.3 \\
.\end{array}$ & $\begin{array}{l}6(6) \\
0\end{array}$ & \\
\hline
\end{tabular}

Tabla 3.39. Utilización de las ayudas a la comprensión lectora (Glosario) (VS2)

(la salida completa de este procedimiento se encuentra en el Anexo II. 13 tabla 27)

\section{Resultados para Opinión del alumnado (VS3)}

En lo que se refiere a la variable Opinión del alumnado (VS3), también existían diferencias significativas entre los grupos de estudio (n.s.=.05); pero, esta vez, las diferencias estaban relacionadas con el tipo de formato en el que se realizaba la tarea. De manera que, mientras los grupos PSP hipertexto (95.2\%) y EDP hipertexto (87.1\%) consideraban mayoritariamente que era importante saber realizar un resumen, los grupos PSP texto y PSP hipertexto se repartían entre los que consideraban que era importante saber hacer un resumen (46.2\% en el grupo PSP texto, y $38.7 \%$ en el grupo EDP texto) y los que no decían nada al respecto (53.8\% en el grupo PSP texto, y $45.2 \%$ en el grupo EDP texto). 


\begin{tabular}{|c|c|c|c|c|c|}
\hline \multicolumn{6}{|c|}{ VS3. Opinión del alumnado } \\
\hline & \multicolumn{4}{|c|}{ GRUPO DE ESTUDIO } & \multirow[b]{2}{*}{$\begin{array}{l}\text { Total alumnos } \\
\text { según tipo de } \\
\text { respuesta }\end{array}$} \\
\hline & $\begin{array}{c}\text { PSP } \\
\text { Hipertexto }\end{array}$ & $\begin{array}{c}\text { EDP } \\
\text { Hipertexto }\end{array}$ & PSP Texto & EDP Texto & \\
\hline $\begin{array}{l}\text { Es importante saber realizar un } \\
\text { resumen }\end{array}$ & $\begin{array}{c}20 \\
95.2 \% \\
\end{array}$ & $\begin{array}{c}27 \\
87.1 \% \\
\end{array}$ & $\begin{array}{c}6 \\
46.2 \% \\
\end{array}$ & $\begin{array}{c}12 \\
38.7 \% \\
\end{array}$ & $\begin{array}{r}65 \\
67.7 \% \\
\end{array}$ \\
\hline $\begin{array}{l}\text { No es importante saber realizar } \\
\text { un resumen }\end{array}$ & $\begin{array}{c}0 \\
.0 \% \\
\end{array}$ & $\begin{array}{c}0 \\
.0 \% \\
\end{array}$ & $\begin{array}{c}0 \\
.0 \% \\
\end{array}$ & $\begin{array}{c}5 \\
16.1 \% \\
\end{array}$ & $\begin{array}{c}5 \\
5.2 \% \\
\end{array}$ \\
\hline$N S / N C$ & $\begin{array}{c}1 \\
4.8 \% \\
\end{array}$ & $\begin{array}{c}4 \\
12.9 \% \\
\end{array}$ & $\begin{array}{r}7 \\
53.8 \% \\
\end{array}$ & $\begin{array}{r}14 \\
45.2 \% \\
\end{array}$ & $\begin{array}{c}26 \\
27.1 \% \\
\end{array}$ \\
\hline Total de alumnos de cada carrera & $\begin{array}{c}21 \\
100.0 \%\end{array}$ & $\begin{array}{c}31 \\
100.0 \%\end{array}$ & $\begin{array}{c}13 \\
100.0 \%\end{array}$ & $\begin{array}{c}31 \\
100.0 \%\end{array}$ & $\begin{array}{c}96 \\
100.0 \%\end{array}$ \\
\hline $\begin{array}{l}\chi^{2}(\mathrm{gl}) \\
p\end{array}$ & & & & $\begin{array}{l}641(6) \\
000\end{array}$ & \\
\hline
\end{tabular}

Tabla 3.40. Opinión del alumnado (VS3)

(la salida completa de este procedimiento se encuentra en el Anexo II. 13 tabla 29)

\section{Resumen de otras variables (Variables secundarias)}

Parece que el alumnado no tuvo problemas excesivos para realizar la tarea tanto en formato impreso (a pesar de que hay un número importante de alumnos que no dijeron nada al respecto) como en formato hipertextual. Únicamente, se puede destacar un pequeño porcentaje de alumnos del grupo PSP texto que señalaron que dispusieron de poco tiempo; y otro pequeño porcentaje de alumnos del grupo PSP hipertexto que mencionaron haber tenido problemas de navegación.

Sin embargo, sí se manifestaron diferencias significativas entre grupos en Utilización de las ayudas a la comprensión lectora (glosario) (VS2) y en Opinión del alumnado (VS3). Como hemos indicado, mientras en la primera variable las diferencias correlacionan con el momento formativo del alumnado (los alumnos de Psicopedagogía utilizaron en mayor medida el glosario que los de Educación Primaria); en la segunda, las diferencias se relacionan con el formato textual en el los alumnos realizaron la tarea (la tarea con texto en formato impreso les parecía útil; mientras la tarea con texto en formato hipertextual, bien les parecía útil, o bien no decían nada al respecto). 


\section{CAPÍTULO IV. DISCUSIÓN Y CONCLUSIONES}

Una vez revisados los resultados obtenidos en los dos diseños de nuestra investigación, discutiremos las implicaciones de los mismos en relación a nuestro marco teórico, realizaremos una serie de conclusiones a nivel de contenido y a nivel metodológico y, partiendo de estas últimas, señalaremos las líneas de investigación que se abren para el futuro.

\subsection{DISCUSIÓN DE RESULTADOS}

Teniendo en cuenta que la investigación consta de dos diseños diferentes, hemos dividido nuestra argumentación en dos partes: Discusión de los resultados del Diseño I y Discusión de los resultados del Diseño II.

\subsubsection{Discusión de los resultados del Diseño I}

Como hemos visto en el capítulo anterior, no parecen existir diferencias entre los alumnos que comienzan el Grado de Maestro (alumnos de nuevo ingreso en la universidad) y los que inician la Licenciatura en Psicopedagogía (titulados universitarios) en la variable dependiente general: Habilidades básicas de comprensión y expresión escrita para la construcción conocimiento. Frente a lo esperable, ambos grupos manifiestan un nivel bastante bajo en dichas habilidades cuando consideramos conjuntamente las variables: Formación de la idea principal de cada párrafo (VD1), Dificultades para formar la idea principal de cada párrafo (VD2), Construcción de un mapa conceptual donde se recoja la macroestructura del texto leído (VD3) y Dificultades en la construcción del mapa conceptual (VD4).

Para clarificar lo que esto supone, comenzaremos explicando las implicaciones que tienen los resultados de la tarea 1 (Identificar la idea principal de cada párrafo), haremos lo propio con los de la tarea 2 (Construcción de un mapa conceptual que recoja las relaciones jerárquicas que se dan entre las ideas del texto) y finalizaremos analizándolos en conjunto. 


\subsubsection{Discusión sobre los resultados de la tarea 1: Identificar la idea principal de cada párrafo}

El alumnado manifestaba un nivel desempeño entre Bajo y Muy Bajo en VD1: Formación de la idea principal de cada párrafo. En particular, como revela VD2: Dificultades para formar la idea principal de cada párrafo, los alumnos mostraban principalmente problemas de expresión (relacionados con la correferencia argumental de la idea extraída, la estructuración de la misma y/o el modelo de la situación en el que ésta se enmarca) que reflejaban dificultades de comprensión (deficiencias en el uso de la progresión temática, uso de estrategia de listado o decir algo del texto y/o ausencia de supervisión del grado de comprensión).

Estos resultados, en relación con el cuadro-resumen que construimos a partir de los trabajos de Anderson y Thiede (2008), Block y Pressley (2007), Hernández (1999), y otros autores (véanse páginas 59 y 60), nos permiten categorizar al alumnado que fue objeto de nuestro estudio como lectores inmaduros, en lo que se refiere a la puesta en marcha de Habilidades/estrategias de comprensión lectora vinculadas a:

- la identificación de microestructura (habilidad para seguir la progresión temática durante el proceso de lectura y habilidad para el uso de la microestructura textual con el fin de construir macroproposiciones durante el proceso de comprensión lectora); y

- la regulación y supervisión del proceso de comprensión (habilidades metacognitivas).

Debemos recordar que, de acuerdo con el modelo Construcción-Integración de Kintsch $(1988,1998)$, la limitada capacidad de la memoria de trabajo obliga al lector a: extraer las proposiciones más importantes dentro de cada ciclo de procesamiento, guardarlas en el retén cognitivo, y conectarlas con el siguiente ciclo con el fin de mantener el hilo conductor del texto (o progresión temática). El modelo, además, señala que en el caso de que las ideas extraídas dentro un ciclo no conecten con la información del siguiente ciclo, será necesario recuperar de la memoria a largo plazo ideas almacenadas de ciclos anteriores; y si ninguna de ellas favoreciese la conexión, el lector tendría que realizar inferencias puente basadas en sus conocimientos previos.

Por tanto, si tenemos en cuenta que el alumnado de nuestro estudio mostraba grandes dificultades para extraer la idea principal de cada párrafo, parece claro que difícilmente podría seguir el hilo conductor del texto, ya que tendría muchos problemas para conectar la información de los diferentes ciclos. Ésto, desde el punto de vista de la teoría de la carga cognitiva (Sweller, 1988, 2005; Pass y Sweller, 2014; Sweller, Ayres y Kalyuga, 2011), supondría una importante carga inefectiva para la memoria operativa, a pesar de que los alumnos expresaban las ideas extraídas por escrito (descargándolas de su memoria de trabajo); puesto que la poca correspondencia de dichas ideas con las 
macroproposiciones textuales les obligaría utilizar conocimientos previos de la memoria a largo plazo ${ }^{24}$ para tratar de solventar la falta de coherencia entre las mismas.

Tomando todo ello en consideración, expresar por escrito las ideas extraídas de cada párrafo no parece promover la metacomprensión tal como sugieren Thiede et al. (2005). Estos autores, realizaron un estudio que indica que un lector es más consciente del grado de comprensión alcanzando si al finalizar la lectura expresa por escrito las ideas claves del texto (macroproposiciones), fundamentalmente, si antes de comenzar a escribir dedica tiempo a la reflexión. La aparente divergencia entre nuestro estudio y el de Thiede et al. (2005) se reduce si tenemos en cuenta que, en este último, los lectores extraían las ideas una vez leído el texto completo; pero sobre todo, si observamos el desempeño del alumnado de nuestro estudio desde la óptica del modelo MD-TRACE (Rouet y Britt, 2011). Los alumnos autorregulan el proceso de lectura en función del modelo de tarea que elaboran, por lo que si su objetivo principal se reduce a tratar de decir algo de cada párrafo, apenas van a necesitar establecer un control metacognitivo de la lectura; como consecuencia de ello, expresar por escrito las ideas extraídas no les supondrá beneficio alguno en el sentido que señalan Thiede et al. (2005). En definitiva, el alumnado de nuestra investigación no es consciente de lo que implica realizar la tarea que se le demanda, principalmente, porque no dispone de habilidades/estrategias adecuadas para llevarla a cabo; y ello hace que el proceso metacognitivo que se plantea no sea el adecuado para acometer satisfactoriamente dicha tarea.

Por otra parte, ubicando los resultados obtenidos en esta tarea dentro los estudios de Bereiter y Scarmadalia (1992), Madin et al. (2007) y otros autores anteriormente referidos (véanse páginas 82 y 83), observamos que las dificultades de expresión escrita que muestra el alumnado parecen responder a un alto grado de inmadurez en el uso de estrategias de síntesis, que está directamente ligado a la deficiencia en el uso de las Habilidades/Estrategias de comprensión lectora que hemos mencionado.

Como vimos en el marco teórico, la carencia de habilidades/estrategias de lectura adecuadas suele llevar al lector a usar estrategias de síntesis muy vinculadas al código de superficie del texto original (Hirvela y Du, 2013; Howard, 1995, 1999; Pecorari, 2003, 2008, Winograd, 1984; Mandin et al., 2007). En este sentido, la mayor parte de los alumnos tenía dificultades de expresión escrita a la hora de mantener la correferencia argumental, de estructurar adecuadamente la idea y/o de generar un modelo de la situación claro, que se pueden relacionar con el uso de estrategias de omisiónselección como:

\footnotetext{
${ }^{24}$ Lo que, según Sánchez et. al. (2010), "no sale gratis”, ya que recuperar una idea almacenada en la memoria a largo plazo precisa gastar de recursos cognitivos de la memoria de trabajo.
} 
- la paráfrasis cercana a la copia o patchwriting, que supone retocar frases textuales modificando sus estructuras gramaticales, omitiendo algunas de sus palabras y/o sustituyendo otras por sinónimos:

EDP 97. "El Tíbet se encuentra en el centro de Asia, pero desconocido hasta la invasión China"

- la combinación enlazada, que supone integrar de forma poco estructurada dos o más frases copiadas o parafraseadas del texto original:

PSP19 "El tíbet se encuentra en el centro de Asia. Poco conocido"

\subsubsection{Discusión resultados tarea 2: Construcción de un mapa conceptual que recoja las relaciones jerárquicas que se dan entre las ideas del texto}

En cuanto a la Construcción de un mapa conceptual donde se recoja la macroestructura del texto leído (VD3), interesa resaltar que ningún alumno logra reflejar en su mapa conceptual las relaciones jerárquicas que se dan entre las ideas fundamentales del texto. Únicamente un $3.1 \%$ organiza dichas ideas en torno a una estructura subordinada; mientras el resto del alumnado (un 96.9\%) muestra Dificultades en la construcción del mapa conceptual (VD4) vinculadas, mayoritariamente, a problemas para clarificar el significado global del mapa (64.3\%).

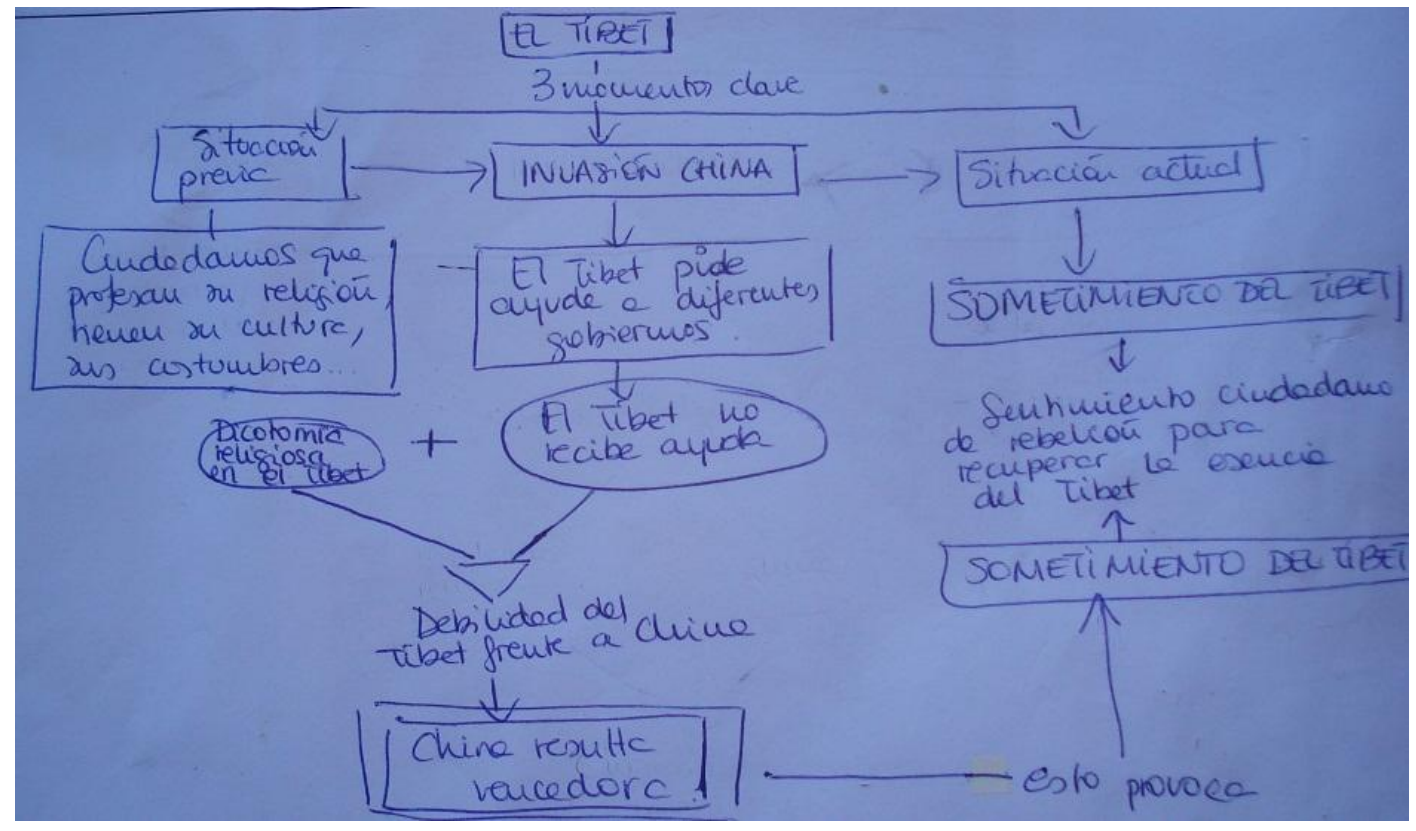

Imagen 4.1. Ejemplo de mapa conceptual que organiza las ideas en torno a una estructura subordinada 


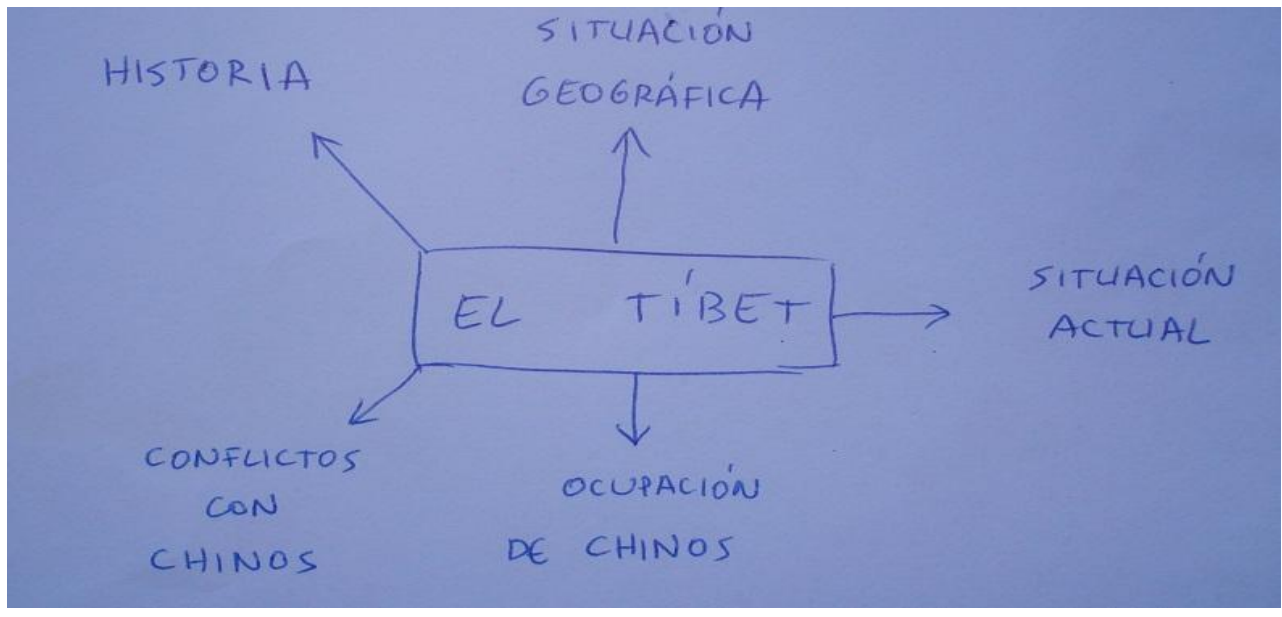

Imagen 4.2. Ejemplo de mapa conceptual que muestra dificultades para realizar la tarea satisfactoriamente

Situando estos resultados dentro de los trabajos de Anderson y Thiede (2008), Block y Pressley (2007), Hernández (1999), Thiede et al. (2005), Thiede et al. (2009) y Thiede et al. (2010), podemos categorizar al alumnado objeto de nuestra investigación como lectores inmaduros, en lo que se refiere a la puesta en marcha de Habilidades/estrategias de comprensión lectora vinculadas a:

- la extracción de la macroestructura (en particular, la habilidad para identificar la superestructura del texto durante el proceso de comprensión lectora y la habilidad para el uso de la superestructura textual con el fin de extraer la macroestructura); y

- la regulación y supervisión del proceso de comprensión (habilidades metacognitivas).

De acuerdo con los estudios de Escoriza (2003, 2006), Van Dijk (2006a), Van Dijk y Kintsch (1983), Madler y Johnson (1977), Meyer (1975) y Meyer y Ray (2011), comprender un texto globalmente implica acceder a un nivel semántico profundo llamado macroestructura, utilizando estratégicamente la superestructura textual (la forma organizativa predominante del texto) para determinar qué ideas de la microestructura recogen la esencia del texto (las macroproposiciones) y para re/organizarlas en función la posición que ocupan dentro de la jerarquía textual. En este sentido, la elaboración de un mapa conceptual, al exigir al alumnado descargar sobre un papel la representación mental que construye del texto, nos permitió observar hasta qué punto la distribución de las ideas extraídas en el mapa se corresponde con la macroestructura textual.

Así pues, el hecho de que la mayor parte de los alumnos encontraran grandes dificultades para clarificar el significado global del mapa conceptual, indica que éstos habían tenido problemas a la hora de usar estratégicamente la superestructura textual con 
el fin de extraer la macroestructura. Recordemos que el texto que debían leer ${ }^{25}$ tenía una organización global más implícita que explícita, y en casos como éste, de acuerdo con Sánchez (1993, 1998), es imprescindible disponer de ciertas nociones sobre la tipología en la que se puede enmarcar el texto, y utilizarlas estratégicamente para determinar cuáles son las ideas más importantes y para organizarlas de forma más clara.

Además, de manera similar a la tarea 1, la elaboración del mapa conceptual tampoco parecía promover la metacomprensión. Lo que contradice el estudio de Thiede et al. (2010), que indica que un lector es más consciente del grado de comprensión alcanzado si elabora un mapa conceptual justo al finalizar la lectura del texto. Esta aparente controversia se resuelve si volvemos a situarnos desde la perspectiva del modelo MD-TRACE (Rouet y Britt, 2011), ya que si el alumnado parte de un modelo de tarea erróneo (decir algo del texto), el control metacognitivo será mínimo, y por tanto, el mapa conceptual no será utilizado como herramienta para mejorar la metacomprensión.

\subsubsection{Análisis conjunto de los resultados de las tarea 1 y 2}

Las dificultades que muestran los alumnos a la hora de realizar ambas tareas indican que tenían problemas para:

- seguir la progresión temática del texto, ya que las ideas que expresaban por escrito no se correspondían como las macroproposiciones de cada párrafo;

- procesar el texto globalmente, puesto que el mapa conceptual elaborado no reflejaba la macroestructura textual.

Estas deficiencias pueden suponer un alto riesgo de sobrecarga mental para la memoria de trabajo, cuando el alumnado se enfrente con textos más extensos y específicos (como el texto académico utilizado en la fase Pos-test del Diseño II). Tengamos en cuenta que, de acuerdo con Sánchez et al. (2010), Sánchez et al. (2009a) y Sánchez et al. (2009b), los lectores difícilmente procesan el texto a nivel local y global simultáneamente, ya que esto implicaría un importante gasto de recursos cognitivos dentro de cada ciclo de procesamiento. Por ello, es necesario simplificar la tarea de lectura, dedicando cada ciclo al procesamiento del texto en un nivel concreto. Esto requiere que el lector sea capaz de gestionar adecuadamente sus recursos para pasar de un ciclo microestructural a un ciclo macroestructural (deberá recuperar de su memoria a largo plazo ideas extraídas de ciclos macroestructurales anteriores); y en este sentido, es

\footnotetext{
${ }^{25}$ Era un texto de baja coherencia que recogía términos que no deberían acarrear dificultad para el alumnado. Estos términos se enmarcaban dentro de una estructura clásica que era fácilmente inferible (las historias sobre guerras o invasiones coinciden en presentar antecedentes, consecuentes, contendientes, etc.), por lo que la carga cognitiva intrínseca del material no era alta.
} 
muy útil que el alumno sepa cómo utilizar técnicas como la extracción de ideas clave o el mapa conceptual, ya que le permiten descargar sobre el papel tanto ideas como relaciones entre ideas, que no tendrá que recuperar de su memoria a largo plazo en el momento en el que las necesite.

En el caso del alumnado de nuestra investigación, sus dificultades para realizar tanto la tarea 1, que permite descargar aspectos vinculados con la progresión temática del texto (Identificar la idea principal de cada párrafo), como la tarea 2, que permite descargar la macroestructura del texto (Construcción de un mapa conceptual que recoja las relaciones jerárquicas que se dan entre las ideas del texto); nos lleva a pensar que cuando se enfrenten un texto más complejo (el del Diseño II), tendrán grandes problemas a la hora de gestionar sus recursos para alcanzar un desempeño adecuado.

\subsubsection{Discusión de los resultados del Diseño II}

Como vimos en el capítulo II, el objetivo principal de este segundo diseño era comprobar la influencia que tenía el formato textual (impreso o hipervinculado) en alumnos que se encontraban en diferentes momentos formativos (alumnos que comenzaban el Grado de Maestro y alumnos que iniciaban la Licenciatura en Psicopedagogía) a la hora de utilizar las estrategias de comprensión y expresión escrita necesarias para realizar una tarea académica concreta (en nuestro caso, resumir un documento académico). Con este fin, dividimos el estudio en dos fases:

Una fase Pre-test, con la que pretendíamos averiguar cuál era el nivel de desempeño de los cuatro grupos que conformaban la muestra (PSP texto, PSP hipertexto, EDP texto, EDP hipertexto) en la variable dependiente general Habilidades básicas de comprensión y expresión escrita para la construcción conocimiento, que analizamos en el diseño anterior. Y una fase Pos-test, en la que estudiamos la variable dependiente: Habilidades específicas de comprensión y expresión escrita para la síntesis de información.

\subsubsection{Discusión de los resultados de la fase Pre-test}

Teniendo en cuenta los resultados obtenidos, no existen diferencias significativas entre los cuatro grupos de la muestra en las variables Formación de la idea principal de cada párrafo (VD1), Dificultades para formar la idea principal de cada párrafo (VD2) y Construcción de un mapa conceptual donde se recoja la macroestructura del texto leído (VD3); siendo el nivel de desempeño general del alumnado en las mismas, similar al del primer diseño (alumnos que tenían dificultades para seguir la progresión temática del texto y para procesarlo globalmente). Únicamente encontramos diferencias en la variable Dificultades en la construcción del mapa conceptual (VD4), que mostraba que el grupo PSP hipertexto, el grupo EDP hipertexto y el grupo EDP texto, 
mayoritariamente, tenían problemas para clarificar significado global del mapa conceptual (un $73.7 \%$, un $77.4 \%$ y un $58.6 \%$ respectivamente), mientras que los alumnos del grupo PSP texto manifestaban dificultades a la hora de: organizar en diferentes niveles jerárquicos el mapa conceptual (un 30.8\%), clarificar significado global del mapa (un $38.5 \%$ ) y construir un mapa que se centre en las ideas importantes del texto (un $30.8 \%)$.

Debido a esto, lo único que cabe destacar de esta fase Pre-test, con respecto a lo que habíamos señalado en el diseño anterior, es que en la variable Dificultades en la construcción del mapa conceptual (VD4), el grupo "PSP texto" recoge en similar porcentaje: alumnos que no sabían cómo organizar los conceptos para elaborar un mapa conceptual (no organizan los conceptos de modo jerarquizado); alumnos que sabían organizarlos jerárquicamente, pero tenía dificultades para clarificar el significado global de las relaciones que establecían en el mapa; y alumnos que sabían organizarlos jerárquicamente dándoles un significado global claro, pero que se centraban ideas secundarias del texto.

Las dificultades de los que no podían aclarar el significado del texto y de los que se centraban en las ideas secundarias del texto, parecen responder a problemas a la hora de usar estratégicamente la superestructura textual con el fin de extraer la macroestructura. Los primeros, porque no eran capaces de estructurar de forma coherente los conceptos extraídos; y los segundos, porque, a pesar de que eran capaces de estructurar coherentemente los conceptos extraídos, no recogía las ideas fundamentales del texto.

Por su parte, los problemas de los que no sabían organizar jerárquicamente los conceptos del mapa conceptual, parecen responder al hecho de que quizá no supieran utilizar esta técnica, pero también, observando los conceptos que extraen (ideas secundarias, ideas mal expresadas), a problemas a la hora de usar estratégicamente la superestructura textual.

\subsubsection{Discusión de los resultados de la fase Pos-test}

La variable dependiente Habilidades específicas de comprensión y expresión escrita para la síntesis de información fue estudiada a través de dos variables: Habilidades de comprensión y expresión escrita para realizar la tarea $\left(\mathrm{VDTH}_{1}\right)$ y Procedimientos que el alumno considera haber seguido para realizar la tarea $\left(\mathrm{VDTH}_{2}\right)$.

a) Análisis de Habilidades de comprensión y expresión escrita para realizar la tarea $\left(\mathrm{VDTH}_{1}\right)$

Los resultados indican que el alumnado, independientemente del momento formativo y del formato textual en el que realizaba la tarea, manifestaba dificultades para 
realizar el Resumen de la información de texto/hipertexto $\left(\mathrm{VDTH}_{1.6}\right)$; que, como revela la variable Dificultades en la realización del resumen $\left(\mathrm{VDTH}_{1.7}\right)$, se debían principalmente a que la mayoría construía un texto cuyo significado global no estaba claro. Concretamente, esas dificultades se percibían a nivel de párrafo, interpárrafo y de texto, a través aspectos como la estructuración de las ideas, el modelo de la situación que se derivaba de dichas ideas, la correferencia argumental entre las mismas, etc. (Ver Anexo II.10).

\section{Resumen del hipertexto.}

La escritura siempre ha estado en la escuela de tal forma que la escuela lo que busca es la descodificación de la lectura y la escritura, la alfabetización consistió en el dominio de eso códigos que están expresos en los libros.

La homogeneidad de la educación es lo que se ha pretendido en todos las culturas, es decir que las bases de la educación fueran las mismas para todos, esto se consigue a tabes del currículo educativo que es para todos los alumnos de la comunidad y del estado el mismo.

Hoy en día las Tic están permitiendo que todos estemos relacionados y nos podamos comunicar con gentes de otros países y culturas, también se ha desarrollado otro tipo de lenguaje que es el lenguaje audiovisual, los nuevos modelos curriculares electrónicos fomentan la hipertextualidad.

Hoy en día los medios audiovisuales fomentan el desarrollo de la educación y de su creatividad, fomentan el aprendizaje, pero sin embargo, los recortes en educación y la falta de conocimientos de los profesionales hacen que estos medios se utilicen muy poco en la educación

En definitiva de lo que habla todo el texto es de que en el currículo educativo tiene gran importancia los procesos de enseñanza audiovisual y digital, pero en las escuelas e institutos están ausentes por varias causas algunas de ellas ya enmarcadas en este resumen.

Cuadro 4.1. Ejemplo de resumen que muestra las dificultades de un alumno (EDP56) a nivel de párrafo, interpárrafo y de texto

Situando estos hallazgos dentro los estudios de Escoriza (2003, 2006), Van Dijk (2006a), Van Dijk y Kintsch (1983), Madler y Johnson (1977), Meyer (1975) y Meyer y Ray (2011), podría parecer que los alumnos habían tenido problemas a la hora de usar estratégicamente la superestructura textual con el fin de extraer la macroestructura del texto. De hecho, existen varios indicadores que apuntan hacia esta dirección.

El primer indicador es que las deficiencias que hemos señalado (en la estructuración de ideas, clarificación del modelo de la situación, correferencia argumental) se asocian a las estrategias de síntesis que ponen en marcha los lectores inmaduros a la hora de elaborar los resúmenes (Hirvela y Du, 2013; Howard, 1995, 1999; Pecorari, 2003, 2008; Winograd, 1984; Mandin et al., 2007).

Tengamos en cuenta que este tipo de lectores, al no disponer de habilidades/estrategias estructurales, realizan el resumen utilizando estrategias de síntesis ligadas al código de superficie del texto original, como la copia literal-omisión de información (copy-delete), la paráfrasis cercana a la copia (patchwriting) y la combinación enlazada; y éstas (sobre todo las dos últimas) le pueden llevar a: 
reorganizar gramaticalmente frases del texto original de forma poco estructurada, sustituir una palabra por otra que no tenga sentido en el contexto oracional, omitir un referente que permite mantener la correferencia argumental del resumen, integrar de forma poco estructurada dos o más frases copiadas o parafraseadas del texto original, etc.

Un segundo indicador, lo encontramos en las variables Tipo información subrayada (Texto impreso) $\left(\mathrm{VDTH}_{1.1}\right)$ y Anotaciones realizadas en el artículo (Texto impreso) $\left(\mathrm{VDTH}_{1.2}\right)$, que muestran que la gran mayoría de los alumnos que leyeron el documento en formato impreso (93.2\%) no hacía anotaciones en el texto, y que muy pocos, cuando subrayaban, destacaban la mayor parte de los aspectos estructurales del texto (títulos, y señales estructurales que aparecen en la introducción y en las conclusiones) (un $15.4 \%$ de PSP texto, y un 9.7 de EDP texto).

De acuerdo con Gil et al. (2008) y McNamara et al. (2007), el uso de técnicas como el subrayado y la toma de notas permiten al lector destacar aquella información que considera importante (y en el caso de la toma de notas, además, sintetizarla y/o relacionarla con otras partes del texto); por lo que si nuestro alumnado tenía problemas para localizar donde se encontraba la información importante, no parece probable que utilizara estratégicamente la superestructura textual para extraer la macroestructura.

Además de los dos indicadores señalados, cabe señalar otro aspecto que refleja aquello a lo que nos estamos refiriendo, concretamente, que la mayoría del alumnado no requirió el uso de borrador. Lo que supone un modelo Decir contenido textual (Retell) caracterizado por la ausencia de planificación global del proceso de redacción, por la escritura basada en el escritor y por la revisión superficial del producto escrito (véase el cuadro 1.15 en la página 83). Todo ello, desde la perspectiva del modelo MD-TRACE de Rouet y Britt (2011), implica que el alumnado parte de un modelo de tarea erróneo (decir algo del texto) que exige un control metacognitivo mínimo (ausencia de planificación global del proceso de redacción) y, por tanto, no va a necesitar el uso de borrador (ya sea estructurado, como el texto lineal o el mapa conceptual; o desestructurado, como la extracción de ideas clave del texto) para satisfacer sus objetivos de lectura. De esta manera, como adelantamos cuando analizamos las tareas del Diseño I (el Pre-test del Diseño II), el alumnado, al no saber (o no considerar) el potencial de técnicas como la expresión de ideas clave del texto, el mapa conceptual o el resumen para gestionar los recursos cognitivos de la memoria de trabajo; tendrá mayor riesgo de sobrecarga mental durante el proceso de comprensión.

Observando lo hemos señalado hasta ahora, podría parecer que el resumen, en lugar de mejorar la compresión, como sugieren los informes Writing to Read Report (Graham y Hebert, 2010) y National Reading Panel (2000), y de mejorar la precisión de la metacompresión, como afirman Thiede y Anderson (2003), Anderson y Thiede (2008) y Thiede et al. (2010); empeora tanto la una como la otra (Leopold y Leutner, 2012; Leopold, Sumfleth y Leutner, 2013). No obstante, teniendo en cuenta el Modelo MD- 
TRACE de Rouet y Britt (2011), parece claro que si el modelo de tarea que elabora el alumno no se corresponde con las demandas de dicha tarea, el producto de tarea (en este caso, el resumen) tampoco será adecuado. De hecho estudios como el de Westby et.al (2010), en el ámbito universitario, y Hernández (1999), en el contexto de la Educación Secundaria, muestran que los alumnos instruidos en la técnica de resumen obtienen puntuaciones en comprensión lectora significativamente más altas que los no instruidos.

Por otra parte, en lo que se refiere a la integración intertextual, la mayor parte de los alumnos que leyeron el hipertexto, no utilizaron información de los hipervínculos en el resumen que elaboraron; y los pocos que lo hicieron, el 19.9\% del grupo EDP hipertexto y el 9.5\% del grupo PSP hipertexto, tenían problemas para integrar la información o no tomaban como referencia la estructura hipertextual a la hora de integrarla. Recordemos que el hipertexto recogía todos los aspectos estructurales en la página principal, por lo que el alumnado podría realizar un buen resumen sin necesidad de utilizar el contenido de los hipervínculos. Cabe la posibilidad de que los alumnos hubieran descartado utilizar la información de los hipervínculos en el resumen, porque no la consideraban necesaria para realizar la tarea. Sin embargo, esto no parece factible, viendo las dificultades que manifestaban en el resumen escrito, y teniendo en cuenta la ausencia de borrador. Algo similar podemos señalar para los alumnos que leyeron el texto, quienes, en su mayoría (97.7\%), no utilizaron la información del pie de página en el resumen.

b) Análisis de Procedimientos que el alumno considera haber seguido para realizar la tarea (metacognición) $\left(\mathrm{VDTH}_{2}\right)$

A la vista de los resultados obtenidos, existían diferencias significativas (n.s.=.05) en la variable Procedimientos que el alumno considera haber seguido para realizar la tarea $\left(\mathrm{VDTH}_{2}\right)$, que dependían fundamentalmente del momento formativo.

El Procedimiento lectura (Texto impreso) $\left(\mathrm{VDTH}_{2.1}\right)$ que la mayoría de los alumnos afirmaron haber utilizado es leer el texto dos o más veces y subrayarlo (PSP texto $46.2 \%$ y EDP texto $45.2 \%$ ); sin embargo existían diferencias entre grupos en lo que respecta a otros aspectos. Por un lado, un 53.8\% de los alumnos del grupo PSP texto aseguraron leer un vez el texto y subrayarlo, por un $19.4 \%$ de los del grupo EDP texto que señalaron lo mismo. Y por otro, un $26.6 \%$ del grupo EDP texto indicaron que leyeron una vez el texto sin subrayarlo, pero nadie del grupo PSP texto mencionó haberlo hecho.

Autores como Sánchez $(1993,1998)$, Scardamalia y Bereiter (1984) y Salmerón y Gutiérrez Braojos (2012) señalan que los lectores maduros, antes de la lectura propiamente dicha, establecen objetivos y utilizan estrategias de pre-lectura como la exploración textual (revisar las partes clave del texto) o el ojeado (lectura rápida del texto); las cuales permiten definir objetivos de lectura planteados, activar el 
conocimiento previo e identificar y tomar ventaja de la estructura del texto (superestructura). En este sentido, consideramos que el alumnado que afirmó haber leído el texto dos o más veces, probablemente, utilizó la técnica del ojeado, ya que la exploración textual quedaría descartada, si tenemos en cuenta que cuando analizamos las Habilidades de comprensión y expresión escrita para realizar la tarea $\left(\mathrm{VDTH}_{1}\right)$, la mayoría del alumnado tenían dificultades para usar estratégicamente la superestructura del texto.

Por otra parte, estos autores, y otros como McNamara et.al. (2007) y Meyer y Ray (2009), sugieren que, durante la lectura, el lector maduro toma notas en el texto, subraya y/o relee partes del texto, se plantea preguntas acerca de lo que sabe y lo que no sabe y trata de resolver problemas de comprensión a través de autoexplicaciones. Partiendo de esto, la madurez lectora del alumnado durante el proceso de lectura, en el mejor de los casos, queda limitada al uso de la técnica del subrayado, puesto que un pequeño porcentaje del grupo EDP texto ni si quiera subrayaba la información textual. A ello se une que, como vimos al analizar Habilidades de comprensión y expresión escrita para realizar la tarea $\left(\mathrm{VDTH}_{1}\right)$, la utilización de la técnica del subrayado por parte del alumnado no era funcional para el desempeño de la tarea, ya que muy pocos destacaban la mayor parte de los aspectos estructurales del texto.

En lo que se refiere al Procedimiento escritura (Texto impreso) $\left(\mathrm{VDTH}_{2.2}\right)$, la mayoría alumnos PSP texto dicen hacer el resumen a partir de lo subrayado (61.5\%), mientras que la mayoría de los de EDP texto sugieren haberlo hecho directamente del texto $(74.4 \%)$.

Recordemos, por un lado, que Anderson y Thiede (2008), Thiede y Anderson (2003), Thiede et al. (2005), Thiede et al. (2010) y Thiede, Griffin, Wiley y Anderson (2010) aseguran que ciertas técnicas de síntesis, particularmente, expresar por escrito ideas clave del texto, realizar resúmenes y/o construir mapas conceptuales, mejoran la precisión de la metacomprensión; y por otro lado, que el modelo MD-TRACE de Rouet y Britt (2011) contempla productos intermedios de tarea (borradores) que se van transformando hasta conseguir el producto de tarea final. Por tanto, el que alumnado no se planteara el uso del borrador, lo sitúa dentro de la categoría de lector inmaduro (véanse cuadro 1.13 en la página 60 y 1.15 en la página 83 ) que parte de un modelo de tarea inapropiado y genera un producto de tarea inadecuado.

No obstante, admitiendo esa inmadurez general, existen ciertas diferencias entre grupos. Los alumnos de Psicopedagogía dicen utilizar la información subrayada para hacer el resumen; y por contrario, los de Educación Primaria señalan haber hecho el resumen directamente del texto, a pesar de que, como vimos al analizar la variable Tipo información subrayada (Texto impreso) $\left(\mathrm{VDTH}_{1.1}\right)$, el $60.3 \%$ de ellos subrayaban la información textual. Esto nos lleva a pensar que el uso de la técnica del subrayado por parte del alumnado de Psicopedagogía es más funcional que en el alumnado de 
Educación Primaria, en el sentido de que los primeros destacaban información para luego utilizarla en el resumen, mientras que los segundos subrayaban información pero luego hacían el resumen partiendo de todo el contenido textual.

En cuanto al Procedimiento lectura (Hipertexto) $\left(\mathrm{VDTH}_{2.3}\right)$, cabe señalar que mientras el 64.5\% del grupo EDP hipertexto dice que no lee los hipervínculos, la mayoría del grupo PSP hipertexto (el 70.4\%) afirma que sí lo hace; de manera que la lectura intertextual que aseguraron llevar a cabo los alumnos de Psicopedagogía es claramente más adecuada que la que afirmaron utilizar los de Educación Primaria, por el simple hecho de que estos últimos no consultaron los hipervínculos.

Relacionando estos hallazgos con la variable Integración intertextual (Hipertexto) $\left(\mathrm{VDTH}_{1.3}\right)$, el gran número de alumnos de Educación Primaria que sostenían no haber leído los hipervínculos clarifica, en parte, por qué éstos no utilizaron información hipervinculada en el resumen que elaboraron; pero no aclara por qué tampoco la utilizaron los pocos alumnos de este grupo que sí leyeron los hipervínculos. Del mismo modo, el que los alumnos del grupo PSP hipertexto manifestaran mayoritariamente haber leído los hipervínculos, no clarifica por qué la mayor parte de ellos no utilizó dicha información en el resumen. En este sentido, cuando analizamos la variable Integración intertextual (Hipertexto) $\left(\mathrm{VDTH}_{1.3}\right)$, señalamos que las enormes dificultades del alumnado para realizar el resumen y la ausencia generalizada de borradores; hacían poco factible que los alumnos que leyeron los hipervínculos usaran estratégicamente los aspectos estructurales de la página principal del hipertexto, para determinar que la tarea de resumen no precisaba el uso de la información hipervinculada. En virtud de ello, parece más probable que la razón por la que los alumnos que leyeron los hipervínculos no utilizaran su información en el resumen, estuviera vinculada a las deficiencias de su proceso de comprensión.

Por su parte, el Procedimiento escritura (Hipertexto) $\left(\mathrm{VDTH}_{2.4}\right)$ que mayoritariamente el alumnado afirmaba haber utilizado, consistía en resumir directamente la información del hipertexto; aunque hemos de destacar que entre los que indicaron haber utilizado otros procedimientos existían diferencias intergrupales (n.s.=.05). Por un lado, mientras un 9.5\% del grupo PSP hipertexto afirmó haber utilizado un documento Word para destacar información (a modo de subrayado), nadie del grupo EDP hipertexto mencionó haber hecho lo mismo. Y por otro lado, mientras un 23.8\% del grupo PSP hipertexto aseguró releer el resumen y omitir información, ningún alumno del grupo EDP hipertexto indicó haber realizado lo propio.

Partiendo del hecho de que la mayoría de los alumnos que leyeron el hipertexto no consideraron necesario realizar un borrador previo al resumen, vamos a categorizar a este alumnado, al igual que hicimos con los lectores que leyeron el texto impreso, como lectores inmaduros que parten de un modelo de tarea inapropiado y generan un producto de tarea inadecuado. 
c) Análisis conjunto resultados de Habilidades de comprensión y expresión escrita para realizar la tarea $\left(\mathrm{VDTH}_{1}\right)$ y Procedimientos que el alumno considera haber seguido para realizar la tarea $\left(\mathrm{VDTH}_{2}\right)$

Las dificultades que muestran los alumnos a la hora de realizar el resumen, indican que éstos tenían problemas para usar estratégicamente la superestructura con el fin de extraer la macroestructura: en primer lugar, seguían estrategias de síntesis muy ligadas al código de superficie, en segundo lugar, no hacían anotaciones en el texto y apenas lograron centrarse en los aspectos estructurales del texto cuando subrayaban, y en tercer lugar, no usaban borrador. La principal causa que parece provocar esto, a la vista de los estudios anteriormente citados, es que los alumnos no habían sido formados para desempeñar adecuadamente la tarea. Además, hemos observado que los alumnos que leyeron hipertexto no utilizaban en el resumen la información de los hipervínculos; cosa que, teniendo en cuenta las dificultades que acabamos de señalar, parece responder en mayor medida a problemas de comprensión que al uso de criterios estructurales.

En lo que respecta a los procedimientos que el alumno considera haber seguido, observamos que, en general, tanto los alumnos de Psicopedagogía como los de Educación Primaria utilizaban procedimientos que se pueden incluir dentro de la categoría de lector inmaduro. No obstante, específicamente, existían ciertas diferencias en los procedimientos utilizados por unos y otros a la hora de realizar la tarea. Concretamente, el alumnado de Psicopedagogía utilizaba la técnica del subrayado con el fin destacar la información que luego iba a utilizar en el resumen; mientras que, por el contrario, el alumnado de Educación Primaria subrayaba el texto, pero luego no se centraba en lo que había subrayado a la hora de realizar el resumen. Además, en cuanto a la lectura de hipertexto, hay que destacar que la mayoría de alumnos de Educación Primaria señalaron no haber accedido a ninguno de los hipervínculos, mientras que la mayoría de los de Psicopedagogía afirmaron haber accedido al menos a algún hipervínculo.

En definitiva, el alumnado estaba fundamentalmente compuesto por lectores inmaduros que tenían dificultades de expresión que reflejaban problemas para usar estratégicamente los aspectos estructurales del texto/hipertexto. Y ello, entre otras razones, se debía a los deficientes procedimientos de lectura y escritura que pusieron en marcha.

d) Análisis de resultados en variables secundarias: percepción de dificultades, uso de glosario y utilidad de la tarea

Para finalizar este epígrafe, creemos que es significativo destacar otras variables que, aunque son secundarias en esta investigación, nos ofrecen datos interesantes para apoyarla. 
En primer lugar, la mayoría del alumnado, independientemente del momento formativo en el que se encontraba y del formato textual en el que realizó la tarea, indicó que no tuvo dificultades a la hora de realizar el resumen. Por lo que podríamos descartar que los problemas de comprensión y expresión escrita que el alumnado en general manifestó para realizar la tarea; se deban a factores externos que pueden incrementar la carga cognitiva inefectiva (como el tiempo, o en el caso de hipertexto, la navegación).

En segundo lugar, existían diferencias intergrupos (n.s.=.05) a la hora de usar el glosario de términos relacionadas con el momento formativo. Sorprendentemente, los alumnos que más utilizaron el glosario fueron los que supuestamente menos deberían necesitarlo (los de Psicopedagogía), mientras que los que menos lo utilizaron fueron los supuestamente más lo necesitaban (los de Educación Primaria). Esto puede asociarse a que los alumnos de Psicopedagogía utilizan procedimientos más adecuados que los de Educación Primaria.

Por último, existían diferencias significativas (n.s.=.05) vinculadas con el formato textual a la hora de determinar la importancia de la tarea de resumen. Mientras que los alumnos que leyeron el hipertexto la consideran útil, los alumnos que leyeron el texto la perciben como útil o no dicen nada al respecto. En este sentido, a pesar de las diferencias intergrupales, parece que claro que los alumnos, en general, son conscientes de la importancia de este tipo de tarea; aunque, como hemos visto, no son capaces de satisfacer las demandas de dicha tarea.

\subsection{CONCLUSIONES}

\subsubsection{A nivel de contenido}

Partiendo de lo que hemos visto en nuestra investigación, a modo de conclusión podemos señalar que:

- El momento formativo en el ámbito universitario no era un factor determinante para la posesión de habilidades básicas de comprensión y expresión escrita, puesto que, tanto los alumnos que comenzaron el Grado de Maestro en la Universidad de Salamanca, como aquellos que accedían a Licenciatura de Psicopedagogía desde alguna de las titulaciones de Maestro de la misma universidad, mostraron deficiencias a la hora de:

- seguir la progresión temática del texto;

- usar estratégicamente la superestructura textual para procesarlo globalmente el texto; y 
- autorregular la metacomprensión a través de técnicas, como la expresión escrita de ideas clave del texto y la elaboración de un mapa conceptual, que tienen un enorme potencial para ayudar al lector a gestionar sus recursos cognitivos.

- El formato textual y el momento formativo no fueron determinantes para predecir un mejor nivel de desempeño del alumnado a la hora de realizar una tarea híbrida en particular, resumir por escrito un documento académico:

- El alumnado, en general, construía resúmenes cuyo significado global no estaba claro, percibiéndose en ellos deficiencias a la hora de estructurar ideas, de clarificar el modelo de la situación de las ideas y de mantener la correferencia argumental entre las ideas; las cuales indicaban el uso estrategias de síntesis ligadas al código de superficie, como la paráfrasis cercana a la copia y la combinación enlazada. Además, la mayor parte de los alumnos no utilizaron borrador (ideas clave, mapa conceptual o borrador del resumen), por lo que difícilmente podrían gestionar adecuadamente sus recursos cognitivos para procesar globalmente el texto. Teniendo en cuenta lo que hemos mencionado, el alumno no parecía utilizar estratégicamente la estructura del texto/hipertexto para extraer la macroestructura, que era lo que en definitiva debía recoger el resumen escrito.

- El alumnado que leyó el documento académico en formato impreso, no usaba técnicas como la toma de nota en el texto, que permite destacar y sintetizar la información importante; y aunque la mayoría utilizaba la técnica del subrayado, muy pocos se centraban en los aspectos relacionados con la estructura del texto.

- La mayoría del alumnado que leyó el documento académico en formato hipertextual, mayoritariamente, no utilizaba la información hipervinculada en el resumen. Del mismo modo, la mayor parte del alumnado que leyó el documento en formato impreso no utilizó la información del pie de página en el resumen que escribió. Partiendo de que el alumnado, en general, no era capaz de utilizar estratégicamente la superestructura para extraer la macroestructura del texto/hipertexto, consideramos que la ausencia de información hipervinculada en los resúmenes, podría deberse más a dificultades de comprensión que al uso de criterios estructurales.

- Los procedimientos que el alumnado afirmaba haber utilizado para realizar el resumen no eran adecuados, como cabía esperar de su nivel de desempeño en la tarea. Sin embargo, existían diferencias significativas (n.s.=.05) vinculadas fundamentalmente al momento formativo, que indicaban que, en ciertos aspectos, 
los procedimientos utilizados por los alumnos de Psicopedagogía eran mejores que los usados por los de Educación Primaria:

- En general ningún alumno mencionaba plantearse objetivos antes de la lectura; tomar notas en el texto, formular preguntas acerca de lo que sabe y lo que no, o resolver problemas de comprensión durante la lectura; o elaborar un borrador tras la lectura.

- La mayoría de los que leyeron el texto impreso afirmaron haberlo subrayado, aunque, como comprobamos al revisar lo que habían subrayado, muy pocos se centraban en los aspectos estructurales del texto.

- A la hora de usar la información subrayada para realizar el resumen del texto impreso, existían diferencias significativas (n.s.=.05) en función del momento formativo. Mientras los alumnos de Psicopedagogía aseguraban realizar el resumen partiendo de la información subrayada, los de Educación Primaria afirmaban hacer el resumen directamente de la información del texto (a pesar de haberlo subrayado). En consecuencia, el procedimiento de los alumnos de Psicopedagogía era mejor que el de los de Educación Primaria.

- Gran parte de los alumnos que leyeron el documento en formato impreso señalaron haberlo leído dos o más veces, lo que indica que utilizaron algún tipo de técnica de pre-lectura. A la vista de los problemas del alumnado para usar estratégicamente la superestructura textual, no parece que esta técnica tuviera como finalidad la exploración estructural, sino más bien, la lectura rápida u ojeado.

- El momento formativo constituyó un factor importante a la hora de leer intertextualmente el hipertexto. Los alumnos de Psicopedagogía afirmaron haber leído al menos parte de los hipervínculos, mientras que la mayoría de los de Educación Primaria señalaron no haber accedido a ninguno de ellos; de manera que el procedimiento utilizado por los primeros mejoraba el de los segundos. Sin embargo, como hemos visto anteriormente, las dificultades de comprensión que mostraban los alumnos de ambos grupos hizo que, la mayor parte de ellos, no utilizaran la información hipervinculada en el resumen que elaboraron.

- El momento formativo fue, igualmente, un factor importante a la hora de usar el glosario de términos. La mayor parte del alumnado de Psicopedagogía utilizó el glosario, mientras que la mayoría de Educación Primaria no lo hizo. Esto significa que los primeros, cuando encontraron dificultades terminológicas durante la lectura del texto/hipertexto, 
consultaron el glosario para tratar de resolverlas; y que por el contrario, los segundos no lo hicieron a pesar de que, supuestamente, deberían estar menos familiarizados con los términos que aparecían en el documento.

- El alumnado que leyó el hipertexto, mayoritariamente, realizaba el resumen directamente del mismo. Teniendo en cuenta que los alumnos de Psicopedagogía que leyeron texto impreso hacían el resumen a partir de lo subrayado, parece que el cambio de formato les llevó a un peor procedimiento.

- Los alumnos, en general, afirmaban que la tarea de resumen era muy útil, y además, consideraban no haber tenido dificultades a la hora de realizarla. Lo cual, tomando en consideración lo que hemos dicho hasta ahora, nos sugiere que, a pesar de conocer la importancia de la tarea, los estudiantes no eran conscientes de su desconocimiento, tanto en lo que se refiere al concepto de resumen cuanto a cómo debían realizarlo adecuadamente.

En definitiva, todo lo que hemos señalado indica que el lector, independientemente del momento formativo en el que se encontraba ( $y$ en el caso de la tarea de resumen, del formato textual en el que leía el texto); no partía de un modelo de tarea adecuado que le permitiera obtener un producto de tarea final satisfactorio. Esto resultados, tal y como vislumbrabámos en dos estudios previos (Herrada Valverde, Cobo y Herrada, 2008; Herrada Valverde y Quintero, 2011), refleja un problema al que han hecho referencia autores como Wade-Stein y Kintsch (2004); y es que, a pesar de que es más que conocido el gran potencial del resumen (y de otras técnicas como el mapa conceptual o la extracción de ideas clave) para mejorar el aprendizaje del alumnado, desafortunadamente la enseñanza-aprendizaje de esta tarea se descuida a lo largo de la formación académica: "Summarization clearly has a great deal of potential for improving students' learning and writing. Hence, it is unfortunate that is largely neglected throughout children's academic training" (p.7). De hecho, según estos autores, un gran número de estudios han documentado que algunas de las debilidades que presentan los alumnos de niveles educativos inferiores a la hora de realizar tareas de resumen, persisten hasta la etapa universitaria; entre otras razones, porque los profesores asumen que los estudiantes adquirirán esa habilidad por su cuenta.

\subsubsection{A nivel metodológico (validez interna y externa)}

En esta investigación realizamos observaciones múltiples para sustituir el control experimental y tuvimos en cuenta un conjunto de variables de control, con el fin de minimizar los efectos de las fuentes de validez interna, tales como la selección muestral, historia intersensorial, maduración y regresión hacia la media. Pero sin duda, el principal riesgo para la validez interna de nuestro estudio es, al mismo tiempo, su principal virtud: 
el arduo proceso de análisis realizado por los investigadores para validar los instrumentos de evaluación, y evaluar el nivel desempeño de los alumnos en las diferentes tareas que realizaron (véanse los análisis realizados en los Anexos).

Admitimos que si hubiéramos utilizado el software del Latent Semantic Analysis $(\mathrm{LSA})^{26}$ para llevar a cabo todos estos análisis, habríamos dispuesto una medida de análisis más estándar, y habríamos agilizado enormemente todo el proceso. Sin embargo, las dificultades que encontramos para localizar este tipo de software, y sobre todo, la convicción de que un análisis realizado por los propios investigadores, siempre que estuviera apoyado por un marco teórico fuerte, daría mayor riqueza a la hora de interpretar los resultados y de establecer las conclusiones; nos llevó a obviar el LSA.

En cuanto a la validez externa, el estudio está dirigido a unos alumnos de una universidad concreta (la de Salamanca) que comenzaban o habían finalizado una carrera en particular (titulaciones de Maestro); por lo que, más allá del propio contexto en el que se llevó a cabo, no se pueden generalizar los resultados a otras universidades, ni otras carreras dentro de la misma universidad.

\subsection{PROSPECTIVA}

Partiendo de las conclusiones que hemos extraído de nuestra investigación, pensamos que podrían abrise varias líneas de trabajo y estudio.

Consideramos imprescindible la formación del profesorado, tanto en la etapa formativa inicial (los Grados de Maestro) como en el ejercicio de su profesión (formación permanente), para el uso de técnicas como el resumen, el mapa conceptual y la extracción de ideas clave, que, como hemos visto, mejoran la comprensión y favorecen la metacomprensión de textos. En este sentido, sería necesario:

- El desarrollo de programas para la formación del profesorado de Educación Primaria y Secundaria, que permitan a los docentes, por un lado, aprender a usar estratégicamente los aspectos estructurales del texto para extraer la macroestructura, y por otro lado, enseñar a su alumnado el potencial de técnicas, entre las que destacamos, el resumen o el mapa conceptual para la mejora de la comprensión lectora.

\footnotetext{
${ }^{26}$ Landauer y Dumais $(1994,1996)$ y Landauer, Foltz, Laham (1998), utilizado en trabajos como Kintsch, E., Caccamise, D., Franzke, M., Johnson, N. y Dooley, S. (2007). Summary Street®: Computer-guided summary writing. En T. K. Landauer, D. M., McNamara, S. Dennis, \& W. Kintsch (Eds.), Latent Semantic Analysis (pp. 263-277). Mahwah, NJ: Erlbaum.
} 
- El desarrollo de programas para la capacitación del alumnado de los Grados de Maestro que favorezcan que los futuros docentes aprendan a utilizar dichas técnicas con el fin de que:

- su proceso de aprendizaje durante esta etapa universitaria esté menos ligado a lo memorístico y más a la construcción de conocimiento;

- cuando comience a trabajar en un centro educativo enseñe dichas técnicas a sus alumnos.

También sería interesante realizar un estudio similar al nuestro, bien en otras titulaciones de la Universidad de Salamanca, o bien en la misma carrera en otras Universidades españolas, para comprobar si los resultados obtenidos en nuestra investigación son generalizables o no a otros contextos. Y en el caso de que lo sean abordar este tipo de formación al inicio de sus carreras universitarias, con el fin de enseñarles, desde el principio, a construir conocimiento a partir de la lectura de textos académicos, poniendo así fin al aprendizaje meramente memorístico y a los trabajos tipo "collage" que habitualmente se realizan.

Para finalizar, cabría la posibilidad de reproducir nuestra investigación, utilizando el software Latent Semantic Analysis, con el fin de observar el grado de similitud de los resultados obtenidos ese estudio con respecto a los nuestros.

\subsection{PUBLICACIONES VINCULADAS A LA TESIS DOCTORAL}

\subsubsection{Artículos en revistas científicas}

Herrada Valverde, G., Cobo, C. y Herrada, R, I. (2008). Querer acabar antes de comenzar: Las prisas por llegar al resultado. Enseñanza \& Teaching, 26, 165185. ISSN: 0212-5374

Herrada, R.I. y Herrada Valverde, G. (2011). Adaptación de los estudios de magisterio al EEES: las TIC en los nuevos planes de estudio. Edutec- E: Revista Electrónica de Tecnología Educativa, 36. ISSN: 1135-9250.

Herrada, R.I. y Herrada Valverde, G. (2012). El fin de las diplomaturas de Magisterio: Motivaciones, dificultad y satisfacción con la formación de sus últimos alumnos. Tendencias Pedagógicas, 19, 175-188. ISSN:1989-8614. 


\subsubsection{Contribuciones a congresos}

Herrada Valverde, G. y Quintero, A. (2011). Habilidades básicas implicadas en la construcción del conocimiento en los alumnos universitarios a través de textos hipervinculados. Presentado en XIX Jornadas Universitarias de Tecnología Educativa. Sevilla, 17-18 Noviembre. 


\section{REFERENCIAS BIBLIOGRÁFICAS}

Afflerbach, P. (1986).The influence of prior knowledge on expert readers' importance assignment processes. En J.A. Niles (Ed.), Solving problems in literacy: learners, teachers, and researchers (pp. 30-40). Chicago: National Reading Conference.

Afflerbach, P., Pearson, P. D., \& Paris, S. G. (2008). Clarifying differences between reading skills and reading strategies. The Reading Teacher, 61 (5), 364-373.

Ainley, M., Hidi, S., \& Berndorff, D. (2002). Interest, learning, and the psychological processes that mediate their relationship. Journal of Educational Psychology, 94, 545-561.

Alonso Tapia, J., Carriedo, N., \& Mateos, M. (1992). Evaluación de la supervisión y regulación de la comprensión. La Batería SURCO. En J. Alonso Tapia, N. Carriedo, E. González, F. Gutiérrez \& M. Mateos (Eds.), Leer, comprender y pensar. Nuevas estrategias y técnicas de evaluación (pp. 11-57). Madrid: CIDE

Amadeu, F., \& Salmerón, L. (2014). Concept maps for comprehension and navigation of hypertexts. En D. Ifenthaler \& R. Hanewald (Eds.), Digital knowledge maps in education (pp. 41-59). New York: Springer.

Amadeu, F., Tricot, A., \& Mariné, C. (2009a). Prior knowledge in learning from a nonlinear documents: disorientation and coherence of the reading sequencies. Computers \& Human Behavior, 25, 381-388.

Amadeu, F., Tricot, A., \& Mariné, C. (2009b). Exploratory study of relations between prior knowledge, comprehension, disorientation and on-line processes in hypertext. The Ergonomics Open Journal, 2, 49-57. 
Amadeu, F., Tricot, A., \& Mariné, C. (2010). Interaction between prior knowledge and concept-map structure on hypertext comprehesion, coherence of reading orders and disorientation. Interacting with Computers, 22, 88-97.

Anderson M.C.M., \& Thiede K.W. (2008). Why do delayed summaries improve metacomprehension accuracy? Acta Psychologica, 128, 110-118. doi:10.1016/j.actpsy.2007.10.006 (9/1/2015).

Area, M. (2001). Usos y prácticas con medios y materiales en el contexto escolar: de la cultura impresa a la cultura digital. Kikirikí. Cooperación Educativa, 61, 39-44.

Ausubel, D. (1968). Psicología educativa: Un punto de vista cognoscitivo. México: Trillas.

Baddeley, A. D. (1966a). The influence of acoustic and semantic similarity on long-term memory for word sequences. Quarterly Journal of Experimental Psychology, 18, 302-309.

Baddeley, A. D. (1966b). Short-term memory for word sequences as a function of acoustic, semantic, and formal similarity. Quarterly Journal of Experimental Psychology, 18, 362-365.

Baddeley, A. D. (2003). Working memory and language: an overview. Journal of Communication Disorders, 36, 189-208.

Baddeley, A. D., \& Hitch, G. J. (1974). Working memory. En G. A. Bower (Ed.), Recent advances in learning and motivation (Vol. 8, pp. 47-90). New York: Academic Press.

Baddeley, A. D., \& Logie, R. H. (1999). Working memory: The multiple-component model. En A. Miyake \& P. Shah (Eds.), Models of working memory, (pp. 2861). New York: Cambridge University Press.

Barab, S.A., Bowdish, B.E., Young, M.F., \& Wang, S.V. (1996). Understanding kiosk navigation: Using log files to capture hypermedia searches. Instructional Science, 24, 337-395.

Barab, S.A., Bowdish, B.E., \& Lawless, K.A. (1997). Hypermedia navigation: profiles of hypermedia users. Educational Technology Research \& Development, 45, 23-42. 
Barab, S.A., Young, M.F., \& Wang, S.V. (1999). The effects of navigational and generative activities in hypertext learning on problem solving and comprehension. International Journal of Instructional Media, 26, 283-309.

Bartlett, F.C. (1932). Remembering: A Study in Experimental and Social Psychology. Cambridge: Cambridge University Press.

Beck, I. L., McKeown, M.G., Sinatra, G.M., \& Loxterman, J.A. (1991). Revising social studies text from a text-processing perspective: evidence of improved comprehensibility. Reading Research Quartely, 26, 251-276.

Bereiter, C., \& Scardamalia, M. (1992). Dos modelos explicativos de los procesos de composición escrita. Infancia y Aprendizaje, 58, 43-64.

Block, C. C., \& Pressley, M. (2007). Best practices in teaching comprehension. En L. B. Gambrell, L. M. Morrow \& M. Pressley (Eds.), Best practices in literacy instruction (pp. 220-242). New York: Guilford.

Bovair, S., \& Kieras, D.E. (1985). A guide to propositional analysis for research on tecnical prose. En Britton \& J.B. Black (Eds.), Understanding expository text (pp. 315-362). Hillsdale, NJ: Lea.

Bransford, J.D., \& Johnson, M.K. (1990). Consideraciones sobre algunos problemas de comprensión. En F. Valle, F. Cuetos, J.M. Igoa \& S. del Viso (Eds.), Lecturas de Psicolinguística 1 (pp. 229-263). Madrid: Alianza.

Braten, I., \& Stromso, H.I. (2006a). Effects of personal epistemology on the understanding of multiple texts. Reading Psychology, 27, 457-484.

Braten, I., \& Stromso, H.I. (2006b). Constructing meaning from multiple information sources as a function of personal epistemology: The role of text-processing strategies. Information Design Journal, 14, 56-67.

Britt, M.A., \& Sommer, J. (2004). Facilitating textual integration with macro-structure focusing tasks. Reading Psychology, 25, 313-339.

Brown, A.L., \& Day, J.D. (1983). Macrorules for summarizing texts: The development of expertise. Journal of Verbal Learning and Behaviour, 22, 1-14. 
Brown, J.I., Fishco, V.V., \& Hanna, G. (1993). Nelson-Denny reading test. Chicago: Riverside publishing company.

Buendía, L., Colas, P., \& Hernández Pina, F. (1998). Métodos de investigación en Psicopedagogía. Madrid: McGraw Hill.

Cabero Almerana, J., \& Barroso, J. (2013). La utilización del juicio de experto para la elaboración de TIC: el coeficiente de competencia experta. Bordón, 65 (2), 2538.

Calisir, F., Eryazici, M., \& Lehto, M.R. (2008). The effects of text structure and prior knowledge of the reader on computer-based learning. Computers in Human Behavior, 24 (2), 439-450.

Calisir, F., \& Gurel, Z. (2003). Influence of text structure and prior knowledge of the learner on reading comprehension, browsing and perceived control. Computers in Human Behavior, 19 (2), 135-145.

Campbell, D., \& Stanley, J. (1967). Experimental and cuasiexperimental desings for research. Chicago: Rand McNally.

Campbell, D., \& Stanley, J. (1978). Diseño experimental y cuasiexperimentales en la investigación social. Buenos Aires: Amorrortu.

Cerdán, R., \& Vidal-Abarca, E. (2008). The effects of tasks on integrating information from multiple documents. Journal of Educational Psychology, 100, 209-222.

Cerdán, R., Vidal-Abarca, E., Martínez; T., Gilabert, R., \& Gil, L. (2009). Impact of question-answering tasks on search processes and reading comprehension. Learning and Instruction, 19, 13-27.

Cerdán, R., Vidal-Abarca, E., Salmerón, L., Martínez, T., \& Gilabert, R. (2009). Read\&Answer, a tool to capture on-line processing of texts. The Ergonomics Open Journal, 2, 133-140.

Cerdán, R., Gil., L., \& Vidal-Abarca, E. (2011). Question-driven processing in single and multiple texts. En M.T. McCrudden, J. P. Magliano, \& G. Schraw (Eds.), Relevance instructions and goal-focusing in text learning (pp. 295-319). Greenwich, CT: Information Age Publishing. 
Chi, M.T.H (1978). Knowledge structures and memory development. En R. Siegler (Ed.), Children's thinking: What develops? (pp. 73-96). Hillsdale, NJ: Erlbaum.

Chi, M.T.H, Feltovich, P.J., \& Glaser, R. (1981). Categorization and representation of physics problems by experts and novices. Cognitive Science, 5, 121-52.

Chomsky, N. (1965). Aspects of the theory of sintax. Cambridge: The M.I.T. Press.

Chomsky, N. (1972). Studies on semantics in generative grammar. The Hague: Mouton Publishers.

Codina, L. (1998). H de hypertext, o la teoría de los hipertexto revisada. Cuadernos de Documentación Multimedia, 6-7. Recuperado de:

\section{http://www.ucm.es/info/multidoc/multidloc/revista//cuad6-7/codina.htm}

$(6 / 10 / 2014)$

Codina, L. (2000). El libro digital y la www. Madrid: Tauro Ediciones.

Codina, L. (2001). El diseño de la navegación en hipertexto informativos. Temes de Disseny, 18, 39-48.

Codina, L., \& Rovira, C. (2001). Diseño hipertextual basado en la evidencia: nuevos resultados del proyecto de documentación digital de la Universidad Pompeu Fabra de Barcelona. Revista Española de Documentación Científica, 1,85-89.

Daneman, M., \& Hannon, B. (2001). Using working memory theory to investigate the construct validity of multiple-choice reading comprehension tests such as the SAT. Journal of Experimental Psychology: General, 130, 208-223.

Dee-Lucas, D., \& Larkin, J.H. (1995). Learning from electronic texts: effects of interactive overviews for information Access. Cognition and Instruction, 13, 431-468.

De Vega, M., Carreiras, M., Guitiérrez-Calvo, M., \& Alonso-Quecuty, M.L. (1990). Lectura y comprensión. Una perspectiva cognitiva. Madrid: Alianza Psicología.

De Stefano, D., \& Le Fevre, J.A. (2007). Cognitive load in hypertext reading: A review. Computers in Human Behavior, 23, 1616-1641. 
Dochy, F., Segers, M., \& Buehl, M. (1999). The Relation Between Assessment Practices and Outcomes of Studies: The Case of Research on Prior knowledge. Review of Educational Research, 69 (2), 147-188.

De Jong, T., \& Van der Hulst, A. (2002). The effects of graphical overiews on knowledge acquisition in hypertext. Journal of Computer Assisted Learning, 18 (2), 219-231.

Escoriza, J. (2003). Evaluación del conocimiento de las estrategias de comprensión lectora. Barcelona: Ediciones Universidad de Barcelona.

Escoriza, J. (2006). Estrategias de comprensión del discurso escrito expositivo. Evaluación e intervención. Barcelona: Ediciones Universidad de Barcelona.

Eveland, W. P., Cortese, J., Park, H., \& Dunwoody, S. (2004). How Web site organization influences s free recall, factual knowledge, and knowledge structure density. Human Communication Research, 30 (2), 208-233.

Ferretti, T., Kutas, M., \& McRae, K. (2007). Verb aspect and the activation of event knowledge. Journal of Experimental Psychology: Learning, Memory, and Cognition, 33, 182-196.

Ferretti, T., Rohde, H., Kehler, A., \& Crutchley, M. (2009). Verb aspect, event structure, and coreferential processing. Journal of Memory and Language, 61, 191-205.

Flower, L. (1990). The rol of task representation in reading-to-write. En L. Flower, V. Stein, J. Ackerman, P.Kanz, K. McCormick \& V. Peck, Reading to write: Exploring a cognitive and social process (pp. 35-75). New York: Oxford University Press.

Flower, L. (1993). Problem solving strategies for writing. Orlando: Hanrcourt Brave Jovanovich, Inc.

Flower, L., \& Hayes, J.R. (1980). The dynamics composing. Making plans and juggling constrints. En L.W. Gregg \& E.R. Steinberg (Eds.), Cognitive processes in writing. Interdisciplinary symposium on cognitive processe in writing (31-50). Hillsdale, NJ: Erlbaum.

Flower, L., \& Hayes, J.R. (1981). A cognitive process theory of writing. College Composition and Communication, 32 (4), 365-387. 
Foltz, P.W. (1996). Comprehension, Coherence and Strategies in Hpyertext and Linear text. En J.F. Rouet, J.J. Levonen, A.P. Dillon \& Spiro, R.J. (Eds.), Hypertext and Cognition (pp. 109-136). Hillsdale, NJ: Erlbaum.

García Madruga, J. A., Martín Cordero, J. I., Luque, J. L. y Santamaría, C. (1995). Comprensión y adquisición de conocimientos a partir de textos. Madrid: Siglo XXI.

García Madruga, J. A., Gómez, I., \& Carriedo, N. (2002). El desarrollo de la comprensión lectora. En F. Gutierrez; J. A. Garcia Madruga \& N. Carriedo (Eds.), Psicología Evolutiva II. Desarrollo cognitivo y lingüístico (Vol 2, pp.200-237). Madrid: UNED.

Gatti, A. (2008). Comprensión de textos y aprendizaje en la formación universitaria. Recuperado de:

http://e-spacio.uned.es/fez/view.php?pid=tesisuned:PsicologiaPsicoevolyedu-Aegatti (7/3/2013)

Gentner D., \& Gentner D.R. (1983). Flowing waters or teeming crowds: Mental models of electricity. En D. Gentner \& A.L. Stevens (Eds.), Mental Models (pp. 99129). Hillsdale, NJ: Erlbaum.

Gil, L.,Vidal-Abarca, E., \& Martínez, T. (2008). Eficacia de tomar notas para integrar información de varios textos. Infancia y Aprendizaje, 31, 259-272.

Gilabert, R., Martínez, G., \& Vidal-Abarca, E. (2009). Some good texts are always better: text revision to foster inferences of readers with high and low prior background knowledge. Learning and Instruction, 15, 45-68.

Givón, T. (1995). Coherence in the text and coherence in the mind. En M.A. Gernsbacher y T. Givón (Eds.), Coherence in spontaneous text (pp. 59-115). Amsterdam: Benjamins.

Goodman, K.S. (1967). Reading: A psycholinguistic guessing game. Journal of the Reading Specialist, 6 (1), 126-135.

Goodman, K.S. (1971). Psycholinguistic universals in the reading process. En P. Pimsleur \& T.Quinn (Eds.), The psychology of second language reading, (pp. 135-142). Cambridge: Cambridge University Press. 
Gough, P.B. (1972). One second of reading. En J.F. Kavanagh \& I.G. Mattingly (Eds.), Language by ear and by eye: The relationships between speech and reading (pp. 331-358). Cambridge: MIT Press.

Gough, P.B. (1985). One second of reading: Postscript. En H. Singer \& R.B. Ruddell (Eds.), Theoretical models and processes of reading (pp. 687-688). Newark: International Reading Association.

Gough, P.B. (1991). The complexity of reading. En R. Hofman \& D.S. Palermo (Eds.), Cognition and the simbolic procceses: Applied and ecological perspectives (pp. 141-149). Hillsdale, NJ: Erlbaum.

Graesser, A.C., Hoffman, N.L., \& Clark L.F. (1980). Structural components of reading time. Journal of Verbal Learning Behavior, 19, 135-151.

Graesser, A.C., McNamara, D.S., \& Louwerse, M.M. (2003). What do readers need to learn in orden to process coherence relations in narrative and expository text? En A. Sweet \& C.E. Snow (Eds.), Rethinking reading comprehension (pp. 82-98). New York: Guilford.

Graesser, A.C., McNamara, D.S., Louwerse, M.M., \& Cai, Z. (2004). Coh-metrix: Analysis of text of cohesion and language. Behavior research methods, instruments, and computers, 36 (2), 193-202.

Graham, S. y Hebert, M. (2010). Writing to read: Evidence for how writing can improve reading. A Carnegie Corporation Time to Act Report. Washington, DC: Alliance for Excellent Education.

Grellet, F. (1981). Developing Reading Skills. Cambridge: Cambridge University Press.

Habertlandt, K.T., Beria, C., \& Sandson, J. (1980). The episode schema in story procecessing. Journal of Verbal Learning Behavior, 19, 635-650.

Halliday, M.A.K. (1961). Categories of the Theory of Grammar. Word, 17(3), 241-292.

Halliday, M.A.K. (1970). Language Structure and Language Function. En J. Lyons (Ed.), New Horizons in Linguistics (140-165). London: Penguin.

Hare, V.C., \& Borcharst, K.M. (1984). Direct instruction of summarizations skills. Reading Research Quarterly, 20, 62-78. 
Hedgcock, J., \& Ferris, D. (2009). Teaching readers of English: Students, texts, and contexts. New York, NY: Routledge/Taylor \& Francis.

Hernández, A. (1999). Enseñanza de estrategias de comprensión lectora y expresión escrita con alumnos de E.S.O. (Tesis doctoral inédita). Universidad de Salamanca, Salamanca.

Hernández, A., \& Quintero, A. (2001). Comprensión y composición escrita: estrategias de aprendizaje. Aplicación en el aula. Madrid: Síntesis.

Hernández, A., \& Quintero, A. (2002). Composición escrita: proceso de enseñanza. Revista de Educación, 329, 421-442.

Herrada Valverde, G., Cobo, C y Herrada, R, I. (2008). Querer acabar antes de comenzar: Las prisas por llegar al resultado. Enseñanza \& Teaching Vol 26, 165185.

Herrada Valverde, G. y Quintero, A. (2011). Habilidades básicas implicadas en la construcción del conocimiento en los alumnos universitarios a través de textos hipervinculados. Presentado en XIX Jornadas Universitarias de Tecnología Educativa. Sevilla, 17-18 Noviembre.

Herrada, R.I. y Herrada Valverde, G. (2011). Adaptación de los estudios de magisterio al EEES: las TIC en los nuevos planes de estudio. Edutec- E: Revista electrónica de tecnología educativa, 36. Recuperado de:

http://edutec.rediris.es/Revelec2/Revelec36/pdf/Edutece_n36_Herrada_Herrada.pdff (20-06-2015).

Herrada, R.I. y Herrada Valverde, G. (2012). El fin de las diplomaturas de Magisterio: Motivaciones, dificultad y satisfacción con la formación de sus últimos alumnos. Tendencias pedagógicas, 19, 175-188. Recuperado de: http://www.tendenciaspedagogicas.com/revista monografico.asp? numero= $\underline{19}(20-06-2015)$.

Hirvela, A., \& Du, Q. (2013). Why am I paraphrasing: Undergraduate ESL writers' engagement with source-based academic writing and reading. Journal of English for Academic Purposes, 12, 87-98. 
Hofman, R., \& Van Oostendorp, H. (1999). Cognitive effects of a structural overview in a hypertext. British Journal of Educational Technology, 30 (2), 129-140.

Howard, R.M. (1995). Plagiarism, authorships, and the academic death penalty. College English, 57, 788-806.

Howard, R.M. (1999). Standing in the shadow of giants. Stamford, CT: Ablex.

Hunt, E.B. (1978). Mechanic of verbal ability. Psychological Review, 85 (5), 109-130.

Iriarte, F (2004). Influencia de diferentes tipos de hipertextos en la comprensión lectora. (Tesis doctoral inédita). Universidad de Salamanca, Salamanca.

Iza, M., \& Ezquerro, J. (1999). Representación conexionista y procesamiento del discurso. Anales de Psicología, 15 (2), 303-318.

Jáñez, A. (2014). Efectos de las instrucciones de lectura sobre la comprensión y navegación de hipertextos en sujetos con bajo conocimiento de dominio. (Tesis doctoral inédita). Universidad de Salamanca, Salamanca.

Johnson-Laird, P.N. (1983). Mental models: Towards a cognitive science of language, inference, and consciousness. Cambridge, MA: Harvard University Press.

Johnson-Laird, P.N. (2010a). Mental models and language. En P.C. Hogan (Ed.), Encyclopedia of language sciencies (479-481). Cambridge: Cambridge University Press.

Johnson-Laird, P. N. (2010b). Mental models and human reasoning. Proceedings of the National Academy of Sciences, 107 (43), 18243-18250.

Johnson-Laird, P.N (2012). Inference in mental models. En K.J. Holyoak \& R.G. Morrison (Eds.), The Oxford handbook of thinking and reasoning (134-154). New York: Oxford University press.

Just, M.A., \& Carpenter, P. A. (1980). A theory of reading: from eye fixation to comprehension. Psychological Review, 87, 329-354

Just, M.A., \& Carpenter, P. A. (1984). Using eye fixations to study reading comprehension. En D.E. Kieras y M.A. Just (Eds.), New methods in reading comprehension (pp. 151-182). Hillsdale, N.J: LEA 
Juvina, I., \& Van Oostendorp, H. (2008). Modeling Semantic and Structural Knowledge in Web Navigation. Discourse Processes, 45(4-5), 346-364.

Kalyuga, S. (2007). Expertise reversal effect and its implications for learner-tailored instruction. Educational Psychology Review, 19, 509-539.

Kalyuga, S. (2013). Effects of learner prior knowledge and working memory limitations on multimedia learning. Procedia- Social and Behavioral Sciencies, 83, 25-29.

Kendeou, P., \& Van den Broek, P. (2005). The effects of readers' misconceptions on comprehension of scientific text. Journal of Educational Psychology, 97, 235245.

Kendeou, P., \& Van den Broek, P. (2007). Interactions between prior knowledge and text structure during comprehension of scientific texts. Memory \& Cognition, 35, 1567-1577.

Kintsch, E. (1990). Macroprocesses and microprocesses in development of summarization skill. Cognition and Instruction, 7, 161-195.

Kintsch, E., Caccamise, D., Franzke, M., Johnson, N., \& Dooley, S. (2007). Summary Street ${ }^{\circledR}$ : Computer-guided summary writing. En T. K. Landauer, D. M., McNamara, S. Dennis \& W. Kintsch (Eds.), Latent semantic analysis (pp. 263277). Mahwah, NJ: Erlbaum.

Kintsch, W. (1972). Notes on the structure of semantic memory. En E. Tulving \& W. Donaldson (Eds.), Organization of memory (pp. 249-308). New York: Academic Press.

Kintsch, W. (1974). The representation of meaning in memory. Hillsdale, NJ: Erlbaum.

Kintsch, W. (1977). Memory and cognition. New York: Wiley.

Kintsch, W. (1988). The role of knowledge in discourse comprehension: a constructionintegration model. Psychological Review, 95 (2), 163-183.

Kintsch, W (1992). How readers construct situation models for stories: The rol of syntantic cues and causal inferences. En A.F. Healy, S.M. Kosslyn \& R.M. Shiffrin (Eds.), From learning processes: Essays in honor of William K. Estes (Vol 2, pp. 261-278). Hillsdale, NJ: Erlbaum. 
Kintsch, W. (1994). Text comprehension, memory, and learning. American Psychologist, 49 (4), 294-303.

Kintsch, W. (1995). How readers construct situation models for stories: the role of syntactic cues and causal inferences. En M.A. Gernsbacher \& T. Givon (Eds.), Coherence in spontaneous text (pp.139-160). Amsterdam: Benjamins.

Kintsch, W. (1998). Comprehension: A paradigm for cognition. New York: Cambridge University Press.

Kintsch, W. (2001). Predication. Cognitive Science 25, 173-202

Kintsch, W. (2002). On the notions of theme and topic in psychological process models of text comprehension. En M. Lowerse \& W. Van Peer (Eds.), Thematics: interdiciplinary studies (pp 157-170). Amsterdam: Benjamins.

Kintsch, W. (2004). The construction-integration model of text comprehension and its implications for instruction. En R.B. Rudell \& N. Unrau (Eds.), Theoretical models and processes of reading (pp 1270-1328). Newark: International reading association.

Kintsch, W. y Greeno, J. (1985).Understanding and solving word arithmetic problems. Psychological Review, 92 (1), 109- 129.

Kintsch, W. y Keenan, J.M. (1973). Reading rate and retention as a function of the number of propositions in the base structure of sentenses. Cognitive Psychology, $5,257-274$.

Kintsch, W., \& Van Dijk, T.A. (1978). Toward a model of text comprehension and production. Psychological Review, 85 (5), 363-394.

Kintsch, W., \& Welsch, D. (1991). The construction integration model. A framework for studying memory for text. En W.E. Hocley \& S. Lewandowsky (Eds.), Relating theory and data: Essays in human memory in honor of Bennet B. Murdock (pp 367-385). Hillsdale, NJ: Erlbaum

Kissner, E. (2006). Summarizing, paraphrasing and retelling: skills for a better reading, writing and test taking. Poshmouth, $\mathrm{NH}$ : Heinemann. 
Laberge, D., \& Samuels, J. (1974). Towards a theory of automatic information processing in reading. Cognitive Psychology, 6, 293-323.

Landau, G.P. (2006). Hypertext 3.0. Critical theory and new media in an era of Globalitation. Maryland: The John Hopkins University Press.

Landauer, T.K. \& Dumais, S.T. (1994). Latent semantic analysis and the measurement of knowledge. En R. M. Kaplan \& J. C. Burstein (Eds), Educational testing service conference on natural language processing techniques and technology in assessment and education. Princeton, NJ: Educational testing service.

Landauer, T. K., \& Dumais, S. T. (1996). How come you know so much? From practical problems to new memory theory. En D. J. Hermann, C. McEvoy, C. Hertzog, P. Hertel \& M. K. Johnson (Eds.), Basic and applied memory research: Vol. 1. Theory in context (pp. 105-126). Mahwah, N.J: Erlbaum.

Landauer, T. K., Foltz, P. W., \& Laham, D. (1998). Introduction to latent semantic analysis. Discourse Processes, 25, 259-284.

LaTorre, A., Del Rincón, D., \& Arnal, J. (1996). Bases metodológicas de la investigación educativa. Barcelona: GR92.

Lawless, K.A., Brown, S.W., Mills, R., \& Mayall, H.J. (2003). Knowledge, interest, recall and navigation: A look at hypertext processing. Journal of Literacy Research, 35, 911-934.

Lawless, K.A., \& Kulikowich, J.M. (1998). Domain knowledge, interest, and hypertext navigation: a study of individual differences. Journal of Research on Computing in Education, 34, 274-284.

Lawless, K.A., Mills, R., \& Brown, S.W. (2002). Children’s hypermedia navigational strategies. Journal of Research on Computing in Education, 34, 274-284.

Le Bigot, L., \& Rouet, J.F. (2007). The impact of presentation format, task assignment, and prior knowledge on students' comprehension of multiple online documents. Journal of Literacy Research, 39 (4), 445- 470.

Leopold, C., \& Leutner, D. (2012). Science text comprenhension: Drawing, main idea selection, and summarizing as learning strategies. Learning and Instruction, 22, 16-26. 
Leopold, C., Sumfleth, E., \& Leutner, D. (2013). Learning with summaries: Effects of representation mode and type of learing activity on comprehension and transfer. Learning and Instruction, 27, 40-49.

Lin, D.M. (2003a). Hypertext for the aged: Effects of text topologies. Computers in Human Behavior, 19, 201-209.

Lin, D.M. (2003b). Age differences in the performance of hypertext perusal as a function of text topology. Behaviour \& Information Technology, 22 (4), 219-226.

Louwerse, M.M. (2004). Un modelo conciso de cohesión en el texto y coherencia en la comprensión, Revista Signos, 37 (56), 41-58. Recuperado de: http://dx.doi.org/10.4067/S0718-09342004005600004 (10/4/2013)

Louwerse, M.M., \& Graesser A.C. (2005). Coherence in discourse. En P. Strazny (Ed.), Encyclophedia of linguistics (pp. 216-218). Chicago: Fitzroy Dearborn.

Madden, C. J., \& Zwaan, R. A. (2003). How does verb aspect constrain event representations? Memory and Cognition, 31(5), 663-672.

Madler, J.M., \& Johnson, N.S. (1977). Remembrance of things parsed: Story structure and recall. Cognitive Psychology, 9, 111-151.

Madrid, R.I. (2010). Hacia un modelo de comprensión del hipertexto: el papel de las estrategias de lectura y la carga cognitiva. Recuperado de: http://digibug.ugr.es/bitstream/10481/5584/1/18811255.pdf $\underline{(8 / 3 / 2013)}$

Madrid, R.I., \& Cañas, J. (2009). The effect of reading strategies and prior knowledge on cognitive load and learning with hypertext. The Ergonomics Open Journal, 2, 124-132.

Madrid, R.I., Van Oostendorp, H., \& Puerta, M.C. (2009). The effects of the number of links and navigation support on cognitive load and learning with hypertext: The mediating role of reading order, Computers in Human Behavior, 25, 66-75

Magliano, J., \& Schliech, M. C. (2000). Verb aspect and situation models. Discourse Processes, 29 (2), 83-112.

Mohageg, M.F. (1992). The influence of hypertext linking structures on the efficiency of information retrieval. Human Factors 34 (3), 351-367. 
Mandin, S., Lemaire, B., \& Dessus, P. (2007). Modeling summarization assessment strategies with LSA. En F. Wild, M. Kalz, J. van Bruggen \& R. Koper (Eds.), First European workshop on latent semantic analysis in technology enhanced learning (pp.20-21). Heerlen: Open University of Netherlands.

Mann, W. C., \& Thompson, S. A. (1986). Relational propositions in discourse. Discourse Processes, 9, 57-90.

Mann, W. C., \& Thompson, S. A. (1988). Rhetorical structure theory: Toward a functional theory of text organization. Text, 8 (3), 243-281.

Mayer, R. E. (2001). Multimedia learning. New York: Cambridge University Press.

Mayer, R.E. (2005). Cognitive Theory of multimedia learning. En R.E. Mayer (Ed.), The Cambridge handbook of multimedia learning (pp. 31-48). New York: Cambridge University Press.

Mayer, R. E. (2014). Cognitive Theory of multimedia learning. En R.E. Mayer (Ed.), The Cambridge handbook of multimedia learning (pp. 43-71). New York: Cambridge University Press.

McClelland, J. L. (1979). On the time relations of mental processes: An examination of systems of processes in cascade. Psychological Review, 86, 287-330

McClelland, J. L. (1987). The case for interactionism in language processing. En M. Coltheart (Ed.), Attention and performance XII: The psychology of reading (pp. 1-36). London: Erlbaum.

McCrudden, M.T., \& Schraw, G. (2007). Relevance and goal-focusing in text processing. Educational Psychology Review, 19 (2), 113-139.

McDonald, S., \& Stevenson, R.J. (1996). Disorientation in hypertext: The effects of three text structures on navigation performance. Applied Ergonomics, 27, 61-68.

McDonald, S., \& Stevenson, R.J. (1999). Navigation in hyperspace: An evaluation of the effects of navigational tools and subject matter expertise on browsing and information retrieval in hypertext. Interacting with Computers, 10, 129-142. 
McNamara, D.S. (2001). Reading both high-coherence and low-coherence texts: Effects of text sequence and prior knowledge. Canadian Journal of Experimental Psychology, 55, 51-62.

McNamara, D.S. (2004). SERT: Self-explanation reading training. Discourse Processes, $38,1-30$.

McNamara, D.S., Cai, Z., \& Louwerse, M.M. (2013). Optimizing LSA measures of cohesion. En T.K. Laudamer, D.S. McNamara, S. Dennis \& W. Kintsch (Eds), Handbook of Latent Semantic Analysis (pp 379-400). New York: Taylor and Francis.

McNamara, D.S., \& Kintsch, W. (1996). Learning from texts: Effects of prior knowlege and text coherence. Discourse Processes, 22 (3), 247-288.

McNamara, D.S., Kintsch, E., Songer, N.B., \& Kintsch, W. (1996). Are good texts always better? Interactions of text coherence, background knowledge, and levels of understanding in learning from text. Cognition and Instruction, 14, 1- 43.

McNamara, D.S., \& Magliano, J.P. (2009). Towards a comprehensive model of comprehension. En B. Ross (Ed.), The psychology of learning and motivation, (Vol 51, pp.297-284). New York: Elservier Sciencie.

McNamara, D. S., Ozuru, Y., Best, R., \& O’Reilly, T. (2007). The 4-Pronged Comprehension Strategy Framework. En D. S. McNamara (Ed.), Reading comprehension strategies: Theories, interventions, and technologies (pp. 465496). Mahwah, NJ: Erlbaum.

Means, M. y Voss, J. (1985). Stars Wars: A developmental study of expert and novice knowledge structures. Journal of Memory and Language, 24 (6), 746-757.

Meyer, B. (1975). The organization of prose and its effects on memory. Amsterdam: North- Holland.

Meyer, B. J. F. (1984). Text dimensions and cognitive processing. En H. Mandl, N. Stein \& T. Trabasso (Eds.), Learning and comprehension of text (pp. 3-47). Hillsdle, NJ: Erlbaum. 
Meyer, B.J.F. (1985). Prose analysis: purposes, procedures and problems. En B. K. Britton \& J. Black (Eds.), Analyzing and understanding expository text (pp. 1164). Hillsdale, NJ: Erlbaum.

Meyer, B.J.F.; Young, C.J., \& Barttle, B. (1989). Memory improved: reading and memory enhancement across the life span through strategic text structures. Hillsdle, NJ: Erlbaum.

Meyer, B.J.F., \& Ray, M.N. (2011). Structure strategy interventions: Increasing reading comprehension of expository text, International Electronic Journal of Elementary Education, 4 (1), 127-152.

Miikkulainen, R., \& Dyer, M.G. (1989). Encoding input/output representations in connectionist cognitive systems. En D.S. Touretzky, G.E. Hinton \& T.J. Sjenowski (Eds.), Proceedings of the 1988 Connectionist models summer school. Los Altos, CA: Morgan-Kaufmann.

Miikkulainen , R. \& Dyer, M.G. (1991). Natural language processing with modular PDP networks and distributed lexicon. Cognitive Science, 15, 343-399.

Minsky, M. (1975). A framework for representing knowledge. En J. Haugeland (Ed.), Mind Desing (pp 95-128). Cambridge, England: The M.I.T. Press.

Mulcahy-Ernt, P.I., \& Carverly, D.C. (2009). Strategic study reading. En R.F. Flippo y D.C. Caverly (Eds.), Handbook of college reading and study strategy research, (177-198). New York: Routledge.

Muller-Kalthoff, T., \& Muller, J. (2003). The effects of graphical overviews, prior knowledge and self-concept on hypertext disorientation and learning achievement. Journal of Educational Multimedia and Hypermedia, 12 (2), 117 134.

National Reading Panel (2000). Teaching children to read: An evidence-based assessment of the scientific literature on reading and its implications for reading instruction. Reports of the subgroups. Recuperado de: http://www.nichd.nih.gov/publications/pubs/nrp/documents/report.pdff $\underline{(17 / 9 / 2014)}$ 
Nielsen, J. (1995). Multimedia and hypertext: the Internet and beyond. Boston: Academic Press.

Nielsen, J. (1996). Multimedia and hypertext: Internet and beyond. New York: Academic Press.

Nielsen, J. (2004). Guidelines for visualizing links. Jakob Nielsen's Alertbox, May 10. Recuperado de: http://www.nngroup.com/articles/guidelines-for-visualizinglinks/ (06/05/2015).

Nielsen, J. (2012). Usability 101: Introduction to usability. Jakob Nielsen's Alertbox, January 4. Recuperado de: http://www.nngroup.com/articles/usability-101introduction-to-usability/ (06/05/2015).

Nilsson, R.M., \& Mayer, R.E. (2002). The effects of graphic organizers giving cues to the structure of a hypertext document on users' navigation strategies and performance. International Journal of Human-Computer Studies, 57, 1-26.

Nist, S.L., \& Simpson, M.L. (2000). College studying. En M Kamil, P. Mosenthal \& P.D. Pearson (Eds.), Handbook of reading research (pp.645-666). Mahwah, NJ: Erlbaum.

Novak, J.D. (1972). Audio-tutorial techniques for individualized science instruction in the elementary school. En H. Triezenberg (Ed.), Individualized science: like it is (pp 14-30). Washsington, DC: National Science teaching association.

Novak J. D. (2010). Learning, creating and using knowledge: concepts maps as facilitative tools in schools and corporations. Journal of E-learning and Knowledge Society, 6 (3), 21-30.

Novak J. D., \& Cañas A. J. (2006). The theory underlying concept maps and how to construct them. Pensacola, FL: Institute for Human and Machine Cognition

Novak J. D. \& Musonda D. (1991). A twelve-year longitudinal study of science concept learning. American Educational Research Journal, 28(1), 117-153.

Oakhill, J. V., Cain, K., \& Bryant, P. E. (2003). The dissociation of single-word reading and text comprehension: Evidence from component skills. Language and Cognitive Processes, 18, 443- 468. 
OCDE (2012). Programa para la evaluación internacional de los alumnos: informe español. Madrid: Ministerio de Educación, Cultura y Deporte. Recuperado de http://www.mecd.gob.es/inee/Ultimos_informes/PISA-2012-resolucion-deproblemas.html $(17 / 1 / 2014)$

OCDE (2013). Programa internacional para la evaluación de las competencias de la población adulta: informe español. Madrid: Ministerio de Educación, Cultura y Deporte. Recuperado de:

http://www.mecd.gob.es/detm/inee/internacional/piaac/piaac2013vol1.pdlf?d ocumentId $=0901 \mathrm{e} 72 \mathrm{~b} 81741 \mathrm{bbc}(17 / 1 / 2014)$

Orrantia, J., Tarín, J., \& Martín, S.V. (2011). El uso de la información situacional en la resolución de problemas aritméticos. Infancia y Aprendizaje, 34 (1), 81-94.

O'Reilly, T., \& McNamara, D.S. (2007). Reversing the reverse cohesion effect: Good texts can be better for strategic high-knowledge readers. Discourse Processes, 43 (2), 121-152.

Ozoru, Y., Dempsey, K., \& McNamara, D.S. (2009). Prior knowledge, reading skill, and text cohesion in the comprehension of science texts. Learning and Instruction, 19 (3), 228-242.

Parush, A., Shwartz, Y., Shtub, A., \& Chandra, M. J. (2005). The impact of visual layout factors on performance in web pages: a cross-language study. Human Factors, 47 (1), 141-157.

Pass, F., \& Sweller, J. (2014). Implications of cognitive load of theory for multimedia learning. En R. E. Mayer (Ed.), The Cambridge handbook of multimedia learning (pp. 27-42). Cambridge: Cambridge University Press.

Pecorari, D. (2003). Good and original: plagiarism and patchwriting in academic second language writing. Journal of Second Language Writing, 12, 317-345.

Pecorari, D. (2008). Academic writing and plagiarism: A linguistic analysis. London: Continuum.

Perfetti, C.A., \& Roth, S.F. (1981). Some of the interactive processesin reading and their role in reading skill. En A.M. Lesgold \& C.A. Perfetti (Eds.), Interactive processes in reading (pp. 269-297). Hillsdale, N.J.: LEA. 
Perfetti, C.A., Rouet, J.F., \& Britt, M.A. (1999). Towards a theory of documents representation. En H. Van Oostendorp \& S.R. Goldman (Eds.), The Construction of mental representations during reading (pp. 99-122). Mahwah, NJ: Lawrence Erlbaum Associates.

Perrig, W., \& Kintsch, W. (1985). Propositional and situational representational of text. Journal of Memory and Language, 24, 503-518.

Petofi, J.S. (1973). Toward an empirically motivated gramatical theory of verbal texts. En J.S. Petofi y Rieser (Eds.), Studies in text grammar (Vol 19, pp. 205-275). Dordrecht-Holland: Springer Netherlands.

Potelle, H., \& Rouet, J.F. (2003). Effects of context representation and readers prior knowledge on the comprehension on hypertext. International Journal of Human Computers Studies, 58 (3), 327-345.

Pressley, M. (2002). Comprehension strategies instruction: A turn-of-the-century status report. En C.C. Block \& M. Pressley (Eds.), Comprehension instruction: Research-based best practices (pp. 11-27). New York: Guilford.

Quintero, A. (1995). Un programa de intervención para la comprensión de textos. Desarrollo de la fase previa. Comunicación, Lenguaje y Educación, 28, 77-90.

Quintero, A. (1998). Aprendiendo a construir el significado de los textos. El tema, la idea principal y global. Cultura y Educación, 11-12, 195-218.

RAND Reading Study group (2002). Reading for understanding: Toward and $R \& D$ program in reading comprehension. Santa Mónica: RAND. Recuperado de: http://www.rand.org/content/dam/rand/pubs/monograph_reports/2005/MR 1465.pdff $(11 / 9 / 2014)$

Ratcliff, R., \& McKoon, G. (1978). Priming in item recognition: Evidence for the propositional structure of sentences. Journal of Verbal Learning and Verbal Behavior, 17, 403-418.

Recht, D. R., \& Leslie, L. (1988). Effect of prior knowledge on good and poor readers' memory of text. Journal of Educational Psychology, 80, 16-20. 
Ribas, V. (2006). El Hipertexto electrónico: un nuevo paradigma para los papeles de autor, lector y texto, Espéculo Revista de estudios literarios, 34. Recuperado de: http://www.ucm.es/info/especulo/numero34/hptxt.html (10/11/2014)

Romance, N. R., \& Vitale, M. R. (2001). Implementing an in-depth expanded science model in elementary schools: Multi-year findings, research issues, and policy implications. International Journal of Science Education, 23, 373-404.

Rosales, J., Orrantia, J., Martín, S.V., \& Chamoso, J.M. (2008). La resolución de problemas artiméticos en el aula: ¿qué hacen los profesores cuando trabajan conjuntamente con sus alumnos? Cultura y Educación: revista de teoría, investigación y práctica, 20 (4), 423-439.

Rouet, J.F. (2003). What was I looking for? The influence of task specificity and prior knowledge on students' search strategies in hypertext. Interacting with Computers, 15, 409-428

Rouet, J.F. (2006). The skills of document use: From text comprehension text to Webbased learning. Mahwah, NJ: Erlbaum.

Rouet, J.F. y Britt, M.A. (2011). Relevance processes in multiple document comprehension. En M.T. McCrudden, J.P. Magliano \& G. Schraw (Eds.), Relevance instruction and goal-focusing in text learning (pp. 19-52). Greenwich, CT: Information age publishing.

Rouet, J.F., \& Vidal-Abarca, E. (2002). Mining for meaning: A cognitive examination of inserted questions in learning from a scientific text. En J. Otero, J.A. León \& A.C. Graesser (Eds), The psychology of science (pp. 417-436). Mahwah, NJ: Lawrence Erlbaum Associates.

Rouet, J.F., Vidal-Abarca, E., Bert-Erboul, A., \& Millogo, V. (2001). Effects of information search tasks on the comprehensión of intructional text. Discourse Processes, 31, 163-186.

Rovira, C. (1999). La orientación a objetos en el diseño de hipertextos para la enseñanzaaprendizaje. Cuadernos de documentación Multimedia, 8. Recuperado de: http://pendientedemigracion.ucm.es/info/multidoc/multidoc/revista/num8/ro vira.html (23/9/2014) 
Rumelhart, D.E. (1980). Schemata. The building blocks of cognition. En R.J. Spiro. B. Bruce \& W. Brewer (Eds.), Theoretical issues in reading comprehension (pp. 33-58). Hillsdale, NJ: Erlbaum.

Rumelhart, D.E., \& Ortony, A. (1977). The representation of knowledge in memory. En R.C. Anderson, R.J. Spiro \& W.E. Montague (Eds.), Schooling and the acquisition of knowledge (pp. 93-137). Hillsdale, NJ: LEA.

Rumelhart, D.E. \& McClelland, J.L. (1981). Interactive processing through spreading activation. En A.M. Lesgold \& C.H. Perfetti (Eds.), Interactive processes in reading (37-60). Hillsdale, NJ: LEA.

Rumelhart, D.E., \& McClelland, J.L. (1982). An interactive activation model of context effects in letter perception: Part 2. The contextual enhancement effect and some tests and extensions of the model. Psychological Review, 89, 60-95.

Salmerón, L. (2006). Estrategias de comprensión de textos en hipertextos. Recuperado de: http://hera.ugr.es/tesisugr/16098158.pdff (29/2/2012)

Salmerón, L., Cañas, J.J., \& Fajardo, I. (2005). Are expert users' always better searchers? Interaction of expertise and semantic grouping in hypertext search tasks. Behaviour and Information Technology, 24, 471-475.

Salmerón, L., Baccino,T., \& Cañas, J.J. (2006). How prior knowledge y text coherence affect eye fixations in hypertext overviews. En R. Sun \& N. Miyake (Eds.), Proceedings of the 28th annual conference of the Cognitive Science Society (pp.715-719). Mahwah, NJ: Erlbaum.

Salmerón, L., Cañas, J., Kintsch, W., \& Fajardo, I. (2005). Reading Strategies and Hypertext Comprehension. Discourse Processes, 40 (3), 171-191.

Salmerón, L., Kintsch, W., \& Cañas, J. (2006a). Reading strategies and prior knowledge in learning from hypertext. Memory and Cognition, 34 (5), 1157-1171.

Salmerón, L., Kintsch, W., \& Cañas, J. (2006b). Coherence or interest as basis for improving hypertext comprehension. Information Design Journal, 14 (1), 45-55.

Salmerón, L., Baccino, T., Cañas, J.J., Madrid, R. I., \& Fajardo, I. (2009). Do graphical overviews facilitate or hinder comprehension in hypertext? Computers \& Education, 53, 1308-1319. 
Salmerón, L., Cañas, J., Kintsch, W., \& Kintsch. E. (2010). Self regulation and link strategies in Hypertext, Discourse processes, 47 (3), 175-211.

Salmerón, L., \& García, V. (2011). Reading skills and children's navigation strategies in hypertext. Computers in Human Behaviour, 27, 1143-1151.

Salmerón, H., \& Gutierrez-Braojos, C. (2012). La competencia de aprender a aprender y el aprendizaje autorregulado. Posicionamientos teóricos. Profesorado. Revista de Curriculum y Formación del Profesorado, 16 (1), 6-13.

Samuels, J. (1987). Information processing abilities and reading. Journal of Learning Disabilities, 20, 18-22.

Sánchez, E. (1989). Procedimientos para instruir en la comprensión de textos. Madrid: C.I.D.E.

Sánchez, E. (1993). Los textos expositivos. Estrategias para mejorar su comprensión. Madrid: Santillana.

Sánchez, E. (1998). Comprensión y redacción de textos. Barcelona: Edebé.

Sánchez, E., Solé, I., \& Gallart, N. (2009). Avanzando en la lectura. Aula Innovación Educativa, 179, 8-11.

Sánchez, E., García, R., \& Rosales, J. (2009). Para ayudar a comprender: ¿Qué se debe hacer? ¿Qué se hace? ¿Qué se puede hacer? Aula de Innovación Educativa, 180, 65-70.

Sánchez, E., García, R., \& Rosales, J. (2010). La lectura en el aula: qué se hace, qué se puede hacer, qué se debe hacer. Barcelona: Grao.

Scardamalia, M., \& Bereiter, C. (1984). Development of strategies in text procesing. En H. Mandl, N. L. Stein \& T. Trabaso (Eds.), Learning and comprehension of text (p. 379-406). Hilsdale, NJ: Lawrence Erlbaum Asociates.

Schaeken, W., Johnson-Laird, P.N., \& D'ydewalle, G. (1996). Mental models and temporal reasoning. Cognition, 60, 205-234.

Schank, R., \& Abelson, R. (1977). Script, plans, goals, and understanding. Hillsdale, N.J: Erlbaum. 
Schoon , P., \& Cafolla, R. (2002). World Wide Web hypertext linkage patterns. Journal of Educational Multimedia and Hypermedia, 11 (2), 117-139.

Scheiter, K., \& Gerjets, P. (2007). Learner control in hypermedia environments. Educational Psychology Review, 19 (3), 285-307.

Scheiter, K., Gerjets, P., Vollmann, B,. \& Cantrambone, R. (2009). The impact of learner characteristics on information utilization strategies, cognitive load experienced, and performance in hypermedia learning. Learning and Instruction 19 (5), 387401.

Scott, B., \& Schwartz, N.H. (2007). Navigational spatial displays: The Role of Metacognition as Cognitive Load. Learning and Instruction. 17, 89-105

Shadish, W. R., Cook, T. D., \& Campbell, D. T. (2002). Experimental and quasiexperimental designs for generalized causal inference. Boston, MA: Houghton Mifflin.

Shadish, W. R., Luellen, J. K., \& Clark, M. H. (2006). Propensity scores and quasiexperimentation. En R. R. Bootzin \& P. McKnight (Eds.), Strengthening research methodology: Psychological measurement and evaluation (pp. 143157). Washington, DC: American Psychological Association.

Shapiro, A. (1998). Promoting between prior knowledge and interactive overviews during hypermedia-aided learning: the role of system structure in learning from hypertext. Human-Computer Interaction, 13 (1), 1-35.

Shapiro, A. (2004). How including prior knowledge as a subject variable may change outcomes of learning. Research. American Educational Research Journal, 41 (1), 159-189.

Shapiro A.M., \& Niederhauser, D. (2004). Learning form hypertext: Research issues and findings. En D.h. Jonassen (Ed.), Handbook of research on educational communications and technology (pp.605-620). Mahwah, NJ: Erlbaum.

Shi, L. (2004). Textual borrowing in second-language writing. Written Communication, $21,171-200$.

Shi, L. (2008). Textual appropriation and citing behaviors of university undergraduates. Applied Linguistics, 31, 1-24. 
Smeets, W., \& Solé, I. (2008). How adequate task representation can help students write a successful synthesis. Zeitschrifts Schreiben. Recuperado de: http://www.zeitschrift-schreiben.eu/Beitraege/smeets_Adequate_Task.pdf $(2 / 3 / 2014)$

Smith, F. (1971). Understanding reading. New York: Holt, Rinehart and Winston

Smith, F. (1973). Psycholinguistics and reading. New York: Holt, Rinehart and Winston

Schnotz, W. (2005). An integrated model of text and picture comprehension. En R. E. Mayer (Ed.), The Cambridge handbook of multimedia learning (pp. 49-69). Cambridge: Cambridge University Press.

Schnotz, W., \& Bannert, M. (2003). Construction and interference in learning from multiple representations. Learning and Instruction, 13, 141-156.

Solé, I. (1987). Las posibilidades de un modelo teórico para la enseñanza de la comprensión lectora. Infancia y Aprendizaje, 39-40, 1-13.

Strage, M. (1980). Instructional implications of a conceptual theory of reading comprehension. The Reading Teacher, 33, 391-397.

Stromso, H.I., Braten, I., \& Samuelstuen, M.G. (2003). Students' strategic use of multiple sources during expository text reading: A longitudinal think-aloud study. Cognition and Instruction, 21, 113-147.

Sweller, J. (1988). Cognitive load during problem solving. Cognitive Science, 12 (2), 257-285.

Sweller, J. (2005). Implications of cognitive load of theory for multimedia learning. En R. E. Mayer (Ed.), The Cambridge handbook of multimedia learning (pp.19-30). Cambridge: Cambridge University Press.

Sweller, J., Ayres, P. L., Kalyuga, S., \& Chandler, P. A. (2003). The expertise reversal effect. Educational Psychologist, 38 (1), 23-31.

Sweller, J., Ayres, P., \& Kalyuga S. (2011). Cognitive load theory. New York: Springer.

Su, Y., \& Klein, J.D. (2006). Effects of navigation tolos and computer confidence on perfomance and attitudes in a hipermedia learning environment. Journal of Educational Multimedia and Hypermedia, 15 (1), 87-106. 
Tejedor, J. (1994). La experimentación como método de investigación educativa. En V. García (Coord.), Problemas y métodos de investigación en educación personalizada (pp. 256-285). Madrid: Rialp.

Thevenot, C. (2010). Arithmetic word problem solving: evidence for the construction of a mental model. Acta Psychologica, 133 (1), 90-95.

Thiede, K. W., \& Anderson, M. C. M. (2003). Summarizing can improve metacomprehension accuracy. Contemporary Educational Psychology, 28, 129160.

Thiede, K. W., Dunlosky, J., Griffin, T. D., \& Wiley, J. (2005). Understanding the Delayed-Keyword Effect on Metacomprehension Accuracy. Journal of Experimental Psychology: Learning, Memory and Cognition, 31, 1267-1280.

Thiede, K. W., Griffin, T. D., Wiley, J., \& Anderson, M. (2010). Poor metacomprehension accuracy as a result of inappropriate cue use. Discourse Processes, 47, 331-362.

Thiede, K. W., Griffin, T. D., Wiley, J., \& Redford, J. (2009). Metacognitive monitoring during and after reading. En D. J. Hacker, J. Dunlosky \& A. C. Graesser (Eds), Handbook of Metacognition in Education (pp. 85-106). New York: Routledge.

Tierney, R.J., \& Shanahan, T. (1991). Research on the reading-writing relationship: Interactions, transactions and outcomes. En R. Barr, M.L. Kamil, P. Mosenthal, \& P.D. Pearson (Eds.), Handbook of reading research (Vol 2, pp. 246-280). Hillsdale, NJ: Erlbaum.

Turner, A. A., \& Greene, E. (1978). The construction and use of a propositional text base. Boulder, CO: University of Colorado.

Van Den Broek, P., \& Kendeou, P. (2008). Cognitive processes in comprehension of science texts: The role of coactivation in confronting misconceptions. Applied Cognitive Psychology, 22 (3), 335-351.

Van Dijk, T. A. (1972). Some aspects of text grammars: A study in theoretical poetics and linguistics. The Hague: Mouton. 
Van Dijk, T. A. (1976). Discourse meaning and memory. Review article of W. Kintsch, The representation of meaning in memory (1974). Journal of Literacy Research, $8(1), 89-110$.

Van Dijk, T. A. (1994). Modelos en la memoria. El papel de las representaciones de la situación en el procesamiento del discurso. Revista Latina de Pensamiento y Lenguaje, 2 (1), 39-55.

Van Dijk, T.A. (1995). Discoure semantics and ideology. Discourse and Society, 6 (2), 43-89.

Van Dijk, T.A. (1998). Ideology. A multidisciplinary aproach. London: Sage publications.

Van Dijk, T. A. (2006a).De la gramática del texto al análisis crítico del discurso: una breve autobiografía académica. Recuperado de:

http://www.dliscourses.org/De\% 20la\% 20gramatica \% 20del\% 20texto\% 20al \% 20analisis \% 20critico\% 20del\% 20discurso.pdf (15/5/2012)

Van Dijk, T. A. (2006b). Discourse, context and cognition. Discourse Studies, 8 (1), 159-177.

Van Dijk, T.A., \& Kintsch, W. (1983). Strategies of discourse comprehension. New York: Academic Press.

Vidal-Abarca, E., Salmerón, L., \& Mañá, A. (2011). Individual differences in taskoriented reading. En M.T. McCrudden, J. P. Magliano, \& G. Schraw (Eds.), Text relevance and learning from text. Greenwich, CT: Information Age Publishing.

Voros, Z., Rouet, J.F., \& Pléh, C. (2011). Effect of high-level content organizers on hypertext learning, Computers in Human Behavior, 27 (5), 2047-2055.

Voss, J., \& Silfies, L. (1996). Learning from history text: interaction of knowledge and comprehension skills with text structure. Cognition and Instruction, 14, 45-68

Waniek, J., \& Ewald, K. (2008). Cognitive costs of navigation aids in hypermedia learning. Journal of Educational Computing Research, 39 (2), 185-204.

Wanner, E (1975). On remembering, forgetting and understanding sentences. La Haya: Mounton. 
Wade-Stein, D., \& Kintsch, E. (2004). Summary Street: Interactive computer support for writing. Learning and Instruction, 22, 333-362.

Westby, C., Culatta, B., Lawrence, B., \& Hall-Kenyon, K. (2010). Summarizing expository texts. Top Lang Disorders, 30 (4), 275-287.

Winograd, T. (1975). Frame representations and the declarative-procedural controversy. En D.G. Bobrow \& A.M. Collins (Eds.), Representation and understanding studies in cognitive science (185-210). New York: Academic Press.

Winograd, T. (1976), Computer memories a metaphor for human memory. En C. Cofer (ed.), The structure of human memory (133-161). San Francisco: Freeman.

Winograd, P.N. (1984). Dificultades de estrategia en el resumen de textos. Infancia y Aprendizaje, 31-32, 67-87.

Zhu, E. (1999). Hypermedia interface design: The effects of number of links and granularity of nodes. Journal of Educational Multimedia and Hypermedia, 8, $331-358$.

Zwaan, R. A. (1999). Situation models: The mental leap into imagined worlds. Current Directions in Psychological Science, 8, 15-18.

Zwaan, R. A., y Radvansky, G. A. (1998). Situation models in language comprehension and memory. Psychological Bulletin, 123, 162-185. 